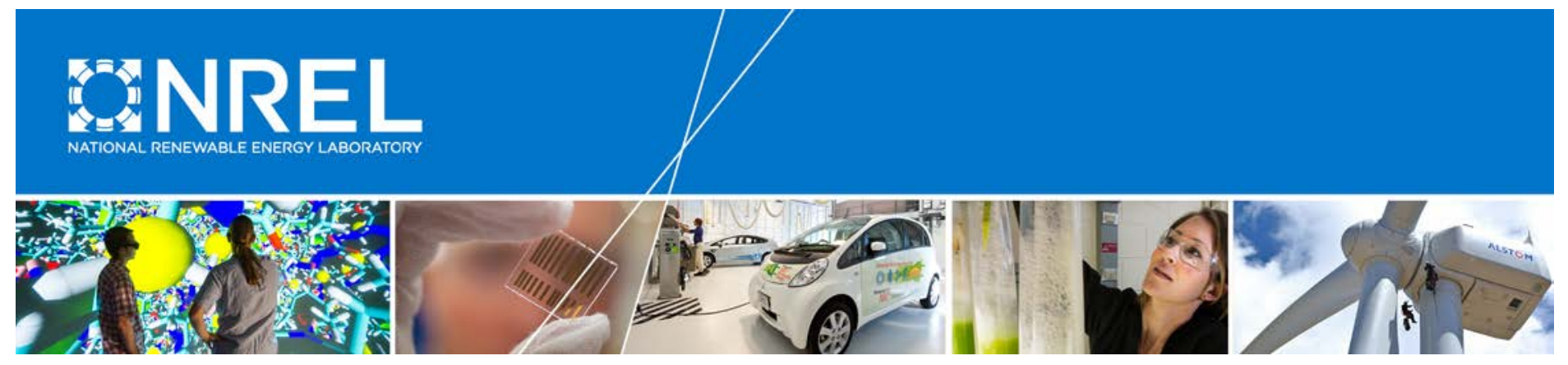

\title{
Estimating Renewable Energy Economic Potential in the United States: Methodology and Initial Results
}

Austin Brown, Philipp Beiter, Donna Heimiller, Carolyn Davidson, Paul Denholm, Jennifer Melius, Anthony Lopez, Dylan Hettinger, David Mulcahy, and Gian Porro

NREL is a national laboratory of the U.S. Department of Energy Office of Energy Efficiency \& Renewable Energy Operated by the Alliance for Sustainable Energy, LLC

This report is available at no cost from the National Renewable Energy Laboratory (NREL) at www.nrel.gov/publications.

Technical Report

NREL/TP-6A20-64503

Revised August 2016

Contract No. DE-AC36-08G028308 


\title{
Estimating Renewable Energy Economic Potential in the United States: Methodology and Initial Results
}

\author{
Austin Brown, Philipp Beiter, Donna Heimiller, \\ Carolyn Davidson, Paul Denholm, Jennifer \\ Melius, Anthony Lopez, Dylan Hettinger, \\ David Mulcahy, and Gian Porro
}

Prepared under Task No. SA12.0336

NREL is a national laboratory of the U.S. Department of Energy Office of Energy Efficiency \& Renewable Energy Operated by the Alliance for Sustainable Energy, LLC

This report is available at no cost from the National Renewable Energy Laboratory (NREL) at www.nrel.gov/publications.

National Renewable Energy Laboratory 15013 Denver West Parkway Golden, CO 80401 303-275-3000 • www.nrel.gov

\section{Technical Report}

NREL/TP-6A20-64503

Revised August 2016

Contract No. DE-AC36-08G028308 


\section{NOTICE}

This report was prepared as an account of work sponsored by an agency of the United States government. Neither the United States government nor any agency thereof, nor any of their employees, makes any warranty, express or implied, or assumes any legal liability or responsibility for the accuracy, completeness, or usefulness of any information, apparatus, product, or process disclosed, or represents that its use would not infringe privately owned rights. Reference herein to any specific commercial product, process, or service by trade name, trademark, manufacturer, or otherwise does not necessarily constitute or imply its endorsement, recommendation, or favoring by the United States government or any agency thereof. The views and opinions of authors expressed herein do not necessarily state or reflect those of the United States government or any agency thereof.

This report is available at no cost from the National Renewable Energy Laboratory (NREL) at www.nrel.gov/publications.

Available electronically at SciTech Connect http:/www.osti.gov/scitech

Available for a processing fee to U.S. Department of Energy and its contractors, in paper, from:

U.S. Department of Energy

Office of Scientific and Technical Information

P.O. Box 62

Oak Ridge, TN 37831-0062

OSTI http://www.osti.gov

Phone: 865.576.8401

Fax: 865.576.5728

Email: reports@osti.gov

Available for sale to the public, in paper, from:

U.S. Department of Commerce

National Technical Information Service

5301 Shawnee Road

Alexandria, VA 22312

NTIS http://www.ntis.gov

Phone: 800.553 .6847 or 703.605 .6000

Fax: 703.605.6900

Email: orders@ntis.gov 


\section{ERRATA}

NREL REPORT NUMBER: NREL/TP-6A20-64503

TITLE: Estimating Renewable Energy Economic Potential in the United States:

Methodology and Initial Results

AUTHORS: Austin Brown, Philipp Beiter, Donna Heimiller, Carolyn Davidson,

Paul Denholm, Jennifer Melius, Anthony Lopez, Dylan Hettinger, David Mulcahy, and Gian Porro

ORIGINAL PUBLICATION DATE: July 2015

DATE OF CORRECTIONS: August 2016

The following corrections were made to this report:

Page xx, paragraph 1, sentences $2-3$ are updated.

Page 67, paragraph 2, sentences 2-3 and 5-6 are updated.

Page 71, Table 13 is updated.

Page 72, bullet point 3, sentences 2-3 are updated. 


\section{Abstract}

This report describes a geospatial analysis method to estimate the economic potential of several renewable resources available for electricity generation in the United States. Economic potential, one measure of renewable generation potential, may be defined in several ways. For example, one definition might be expected revenues (based on local market prices) minus generation costs, considered over the expected lifetime of the generation asset. Another definition might be generation costs relative to a benchmark (e.g., a natural gas combined cycle plant) using assumptions of fuel prices, capital cost, and plant efficiency. Economic potential in this report is defined as the subset of the available resource technical potential where the cost required to generate the electricity (which determines the minimum revenue requirements for development of the resource) is below the revenue available in terms of displaced energy and displaced capacity. The assessment is conducted at a high geospatial resolution (more than 150,000 technology-specific sites in the continental United States) to capture the significant variation in local resource, costs, and revenue potential. This metric can be a useful screening factor for understanding the economic viability of renewable generation technologies at a specific location. In contrast to many common estimates of renewable energy potential, economic potential does not consider market dynamics, customer demand, or most policy drivers that may incent renewable energy generation.

The method is applied to several renewable generation technologies under a variety of assumptions - including land-based wind, utility photovoltaics (UPV), distributed photovoltaics (DPV), hydropower, geothermal (hydrothermal resource only), and biopower (dedicated combustion plants only, not including co-firing), primarily from a 2014 perspective.

Estimates are highly sensitive to the specific assumptions used related to both renewable generation cost and avoided cost. Across the three distinct formulations of the definition used in this analysis, the sum of economic potential estimates for the technologies assessed ranged from one-third to over ten times 2013 total U.S. generation from all sources. The capacity value of renewable generation, external costs and associated discount rates, and the declining value of variable generation with increased penetration have a major impact on estimates. Finally, economic potential can occur in all contiguous U.S. states for at least one of the renewable generation technologies assessed, depending on the specific formulation applied.

This work presents one method for assessing economic potential; as a consequence, future work may deliver different results as the method is further developed and refined. Economic potential cannot be used to predict what technologies will be deployed or when, and should not be expected to match estimates found in deployment scenarios. The preliminary results of this application are intended to demonstrate the utility of the method described, and serve as an initial estimate of the range of economic potential, as well as an exploration of a number of the factors that influence that potential. The model is expected to be updated and refined to reflect new data and analysis as they become available. 


\section{Acknowledgments}

This work was supported by the Office of Strategic Programs and the Solar Energy Technologies Office of the U.S. Department of Energy's (DOE) Office of Energy Efficiency and Renewable Energy (EERE). The authors are greatly indebted to the following for their helpful review comments on preliminary versions of this analysis and this report, as well as suggestions on suitable data sets and methods: Stephen Capanna, Ookie Ma, Kara Podkaminer, Richard Tusing, Jose Zayas, Minh Le, Doug Hollett, Steve Chalk, Mike Carr, Matt Nelson, Carla Frisch, Judi Greenwald, and Caitlin Callaghan (U.S. Department of Energy); Christopher Namovicz (Energy Information Administration); Ryan Wiser and Dev Millstein (Lawrence Berkeley National Laboratory); Steve Clemmer (Union of Concerned Scientists); Thomas Jenkin, Kendra Palmer, Dean Armstrong, Joelynn Schroeder, David Mooney, Doug Arent, Nate Blair, Jeffrey Logan, Ann Brennan, Eric Lantz, Trieu Mai, David Feldman, Robert Margolis, Stuart Cohen, Chad Augustine, Barbara Goodman, and Robin Newmark (National Renewable Energy Laboratory). Any remaining errors or omissions in this report are solely the responsibility of the authors. 


\section{Executive Summary}

\section{Introduction}

Economic potential, one measure of renewable generation potential, is a metric that attempts to quantify the amount of economically viable renewable generation that is available at a location or within an area. Economic potential may be defined in several ways. For example, one definition might be expected revenues (based on local market prices) minus generation costs, considered over the expected lifetime of the generation asset. Another definition might be generation costs relative to a benchmark (e.g., a natural gas combined cycle plant) using assumptions of fuel prices, capital cost, and plant efficiency. Economic potential in this report is defined as the subset of the available resource technical potential where the cost required to generate the electricity (which determines the minimum revenue requirements for development of the resource) is below the revenue available in terms of displaced energy and displaced capacity.

This metric can be a useful screening factor for understanding the economic viability of renewable generation technologies at a detailed geospatial resolution as well as for assessing the impact of technology improvements, policies, and other actions that can affect market access. It differs from many common estimates of renewable energy potential in that it does not directly consider market dynamics, customer demand, or most policy drivers that may incentivize renewable energy generation. As such, economic potential cannot be used to predict what technologies will be deployed or when, and should not be expected to match estimates found in deployment scenarios.

Economic potential for a location can be understood in relation to other types of renewable energy potential (Figure ES-1). The largest potential, resource potential, is the amount of energy physically available. Technical potential takes into account real-world geographic constraints and system performance, but not economics. Economic potential is the subset of the technical potential that is available where the cost required to generate the energy (which determines the minimum revenue requirements for development of the resource) is below the revenues available. Lastly, market potential is the amount of energy we expect to be generated through market deployment of renewable technologies after considering the impact of current or future market factors, such as incentives and other policies, regulations, investor response, and the economic competition with other generation sources. The deployment associated with market potential can be estimated through capacity expansion and dispatch modeling - for example, by using NREL's Regional Energy Deployment System (ReEDS). 


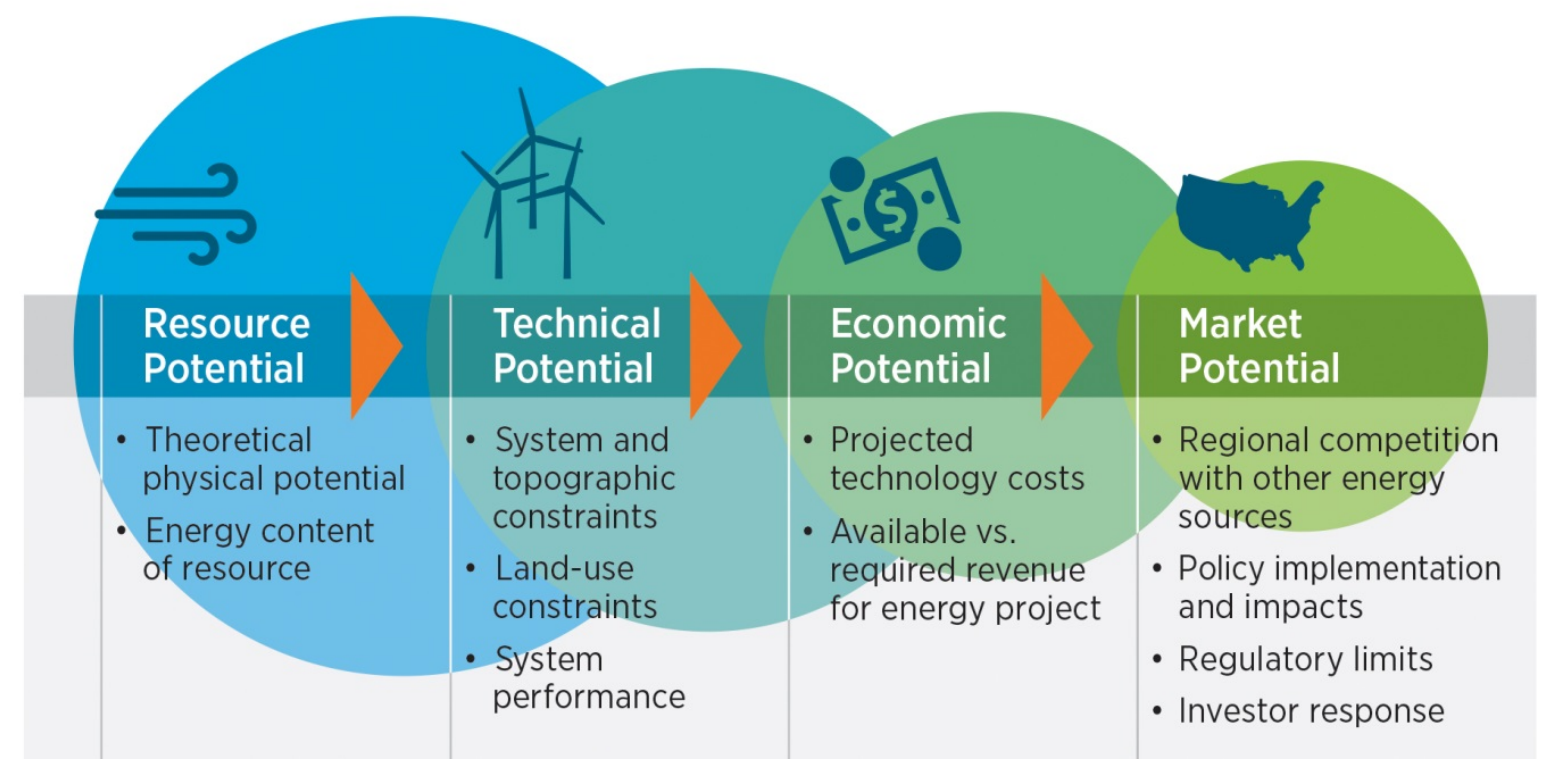

Figure ES-1. Types of Renewable Generation Potential

Development of a consistent method to estimate economic potential across renewable technologies began following the completion of a 2012 NREL analysis that assessed the technical potential of renewable generation technologies (Lopez et al. 2012). That report applied unifying assumptions and methods to generate comparable estimates across technologies and estimated technical potential to be many times greater than current U.S. electricity demand. Concurrently, sufficient data sets on renewable resources, avoided costs, and other parameters had become available for synthesis. This report describes the resulting geospatial analysis method and its initial application to estimate the economic potential of several renewable resources available for electricity generation in the United States using data available as of 2014. The method employs high-resolution geospatial data, including more than 150,000 technologyspecific sites in the continental United States, to reflect the significant variation in local resources, costs, and revenue potential. The initial method is applied to several renewable generation technologies under a variety of assumptions - including wind, utility photovoltaics (UPV), distributed photovoltaics (DPV), hydropower, geothermal (hydrothermal resources only), and biopower (dedicated combustion plants only, not including co-firing). ${ }^{1}$

The preliminary results of this application are intended to demonstrate the utility of the method described, and serve as an initial estimate of the range of economic potential, primarily from a 2014 perspective, as well as an exploration of the factors that influence that potential. These estimates are anticipated to change as technology cost and performance, expected revenues for any given location, and other factors change. This work represents an initial effort to develop and apply a method for assessing economic potential; future work may deliver different results as the method is further developed and refined.

\footnotetext{
${ }^{1}$ This analysis assesses some less mature renewable energy technologies, in terms of existing deployment, but not any technologies that represent less than $0.2 \%$ of total U.S. electricity generation in 2013 , in part due to limited data availability. Future work may consider the economic potential of these technologies, including offshore wind, concentrating solar power (CSP), marine hydrokinetic, and enhanced geothermal systems.
} 


\section{Methodology Summary}

The methodology described is based on high geospatial resolution renewable resource and market price data. The levelized cost of energy generation (LCOE) and the levelized avoided cost of energy (LACE) are calculated for each location of interest (individual site or region) to determine those locations that have positive net value (estimated LCOE less than LACE). The technical potential for those locations with positive net value are then aggregated to the state and broader region level for reporting estimates. This approach compares LCOE and LACE at the same location, implying that renewable generation would be used to satisfy load at that location or within the balancing area in which the location resides. The method does not consider either export or import situations for a particular location that long-distance transmission could enable.

The methodology employs four distinct steps for the centralized generation technologies assessed:

- Step 1. Technical Potential: We use the best available renewable resource geospatial data to estimate the achievable energy generation capacity and corresponding annual generation of specific technologies at specific sites or within defined regions, depending on the technology, given system performance, topographic limitations, environmental, and land-use constraints. This results in a data set of locations across the continental United States defined by resource characteristics. Technical potential annual generation estimates for these locations, assumed to be available in any given future year, are based on updates to methods initially described in Lopez et al. (2012) and applied to resource data sets updated for this analysis. ${ }^{2}$ Estimates for all technologies do not consider the potential for future technology innovation to increase technical potential, specifically locations with low resource quality that could have technical potential as a result of ongoing or new innovations.

- Step 2. Levelized Cost of Energy (LCOE): We estimate the LCOE for each renewable generation technology at these same locations, incorporating regional plant construction costs, technology cost, and performance and estimated intra-regional transmission costs. We then aggregate these site costs into appropriate regional supply curves (as needed) for comparison with LACE. The LCOE estimate is based on methods used and refined at NREL over a number of years (beginning with Short et al. 1995) to develop resource/technology supply curves for NREL's Regional Energy Deployment System (ReEDS) model. For variable resources (i.e., wind and solar), costs are calculated for thousands of individual sites. For other generation technologies, resource data from individual sites or counties are aggregated to supply curves in 134 regions.

- Step 3. Levelized Avoided Cost of Energy (LACE): We estimate a LACE at each of these same locations based on a method established in Namovicz (2013) by estimating the potential revenues available to a renewable generation project at the location, which can be interpreted as the amount the project would be paid for the electrical energy and capacity it can provide (or alternatively, what a utility or other entity would not have to purchase from

\footnotetext{
${ }^{2}$ As in this earlier report and subsequent analysis (e.g., DOE 2015a), wind sites with resource below a technoeconomic threshold, based on resource intensity and regional capital costs, are excluded from the estimated technical potential. More specifically, these estimates do not consider resource in wind techno-resource groups (TRG) 6 and 7. This type of techno-economic limit is not applied for the other technologies assessed. The technical potential of these TRGs is highlighted in the recent DOE report Enabling Wind Power Nationwide (DOE 2015b).
} 
other sources). This estimate is based on a prevailing regional marginal generation price and capacity value in 2014. In most of the cases examined for centralized technologies, a wholesale Market Price (MP) formulation of LACE is used as a proxy for marginal generation prices. The marginal generation price component of this MP approach takes into account projected electricity price increases over the life of a renewable generation plant (based on EIA AEO 2014 Reference Case price projections in EIA 2014a), levelized to an effective present price. As wholesale price data are not available in every region of the country, or for the future, this method relies on an initial synthesis of multiple market data sources, including locational marginal prices (LMPs) and market marginal costs (MMCs or system lambdas). ${ }^{3}$ Capacity values are calculated based on a technology-specific capacity credit and the overnight capital cost of an advanced natural gas-fired combustion turbine (NGCT) plant as proxy for capacity payment.

- Step 4. Economic Potential: For the full supply curve for each technology, we calculate LACE - LCOE as the net value for a location. A specific location is considered economically viable if its net value is positive; the technical potential associated with locations with positive net value is summed and deemed the economic potential.

For DPV, the same four-step approach is applied independently to estimate potential in the residential and commercial sectors, based on a method described in Denholm et al. (2009). For technical potential, annual technical feasible solar energy generation in the United States is estimated by first assessing available roof space within the service areas of approximately 2,000 utilities with retail residential and/or commercial customers, then estimating associated feasible capacity and production based on assumed system sizes for a 'typical' rooftop and locationspecific solar radiation. A single system capital cost is assumed nationally. Avoided cost is based on retail rate information available for about $70-80 \%$ of U.S. residential customers. The net present value of utility bill savings given expected system generation over a project life is estimated for the same utility area, assuming full net metering, where any excess hourly generation is credited at the applicable retail rate. Finally, net value is determined by comparing the value of avoided electricity consumed from the grid (as a result of installing a PV system) to the assumed capital cost of the system.

A number of factors beyond cost of energy and avoided cost are incorporated into the above net value framework, enabling them to be considered individually or in combination in the specific cases examined. Consideration of these factors demonstrates the sensitivity of results to a broader interpretation of economic potential and to the effect of some market factors. These factors can significantly affect estimates of economic potential. The factors include:

- The cost of tying generation into the grid. The LCOEs calculated for wind and UPV, but not other centralized technologies or DPV, include for all cases the cost of building intra-regional

\footnotetext{
${ }^{3}$ Reported electricity prices used in the MP formulation are annual averages based on data reported in the Ventyx Velocity Suite (Ventyx, 2015) within upper and lower thresholds designed to exclude effects due to bidding behavior, transmission constraints, etc., so that they can better meet the proxy objective. An alternate Average Avoided Generator (AAG) method that incorporates regional variation in fuel prices and capital costs instead of electricity prices, is applied in a sensitivity analysis to estimate avoided cost by calculating the value of a renewable generation project in displacing a blended mix of typical "marginal" generators (natural gas combined cycle, combustion turbines, and coal plants), where a single mix is applied nationally.
} 
transmission and substation capacity to connect potential sites to the existing transmission system and load centers, or specific points within each balancing area.

- Technology tax incentives, including the Production Tax Credit (PTC) and Investment Tax Credit (ITC). Permanent incentives reflected in existing federal law are included in the LCOEs of appropriate technologies in most of the cases examined. ${ }^{4}$

- $\quad$ The reduction of capacity and energy value of variable generation that may occur with increasing levels of generation. At high penetration, energy production from a given source may become less valuable to the system as the source's capacity and energy values decline. The variable nature of some resources, such as wind and solar, may lead to the potential for significant declines in value at higher levels of generation unless measures to increase system flexibility are taken. In an initial approach applied to one set of cases considering some potential market effects, decline in value is estimated for wind and UPV based on broad application of published modeled results for California (Mills and Wiser 2012). This decline factor is not considered for DPV or the other technologies examined.

- The value of avoided $\mathrm{CO}_{2}$ emissions, based on an estimate of the social cost of carbon (SCC). This analysis applies an approach based on the method and discount rate scenarios identified in Interagency Working Group (IWG) (2013), applied in five-year increments (EPA 2013). An average SCC with a 3\% discount rate is applied in most of the cases explored.

- The value of avoided health costs. The value of avoided $\mathrm{NO}_{\mathrm{X}}, \mathrm{SO}_{\mathrm{X}}$, and particulate matter from reduced fossil generation is considered in a sensitivity case based on a simplified version of the method described in DOE's WindVision (DOE 2015a).

The four-step calculation flow for centralized generation technologies, including the extended factors described immediately above, is depicted in Figure ES- 2.

\footnotetext{
${ }^{4}$ In most cases, the permanent $10 \%$ ITC is applied to UPV and DPV, and the PTC is not included for wind.

${ }^{5}$ Note that while the declining value of wind and solar is primarily an avoided cost consideration, arithmetically it is equivalently reflected as an incremental cost in the calculation of cost of energy (Step 2).
} 
Resource Potential reflecting system performance (capacity factor)

<remove>

Exclusions, land use constraints

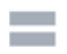

Technical

Potential
2

Site Levelized Cost of Energy (LCOE)

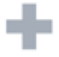

Intra-regional transmission costs

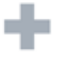

Declining value of wind and solar*

-

Existing Tax Incentives

ㅁ.

Adjusted Levelized Cost of Energy (LCOE)
3

Marginal

Generation Price

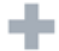

Capacity value

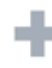

Value of Avoided Emissions

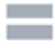

Adjusted Levelized Avoided Cost (LACE)
4

Adjusted Levelized Avoided Cost (LACE)

-

Adjusted Levelized Cost of Energy (LCOE)

\section{단 \\ Net Value}

(LACE - LCOE)

<sum over>

Technical Potential

Economic

Potential
Indicates geographically available data set
* An estimate for the reduced revenue available to wind and solar projects at increasing penetration if systems are not changed to adapt.

\section{Figure ES-2. Generalized method calculation flow for centralized technologies based on high geospatial resolution resource data}

Note: All factors identified in the figure are applied in the "base" methodology, and reflected in all cases assessed, except the following: declining value of wind and solar and value of avoided emissions. In some cases, tax incentives were included at pre-expiration levels. In Step $1,<$ remove $>$ indicates that resource potential that appears in excluded lands is not included in the analysis. In Step $4,<$ sum over $>$ indicates that technical potential at locations where net value is positive is summed to determine economic potential.

LCOE has long been recognized as a useful, but limited metric for a variety of reasons (Short 1995). LACE was developed as a concept by the Energy Information Administration (Namovicz 2013) and applied to its modeling results. This economic potential methodology expands on these earlier works through use of high-resolution resource data (thousands of sites for most technologies), consideration of reported market prices in the estimate of LACE for most cases, and consideration of a broad range of input assumptions for key drivers, including technology cost and the treatment of the value of variable generation as its share of total generation increases.

This methodology can provide an initial estimate of the economic viability of various types of renewable generation at a specific location. This type of estimate can be useful for initial screening applications and in assessing the impact of a variety of factors, including incentives and technology cost, on economic viability. The model applied is generally simpler and offers greater transparency than market models that employ more sophisticated techniques like optimization.

There are several caveats, however, that are important to keep in mind when considering the methodology, and in turn the initial estimates resulting from its application: 
- The methodology does not attempt to project the amount of renewable generation that might actually be deployed in the future. While some market factors are considered in the net value framework, it does not comprehensively consider market conditions and other factors that could affect potential deployment. Instead, the method provides an estimate of the amount of renewable generation that could be economically viable at current and expected future marginal generation prices and capacity values.

- The method described is not intended to replace engineering, project-based, or site analysis, which are necessary to fully assess the economic viability of a technology system by accounting for project-specific issues. The economic potential metric is also not a substitute for capacity expansion or production cost modeling, which takes electricity demand and system operations constraints, including the availability of transmission capacity and market factors into account, such as economic competition among different renewable or conventional resources. ${ }^{6}$

- More specifically, the methodology does not consider the potential costs and impact of interregional transmission on economic potential. In particular, the approach compares cost of energy and avoided cost to arrive at net value only at the same location, implying that renewable generation would be used to satisfy load at that location or within the balancing area in which the location resides. The method does not consider either export or import situations for a particular location that long-distance transmission could enable (i.e., the cost of energy at one location, including inter-regional transmission cost, is not compared to the avoided cost in another location that could be served by that transmission. As such, the economic potential estimates based on this method will not identify all the economically viable potential for specific technologies, like land-based wind, that may have low-cost resources at locations remote from load. ${ }^{7}$

- The framework described is static and considers economic potential only at a particular point in time based on the vintage of underlying data and assumptions, including electricity price projections, technical potential, cost of energy, and avoided cost. As resource data, technology cost and performance, actual renewable technology deployment, transmission infrastructure, fuel prices, wholesale electricity prices, and other factors change, estimates of economic potential will change. Further, the framework does not consider potential dynamic feedbacks that increasing renewable deployment may have on wholesale electricity prices.

- As with other methods that employ renewable resource data, the technical annual generation potential estimates for renewable generation technologies, upon which the net value framework is based, generally rely on typical meteorological year (TMY) statistical profiles. While these underlying data are meant to represent the hourly variability of an average year, significant annual variation in generation can occur based on local/regional weather patterns and storm events.

\footnotetext{
${ }^{6}$ For example, economic potential is based on a different approach than recent and ongoing "vision" studies, including DOE (2012) and DOE (2015a). While some data are common among these analyses, outputs are not expected to be comparable due to the different methods applied and scenarios examined.

${ }^{7}$ This issue is generally addressed in capacity expansion models that include a representation of inter-regional transmission (e.g., NREL's ReEDS model) and has been considered in market -based assessments of renewable generation in recent "vision" studies (e.g., DOE 2012; DOE 2015a).
} 
- The range of estimates shown is based on readily available data sets and simplifying assumptions. Some of the applied methods, for example, for avoided cost based on market prices and declining value, are initial applications that rely on many assumptions and require further refinement. Some methods for extended factors like intra-regional transmission costs and declining value are not applied to all applicable technologies. Further, supporting data assumptions for both cost of energy and avoided cost components of the methodology, especially those in the form of electricity price projections, are inherently uncertain.

- The declining value method is an initial broad application of published modeled results for California (Mills and Wiser 2012) that assessed the decline of both energy and capacity value of wind and PV up to $40 \%$ penetration. There is uncertainty associated with the application of these modeled results beyond California and at penetration levels beyond $40 \%$. The incremental value of PV to the system is reduced by nearly $\$ 55 / \mathrm{MWh}$ at penetration levels of and beyond $40 \%$, effectively reducing economic potential to zero at these penetrations. However, wind's value is only reduced by nearly $\$ 18 / \mathrm{MWh}$ at penetration levels of and beyond $40 \%$. In some locations with high quality wind resource - Texas, for example - wind generation cost may remain less than LACE even after taking this declining value into account. Since this initial method does not reduce the value of wind further as its potential share of generation exceeds $40 \%$, wind potential may be overstated for scenarios where its share of generation in a region exceeds $40 \%$.

- The framework relies on some assumptions related to technology incentives that can have a significant effect on resulting estimates. The continued availability of existing "permanent" incentives is inherently uncertain. Further, simplifying assumptions on state-level policies, primarily in adopting single national approach to distributed PV net metering, were made to make the analysis more tractable.

Rather than generating a single estimate of economic potential, the analysis assesses three Primary Cases (assumption sets) with the intent of exploring the effects of method and assumption selection on the magnitude of estimates. The three Primary Cases are reported based on the following distinct formulations of economic potential consistent the with net-value definition based on LCOE and LACE:

- $\quad$ Primary Case 1 - LACE Only: This case is meant to represent the LACE methodology identified in Namovicz (2013) as closely as possible, with little consideration of market factors that could affect the actual deployment of renewable generation. This formulation includes the cost of intra-regional transmission for variable generation technologies (Wind and UPV).

- Primary Case 2 - LACE including Value of Avoided External Costs: This case extends LACE to consider the value of avoided external costs associated with conventional generation, in particular $\mathrm{CO}_{2}$ emissions.

- Primary Case 3 - LACE including Value of Avoided External Costs and Declining Value of Variable Generation: This case further extends LACE to also consider the potential impact of increasing amounts of variable generation on its value.

The latter two formulations move beyond a strict formulation of economic potential that considers only technology costs and required revenues for project development to one that considers some market factors. These market extensions are considered in this analysis to offer 
additional possible perspectives, in recognition that the demarcation between economic and market potential is subject to interpretation, and to demonstrate that the specific factors considered can have a significant impact on estimates.

\section{Initial Estimates and Observations}

The above methodology is applied to several renewable generation technologies, under various assumptions - including land-based wind, utility photovoltaics (UPV), distributed photovoltaics (DPV), hydropower, geothermal (hydrothermal resource only), and biopower (dedicated combustion plants only, not including co-firing), primarily from a 2014 perspective.

For each of the above Primary Cases, an economic potential estimate range is established through varying assumptions of the applied capacity value of renewable generation. A major determinant of the capacity value is the extent to which additional generation capacity is required for the electricity system. In each of the Primary Cases, the low end of the estimated range of economic potential assumes that no additional capacity is required and reflects no credit for the capacity value of renewable generation in the avoided cost calculation. Conversely, the high end of each range assumes that additional capacity is needed on the system and reflects full credit for the capacity value of renewable generation in the avoided cost calculation.

Collectively, these Primary Cases rely on the following major assumptions:

- Construction Date: 2014 - Both the LCOE and LACE components of net value are calculated assuming a renewable generation project is constructed in 2014 (cost and value time streams that make up these components begin in 2014 and are discounted back to 2014). This approach enables a "current" view of economic potential based on existing 2014 marginal generation prices and existing forward projections of those prices. In contrast, as noted below, renewable technology costs for the Primary Cases are referenced to 2020. The combination of these two assumptions provides a blended view of economic potential illustrative of both the current environment and the near-term future. A sensitivity analysis explores a case with 2014 renewable costs and a 2014 construction date, as well as a case with 2020 renewable costs and a 2020 construction date.

- $\quad$ Renewable Technology Cost: 2020 mid-projection - The 2020 timeframe reflects additional technology improvement for most technologies assessed. The mid-case projected cost from NREL Annual Technology Baseline (ATB) (NREL 2015) is a central estimate.

- Renewable Technology Incentives: Permanent 10\% ITC for UPV, DPV; Accelerated Depreciation (MACRS) - The inclusion of this level of ITC is intended to reflect a representation of existing federal law. As the current 30\% ITC for solar technologies is scheduled to revert to the $10 \%$ level at the end of 2016 , the "permanent" $10 \%$ level is used. The PTC is not included for wind as it required plant construction to begin by the end of 2013. Accelerated depreciation (MACRS) is assumed for all applicable technologies.

- Project Life: 20 years - Renewable generation plants are assumed to have a financial life of 20 years for the purposes of calculating LCOEs. LACE is estimated from marginal generation prices over this assumed 20-year asset life.

- $\quad$ Avoided Cost Method for Central Generation: MP - The MP method, based on a synthesis of locational marginal price data, is applied as a proxy for the revenue a centralized renewable 
project might receive in a given market. The capacity value component of avoided cost assumes a NGCT capital cost of $\$ 682 / \mathrm{kW}$ (consistent with AEO 2015). ${ }^{8}$ For DPV, local retail rates, together with full net metering where the customer is credited for any excess hourly generation at the applicable retail rate, are used as a basis for comparison to generation cost.

- Value of Avoided Health Costs: Not Included - Estimates of this type of external cost are not included in the primary cases as this impact of avoided cost was deemed secondary to consideration of the value of avoided $\mathrm{CO}_{2}$ emissions. Avoided heath costs are considered in a sensitivity case.

The following variables are differentially applied among the three Primary Cases:

- Value of Avoided $\mathrm{CO}_{2}$ Emissions (SCC): IWG (2013) Average SCC using a 3\% discount rate - The value of avoided $\mathrm{CO}_{2}$ emissions is included in Primary Cases 2 and 3.

- Declining Value of Variable Generation: Included for Wind, UPV - Declining value is applied in the net value framework in Primary Case 3 that was designed to more broadly consider market effects. The application is made only to estimates for wind and UPV potential to reflect the possible impact of high levels of variable generation on project economics. This adjustment is not included for any DPV cases (no assumed change in value of solar with increasing DPV generation), given that the topic is an active area of research.

The sum of U.S. economic annual generation potential (excluding Alaska and Hawaii) for the six technologies assessed ranges from nearly 1,500 to 42,000 TWh in excess of 2013 generation for the Primary Cases. This range of aggregate potential represents from nearly three to nearly 80 times total U.S. renewable generation in 2013, or one-third to over ten times 2013 total U.S. generation from all sources, and is a small fraction of the aggregate annual technical generation potential of over $320,000 \mathrm{TWh}$ for these technologies. These estimates simply sum the potentials of the individual technologies. As such, they do not consider any potential competition among the technologies for available land or in economic terms. Further, they do not reflect any impact of the interaction of variable wind and PV generation upon the value of either technology.

More specifically, the following are ranges of aggregate annual generation potential for each the Primary Cases (see Table ES-1):

- $\quad$ Primary Case 1 - LACE Only: 3,200 - 7,100 TWh. UPV contributes the bulk of the economic potential under this formulation.

- $\quad$ Primary Case 2 - LACE including Value of Avoided External Costs (related to $\underline{\mathrm{CO}}_{2}$ emissions): $13,000-42,000 \mathrm{TWh}$. Under this formulation, UPV contributes the bulk of the economic potential, particularly at the high end of the range. Wind economic potential is also significant, representing at least the equivalent of total U.S. generation from all sources in 2013.

- $\quad$ Primary Case 3 - LACE including Value of Avoided External Costs and Declining Value of Variable Generation: 1,500-2,000 TWh. While the total economic potential in this formulation is much lower than in Primary Case 2, all of the technologies except biomass

\footnotetext{
${ }^{8}$ See AEO 2015 Table 8.2: http://www.eia.gov/forecasts/aeo/assumptions/pdf/table_8.2.pdf.
} 
contribute significant potential. The potential shown represents $35-50 \%$ of total U.S. generation from all sources in 2013. Figure ES-3 illustrates this economic potential is additive to existing (2013) generation. Figure ES-4 displays the distribution of economic potential for this Primary Case by state. 
Table ES-1. Aggregated Estimated U.S. Economic Potential for Primary Cases

\begin{tabular}{|c|c|c|c|c|c|c|c|c|}
\hline & \multirow{2}{*}{\multicolumn{5}{|c|}{ Economic Potential - Annual Generation (TWh) }} & \multirow[b]{3}{*}{\begin{tabular}{|l} 
Bio- \\
power
\end{tabular}} & \multirow[b]{3}{*}{$\begin{array}{l}\text { Sum of } \\
\text { Asse ssed }\end{array}$} \\
\hline & & & & & & & & \\
\hline Primary Case & Specific Cases & Wind & UPV & DPV $^{5}$ & $\begin{array}{l}\text { Hydro- } \\
\text { power }\end{array}$ & \begin{tabular}{|l|} 
Geo- \\
thermal
\end{tabular} & & \\
\hline \multirow{2}{*}{ Reference Data } & 2013 Generation $^{1}$ & 168 & 11 & 10 & 269 & 17 & 60 & 534 \\
\hline & Technical Potential $^{2}$ & 22,195 & 297,475 & 1,560 & 278 & 234 & 445 & 322,187 \\
\hline \multirow{2}{*}{ Primary Case 1 - LACE Only ${ }^{3}$} & Primary Case with Full Capacity Value & 319 & 6,468 & 194 & 50 & 109 & 0 & 7,140 \\
\hline & Primary Case with No Capacity Value & 135 & 2,789 & 194 & 38 & 29 & 0 & 3,184 \\
\hline \multirow{2}{*}{$\begin{array}{l}\text { Primary Case } 2 \text { - LACE including } \\
\text { Value of Avoided External Costs }\end{array}$} & Primary Case with Full Capacity Value & 7,870 & 33,523 & 287 & 76 & 153 & 0 & 41,909 \\
\hline & Primary Case with No Capacity Value & 4,590 & 7,713 & 287 & 64 & 131 & 0 & 12,785 \\
\hline \multirow{2}{*}{$\begin{array}{l}\text { Primary Case } 3 \text { - LACE including } \\
\text { Value of Avoided External Costs } \\
\text { and Declining Value of Variable } \\
\text { Generation }\end{array}$} & Primary Case with Full Capacity Value* & 869 & 606 & 287 & 76 & 153 & 0 & 1,991 \\
\hline & Primary Case with No Capacity Value* & 548 & 430 & 287 & 64 & 131 & 0 & 1,460 \\
\hline
\end{tabular}

Notes

1 As reported in 2013 Renewable Energy Data Book (2014); including Alaska and Hawaii. Total generaton from all sources in 2013 was $~ 4100$ Twh.

2 As updated in this report; excluding Alaska and Hawaii. Estimates may differ from prior assessments including Lopez et al. (2012) due to differences in the classification of resources (e.g., in some cases hydropower upgrades are not considered as new technical potential), advancements in technology (e.g., the availability of higher productivity wind turbines), or other factors.

3 Does not include Alaska and Hawaii; in addition to existing generation.

4 Does not include Alaska and Hawaii; in addition to existing generation. Declining value applied to Wind and UPV only. An asterisk symbol (*) to the right of a case name indicates that wind generation potential exceeds $40 \%$ of 2013 total generation in some regions and may be overstated as the declining value method applied does not reduce the value of wind further as its potential share of generation exceeds $40 \%$.

5 Not all cases run for DPV, hydropower, geothermal, and biopower; gray-shaded cells indicate that another case is used as a substitute.

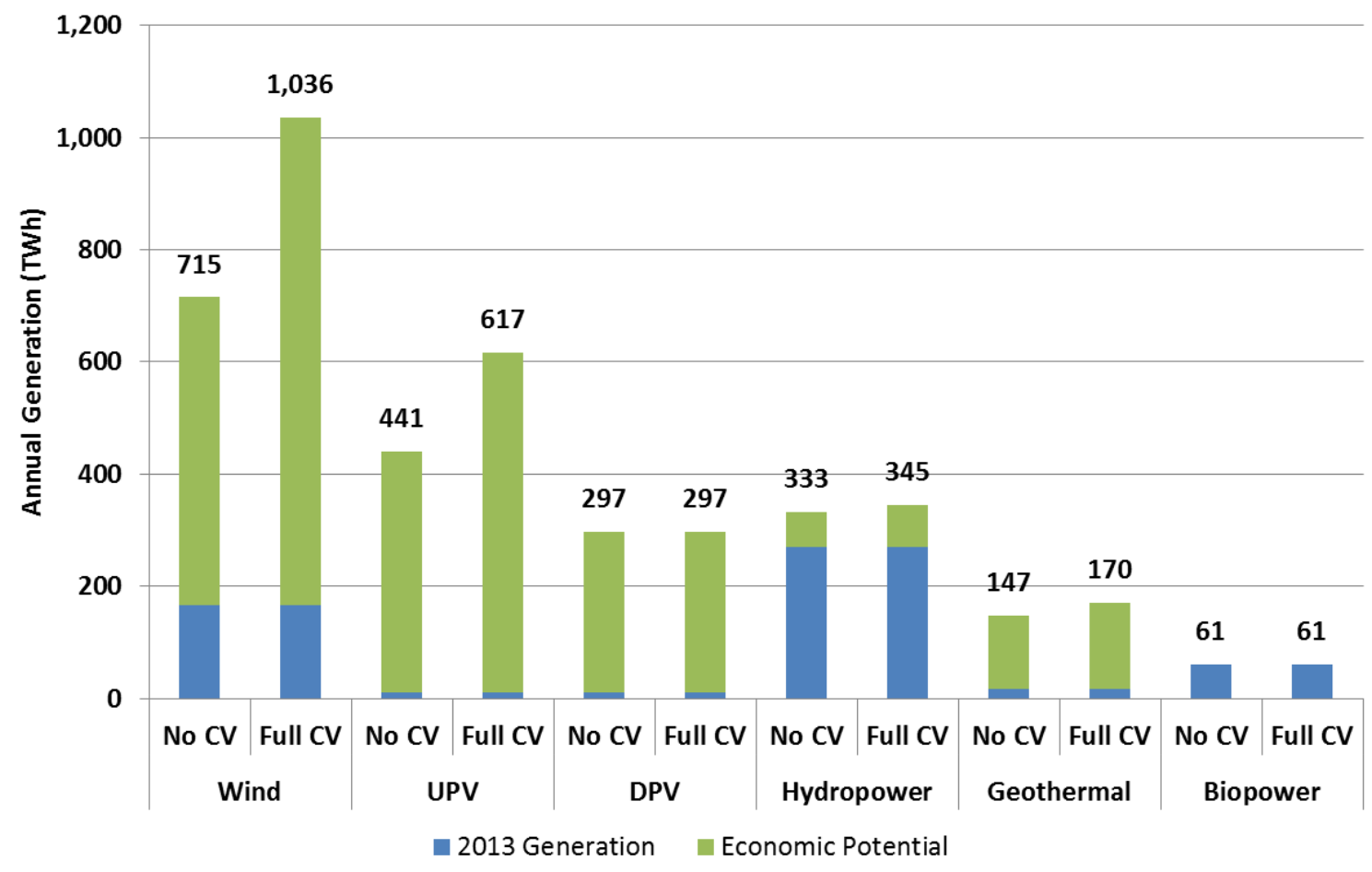

Figure ES-3. Aggregated Estimated U.S. Economic Potential (Primary Case 3)

Note: Numerical values above each column are the sum of 2013 generation and the estimated economic potential. As in Table ES-1 and all tables and graphs of estimates in this report, economic potential is additive to existing generation. 


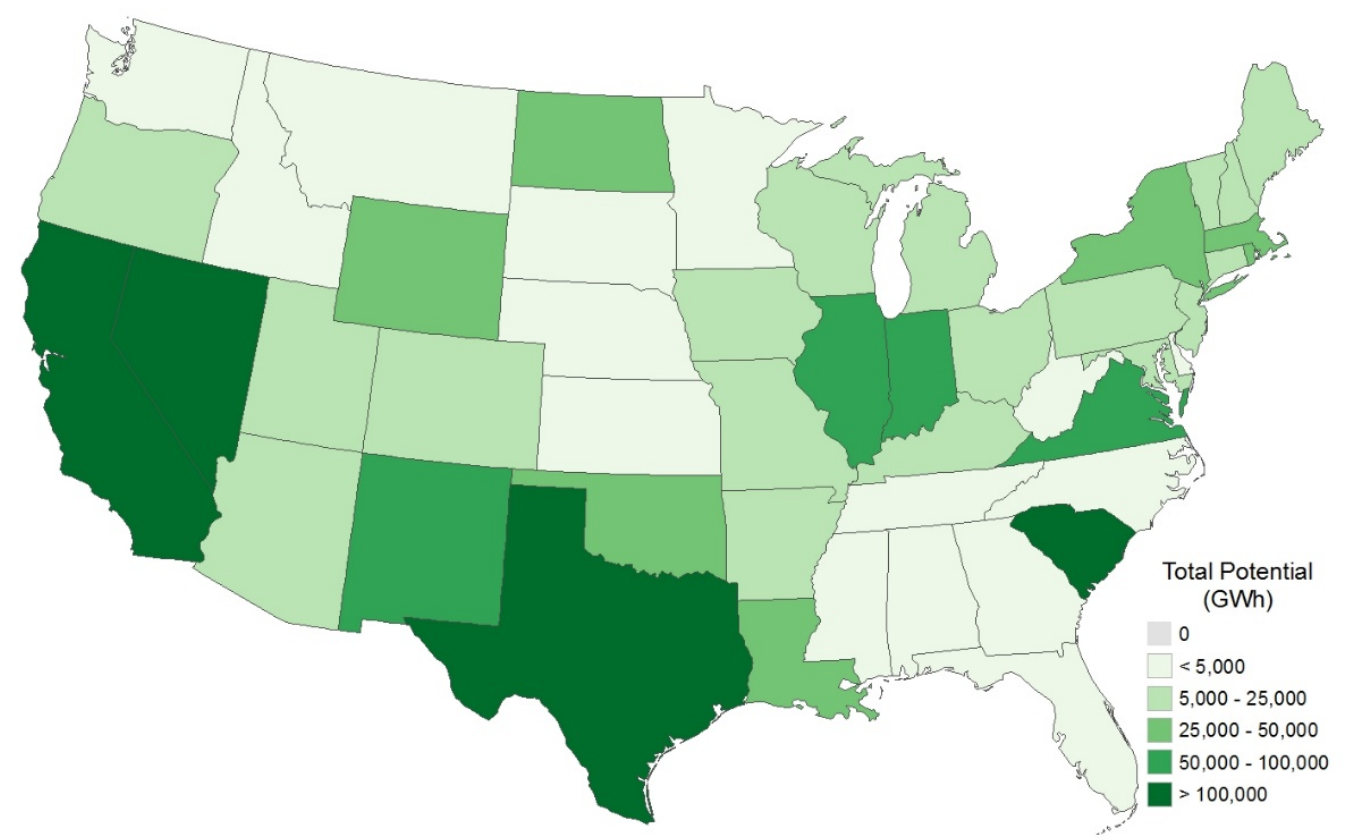

Figure ES-4a. Estimated economic potential by state - annual generation sum of assessed technologies (Primary Case 3 with full capacity value)

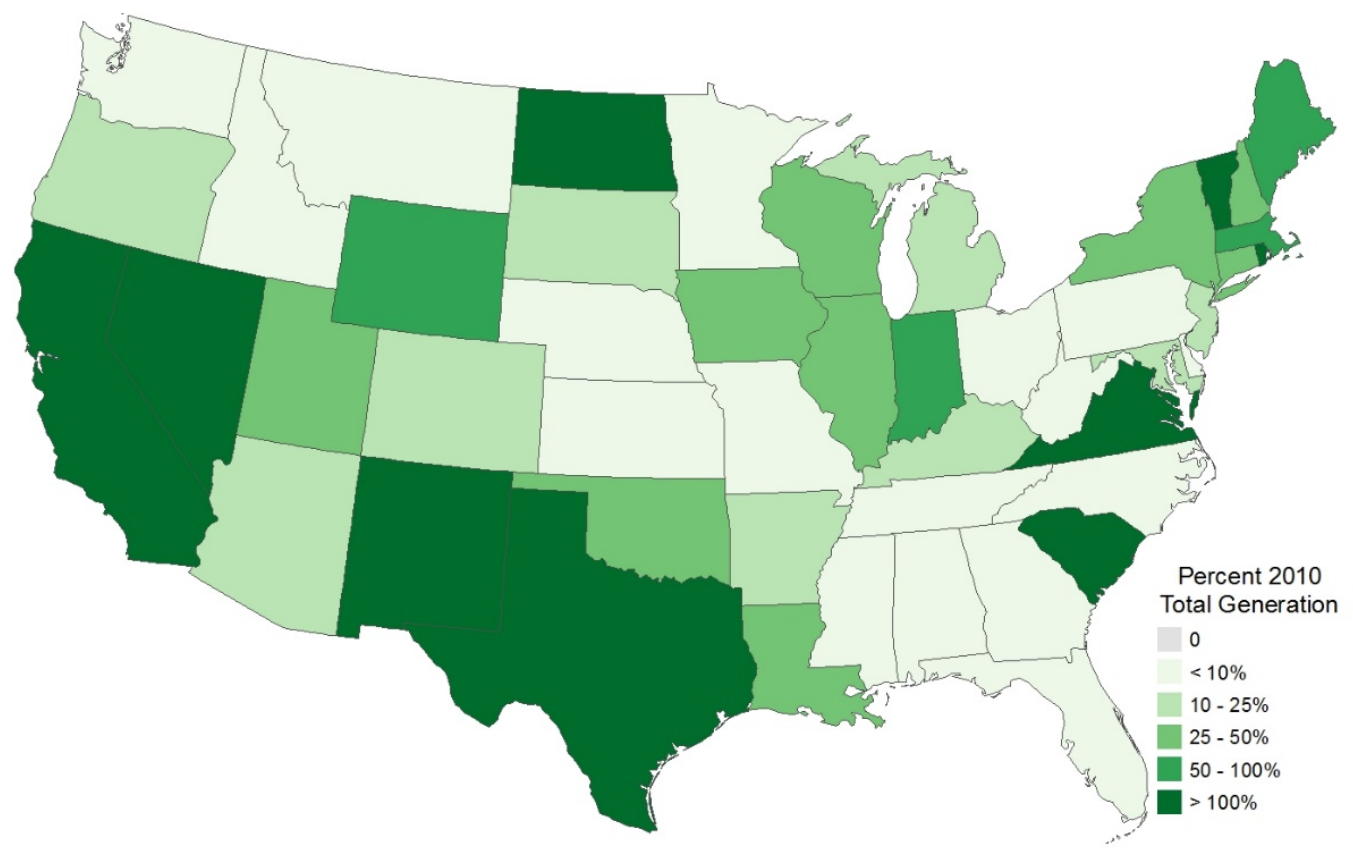

Figure ES-4b. Estimated economic potential by state - annual generation sum of assessed technologies (Primary Case 3 with no capacity value)

Note: Annual generation shown is incremental to 2013 levels. These maps sum the potential estimated independently for the assessed technologies. As such, the estimates do not consider any potential competition among the technologies for available land or in economic terms. Further, the estimate does not reflect any impact of the interaction of variable wind and UPV generation upon the value of either technology. Wind generation potential exceeds $40 \%$ of 2013 total generation in Texas for both Primary Case 3 cases; as a consequence, wind potential for that state may be overstated as the declining value method applied does not reduce the value of wind further as its potential share of generation exceeds $40 \%$. 
Individual technologies make the following contributions to aggregate Primary Case 3 results (see Figure ES-5 for potential by Census division):

- Wind is estimated to provide 550-870 TWh of annual potential in these cases, concentrated in the central part of the country (West South Central Census division). Significant amounts of existing generation also appear in the Pacific region.

- UPV is estimated to provide 430 to nearly $610 \mathrm{TWh}$ of annual potential, which appears in Nevada and Texas (currently small in existing generation), Arizona, and along the Eastern seaboard, including South Carolina.

- Distributed PV (residential and commercial) is estimated to provide 190 to nearly $290 \mathrm{TWh}$ of annual potential, which appears in the southwest (Pacific and Mountain Census division) and along the Eastern seaboard, consistent with existing generation.

- Hydropower is estimated to provide 64 to $76 \mathrm{TWh}$ of annual potential, which appears in every Census division.

- Geothermal (hydrothermal resources only) is estimated to provide $130-150 \mathrm{TWh}$ of annual potential, which appears only in the West (Pacific and Mountain Census divisions), consistent with the location of existing generation.

Biopower, specifically dedicated combustion plants with co-firing not included, shows no economic potential under this formulation. 


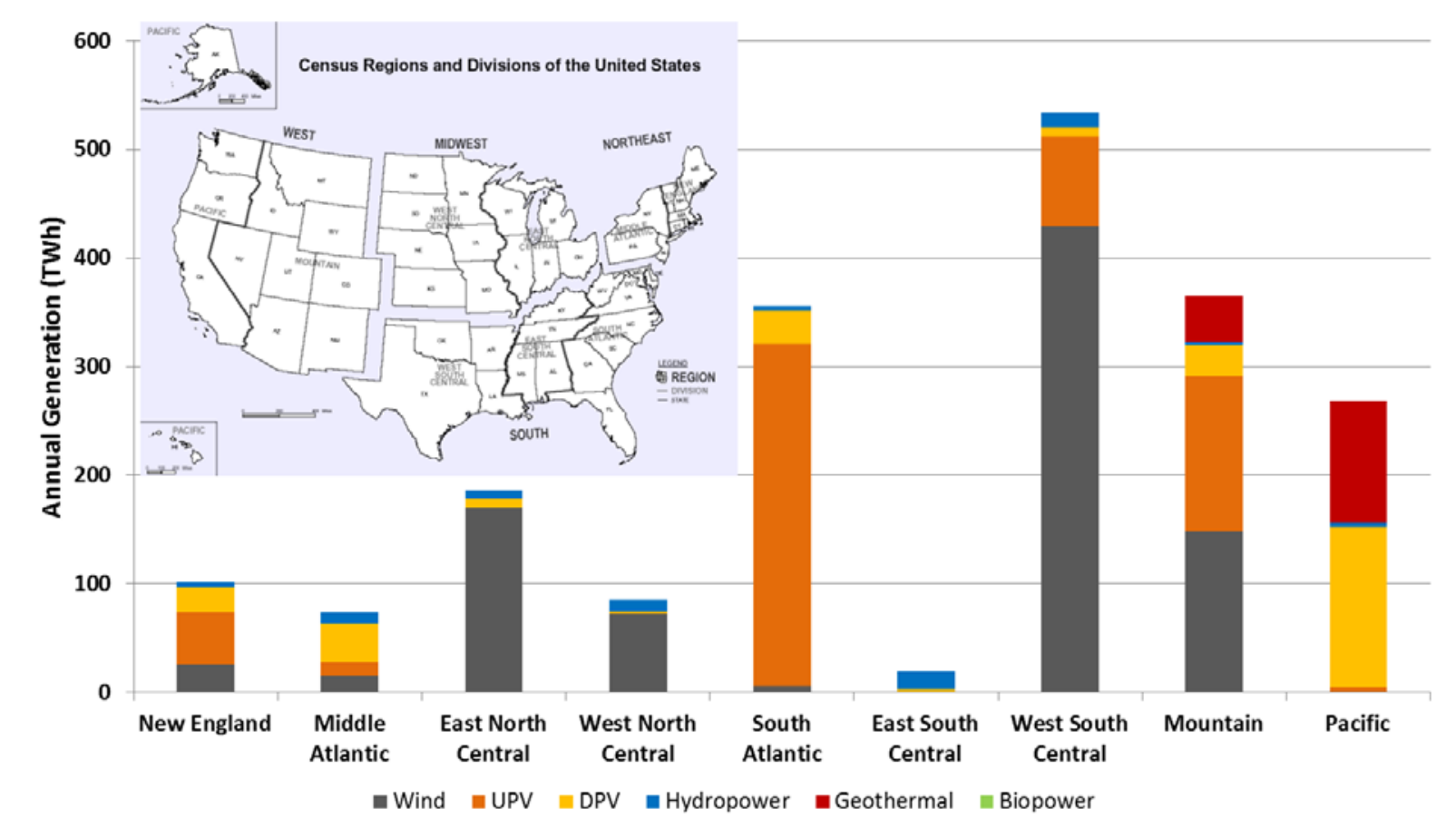

Figure ES-5. Estimated economic potential by Census division - annual generation (Primary Case 3 with full capacity value)

Note: Annual generation shown is incremental to 2013 levels. Wind generation potential exceeds $40 \%$ of 2013 total generation in some regions (primarily West South Central) and may be overstated as the declining value method applied does not reduce the value of wind further because its potential share of generation exceeds $40 \%$. UPV potential estimated in the South Atlantic and Mountain divisions reflects higher than average marginal generation prices in South Carolina and Nevada, respectively, as reported in the data sources used.

The following general findings and trends are observed based on the above initial estimates and in the sensitivity analysis reported in the full text:

- The specific formulation of the economic potential metric is extremely important. Across the three distinct formulations of the definition used in this analysis, economic potential estimates varied by almost 30 -fold. As with all metrics, care should be applied in definition and supporting details to avoid misleading conclusions.

- Estimates of economic potential are highly sensitive to the specific assumptions used related to both renewable generation supply and avoided cost. The capacity value of renewable generation, external costs and associated discount rates, and the declining value of variable generation with increased penetration have a major impact on estimates. The reference year for project construction, renewable technology costs, and the method and assumptions associated with the avoided cost of generation are other variables that have a significant effect on estimates.

- Economic potential appears in all states for at least one of the renewable generation technologies assessed, depending on the specific formulation of economic potential considered. 
- Technology costs are a significant driver for economic potential, as seen in the sensitivity cases in Primary Case 3. Annual generation potential, assuming full credit for the capacity value for renewable generation, is the following for the corresponding assumed costs (highest to lowest costs): 250 TWh (2010), 990 TWh (2014), 2,000 TWh (2020 mid), and 3,500 TWh (2030 mid). Cost reductions already realized for renewable generation technologies between 2010 and 2014, particularly for wind and solar PV technologies, increase aggregate potential under this formulation by nearly $300 \%$.

- Despite recent growth, total renewable energy deployed overall remains small compared to the total technical potential, except for the relatively developed technologies of hydropower, geothermal, and biopower. For wind and distributed solar photovoltaics (DPV), a small amount of technical potential has been developed, and economic potential is significantly more than what has been deployed to date. For utility-scale photovoltaics UPV, technical potential is extremely large (greater than all other renewables together), and deployed and economic potential are small in comparison.

The spreadsheet-based model used to conduct this analysis is expected to be updated and refined to reflect new data and analysis as they become available. In particular, the use of wholesale market price data as a basis for a geospatial representation of avoided costs is an emerging area of analysis. Several improvement opportunities for the methodology, underlying data, and scenario analysis have been identified, which can be developed and applied in future updates. 


\section{Table of Contents}

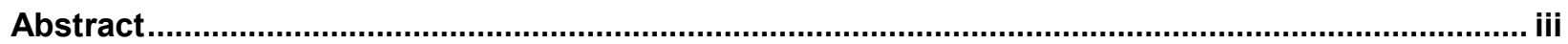

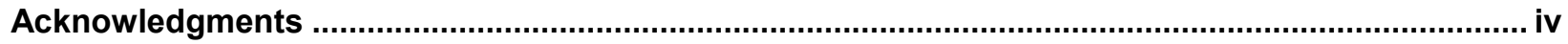

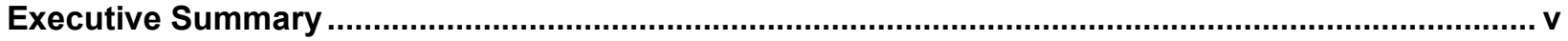

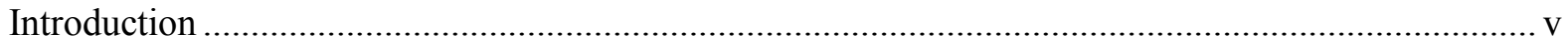

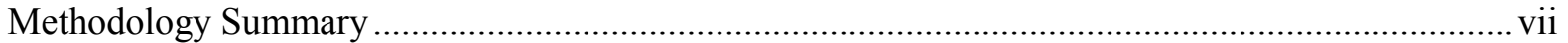

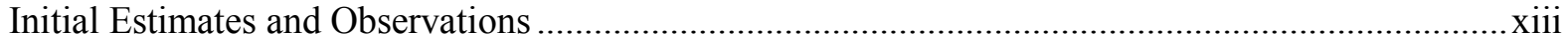

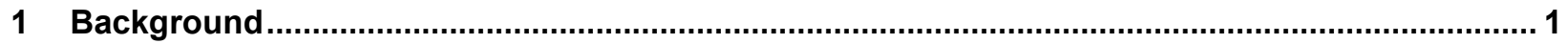

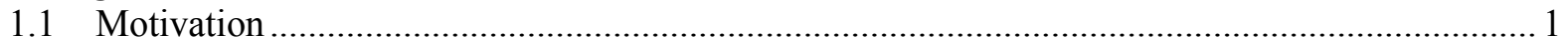

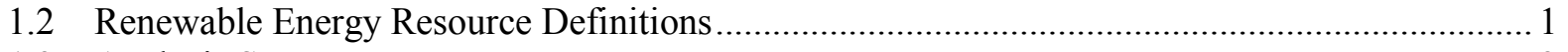

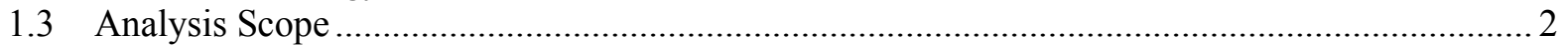

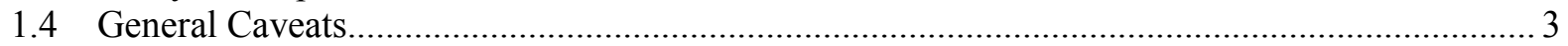

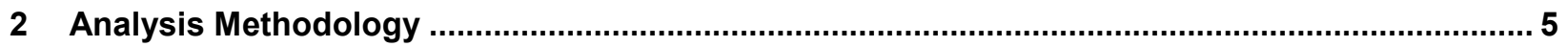

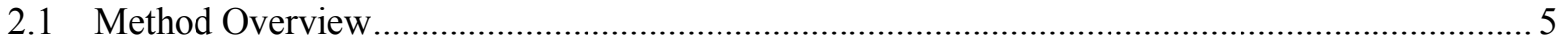

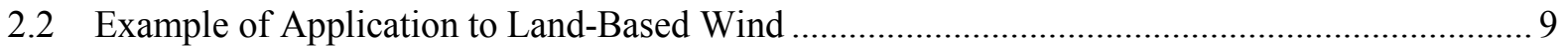

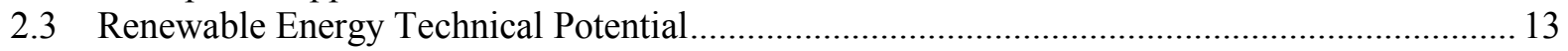

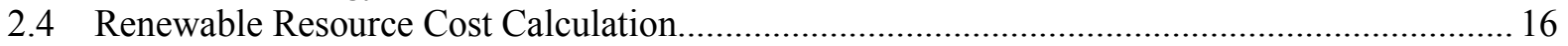

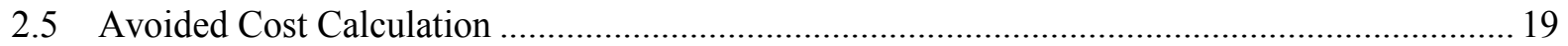

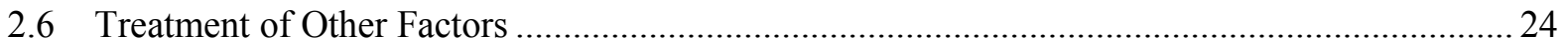

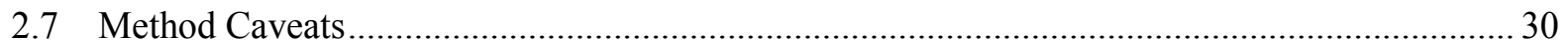

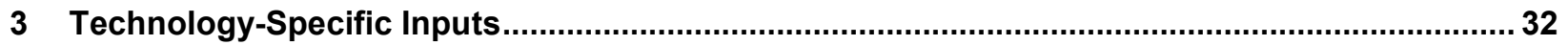

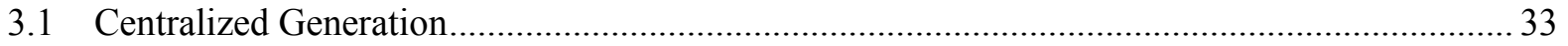

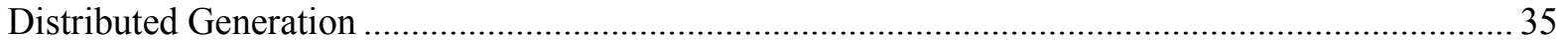

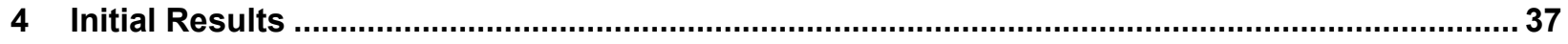

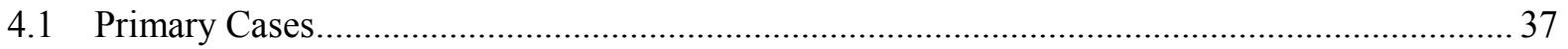

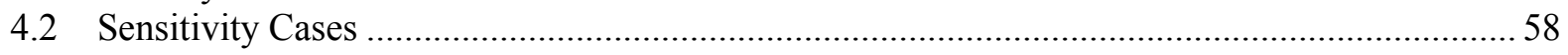

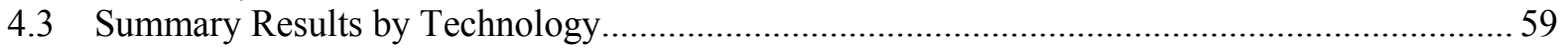

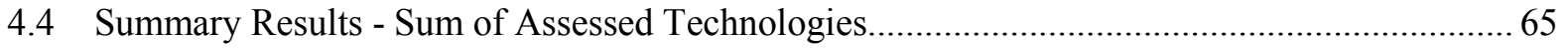

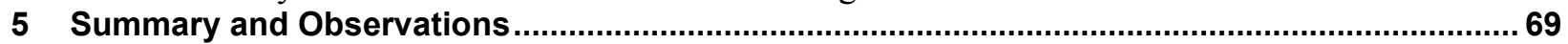

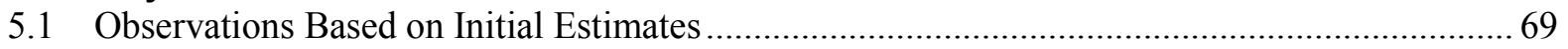

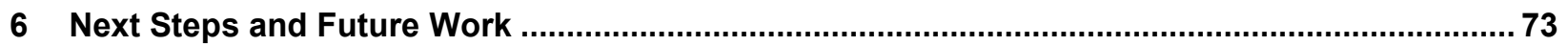

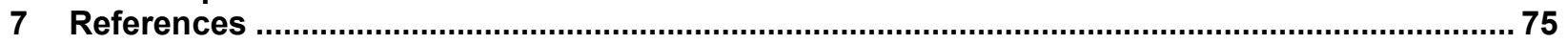

Appendix A. Updated Technical Potential for Assessed Technologies ............................................ 79

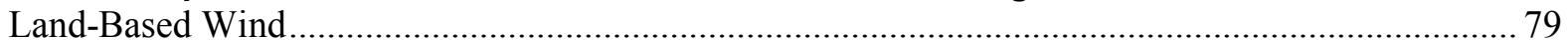

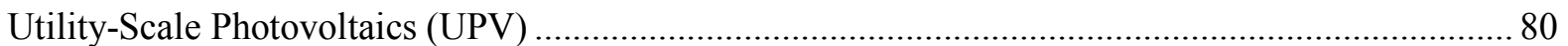

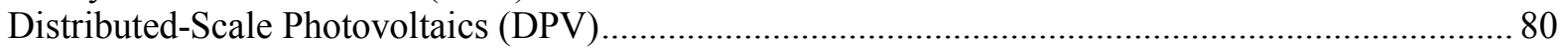

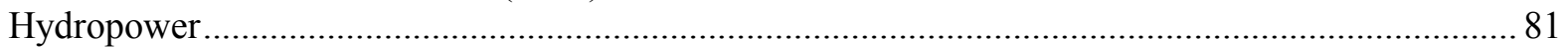

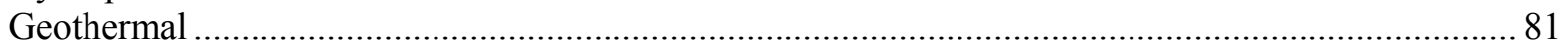

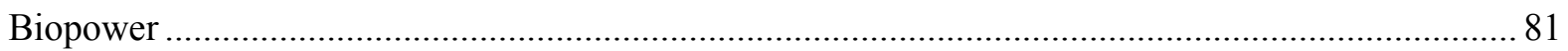

Appendix B. Renewable Generation Potential in the Context of Fossil Energy Resources .............. 90

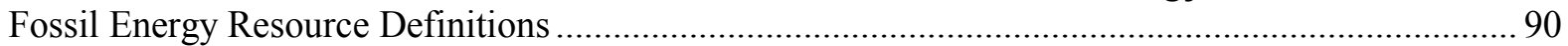

Analogies Between Fossil and Renewable Energy Resource Terms ............................................... 90

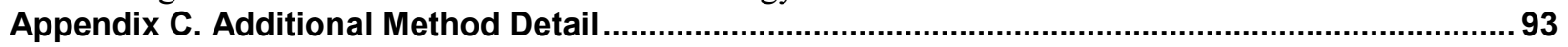

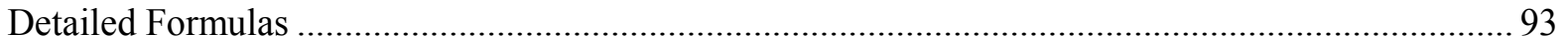

Alternate Average Avoided Generator (AAG) Method for Avoided Generation Cost ....................... 95

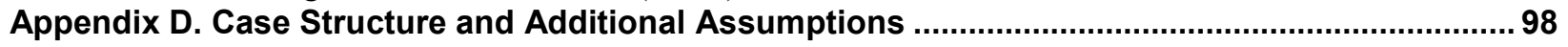

Appendix E. Method Calculation Flow Intermediate Products....................................................... 99

Appendix F. Economic Potential Estimates (Primary Cases) by State ..................................... 117

Appendix G. Economic Potential Maps for Selected Primary Case 3 Sensitivity Cases ................ 123

Scenario Cases - Sum of Assessed Technologies ......................................................................... 123 


\section{List of Tables}

Table ES-1. Estimated Aggregated U.S. Economic Potential for Primary Cases.....................................xvi

Table 1. Centralized Generation Technologies Underlying Resource Data and Resolution ...................... 14

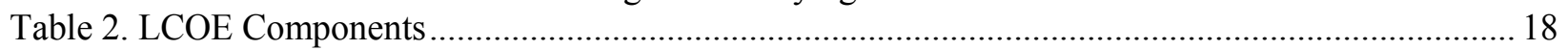

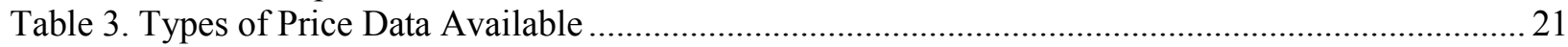

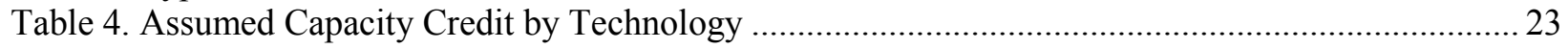

Table 5. Overview of Renewable Technology Cost Assumptions Under Primary Cases ......................... 32

Table 6. Wind Estimated U.S. Economic Potential - Primary Cases .................................................... 40

Table 7. UPV Estimated U.S. Economic Potential - Primary Cases ..................................................... 43

Table 8. DPV Estimated U.S. Economic Potential - Primary Cases ...................................................... 46

Table 9. Hydropower Estimated U.S. Economic Potential - Primary Cases ........................................... 48

Table 10. Geothermal Estimated U.S. Economic Potential - Primary Cases ............................................ 51

Table 11. Biopower Estimated U.S. Economic Potential - Primary Cases ….......................................... 53

Table 12. Estimated Aggregated U.S. Economic Potential for Primary Cases........................................ 54

Table 13. Estimated Aggregated U.S. Economic Potential for All Cases Assessed ................................. 71

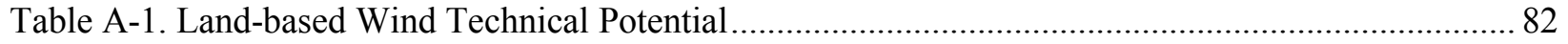

Table A-2. Utility-scale Photovoltaics (UPV) Technical Potential ....................................................... 83

Table A-3. Distributed-scale Residential Photovoltaics (DPV - Residential) Technical Potential............ 84

Table A-4. Distributed-scale Commercial Photovoltaics (DPV - Commercial) Technical Potential ........ 85

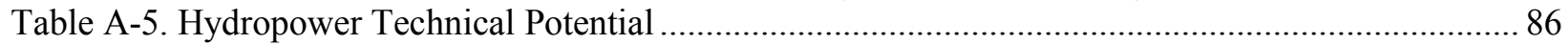

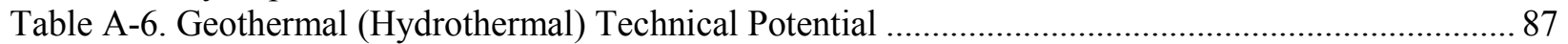

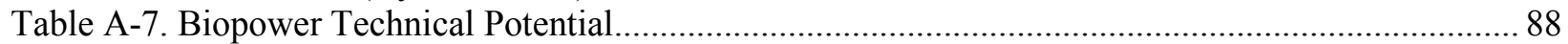

Table A-8. Estimated Aggregated Technical Potential by Technology (Continental United States) ......... 89

Table B-1. Summary of Analogous (Although Not Quantitatively Comparable) Terms ......................... 92

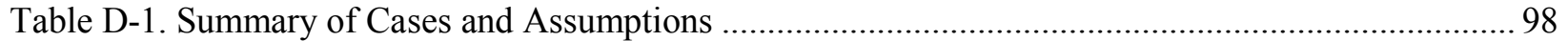

Table F-1. Economic Potential Estimates (Primary Case 1a) by State ................................................... 117

Table F- 2. Economic Potential Estimates (Primary Case 1b) by State ................................................... 118

Table F- 3. Economic Potential Estimates (Primary Case 2a) by State ................................................. 119

Table F- 4. Economic Potential Estimates (Primary Case 2b) by State ................................................. 120

Table F-5. Economic Potential Estimates (Primary Case 3a) by State .................................................. 121

Table F-6. Economic Potential Estimates (Primary Case 3b) by State .................................................. 122

\section{List of Figures}

Figure ES-1. Types of Renewable Generation Potential ......................................................................... vi

Figure ES-2. Generalized method calculation flow for centralized technologies based on high geospatial

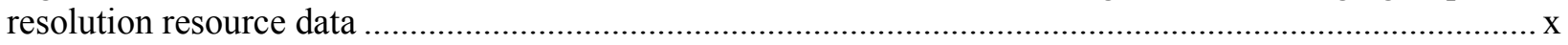

Figure ES-3. Aggregated Estimated U.S. Economic Potential (Primary Case 3) .................................. xvi

Figure ES-4a. Estimated economic potential by state - annual generation sum of assessed technologies

(Primary Case 3 with full capacity value) ..............................................................................................

Figure ES-4b. Estimated economic potential by state - annual generation sum of assessed technologies

(Primary Case 3 with no capacity value) ...............................................................................................

Figure ES-5. Estimated economic potential by Census division - annual generation (Primary Case 3

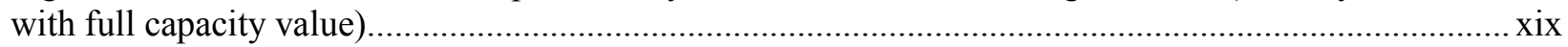

Figure 1. Levels of renewable energy potential ................................................................................... 2

Figure 2. Generalized method calculation flow for centralized technologies based on high geospatial

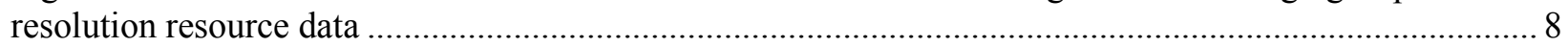

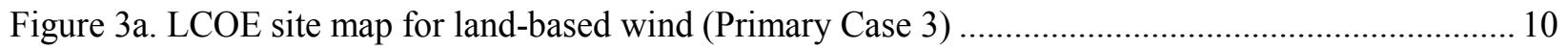

Figure 3b. LACE site map for land-based wind (Primary Case 3 with full capacity value)...................... 11

Figure 3c. Net value map for land-based (Primary Case 3 with full capacity value) ............................... 12 
Figure 3d. Aggregated U.S. net value supply curve for land-based wind (Primary Case 3 with full

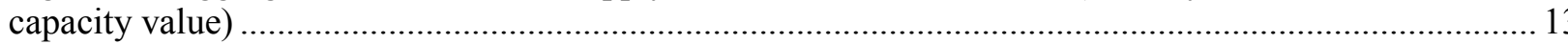

Figure 4. Land-based exclusion areas for land-based wind potential .................................................. 15

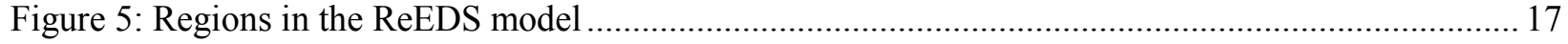

Figure 6. Data sources for market price estimates ........................................................................... 22

Figure 7. Market price estimates with projected price changes from 2014-2034 (EIA 2015) taken into

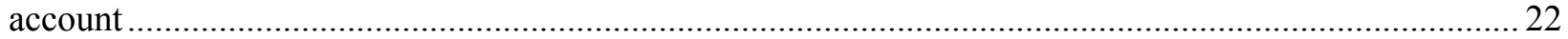

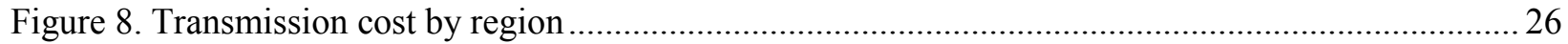

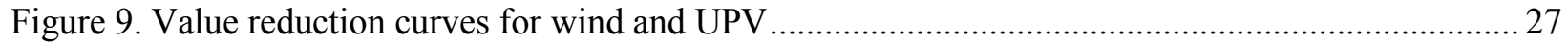

Figure 10. Regions used to estimate existing generation and potential generation share ........................ 28

Figure 11a. Wind economic potential - annual generation (Primary Case 1 with full capacity value) ...... 40

Figure 11b. Wind economic potential - annual generation (Primary Case 2 with full capacity value) ...... 41

Figure 11c. Wind economic potential - annual generation (Primary Case 3 with full capacity value) ...... 41

Figure 11d. Wind economic potential - annual generation (Primary Case 3 with full capacity value)

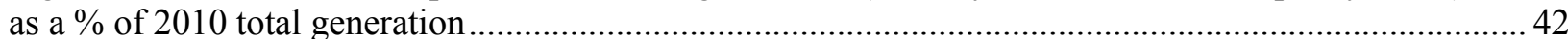

Figure 12a. UPV economic potential - annual generation (Primary Case 1 with full capacity value) ....... 43

Figure 12b. UPV economic potential - annual generation (Primary Case 2 with full capacity value) ....... 44

Figure 12c. UPV economic potential - annual generation (Primary Case 3 with full capacity value) ....... 44

Figure 12d. UPV economic potential - annual generation (Primary Case 3 with full capacity value)

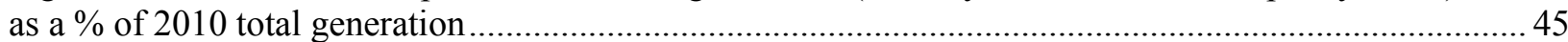

Figure 13a. DPV economic potential: Residential - annual generation (Primary Cases 2 and 3)............. 46

Figure 13b. DPV economic potential: Commercial - annual generation (Primary Cases 2 and 3)............ 47

Figure 13c. DPV economic potential: Residential and Commercial - annual generation (Primary

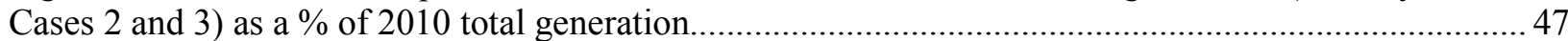

Figure 14a. Hydropower economic potential: annual generation (Primary Cases 2 and 3 with full capacity value)

Figure 14b. Hydropower economic potential: annual generation (Primary Cases 2 and 3 with full

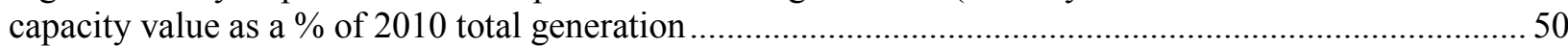

Figure 15a. Geothermal economic potential: annual generation (Primary Cases 2 and 3 with full

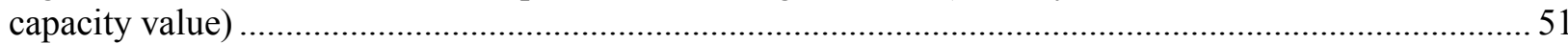

Figure 15b. Geothermal economic potential: annual generation (Primary Cases 2 and 3 with full

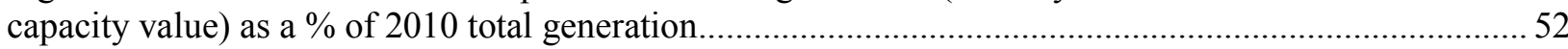

Figure 16a. Sum of assessed technologies: economic potential - annual generation (Primary Case 1)

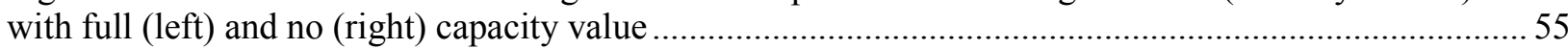

Figure 16b. Sum of assessed technologies: economic potential (Primary Case 1) Annual generation

as $\%$ of 2010 total generation with full (left) and no (right) capacity value ............................................55

Figure 16c. Sum of assessed technologies: economic potential - annual generation (Primary Case 2)

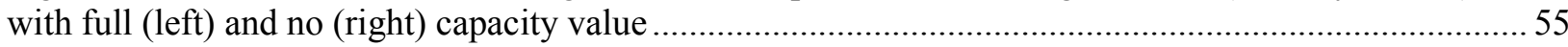

Figure 16d. Sum of assessed technologies: economic potential (Primary Case 2) Annual generation

as $\%$ of 2010 total generation with full (left) and no (right) capacity value .............................................5 56

Figure 16e. Sum of assessed technologies: economic potential - annual generation (Primary Case 3)

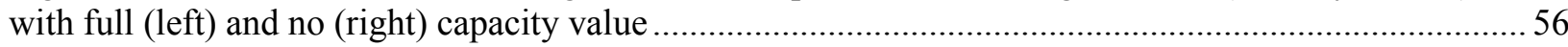

Figure 16f. Sum of assessed technologies: economic potential (Primary Case 3) Annual generation

as $\%$ of 2010 total generation with full (left) and no (right) capacity value ...........................................5 56

Figure 17a. Aggregated Estimated U.S. Economic Potential (Primary Case 3) ...................................... 57

Figure 17b. Economic potential - annual generation (Primary Case 3 with full capacity value) by

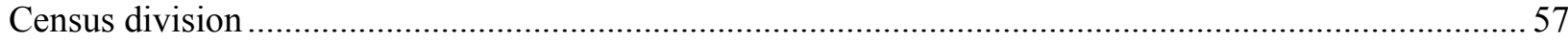

Figure 18: Comparison of deployed, economic, and remaining technical potential in Primary Case 1

(left), 2 (center), and 3 (right) with full capacity value) .................................................................... 58

Figure 19. Wind aggregated U.S. economic potential by sensitivity - annual generation ......................... 60

Figure 20. UPV aggregated U.S. economic potential by sensitivity - annual generation.......................... 61 
Figure 21. DPV aggregated U.S. economic potential by sensitivity - annual generation.....

Figure 22. Hydropower aggregated U.S. economic potential by sensitivity - annual generation.............. 63

Figure 23. Geothermal aggregated U.S. economic potential by sensitivity - annual generation ............... 64

Figure 24a. Sum of estimated U.S. economic potential for assessed technologies - Framework

Sensitivities

Figure 24b. Sum of estimated U.S. economic potential for assessed technologies - Renewable

Technology Cost Sensitivities.

Figure 24c. Sum of estimated U.S. economic potential for assessed technologies - Avoided Generation

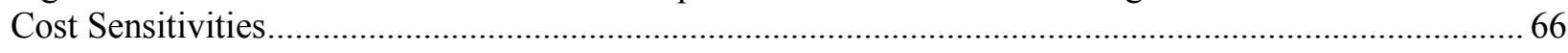

Figure 24d. Sum of estimated U.S. economic potential for assessed technologies - Avoided External

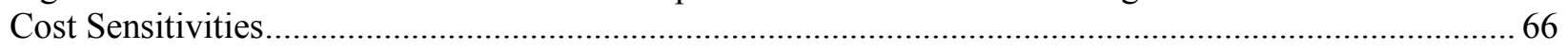

Figure C-1. Marginal price curve for PJM's Day-Ahead Market mapped to marginal unit type............... 95

Figure C-2. Example estimated avoided costs for wind, including generation and capacity components,

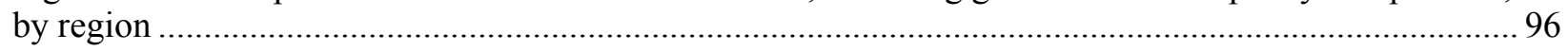

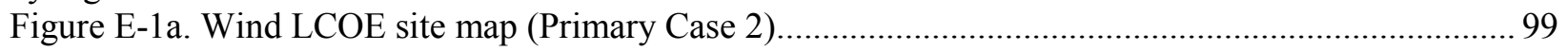

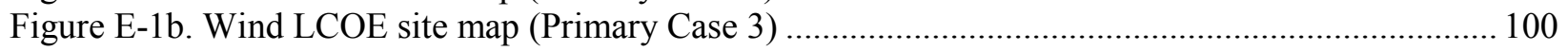

Figure E-1c. Wind aggregated U.S. LCOE supply curve (Primary Case 3) ......................................... 100

Figure E-2. Wind LACE site map (Primary Cases 2 and 3 with full credit for renewable generation

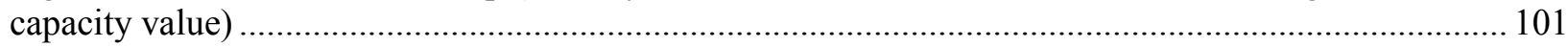

Figure E-3a. Wind net value map (Primary Case 2 with full credit for renewable generation capacity

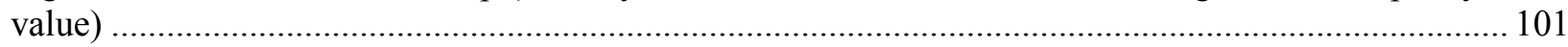

Figure E-3b Wind net value map (Primary Case 3 with full credit for renewable generation capacity

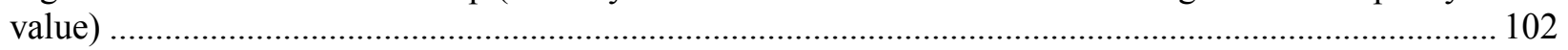

Figure E-3c. Wind aggregated U.S. wind net value supply curve (Primary Case 3 with full credit for

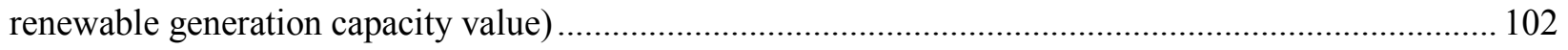

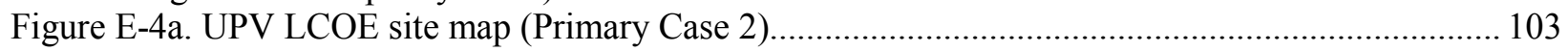

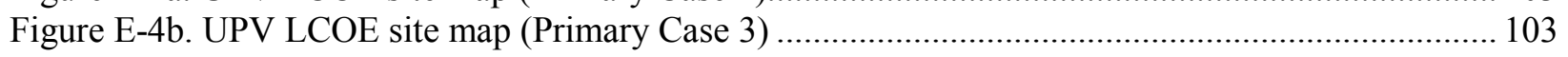

Figure E-4c. UPV aggregated U.S. LCOE supply curve (Primary Case 3) ......................................... 104

Figure E-5. UPV LACE site map (Primary Cases 2 and 3 with full credit for renewable generation

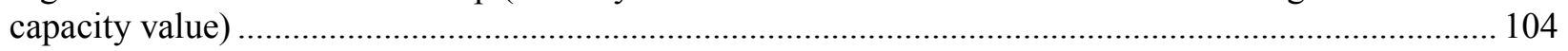

Figure E-6a. UPV net value map (Primary Case 2 with full credit for renewable generation capacity

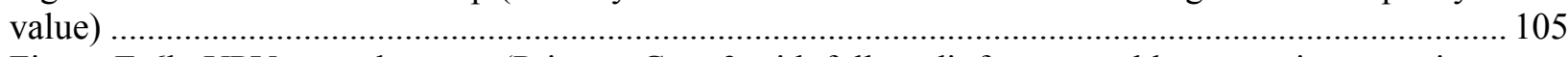

Figure E-6b. UPV net value map (Primary Case 3 with full credit for renewable generation capacity

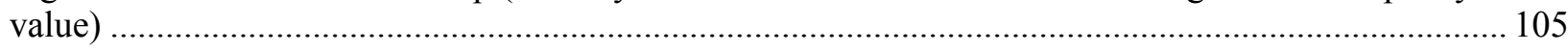

Figure E-6c. UPV aggregated U.S. net value supply curve (Primary Case 3 with full credit for

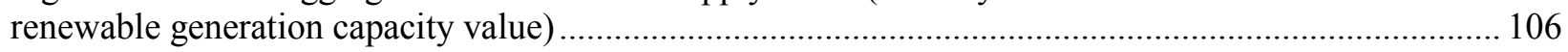

Figure E-7a. DPV - residential retail rate map by utility area (Primary Cases 2 and 3) ....................... 106

Figure E-7b. DPV - commercial retail rate map by utility area (Primary Cases 2 and 3) ...................... 107

Figure E-8a. DPV - residential net value map by utility area (Primary Cases 2 and 3).......................... 107

Figure E-8b. DPV - commercial net value map (medium-sized office building) by utility area (Primary

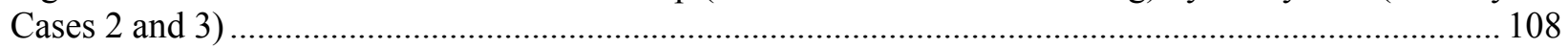

Figure E-9a. DPV - aggregated U.S. residential net value supply curve (Primary Cases 2 and 3)) ......... 108

Figure E-9b. DPV aggregated U.S. commercial net value supply curve (Primary Cases 2 and 3)) ......... 109

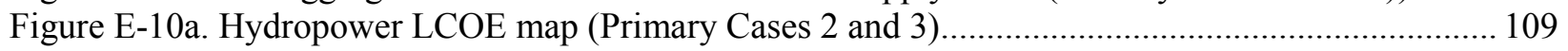

Figure E-10b. Hydropower aggregated U.S. LCOE supply curve (Primary Cases 2 and 3) .................. 110

Figure E-11. Hydropower LACE map (Primary Cases 2 and 3 with full credit for renewable generation

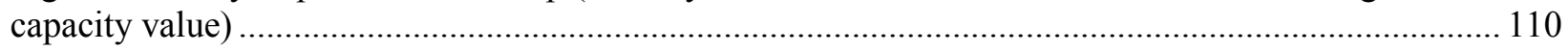

Figure E-12a. Hydropower net value map (Primary Cases 2 and 3 with full credit for renewable

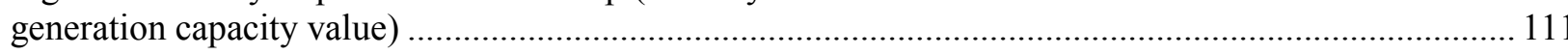

Figure E-12b. Hydropower aggregated U.S. net value supply curve (Primary Cases 2 and 3 with full

credit for renewable generation capacity value). 
Figure E-13a. Geothermal LCOE map (Primary Cases 2 and 3 ).

Figure E-13b. Geothermal aggregated U.S. geothermal LCOE supply curve (Primary Cases 2 and 3)... 112 Figure E-14. Geothermal LACE map (Primary Cases 2 and 3 with full credit for renewable generation capacity value)

Figure E-15a. Geothermal net value map (Primary Cases 2 and 3 with full credit for renewable generation capacity value)

Figure E-15b. Geothermal aggregated U.S. net value supply curve (Primary Cases 2 and 3 with full credit for renewable generation capacity value)

Figure E-16a. Biopower LCOE map (Primary Cases 2 and 3)

Figure E-16b. Biopower aggregated U.S LCOE supply curve (Primary Cases 2 and 3).....

Figure E-17. Biopower LACE map (Primary Cases 2 and 3 with full credit for renewable generation capacity value)

Figure E-18a. Biopower net value map (Primary Cases 2 and 3 with full credit for renewable generation capacity value)

Figure E-18b. Biopower aggregated U.S. net value supply curve (Primary Cases 2 and 3 with full credit for renewable generation capacity value)

Figure G-1a. Economic potential - sum of assessed technologies (2020 construction date) annual generation (Primary Case 3 with full credit for renewable generation capacity value)

Figure G-1b. Economic potential - sum of assessed technologies (2020 construction date) annual generation as \% of 2010 total generation (Primary Case 3 with full credit for renewable generation capacity value)

Figure G-2a. Economic potential - sum of assessed technologies (RE Cost - 2014 with PTC and 30\%

ITC) annual generation (Primary Case 3 with full credit for renewable generation capacity value)........ 124

Figure G-2b. Economic potential - sum of assessed technologies (RE Cost - 2014 with PTC and 30\%

ITC) annual generation as \% of 2010 total generation (Primary Case 3 with full credit for renewable generation capacity value)

Figure G-3a. Economic potential - sum of assessed technologies (Declining Value Increasing with Regional Limits) annual generation (Primary Case 3 with full credit for renewable generation capacity value)

Figure G-3b. Economic potential - sum of assessed technologies (Declining Value Increasing with Regional Limits) annual generation as \% of 2010 total generation (Primary Case 3 with full credit for renewable generation capacity value)

Figure G-4a. Economic potential - sum of assessed technologies (RE Cost - $2030 \mathrm{Mid}$ ) annual generation (Primary Case 3 with full credit for renewable generation capacity value)

Figure G-4b. Economic potential - sum of assessed technologies (RE Cost - $2030 \mathrm{Mid}$ ) annual generation as $\%$ of 2010 total generation (Primary Case 3 with full credit for renewable generation capacity value) 


\section{Background}

\subsection{Motivation}

The economic potential method described in this report attempts to assess and quantify economically viable renewable generation using high resolution geospatial data. This metric can be a useful as a screening factor for understanding what locations may have development potential, as well as for assessing the impact of technology improvements, policies, and other actions that can mitigate market barriers. While estimates of renewable generation technical and market potential have been previously reported, no method has previously been reported for economic potential.

Development of a consistent method to estimate economic potential across renewable technologies began following the completion of a 2012 technical potential assessment (Lopez et al. 2012), which applied unifying assumptions and methods to generate comparable estimates across technologies and estimated technical potential to be many times greater than current U.S. electricity demand. Concurrently, sufficient data sets on renewable resources, avoided costs, and other parameters had become available for synthesis. This report describes the resulting geospatial analysis method and its initial application to estimate the economic potential of several renewable resources available for electricity generation in the United States as of data available in 2014. The method employs high-resolution geospatial data, including more than 150,000 technology-specific sites in the continental United States, to reflect the significant variation in local resource, costs and revenue potential. These estimates are anticipated to change as technology cost and performance, as well as expected revenues for any given location, change.

\subsection{Renewable Energy Resource Definitions}

Economic potential, one form of renewable generation potential, is a metric that attempts to quantify the amount of economically viable renewable generation that is available at a location or within an area. More specifically, economic potential in this report is defined as the subset of the available technical potential where the cost required to generate the energy (which determines the minimum revenue requirements for development of the resource) is below the revenues available in terms of displace energy and displaced capacity.

Economic potential for a location can be understood in relation to other types of renewable energy potential that have previously been broadly defined (Figure 1). The largest potential, resource potential, is the amount of energy physically available. For example, with solar, it is the total light energy striking the location. Technical potential takes into account real-world geographic constraints and system performance, but not economics. For the solar example, technical potential would be the amount of energy available if all technically feasible area were used for solar PV panels, accounting for the efficiency of conversion to electricity. Appendix A provides an update to the earlier technical potential analysis (Lopez et al., 2012) for the set of technologies used as the basis for this work. 


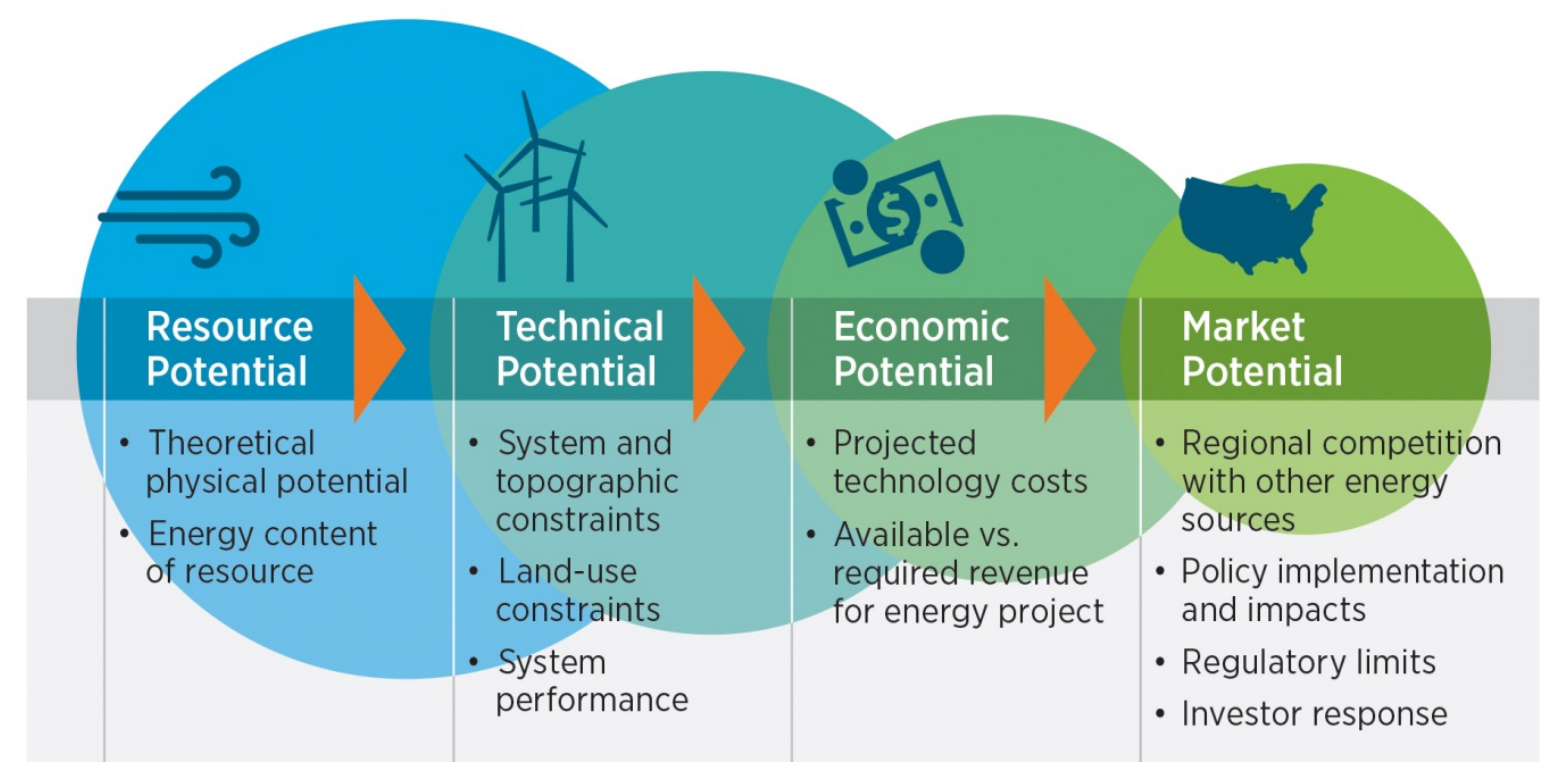

Figure 1. Levels of renewable energy potential

Economic potential is the subset of the technical potential that is available where the cost required to generate the energy (which determines the minimum revenue requirements for development of the resource) is below the revenues available in terms of displaced energy and displaced capacity. Lastly, market potential is the amount of energy we expect to be generated through market deployment of renewable technologies after considering the impact of current or future market factors, such as incentives and other policies, regulations, investor response, and the economic competition with other generation sources. The deployment associated with market potential can be estimated through capacity expansion and dispatch modeling, for example using NREL's Regional Energy Deployment System (ReEDS). ${ }^{9}$

An analogous framework is regularly used to characterize fossil resources. Appendix B employs a simplified version of such a framework and explores its alignment with and differences from the above framework.

\subsection{Analysis Scope}

This report describes a geospatial analysis method to estimate the economic potential of several renewable resources available for electricity generation in the United States. The assessment is conducted at a high geospatial resolution (more than 150,000 technology-specific sites in the continental United States) to capture the significant variation in local resource, costs, and revenue potential. This metric can be a useful screening factor for understanding the economic viability of renewable generation technologies at a specific location or for the country, building up from detailed geospatial resolution data. In contrast to many common estimates of renewable energy potential, economic potential does not consider market dynamics, customer demand or policy drivers that incent renewable energy generation. This work represents an initial effort to develop and apply a method for assessing economic potential; future work may deliver different

\footnotetext{
${ }^{9}$ For example, DOE (2012), NREL (2012), and DOE (2015a) are examples of several recent market analyses. For more information on ReEDS, a multiregional, multi-time period, geographic information system (GIS) and linear programming model, see http://www.nrel.gov/analysis/reeds/.
} 
results as the method is further developed and refined or technology cost and performance and other factors change. The specific definition used for economic potential, and the resulting method to estimate it, is one of many possible; use of other definitions would result in different results. Economic potential cannot be used to predict what will be deployed and should not be expected to match estimates found in deployment scenarios.

The method is applied to several renewable generation technologies under a variety of assumptions - including land-based wind, utility photovoltaics (UPV), distributed photovoltaics (DPV), hydropower, geothermal (hydrothermal resource only), and biopower (dedicated combustion plants only, not including co-firing), primarily from a 2014 perspective. ${ }^{10}$ The preliminary results of this application are intended to demonstrate the utility of the method described, and serve as an initial estimate of the range of economic potential, as well as an exploration of a number of the factors that influence economic potential. While the method is described in general terms, its application to specific technologies is based on available data from related analysis and relies on multiple assumptions.

\subsection{General Caveats}

This methodology can provide an initial estimate of the economic viability of various types of renewable generation at a specific location. This type of estimate can be useful for initial screening applications and in assessing the impact of a variety of factors, including incentives and technology cost, on economic viability. The model applied is generally simpler and offers greater transparency than market models that employ more sophisticated techniques like optimization.

There are several caveats, however, that are important to keep in mind when considering the methodology, and in turn the initial estimates resulting from its application:

- The methodology does not attempt to project the amount of renewable generation that might actually be deployed in the future. While some market factors are considered in the net value framework, it does not comprehensively consider market conditions and other factors that could affect potential deployment. Instead, the method provides an estimate of the amount of renewable generation that could be economically viable at current and expected future marginal generation prices and capacity values, in some cases considering the value of avoided $\mathrm{CO}_{2}$ emissions or the declining value of variable renewable generation with increasing penetration.

- The method described is not intended to replace engineering, project-based, or site analysis, which are necessary to fully assess the economic viability of a technology system by accounting for project-specific issues. The economic potential metric is also not a substitute for capacity expansion or production cost modeling, which takes electricity demand and system operations constraints, including the availability of transmission capacity, and market

\footnotetext{
${ }^{10}$ This analysis assesses some less mature renewable energy technologies, in terms of existing deployment, but not any technologies that represent less than $0.2 \%$ of total U.S. electricity generation in 2013, in part due to limited data availability. Future work may consider the economic potential of these technologies, including offshore wind, concentrating solar power (CSP), marine hydrokinetic, and enhanced geothermal systems.
} 
factors into account, such as economic competition among different renewable or conventional resources. ${ }^{11}$

- More specifically, while the methodology does consider the cost of the cost of tying potential generation into the grid (intra-regional transmission costs), the potential costs and impact of inter-regional transmission on economic potential are not considered. In particular, the approach compares cost of energy and avoided cost to arrive at net value only at the same location, implying that renewable generation would be used to satisfy load at that location or within the balancing area in which the location resides. The method does not consider either export or import situations for a particular location that long-distance transmission could enable (i.e., the cost of energy at one location, including inter-regional transmission cost, is not compared to the avoided cost in another location that could be served by that transmission. As such, the economic potential estimates based on this method will not identify all the economically viable potential for specific technologies, like land-based wind, that may have low-cost resources at locations remote from load. That is, in some cases sitespecific generation may be economically attractive when delivered to another load center, even when transmission and other integration costs are included in the calculation. ${ }^{12}$

- The framework described is static and considers economic potential only at a particular point in time based on the vintage of underlying data and assumptions, including electricity price projections, technical potential, cost of energy, and avoided cost. As resource data, technology cost and performance, actual renewable technology deployment, transmission infrastructure, fuel prices, wholesale electricity prices, and other factors change, estimates of economic potential will change. Further, the framework does not consider potential dynamic feedbacks that increasing renewable deployment may have on wholesale electricity prices.

- The range of estimates shown is based on readily available data sets and simplifying assumptions. Some of the applied methods, for example, for avoided cost based on market prices and declining value, are initial applications that rely on many assumptions. Some methods for extended factors like intra-regional transmission costs and declining value are applied to only variable generation technologies. Further, supporting data assumptions for both cost of energy and avoided cost components of the methodology, especially those in the form of electricity price projections, are inherently uncertain.

- The method described is under active development; it may be updated to reflect improved understanding of any of the various factors affecting economic potential. In addition, the analysis does not consider the opportunity for future technology innovations to convert resource sites currently excluded from the analysis to technical and subsequently economic potential.

Caveats related to specific methods and initial estimates are identified in later sections of the report.

\footnotetext{
${ }^{11}$ For example, economic potential is based on a different approach than recent and ongoing "vision" studies, including DOE (2012) and DOE (2015a). While some data is common among these analyses, outputs are not expected to be comparable due to the different methods applied and scenarios examined.

12 This issue is generally addressed in capacity expansion models that include a representation of inter-regional transmission (e.g., NREL's ReEDS model) and has been considered in market -based assessments of renewable generation in recent" studies (e.g., NREL 2012; DOE 2012; DOE 2015a).
} 


\section{Analysis Methodology}

This analysis is conducted using a spreadsheet-based model incorporating an established levelized cost of energy method and detailed supply curves, and is expected to be replicable based on the method and data sources described. This section gives a description of the general method, a detailed overview of the method applied to wind as an example, and a summary of the application of the method to other technologies.

\subsection{Method Overview}

The methodology described is based on high geospatial resolution renewable resource and market price data. Economic potential may be defined in multiple ways. For example, one definition might be expected revenues (based on local market prices) minus generation costs, over the expected lifetime of the generation asset. Another might be generation costs relative to a benchmark (e.g., a natural gas combined cycle plant) using assumptions of fuel prices, capital cost, and plant efficiency. Our base methodology uses a slightly more complex structure: economic potential in this report is defined as the subset of available technical potential where the levelized avoided cost of energy (LACE) minus levelized cost of energy generation (LCOE) is positive. The levelized cost of energy generation (LCOE) and the levelized avoided cost of energy (LACE) are estimated for each location of interest (individual site or region) to determine those locations that have positive net value (estimated LCOE less than LACE). We estimate LACE based on a method established in Namovicz (2013) by estimating the potential revenues available to a renewable generation project in terms of displaced energy and displaced capacity. The technical potential for those locations with positive net value are then aggregated to the state and broader region level for reporting estimates.

This approach compares LCOE and LACE at the same location, implying that renewable generation would be used to satisfy load at that location or within the balancing area in which the location resides. The method does not consider either export or import situations for a particular location that long-distance transmission could enable.

The methodology employs four distinct steps for the centralized generation technologies assessed:

- Step 1. Technical Potential: We use the best available renewable resource geospatial data to estimate the achievable energy generation capacity and corresponding annual generation of renewable technologies at specific sites or within defined regions, ${ }^{13}$ depending on the technology, across the continental United States given system performance, topographic limitations, environmental, and land-use constraints. This results in a data set of locations defined by resource characteristics. Technical potential estimates for these locations, assumed to be available in any given future year, are based on updates to methods initially described in Lopez et al. (2012) and applied to resource data sets updated for this analysis (see Appendix A). As in Lopez et al. (2012), wind sites with resource below a technoeconomic threshold based on resource intensity and regional capital costs are excluded from the estimated technical potential; this type of techno-economic limit is not applied for the

\footnotetext{
${ }^{13}$ Sites and regions assessed vary with technology and are based primarily on existing approaches used to prepare resource data for use in ReEDS.
} 
other technologies assessed. Estimates for all technologies do not consider the potential for future technology innovation to increase technical potential, specifically locations with low resource quality that could have technical potential as a result of ongoing or new innovations.

- Step 2. Levelized Cost of Energy (LCOE): We estimate the LCOE for each renewable generation technology at these same locations, incorporating regional plant construction costs, technology cost, and performance and estimated intra-regional transmission costs. We then aggregate these site costs into appropriate regional supply curves (as needed) for comparison with avoided cost. The LCOE estimate is based on methods used and refined at NREL over a number of years (beginning with Short et al. 1995) to develop resource/technology supply curves for NREL's Regional Energy Deployment System (ReEDS) model. For variable resources (i.e., wind and solar), costs are calculated for thousands of individual sites. For other generation technologies, resource data from individual sites or counties are aggregated to supply curves in 134 regions.

- Step 3. Levelized Avoided Cost of Energy (LACE): We estimate a LACE at each of these same locations based on a method established in Namovicz (2013) by estimating the potential revenues available to a renewable generation project at the location, which can be interpreted as the amount the project would be paid for the electrical energy and capacity it can provide (or alternatively, what a utility or other entity would not have to purchase from other sources). This estimate is based on a prevailing regional marginal generation price and capacity value in 2014. In most of the cases examined for centralized technologies, a wholesale Market Price (MP) formulation of LACE is used as a proxy for marginal generation prices. The marginal generation price component of this MP approach takes into account projected electricity price increases over the life of a renewable generation plant (based on EIA AEO 2014 Reference Case price projections in EIA 2014a), levelized to an effective present price. As wholesale price data are not available in every region of the country, this method relies on an initial synthesis of multiple market data sources, including locational marginal prices (LMPs) and market marginal costs (MMCs or system lambdas). ${ }^{14}$ Capacity values are calculated based on a technology specific capacity credit and the overnight capital cost of an advanced natural gas-fired combustion turbine (NGCT) plant as proxy for capacity payment.

- Step 4. Economic Potential: For the full supply curve for each technology, we calculate LACE - LCOE as the net value for a location. A specific location is considered economically viable if its net value is greater than zero; the technical potential associated with locations with positive net value is summed and deemed the economic potential. Exports of generation from one site to another, and consequently inter-regional transmission (costs), are not considered in this analysis. The net value calculation is based solely on the site-specific parameters; as such, exports from a given site to another site with higher LACE values are not part of this assessment. Economic potential estimates are incremental to 2013 generation

\footnotetext{
${ }^{14}$ Reported electricity prices used in the MP formulation are annual averages based on data reported in the Ventyx Velocity Suite (Ventyx, 2015) within upper and lower thresholds designed to exclude effects due to bidding behavior, transmission constraints, etc., so that they can better meet the proxy objective. An alternate Average Avoided Generator (AAG) method that incorporates regional variation in fuel prices and capital costs instead of electricity prices, is applied in a sensitivity analysis to estimate avoided cost by calculating the value of a renewable generation project in displacing a blended mix of typical "marginal" generators (natural gas combined cycle, combustion turbines, and coal plants), where a single mix is applied nationally.
} 
levels; the summation described above is done after removing existing generation from consideration, assuming that already developed resources are the highest net value resource.

For DPV, the same four-step approach is applied independently to estimate potential in the residential and commercial sectors, based on a method described in Denholm et al. (2009). For technical potential, annual technical feasible solar energy generation in the United States is estimated by first assessing available roof space within the service areas of approximately 2,000 utilities with retail residential and/or commercial customers, then estimating associated feasible capacity and production based on assumed system sizes for a 'typical' rooftop and locationspecific solar radiation. A single system capital cost is assumed nationally. Avoided cost is based on retail rate information available for about $70-80 \%$ of U.S. residential customers. The net present value of utility bill savings given expected system generation over a project life is estimated for the same utility area, assuming full net metering, where any excess hourly generation is credited at the applicable retail rate. Finally, net value is determined by comparing the value of avoided electricity consumed from the grid (as a result of installing a PV system) to the assumed capital cost of the system.

A number of factors beyond renewable generation technology cost and avoided cost are incorporated into the LACE - LCOE net value framework, enabling them to be optionally considered individually or in combination in the specific cases examined. These factors include: the cost of tying generation into the grid (intra-regional transmission cost to serve load within the immediate regions (balancing area); the reduction of value of variable generation observed as generation increases; technology tax incentives (PTC, ITC); the value of avoided $\mathrm{CO}_{2}$ emissions; and the value of avoided health costs.

The general four-step calculation flow for centralized generation technologies, including the extended factors described immediately above, is depicted in Figure 2. ${ }^{15}$

\footnotetext{
${ }^{15}$ Note that while the declining value of wind and solar is primarily an avoided cost consideration, arithmetically it is equivalently reflected as an incremental cost in the calculation of cost of energy (Step 2).
} 
Resource Potential reflecting system performance (capacity factor) <remove>

Exclusions, land use constraints 들

Technical Potential
2

Site Levelized Cost of Energy (LCOE)

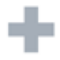

Intra-regional transmission costs

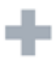

Declining value of wind and solar*

E.

Existing Tax Incentives

ㅁ.

Adjusted Levelized Cost of Energy (LCOE)
3

Marginal

Generation Price

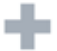

Capacity value

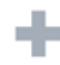

Value of Avoided Emissions

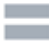

Adjusted Levelized Avoided Cost (LACE)
4

Adjusted Levelized Avoided Cost (LACE)

-

Adjusted Levelized Cost of Energy (LCOE)

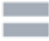

Net Value

(LACE - LCOE)

<sum over>

Technical Potential

Economic Potential
Indicates geographically available data set
* An estimate for the reduced revenue available to wind and solar projects at increasing penetration if systems are not changed to adapt.

\section{Figure 2. Generalized method calculation flow for centralized technologies based on high geospatial resolution resource data}

Note: All factors identified in the figure are applied in the "base" methodology, and reflected in all cases assessed, except the following: declining value of wind and solar and value of avoided emissions. In some cases, tax incentives were included at pre-expiration levels. In Step $1,<$ remove $>$ indicates that resource potential that appears in excluded lands is not included in the analysis. In Step $4,<$ sum over $>$ indicates that technical potential at locations where net value is positive is summed to determine economic potential.

This economic potential methodology expands on the referenced earlier works through use of high-resolution resource data (thousands of sites for most technologies), consideration of reported market prices in the estimate of LACE for most cases, and consideration of a broad range of input assumptions for key drivers, including technology cost and the treatment of the value of variable generation as its share of total generation increases.

Rather than generating a single estimate of economic potential, the analysis assesses three Primary Cases (assumption sets) with the intent of exploring the effects of method and assumption selection on the magnitude of estimates. The three Primary Cases are reported based on the following distinct formulations of economic potential consistent the with net-value definition based on LCOE and LACE:

- Primary Case 1 - LACE Only: This case is meant to represent the LACE methodology identified in Namovicz (2013) as closely as possible, with little consideration of market factors that could affect the actual deployment of renewable generation. This formulation includes the cost of intra-regional transmission for variable generation technologies (Wind and UPV). 
- $\quad$ Primary Case 2 - LACE including Value of Avoided External Costs: This case extends LACE to consider the value of avoided external costs associated with conventional generation, in particular $\mathrm{CO}_{2}$ emissions.

- Primary Case 3 - LACE including Value of Avoided External Costs and Declining Value of Variable Generation: This case further extends LACE to also consider the potential impact of increasing amounts of variable generation on its value.

The latter two formulations move beyond a strict formulation of economic potential that considers only technology costs and required revenues for project development to one that considers some market factors. These market extensions are considered in this analysis to offer additional possible perspectives, in recognition that the demarcation between economic and market potential is subject to interpretation, and to demonstrate that the specific factors considered can have a significant impact on estimates.

\subsection{Example of Application to Land-Based Wind}

As an example, the following four maps and charts (Figure 3) represent intermediate products in the application of the steps described above for land-based wind resources. A similar approach is used for each utility-scale (or centralized generation) technology. This example shows intermediate calculation results, by location, for LCOE, LACE, and net value for one of three Primary Cases explored in the analysis (Primary Case 3). In this Primary Case 3, the net value framework provides a blended perspective of economic potential illustrative of both the current (2014) market environment (marginal generation prices and forward projections of those prices) and the near-term future (regional technology costs in 2020). The framework includes consideration of intra-regional transmission cost, a value of avoided $\mathrm{CO}_{2}$ emissions, and a declining value of wind generation in regions with high levels of existing wind generation and wind potential.

Both the LCOE and LACE components of net value are calculated assuming a renewable generation project is constructed and begins operation in 2014 (cost and value time streams that make up these components begin in 2014 and are discounted back to 2014). This approach enables a "current" view of economic potential based on existing 2014 marginal generation prices and existing forward projections of those prices. In contrast, renewable technology costs for the Primary Cases are referenced to 2020. The combination of these two assumptions provides a blended view of economic potential illustrative of both the current environment and the near-term future. A sensitivity analysis explores a case with 2014 renewable costs and a 2014 construction date, as well as a case with 2020 renewable costs and a 2020 construction date.

Figure 3a, an output of Step 2 above, is a map of calculated LCOE for this case based on approximately 100,000 wind sites. ${ }^{16}$ Wind site costs vary with resource quality and other geographic factors. Intra-regional transmission and the declining value of wind generation with

\footnotetext{
${ }^{16}$ This map, and the other products shown in Figure 3, does not consider sites with resource below a technoeconomic threshold based on resource intensity and regional capital costs, and sites within exclusion areas. More specifically, these estimates do not consider resource in wind techno-resource groups (TRG) 6 and 7. These excluded sites include those that might have technical potential as a result of ongoing or new innovations, as highlighted in the recent DOE report Enabling Wind Power Nationwide (DOE 2015b).
} 
increasing wind penetration (considered on a regional basis as a share of 2013 total generation from all sources) are reflected in the LCOE cost ranges displayed.

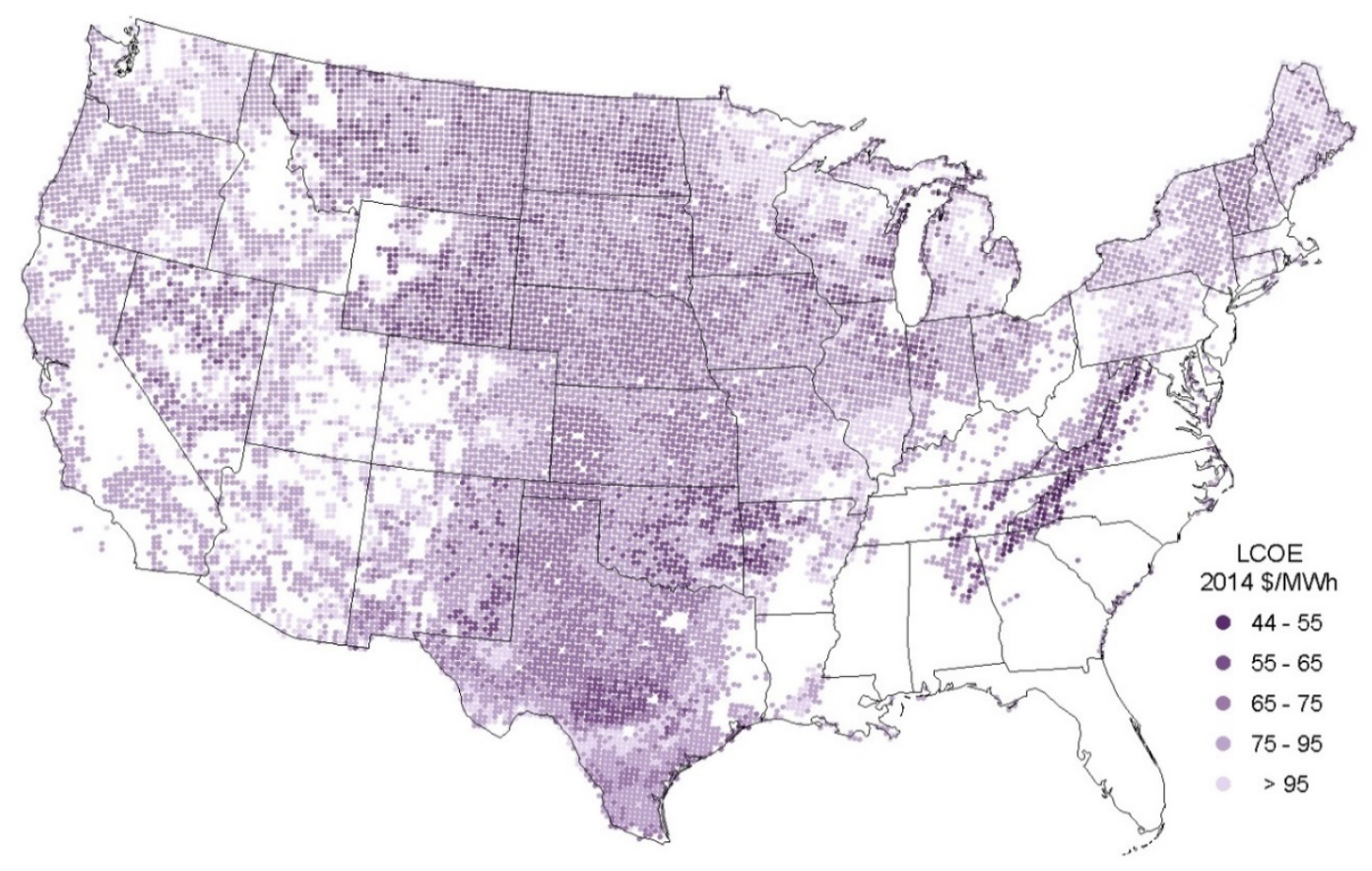

Figure 3a. LCOE site map for land-based wind (Primary Case 3)

Note: Individual map points reflect the lowest LCOE site in each 20x20 km block where the block includes multiple sites. Wind PTC is not included.

Figure $3 b$, an output of Step 3 above, is a map of calculated LACE, including both marginal generation price and capacity value components of the MP method along with a value of avoided $\mathrm{CO} 2$ emissions estimated at each wind site. The marginal generation price component of LACE takes into account projected generation electricity price increases over the life of a renewable generation plant (based on EIA AEO 2014 Reference Case price projections in EIA 2014a). In this case, a capacity credit of $25 \%$ and capacity payment of $682 \$ / \mathrm{kW}$, corresponding to the overnight capital cost of an advanced NGCT, is included in the LACE calculation to approximate capacity value. This level of capacity payment assumes that additional system capacity is needed and therefore that full credit is given for renewable generation capacity value (Primary Cases were also assessed with no capacity value). The value of avoided $\mathrm{CO}_{2}$ emissions, in the form of an average SCC using a 3\% discount rate from IWG (2013) is also included. 


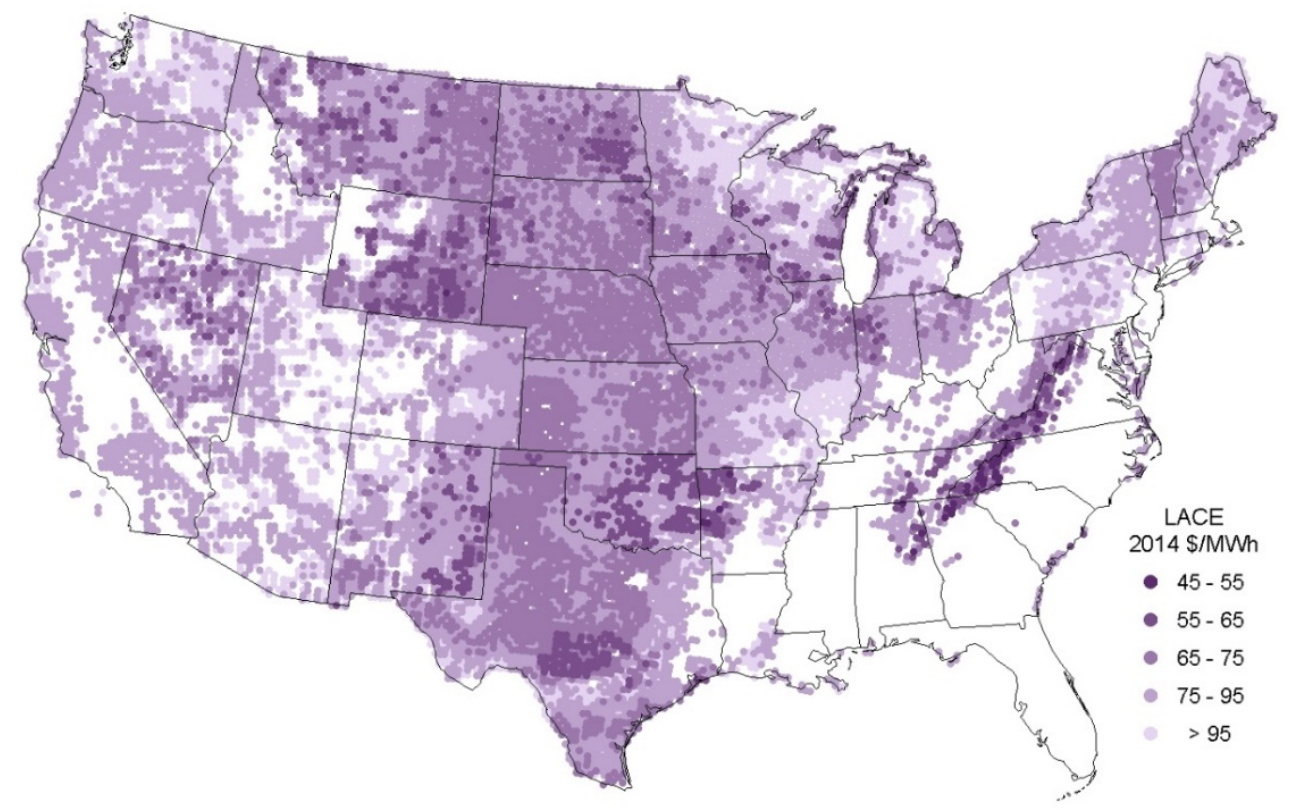

Figure 3b. LACE site map for land-based wind (Primary Case 3 with full capacity value)

Note: Individual map points reflect the highest LACE site in each 20x20 km block where the block includes multiple sites.

Figure 3c, an output of Step 4 above, is a map of calculated net value (LACE - LCOE) at each wind site for the same Primary Case 3. Estimated technical potential from sites with positive net value is summed to determine the economic potential estimate for this case. 


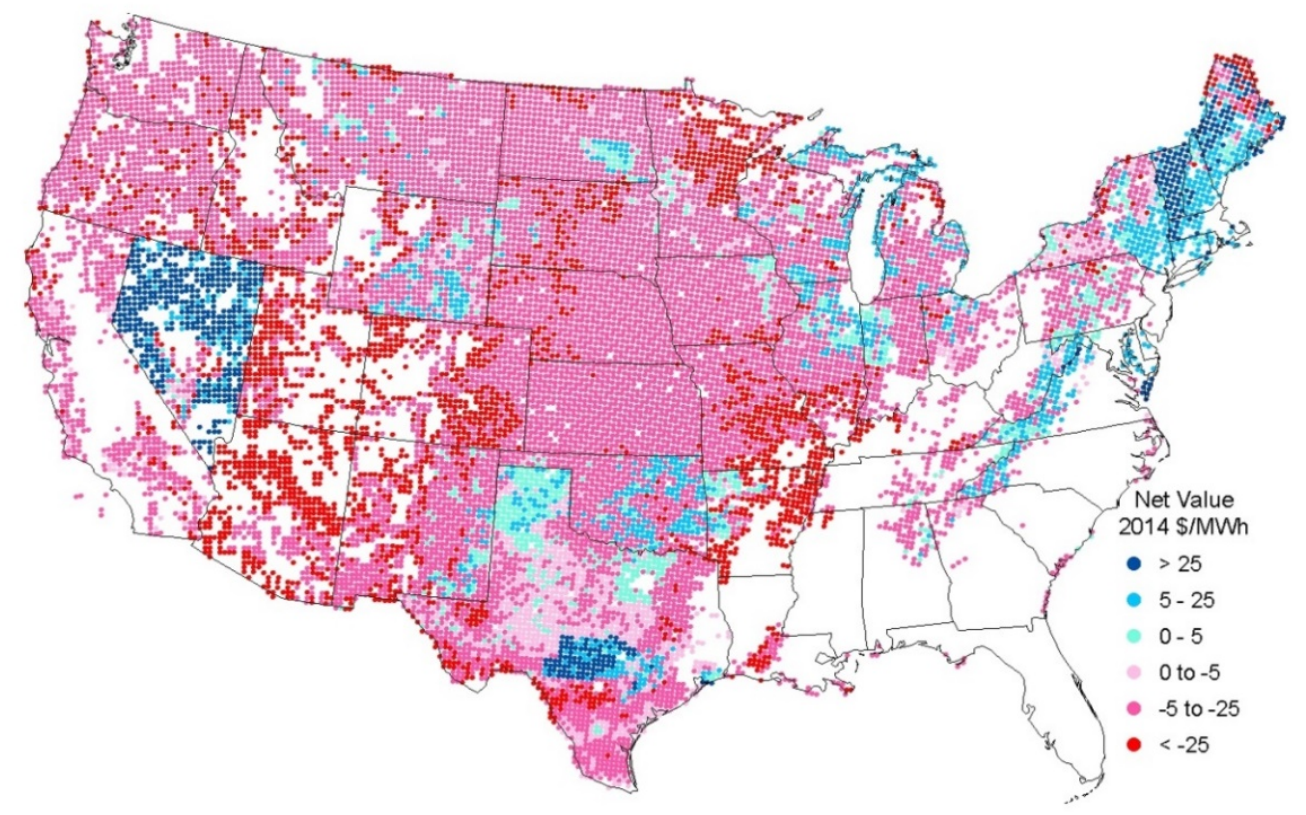

Figure 3c. Net value map for land-based (Primary Case 3 with full capacity value)

Note: Individual map points reflect the highest net value site in each 20x20 km block where the block includes multiple sites

Finally, Figure 3d, another representation of the output of Step 4 above, aggregates the net value estimated for each wind site into a U.S. net value supply curve. Estimated technical potential from sites with positive net value (shown as up to approximately $270 \mathrm{GW}$ in capacity) is aggregated into the economic potential estimate for this case. All economic potential estimates in this report, including net value supply curves, are incremental to 2013 generation levels. ${ }^{17}$

\footnotetext{
${ }^{17}$ This estimate of economic potential for land-based wind is in the form of incremental capacity (additive to the already existing $61 \mathrm{GW}$ of capacity). For reference, a Central Study Scenario market analysis described in DOE 2015a projects nearly $260 \mathrm{GW}$ of cumulative capacity additions for onshore wind (centralized and distributed) by 2050. As noted earlier, this example estimate of market potential is not comparable to the estimate of economic potential as it considers many factors not included in the analysis of economic potential, including further declines in wind technology cost, cost competition with other generation sources, projections of electricity demand and natural gas prices, grid integration costs, and imports and exports of generation at a location.
} 


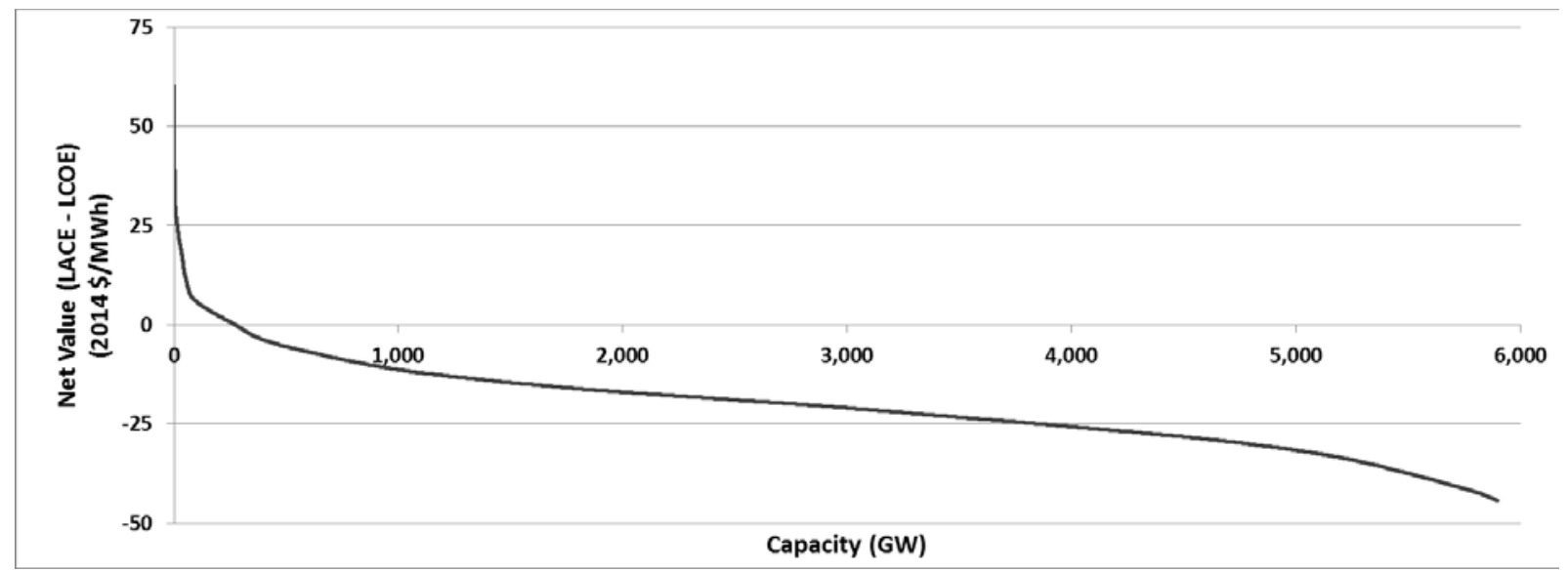

Figure 3d. Aggregated U.S. net value supply curve for land-based wind (Primary Case 3 with full capacity value)

Note: Capacity shown is incremental to 2013 level.

\subsection{Renewable Energy Technical Potential}

Lopez at al. (2012) was a first-of-a-kind effort to apply unifying assumptions and methods to generate comparable estimates of renewable resource technical potential for several renewable generation technologies. Technical potential estimates from the 2012 report were updated for use in this economic potential analysis. A number of changes to the technical potential estimates have occurred since the 2012 analysis, reflecting changes in the underlying resource data, changes in technology characteristics, and improved information from industry on renewable energy development considerations. Specific changes are noted in Appendix A, along with statelevel results reporting available land area (square kilometers), installed capacity (GW), and electric generation (terawatt-hours) for the six assessed technologies.

\section{General Approach - Centralized Generation}

The best available geospatial resource data were used to estimate the achievable energy generation at locations across the continental United States given system performance, topographic limitations, environmental, and land-use constraints. Table 1 identifies the type and number of locations, as well as the underlying resource data used to estimate updated technical potential for the centralized generation technologies assessed. 
Table 1. Centralized Generation Technologies Underlying Resource Data and Resolution

\begin{tabular}{|c|c|c|}
\hline $\begin{array}{l}\text { Resource/ } \\
\text { Technology }\end{array}$ & Sites/Areas & Underlying Resource Data \\
\hline $\begin{array}{l}\text { Land-based } \\
\text { Wind }\end{array}$ & $\sim 100,000$ sites & $\begin{array}{l}\text { Wind resource at } 80 \text { meters }(\mathrm{m}) \text { height above surface } \\
\text { that estimates an annual average gross capacity factor } \\
\text { for typical utility-scale wind turbine power curves } \\
\text { (selection based on annual average wind speed) using } \\
\text { hourly modeled AWS Truepower wind resource data. }\end{array}$ \\
\hline $\begin{array}{l}\text { Utility-scale } \\
\text { Solar PV (UPV) }\end{array}$ & $\begin{array}{l}\sim 710,000 \text { sites (aggregated to } \\
\sim 66,000 \text { sites) }\end{array}$ & $\begin{array}{l}\text { National Solar Radiation Database } 10 \mathrm{~km} \text { Gridded } \\
\text { Model, modeled for a 1-axis tracking collector using the } \\
\text { Systems Advisor Model (SAM). }\end{array}$ \\
\hline Hydropower & $\begin{array}{l}\text { More than } 280,000 \text { individual } \\
\text { sites aggregated to capacity } \\
\text { factor supply curves in } 134 \\
\text { Power Control Areas (PCAs) } \\
\text { used in ReEDS Model, coupled } \\
\text { with national average capital } \\
\text { cost estimates by resource class }\end{array}$ & $\begin{array}{l}\text { Based on an ongoing assessment of the potential of } \\
\text { U.S. streams (new stream development and adding } \\
\text { power generation to non-powered dams). } \\
\text { Data needed to be aggregated to operate within the } \\
\text { spreadsheet model. Aggregation was done by } \\
\text { preserving the unique cost components: resource class, } \\
\text { geographic region, grid tie-in type, and distance to the } \\
\text { grid tie-in point. }\end{array}$ \\
\hline Geothermal & $\begin{array}{l}240 \text { individual sites aggregated } \\
\text { to capital cost and capacity } \\
\text { factor supply curves in } 134 \\
\text { PCAs used in ReEDS Model }\end{array}$ & $\begin{array}{l}\text { Identified: Estimates of electric power generation } \\
\text { potential of conventional geothermal resources } \\
\text { (hydrothermal) in the western United States (Williams et } \\
\text { al. 2008). Costs estimated with GETEM model. } \\
\text { Unidentified: Estimates based on logistic regression } \\
\text { models of the western United States to estimate } \\
\text { favorability of hydrothermal development (Williams et al. } \\
\text { 2009). Costs estimated with GETEM model. }\end{array}$ \\
\hline Biopower & $\begin{array}{l}\sim 3,000 \text { county-level estimates } \\
\text { aggregated to capital cost and } \\
\text { capacity factor supply curves in } \\
134 \text { PCAs used in ReEDS } \\
\text { Model }\end{array}$ & $\begin{array}{l}\text { County-level estimates of solid biomass resource from } \\
\text { crop, forest, primary/secondary mill residues, and urban } \\
\text { wood waste, as well as gaseous biomass (methane } \\
\text { emissions) extracted from the } 2011 \text { Billion Ton Study }\end{array}$ \\
\hline
\end{tabular}

Specific locations are excluded from consideration for based on topographic limitations, environmental, and land-use constraints. Example exclusions include airports, federal parks and wilderness areas, and land with slopes above a certain amount. These exclusions generally vary by technology. A map of exclusions for land-based wind is shown in Figure 4. 


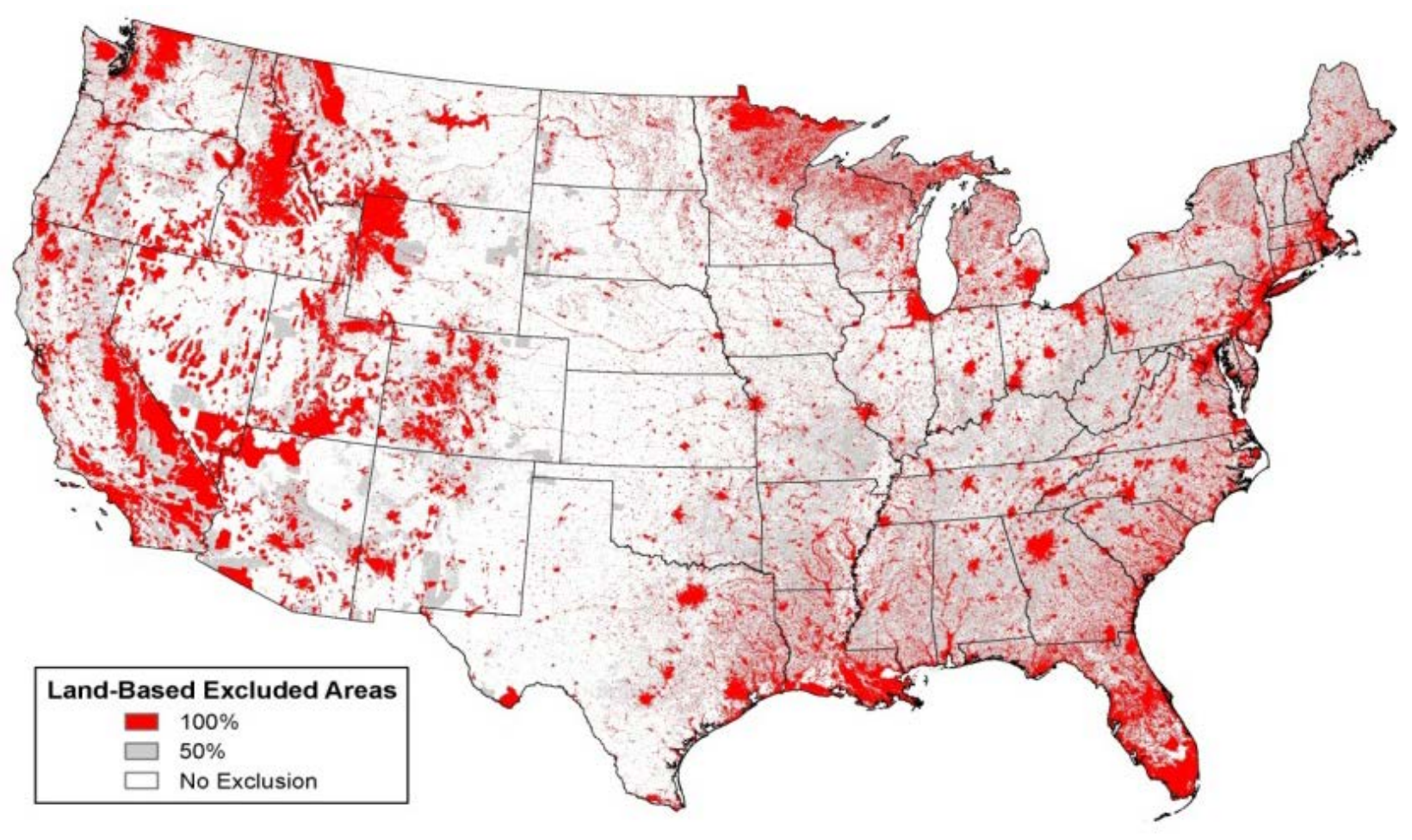

Figure 4. Land-based exclusion areas for land-based wind potential

\section{General Approach - Distributed PV Generation}

This analysis estimated annual technical feasible solar energy generation in the United States by first estimating available roof space for residential and commercial sectors. Then, we estimated associated feasible capacity and production based on assumed system sizes for a 'typical' rooftop and location-specific solar radiation. Calculations for residential rooftop and commercial rooftop differed and are described below. ${ }^{18}$

\section{Residential}

We relied on 2011 American Community Survey five-year estimate census data to estimate the number of single-family detached houses by utility territory. Houses were then reduced in order to account for roofs with excessive shade and/or north, northeast, and northwest aspects-defined as roof surfaces less than $5,000 \mathrm{sq}$. ft. with at least $100 \mathrm{sq}$. ft. of contiguous roof space. ${ }^{19} \mathrm{We}$ estimated this value for 37 cities using processed LIDAR data, and then relied on a sample average of $80 \%$ to determine available rooftops for the remainder of the households. For example, a utility territory that reported 10,000 single detached houses was assumed to have 8,000 technically feasible houses. Residential PV system size was based on the technical potential of the average 'feasible' roof, which was able to fit an $8-\mathrm{kW}$ system given $15 \%$ efficient modules.

\footnotetext{
${ }^{18}$ This approach excludes additional potential for ground-mounted distributed PV generation, particularly large, commercial ground-mounted installations.

${ }^{19}$ This approach includes commercial space under 5,000 sq. $\mathrm{ft}$.
} 


\section{Commercial}

We relied on EIA's Community Building Energy Consumption Survey (CBECS) data to estimate the U.S. building stock, by building type, according to their principal activity.

Commercial buildings are defined as buildings in which at least half of the floorspace is used for a purpose that is not residential, industrial, or agricultural and includes education, food sales, food service, inpatient, outpatient, lodging, mercantile, office, public assembly, public order and safety, religious worship, service, warehouse and storage, other, and vacant. We excluded public assembly, public order and safety, religious worship, other, and vacant from the final building count due to a lack of available data on energy consumption profiles. Each building type was associated with an average roof area based on CBECS data. We assumed that $50 \%$ and $65 \%$ of rooftop space is technically viable for buildings below and above 25,000 square feet, respectively, based on aspect and shading from a LIDAR approach similar to residential. Each building type was assigned a 'typical' system size, based on utilizing all available roof area. System size ranged from $36 \mathrm{~kW}^{20}$ for a large restaurant to $171 \mathrm{~kW}$ for schools.

\subsection{Renewable Resource Cost Calculation}

\section{General Approach - Centralized Generation}

The cost of available supply is estimated as LCOE as described in Short et al. (1995). LCOE represents the average revenue per unit of energy production that would be required by a project owner to recover all investment and operation costs (EIA 2013, p. 1). It is calculated for each specific site (based on resource data granularity) in the continental United States for each technology under a variety of input assumptions. Cost components include annualized capital costs, fixed and variable (if applicable) costs, and fuel costs (if applicable) (see Appendix C for a more detailed version of this general formula):

LCOE $(\$ / M W h)=\frac{\text { Fixed Charge Factor } x \text { Capital Cost }+ \text { Fixed O\&M Cost }}{\text { Annual Expected Generation Hours }}+$ Variable O\&M Cost + Fuel Cost

Capital costs consider intra-regional transmission costs necessary to move energy to the point of consumption or export. Costs do not include inter-regional transmission costs that would enable export of generated power outside of the region, as the analysis as a whole does not consider these exports.

Cost components have varying geographic coverage due to limited data availability. Table 2 provides an overview of geographic coverage for individual cost components. While some cost components (such as the fixed charge factor and transmission costs) are estimated by regions defined in the ReEDS Model (see Figure 5), ${ }^{21}$ other cost items such as capital costs and fixed and variable costs are based on national technology cost averages from NREL's Annual Technology Baseline (ATB) (2015). These technology cost averages are applied to resource classes determined at the site level. For instance, a site that has been assessed with potential for landbased wind resource class 5 (see assessment of technical potential in Lopez et al. 2012), has an assumed capacity factor of $35 \%$, overnight capital costs (OCCs) of $\$ 1,738 / \mathrm{kW}$, and operations

\footnotetext{
${ }^{20}$ Much smaller commercial systems likely exist, particularly for very small retail and small restaurants. However, it is likely that these smaller roof areas were included in the residential count due to the smaller square footage.

${ }^{21}$ The ReEDS model comprises 358 renewable resource regions (Short et al. 2011).
} 
and maintenance (O\&M) costs of $\$ 49 / \mathrm{kW}$ based on national technology cost averages for this resource class and under the Primary Case technology cost assumptions (see Section 3).

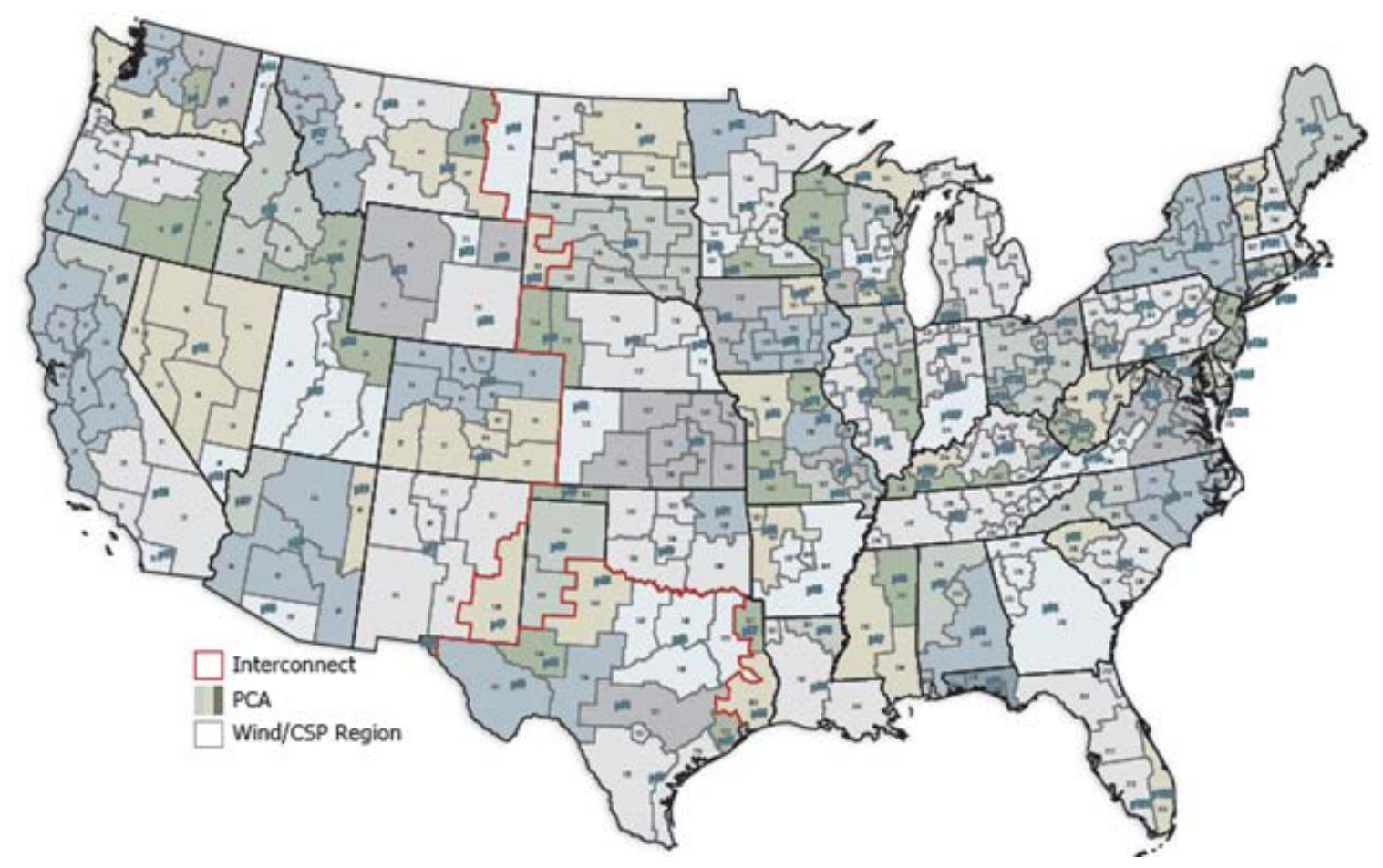

Figure 5. Regions in the ReEDS model

Source: Short et al. 2011, p.7 
Table 2. LCOE Components

\begin{tabular}{|c|c|c|c|}
\hline Variable & Description & $\begin{array}{c}\text { Geographic Coverage of } \\
\text { Source }\end{array}$ & Source \\
\hline $\begin{array}{l}\text { Fixed Charge } \\
\text { Factor }\end{array}$ & $\begin{array}{l}\text { A financial factor to levelize } \\
\text { (annualize) capital costs based on } \\
\text { required rate of return and project } \\
\text { lifetime }\end{array}$ & $\begin{array}{l}\text { ReEDS region (regional capital cost } \\
\text { multiplier) }\end{array}$ & $\begin{array}{l}\text { NREL ReEDS } \\
\text { model input } \\
\text { assumption }\end{array}$ \\
\hline Capital Cost & $\begin{array}{l}\text { Estimated cost of construction of the } \\
\text { resource }\end{array}$ & $\begin{array}{l}\text { National technology cost averages } \\
\text { applied to site-specific resource } \\
\text { classes } \\
\text { ReEDS region for transmission costs } \\
\text { (regional transmission cost } \\
\text { multiplier) }\end{array}$ & $\begin{array}{l}\text { NREL ATB } \\
(2015)\end{array}$ \\
\hline $\begin{array}{l}\text { Annual Expected } \\
\text { Generation Hours }\end{array}$ & $\begin{array}{l}\text { On average, the number of hours in a } \\
\text { year the resource is expected to } \\
\text { generate electricity }\end{array}$ & $\begin{array}{l}\text { Site-specific resource class } \\
\text { determines capacity factors }\end{array}$ & $\begin{array}{l}\text { Calculated as a } \\
\text { resource- } \\
\text { specific } \\
\text { capacity factor } \\
\text { times the } \\
\text { number of } \\
\text { hours in a year }\end{array}$ \\
\hline Fixed O\&M Cost & $\begin{array}{l}\text { Operating and maintenance costs } \\
\text { paid for a plant regardless of how } \\
\text { much it generates }\end{array}$ & $\begin{array}{l}\text { Site-specific resource class } \\
\text { determines fixed O\&M costs }\end{array}$ & $\begin{array}{l}\text { NREL ATB } \\
(2015)\end{array}$ \\
\hline $\begin{array}{l}\text { Variable O\&M } \\
\text { Cost }\end{array}$ & $\begin{array}{l}\text { O\&M costs paid for a plant that vary } \\
\text { with how much it generates }\end{array}$ & $\begin{array}{l}\text { Site-specific resource class } \\
\text { determines variable O\&M costs }\end{array}$ & $\begin{array}{l}\text { NREL ATB } \\
(2015)\end{array}$ \\
\hline Fuel Cost & Fuel cost (if any) & $\begin{array}{l}\text { Site-specific resource class } \\
\text { determines fuel costs }\end{array}$ & $\begin{array}{l}\text { NREL ATB } \\
(2015)\end{array}$ \\
\hline
\end{tabular}

LCOEs are calculated for a range of scenarios (see Results section), including different technology cost assumptions and depreciation benefits from an extended project lifetime. When aggregated across sites, a supply curve can be estimated for the national level.

\section{General Approach - Distributed PV Generation}

Economic potential for distributed PV generation is determined based on where the value of avoided electricity consumed from the grid (as a result of installing a PV system) is greater than or equal to the capital cost of the PV system. We assume the same 2020 capital cost nationwide: $\$ 2.40 / \mathrm{W}$ and $\$ 2.00 / \mathrm{W}$ for the residential and commercial cases, respectively. Capital cost is then reduced to account for the permanent 10\% ITC and Modified Accelerated Cost Recovery 
(MACRS) is applied. ${ }^{22}$ Fuel cost is not applicable; the analysis does not factor in O\&M costs, which are assumed to be small. No additional revenue from state, municipal-level, or utility incentives or REC sales is assumed. Capital cost includes the cost of system installation, including expenditures (fees and associated labor) the PV customer incurs to interconnect and obtain necessary permits; capital cost may not include all additional costs a utility could incur for interconnection to the distribution system.

\subsection{Avoided Cost Calculation}

\section{General Approach - Centralized Generation}

As described above, we estimate a LACE at a location based on a method established in Namovicz (2013) by estimating the potential revenues available to a renewable generation project, which can be interpreted as the amount a project would be paid for the electrical energy and capacity it can provide (or alternatively, what a utility or other entity would not have to purchase from other sources). In our primary method, this estimate is based on a prevailing regional marginal generation price and capacity value in 2014. A Market Price (MP) formulation of LACE is used as a proxy for marginal generation prices for centralized generation technologies. The marginal generation price component of this MP approach takes into account projected electricity price increases over the life of a renewable generation plant (based on EIA AEO 2014 Reference Case price projections), levelized to an effective present price. As wholesale price data are not available in every region of the country, or for the future, this method relies on an initial synthesis of multiple market data sources, including locational marginal prices (LMPs) and market marginal costs (MMCs or system lambdas). Capacity values are calculated based on a technology- specific capacity credit and the overnight capital cost of an advanced natural gas-fired combustion turbine (NGCT) plant as proxy for capacity payment.

LACE as a method to assess economic competitiveness of technologies in the electric power sector has been developed by EIA as a complement to the well-established LCOE method. According to EIA (2013), "LCOE is not a useful tool to compare the cost of different generation options, unless the options being compared have substantially similar operational profiles and system values" (p. 5). The LACE metric captures available revenue to a renewable generation project at a specific location in terms of displaced energy and displaced capacity; LACE can prove particularly useful when assessing the economic competitiveness of "unconventional" resources like wind and solar (EIA 2013). LACE and LCOE are complementary in the sense that LCOE comprises a measure for revenue requirements (based on the cost required to generate electricity) while LACE captures the revenues available to that resource. The two can be compared to provide an intuitive indicator of economic attractiveness (EIA 2013). A positive net value, as defined by LACE - LCOE, indicates that a generation project at a given location is economic.

As a proxy of available revenue, LACE can be derived by estimating the cost of displaced energy and displaced capacity. These two cost components are reflected in the formula below. Marginal generation price and capacity are presented in "levelized" terms (average costs per MWh of generation). The following general formula was used to estimate LACE (see Appendix $\mathrm{C}$ for a more detailed version):

\footnotetext{
${ }^{22}$ Under existing law, the $10 \%$ ITC will only be available after 2016 to commercial customers, as well as thirdparty-owned residential systems. Given the current importance of third-party-owned systems to the residential market, the ITC was assumed to apply to all residential systems as well as commercial.
} 
Marginal generation price is the cost of serving load to meet the demand in a specified time period, which can be determined by the variable cost of the most expensive generating unit that is needed to be dispatched to meet energy demand (EIA 2013). In estimating marginal generation prices for sites across the continental United States, this analysis relies on a range of 2014 market prices (for an overview, see Table 3) that were adopted for ReEDS price regions (PCAs).

\section{Wholesale Electricity Prices (LMP)}

This analysis follows the methodology from Namovicz (2013) in using wholesale electricity prices as the best available proxy for marginal generation prices. Locational marginal prices (LMPs) reflect "the value of generation at different locations, accounting for load patterns, generation, and the physical limits of the transmission system" (ISO New England 2013). LMPs are reported by independent service operators (ISOs) on an hourly basis. For the purpose of this analysis, real-time, day-ahead LMPs were curtailed at the highest generation cost within a NERC region in 2014, as determined by NERC region bid stack curves (Ventyx 2015). Hourly LMPs below zero were also excluded from this analysis. These adjustments serve the purpose of excluding any price outliers reflected in the hourly LMPs that would reduce the capacity of LMPs to serve as a proxy for marginal generation costs. ${ }^{23}$ In a next step, these "adjusted" LMPs were then weighted by the number of hours in each ReEDS time slice ${ }^{24}$ and averaged by ReEDS region (PCA Balancing Authority level).

\section{Market Marginal Cost (MMC) (Lambda)}

Whenever LMP was not available for a given site, MMC data were used. System lambda is the incremental cost of energy of the marginal unit assuming no system constraint exists (FERC 2010). MMC (lambda) data are reported hourly at the Balancing Authority level. For the purpose of this analysis, MMC (lambda) data were weighted by the number of hours in each ReEDS time slice and averaged by ReEDS region.

\section{Partial LMP}

In some regions, including parts of the recently established Energy Imbalance Market, an LMP data series was not available for the entire year. Therefore, Partial LMP is based on the reported subset of wholesale generation prices. Whenever neither (full series) LMP nor MMC (lambda) were available, these partial LMP data were assigned to a ReEDS region.

\section{Alternative ReEDS Region LMP}

In some regions, neither LMP nor MMC (lambda) nor partial LMP were reported for 2014, particularly in the Pacific Northwest and the Southeast. For these regions, price estimates were derived based on ReEDS regions with price data that were located closest to the region with missing price data.

\footnotetext{
${ }^{23}$ Future analyses may explore using the energy component of the LMP only as a more accurate proxy of marginal generation price.

${ }^{24}$ The ReEDS model features 16 time slices capturing the different seasons and times of day (Short et al. 2011).
} 
Table 3. Types of Price Data Available

\begin{tabular}{l|l|l}
\hline \multicolumn{1}{|c|}{ Data } & \multicolumn{1}{|c|}{ Definition } & \multicolumn{1}{c}{ Source } \\
\hline $\begin{array}{l}\text { Locational } \\
\text { Marginal Price } \\
\text { (LMP) }\end{array}$ & $\begin{array}{l}\text { LMP reflects the value of generation at different } \\
\text { locations, accounting for load patterns, } \\
\text { generation, and the physical limits of the } \\
\text { transmission system. For this analysis, LMPs } \\
\text { have been curtailed at highest generation cost } \\
\text { from regional bid stack curves. Hourly LMPs } \\
\text { below 0 were also excluded from this analysis. }\end{array}$ & $\begin{array}{l}\text { ISO Real time Day Ahead } \\
\text { LMP pricing from NYISO, } \\
\text { PJM, ISO New England, } \\
\text { Independent Electricity } \\
\text { System Operator (Ontario), } \\
\text { CAISO, ERCOT, Alberta } \\
\text { ESO, MISO, SPP, New } \\
\text { Brunswick System Operator } \\
\text { (Ventyx) }\end{array}$ \\
\hline $\begin{array}{l}\text { Market Marginal } \\
\text { Costs (Lambda) } \\
\text { (MMC) }\end{array}$ & $\begin{array}{l}\text { System lambda is the incremental cost of } \\
\text { energy of the marginal unit assuming no } \\
\text { system constraints exist. }\end{array}$ & $\begin{array}{l}\text { FERC Form 714 Hourly } \\
\text { System Lambda by Balancing } \\
\text { Authority Area (Ventyx) }\end{array}$ \\
\hline $\begin{array}{l}\text { Partial LMP } \\
\text { Some regions, particularly those covered by }\end{array}$ & $\begin{array}{l}\text { Same as LMP } \\
\text { Energy Imbalance Market (EIM), have no LMP } \\
\text { data series that cover the entire year. Partial } \\
\text { LMP is based on the reported subset of LMPs. }\end{array}$ & \\
\hline $\begin{array}{l}\text { Alternative } \\
\text { ReEDS Region } \\
\text { LMP }\end{array}$ & $\begin{array}{l}\text { For some regions, neither LMP nor MMC is } \\
\text { reported. Alternative ReEDS region LMP is } \\
\text { based on LMP price data from nodes that are } \\
\text { located closest to the missing regions. }\end{array}$ & \begin{tabular}{l} 
Same as LMP \\
\hline Sources: LMP: ISO New England 2015; MMC: FERC 2010
\end{tabular} \\
\hline
\end{tabular}

In choosing between wholesale and MMC prices, this analysis was faced with a trade-off between presumably closer alignment with marginal costs and geographic price resolution. While conceptually MMC prices may be considered to align closer with marginal generation prices, these were only available at the Balancing Authority level. On the other hand, ISOreported wholesale electricity prices (LMP) can be identified at several hundred price nodes across the continental United States.

Projected generation price changes through 2034 (through 2040 for the 2020 construction sensitivity case) were taken into account by means of an annual escalation factor. These price changes were based on projections from the EIA Annual Energy Outlook (2014) Reference Case in EIA (2014a). Figure 6 shows the data sources for these market generation price proxy estimates. LMPs are predominant in ISO market regions; MMC price estimates were used as proxies of marginal generation price mainly in the Southeast and Southwest/Mountain regions. Neither LMPs nor MMC estimates were available in large parts of the Pacific Northwest and the Mountain regions. The analysis relies on LMP price data from nodes that are located closest to these regions. Future revisions of this analysis for the entire continental Unites States could yield more accurate price estimates, particularly for the Pacific Northwest and Mountain regions. Figure 7 features marginal generation price proxy estimates from these various sources. It takes into account price changes over the next 20 years, as projected in EIA (2014). New England, Nevada, and parts of Texas and South Carolina comprise regions with relatively high prices. Large parts of the Midwest, Southeast, and Arizona are generally among zones with lower prices. 


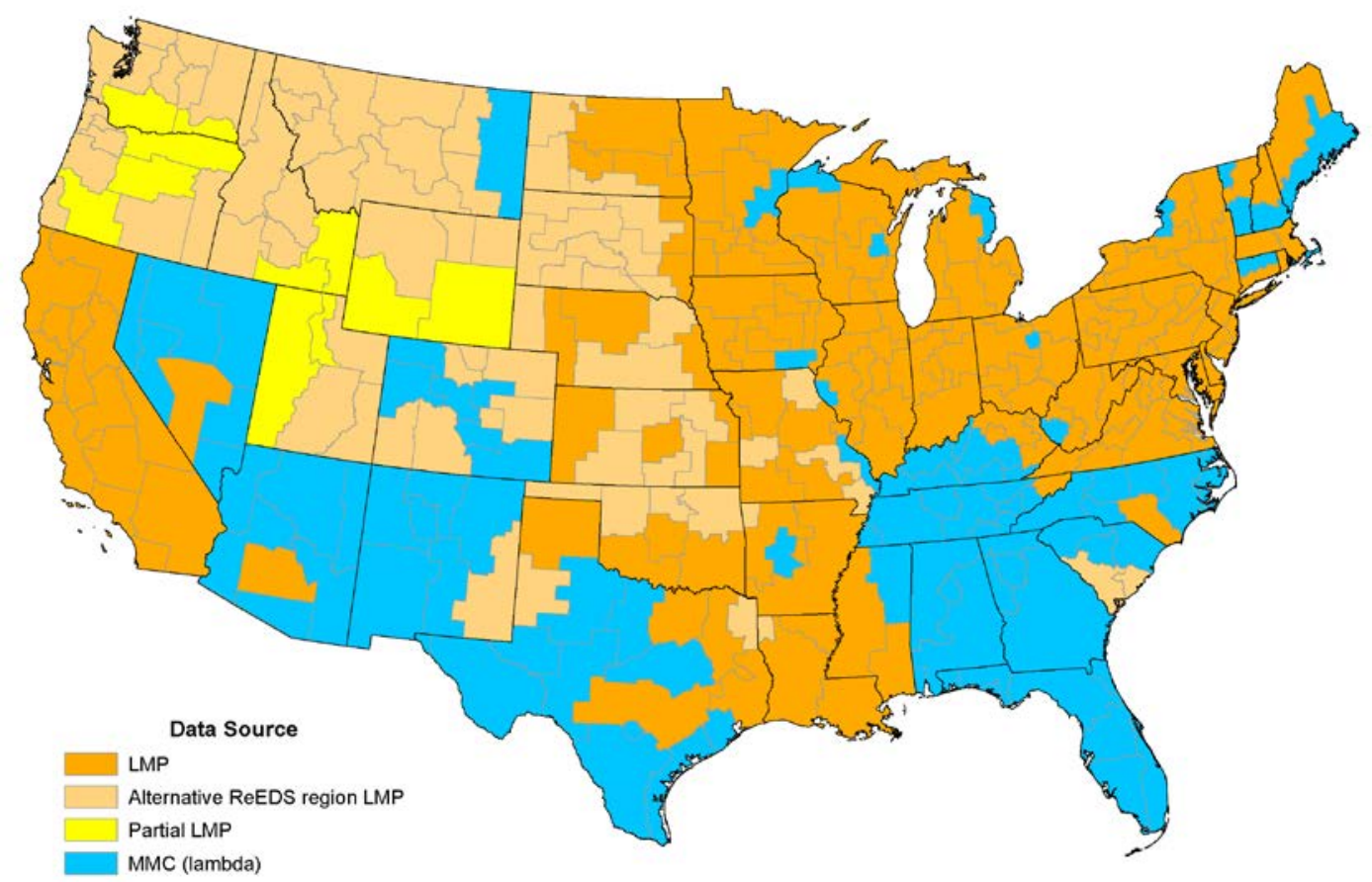

Figure 6. Data sources for market price estimates

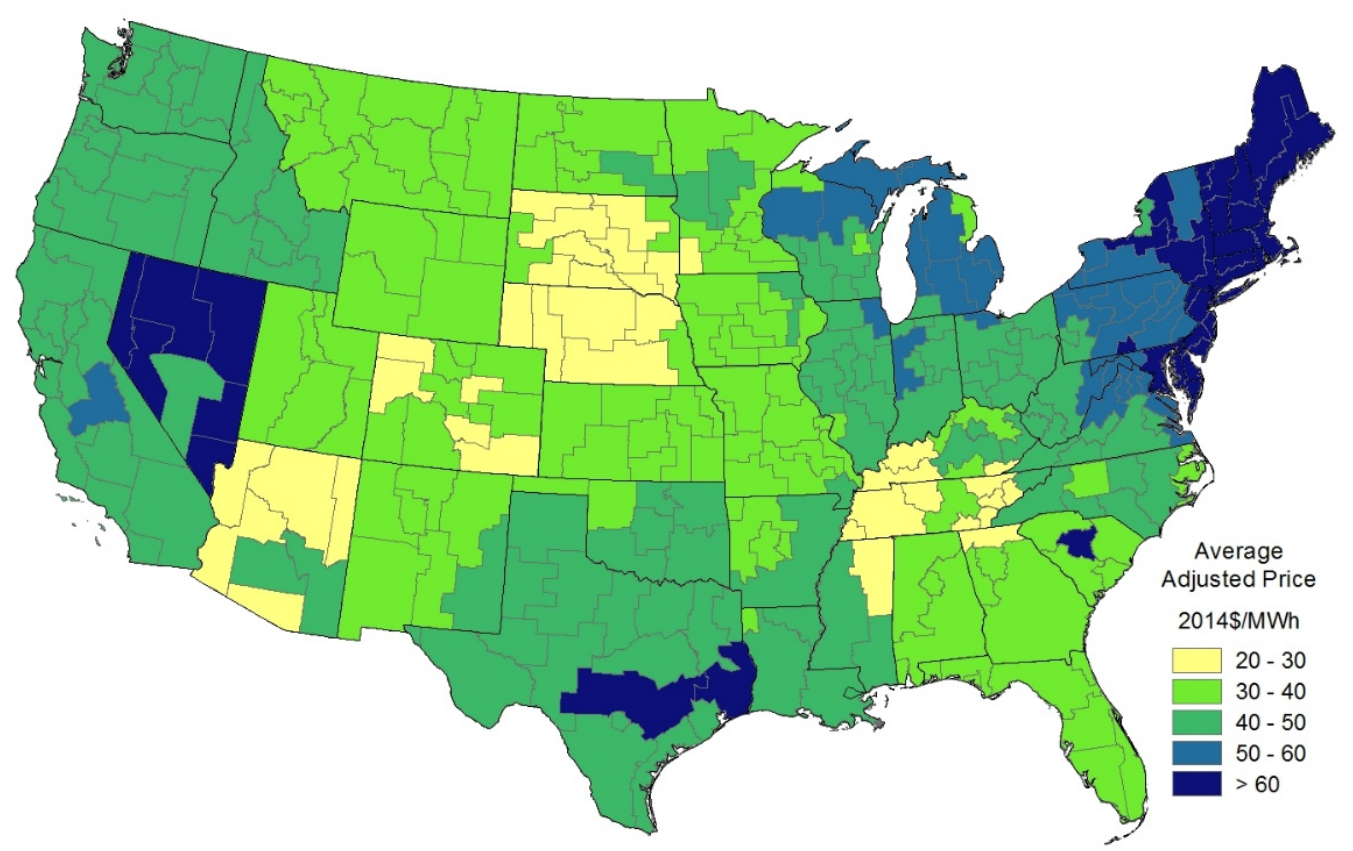

Figure 7. Market price estimates with projected price changes from 2014-2034 (EIA 2015) taken into account

The second LACE component comprises a capacity payment and a technology-specific capacity credit. The product of these two components approximates the capacity value of a generation project (EIA 2013). The capacity payment captures the value a generation project can offer to the 
system in meeting reliability reserve margin, and can be determined by estimating the payment necessary to "incentivize the last unit of capacity needed to satisfy a regional reliability reserve requirement" (EIA 2013). The capacity credit captures "the ability of a unit to provide system reliability reserves" (EIA 2013, p. 3) and depends upon the dispatchability of a generation project. For the purpose of this analysis, the overnight capital cost of a new advanced natural gas combustion turbine (NGCT) plant (AEO 2015 Table 8.2) serves as a proxy of capacity payment. Technology-specific capacity credits assumed in the analysis are shown in Table 4 (based on Milligan and Porter 2008 for wind, Sigrin et al. 2014 for UPV, and NREL 2015 for other technologies.

Table 4. Assumed Capacity Credit by Technology

\begin{tabular}{|l|r|}
\hline \multicolumn{1}{|c|}{ Technology } & $\begin{array}{c}\text { Capacity } \\
\text { Credit }\end{array}$ \\
\hline Wind & 0.25 \\
\hline Utility Solar PV & 0.50 \\
\hline Hydropower & 0.63 \\
\hline Geothermal & 0.99 \\
\hline Biopower & 0.91 \\
\hline
\end{tabular}

Given the importance of avoided cost in the estimation of economic potential, a second approach, Average Avoided Generation (or AAG) is also defined and applied in sensitivity analysis. This AAG approach estimates avoided cost based on the avoided fuel used and operating costs of a mix of avoided generation, and may be comparable to the generation mix that is typically replaced by renewable energy resources. We consider both approaches because they provide complementary views of the economics of renewable generation. The AAG approach is described in Appendix C.

\section{General Approach - Distributed Generation}

Distributed technologies such as rooftop PV displace purchased (retail) electricity, so a wholesale avoided cost is not an appropriate comparator. Rather, utility bill savings reflect the relevant avoided cost from the perspective of the customer. The methodology to estimate avoided cost over the lifetime of a distributed PV project involved estimating the NPV of utility bill savings given expected system generation over a 20-year period. Using NREL's System Advisor Model (SAM) ${ }^{25}$ these estimates were made by estimating present value of avoided electricity payments based on an assumed customer load profile, hourly PV production, and utility rates in a given location. This was simulated for a system in each of the approximately 2,000 utilities with retail residential and/or commercial customers. When possible, the analysis relied on the standard residential or commercial retail rate schedules-including tier schedules, seasonal schedules, and demand or time-of-use components, when relevant. In order to provide the greatest coverage of retail rates, we collected current (as of August 2014) retail rates for the largest utilities in each state by number of customers served. Many utilities offer more than one

\footnotetext{
${ }^{25}$ For more information, see http://sam.nrel.gov/.
} 
rate schedule for residential and commercial customers. For residential customers, we relied on EIA data to select the rate with the most customers. For commercial, we considered only rates applicable to the energy and demand profile for a particular building. When more than one remained, we selected the rate that was the most cost-effective for PV under the assumptions that customers would choose that rate if adopting PV. For the detailed rate schedules pertaining to the remaining small utilities, we relied on EIA average utility rates (total revenue by sector divided by total energy sold). EIA average rates are applied as volumetric rates, and will not account for fixed charges or any quantity, time, or seasonal variation in the volumetric rate-which do critically affect the utility bill savings derived from a PV system. We assumed full net metering, where any excess hourly generation is credited at the applicable retail rate. Further, we assumed that the current rate schedule as of August 2014 would apply over the full analysis period. In reality, many utilities currently have caps on net metering capacity (or may implement caps) that would be reached at lower levels of penetration than what is modeled. In addition, at a certain level of distributed generation penetration, we would expect rate tariff changes to reflect evolving generation patterns and cost recovery requirements.

\subsection{Treatment of Other Factors}

A number of factors beyond renewable generation technology cost and avoided cost are incorporated into the LACE - LCOE net value framework to enable their consideration in specific cases assessed. These factors include the following:

- The cost of tying generation into the grid (intra-regional transmission cost). Included in all cases for utility-scale variable generation.

- The reduction of capacity and energy value of variable generation (wind and solar) that may occur with increasing levels of generation. Included in all Primary Case 3 and related sensitivity cases for utility-scale variable generation.

- Technology tax incentives. ITC at 10\% is applied for utility-scale and distributed PV. Some sensitivity cases consider ITC at $30 \%$ for PV and PTC for wind.

- The value of avoided $\mathrm{CO}_{2}$ emissions, based on an estimate of the SCC.

- The value of avoided health costs.

A more detailed description of each of these follows below. Inclusion of each of these factors involves application of a distinct method, some of which are more mature than others. In particular, the method for estimating the declining value for wind and UPV is a first-time approach based on broad application of published modeled results for California (Mills and Wiser 2012). Inclusion of these factors can significantly affect estimates of economic potential. Future analysis can improve these estimates or suggest new factors for inclusion.

\section{Intra-Regional Transmission Costs for Wind and UPV}

The projected costs for wind and UPV include the cost of building intra-regional transmission and substation capacity to connect the site to the existing transmission system and load centers, or points within the balancing area. Each site connects to the existing grid or balancing area point independently. In reality, we would expect adjacent resource sites to share transmission lines rather than build parallel lines to the existing grid, as this analysis assumes; as such, the method has the effect of over-estimating the amount of intra-regional transmission builds that would be 
necessary. The analysis assumes that $10 \%$ of an existing transmission line or substation's capacity is available to be used by the renewable energy technology (Short et al., 2011); this capacity is allocated to the lowest-cost resource sites (site development + transmission cost) first. The analysis does not consider upgrades to the existing transmission line infrastructure to increase existing line capacity, which in many cases would be cheaper than building new incremental transmission.

The balancing area points represent nodes for bulk inter-regional transmission within the ReEDS model, and as such are modeled with an infinite capacity to accept new resource generation. The ReEDS model contains 132 balancing areas within the continental United States (Figure 5). A balancing area point is determined as the population-weighted center of the balancing area. The cost associated with long-distance (inter-regional) transmission between balancing areas is not included in this analysis.

The base transmission cost assumed is $\$ 3,922 / \mathrm{MW}$-mile, with regional transmission cost multipliers ranging from 0.9 in some locations to 13.65 (Long Island, New York), representing geographic variability in transmission build costs. Besides the transmission spur line cost, a substation build cost of $\$ 14,000 / \mathrm{MW}$ is added if the spur line does not already connect to an existing substation or load center. These costs assumptions are consistent with those used in constructing geospatial resource supply curves for the ReEDS model. Figure 8 shows the range of estimated intra-regional transmission costs by region.

Costs are calculated for each location in the supply curve. The range of these costs reflected in the wind LCOE supply curve are:

- Average distance for transmission spur line for land-based resource is $\sim 51$ miles (range 0 220 miles), with additional cost averaging $\$ 7.8 / \mathrm{MWh}$ (range 0 - $\$ 92 / \mathrm{MWh}$ ); the additional cost includes the cost of grid connection (range $0-\$ 14,000 / \mathrm{MW}$ ).

The range of these costs reflected in the UPV LCOE supply curve are:

- Average distance for transmission spur line is $\sim 27$ miles (range $0-250$ miles), with additional cost averaging $\$ 7.4 / \mathrm{MWh}$ (range 0 - $\$ 729 / \mathrm{MWh}$ ); the additional cost includes grid connection (range 0 - $\$ 14,000 / \mathrm{MW}$ ). 


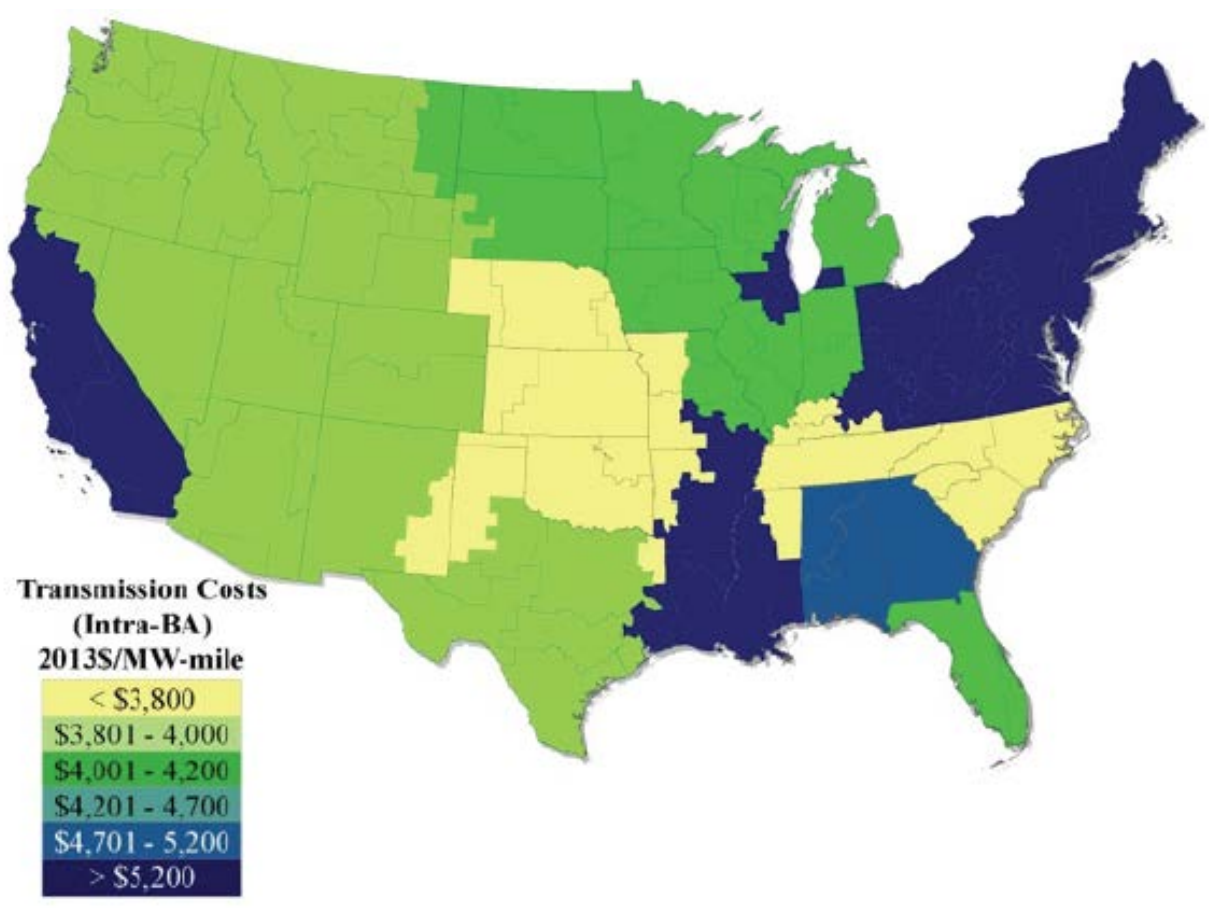

Figure 8. Transmission cost by region

Source: DOE 2015a

\section{Consideration of the Declining Value of Variable Generation}

At high penetration, energy production from a given source may become less valuable to the system as capacity and energy values decline. The variable nature of some resources, such as wind and solar, can lead to the potential for significant declines in system value at higher levels of generation unless mitigation measures are taken.

An initial method to account for this decline in value for variable renewable energy sources is based on Mills and Wiser (2012), a pilot study of this effect that modeled changes in value of wind and solar PV in California based on their penetration levels in the system. This 2012 study explored changes in four value components that can occur with increasing levels of variable renewable energy penetration: capacity value, energy value, day-ahead forecast error, and ancillary services. Modeled reductions in value assumed no mitigating changes would be made in terms of grid flexibility, storage, or operational practices that could support the integration of higher levels of variable generation on the grid.

In the initial declining value methodology applied to economic potential, a region-based penetration level is calculated for each wind or UPV location; a decrease in value at this particular penetration level is then added as a distinct cost component to the location's LCOE, ${ }^{26}$ effectively decreasing the net value (LACE - LCOE) for the site. Estimates are made for wind and UPV separately, and not in combination. This declining value approach was not applied to DPV or the other technologies examined.

\footnotetext{
${ }^{26}$ Alternatively, the decrease in value can also be subtracted from a site's LACE value. Either approach decreases the site's net value (LACE - LCOE) by an equivalent amount.
} 
More specifically, for each technology, locations are first sorted in descending order by their net value (LACE - LCOE) and market region without declining value considered. The sorting process accounts for existing generation in each region by designating locations on the sorted list with the lowest LCOEs within each region as already developed. In a next step, penetration share is calculated for each resource location as the sum of existing 2013 generation levels and all generation potential that has already been determined to be economic within a region, divided by the region's total 2013 generation from all sources. This process assumes that locations with higher net value would be developed first. Reductions in value for each location are then made by comparing the location's variable generation share to a value reduction curve derived from estimates in Mills and Wiser (2012) (Figure 9).

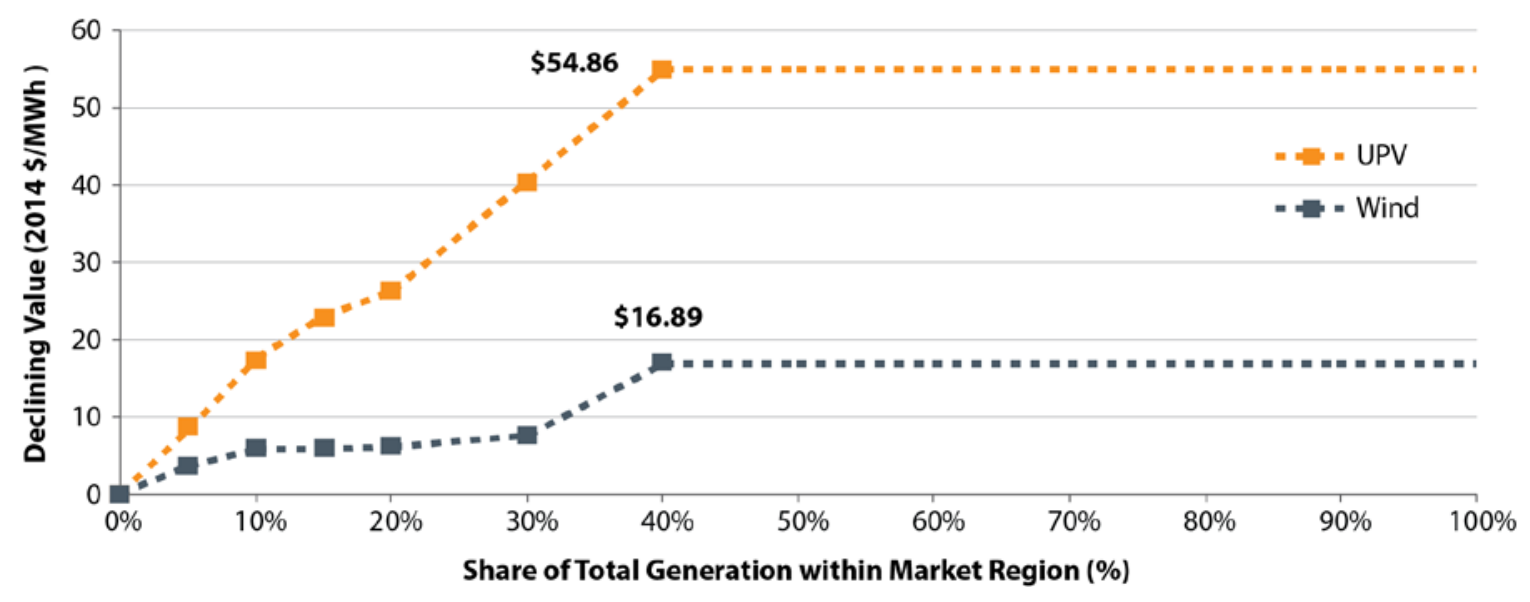

Figure 9. Value reduction curves for wind and UPV

Note: Markers indicate adapted estimates from Mills and Wiser (2012), adjusted for different natural gas price assumptions. Declining value shown as positive to reflect its addition to LCOE; it could also be considered as an equivalent negative value addition to LACE (e.g., reduces LACE). Dashed lines indicate interpolated values for generation level not reported in Mills and Wiser (2012) and extrapolated beyond the generation levels assessed in that study. $\$ 54.86 / \mathrm{MWh}$ is the assumed value reduction assumed for all UPV sites with calculated regional generation shares $>40 \%$; $\$ 16.89 / \mathrm{MWh}$ is assumed for all wind sites with calculated regional generation shares $>$ $40 \%$.

A market region is determined for each site based on the state in which the site is located in (Figure 10). This assignment uses ISOs where they exist and otherwise market regions identified by FERC. For a state split among regions, the entire state was assigned to the region with the largest portion of the state's land area (e.g., both Nevada and Montana were assigned to the Northwest region). This method is intended as a rough approximation for system management and is a simplification. 


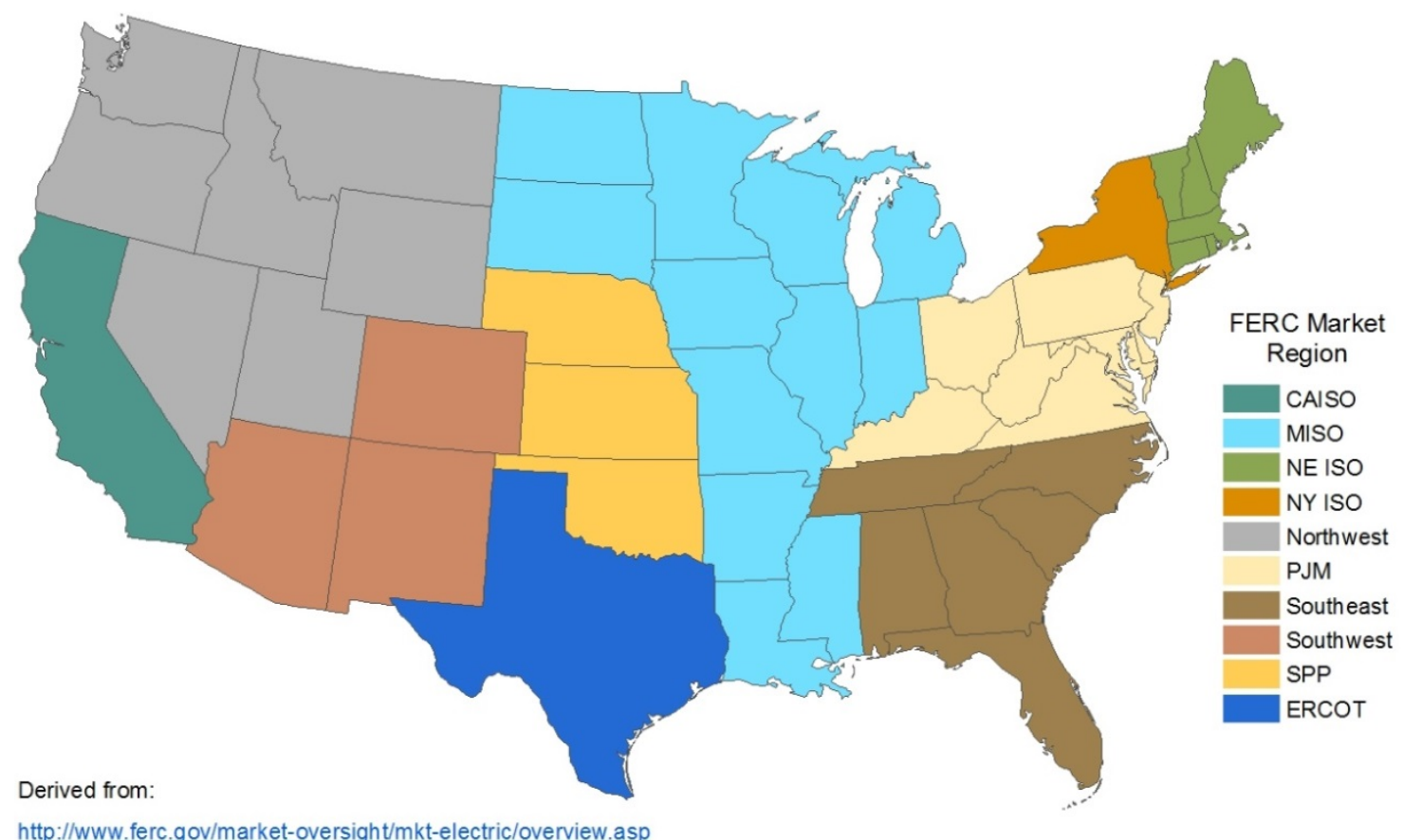

Figure 10. Regions used to estimate existing generation and potential generation share

In constructing the value reduction curves, energy and capacity value effects were treated separately and then combined. For the capacity value component, capacity credits in Table 4 were assumed. For the energy value component, values from Mills and Wiser (2012) were adjusted to reflect current natural gas price levels. Declining values were linearly interpolated for penetration levels not reported in Mills and Wiser (2012). Declining value beyond $40 \%$ penetration levels for both technologies was assumed to remain flat.

For wind, the value reduction curve yields a decrease in value of $\$ 16.89 / \mathrm{MWh}$ for a location with a corresponding regional penetration share of $40 \%$ and beyond. For UPV, the decrease of value reaches $\$ 54.86 / \mathrm{MWh}$ for a share of $40 \%$. Given the assumption of flat declining values beyond $40 \%$, a cut-off was applied in the method to ensure that total generation for either technology did not exceed $100 \%$ total 2013 generation levels within any region.

While the incremental value of PV to the system is effectively reduced to 0 by a $40 \%$ penetration level in the decline curve applied, the initial method adopted does not reduce the value of wind to 0 as its potential share of generation exceeds $40 \%$. As a consequence, wind potential may be overstated for scenarios where its share of generation in a region exceeds $40 \%$.

The wind decline value curve above was modified and applied in a sensitivity case to reduce the incremental value of wind to 0 by $100 \%$ penetration, based on marginal curtailment values from Denholm and Hand (2011). 
This approach implicitly assumes no mitigation is taken in the electricity system to reduce the decline in value (e.g., by increasing system flexibility or bulk power movement between regions). Future analysis may include the impact of such mitigation measures.

\section{Technology Tax Incentives}

Technology-specific federal tax incentives are considered in most of the cases assessed in this analysis based on existing law. For the technologies examined, most cases account for a permanent solar PV investment tax credit (ITC) of 10\% applied as a reduction to overnight capital cost. Technology-specific federal tax incentives are also considered for wind and UPV as part of separate sensitivity cases to explore the implication of an extension of federal incentives available to renewable generation projects in 2014. In this sensitivity case, federal tax incentives are applied as follows: the ITC assumed for solar PV is 30\% and is applied to overnight capital cost as a multiplier; the PTC is assumed to reduce wind LCOEs by \$17/MWh (Bolinger 2014); ITCs or PTCs are assumed to not apply to any other technologies and these incentives are applied in addition to, not in place of, the value of avoided $\mathrm{CO}_{2}$ emissions in most cases.

\section{Value of Avoided $\mathrm{CO}_{2}$ Emissions}

This analysis uses an approach based on the method and discount rate scenarios identified in IWG (2013), applied in five-year increments (EPA 2013). Average SCC with 3\% discount rate is used in two of the three Primary Cases; average SCC with 5\% 95\% percentile SCC with 3\% discount rates are explored in sensitivity cases. For intermediate years, we use the previous fiveyear mark (e.g., 2018 uses the 2015 value). The total value of avoided $\mathrm{CO}_{2}$ is based on the avoided generation mix specified in the Average Avoided Generation (AAG) avoided cost method described in Appendix C. As recommended by IWG, the value of avoided $\mathrm{CO}_{2}$ is discounted at a different rate than technology costs (the same rate used in the case). This results in the following levelized average values over the life of a renewable generation project: Average SCC with 3\%: \$34.9 / ton; Average SCC with 5\%: \$8.6 / ton; 95\% percentile SCC with 3\%: $\$ 105$ / ton. $\mathrm{CO}_{2}$ intensities used (ANL 2014) were: CCGT: $0.4087 \mathrm{~kg} / \mathrm{kWh}$; CT: $0.6008 \mathrm{~kg}$ / $\mathrm{kWh}$; Coal: $0.9375 \mathrm{~kg} / \mathrm{kWh}$. For the $3 \%$ case, the value of avoided generation by technology is: Coal: \$34.6/MWh; NGCC: \$14.8 / MWh; NGCT: \$22.4 / MWh; Average: \$21.1 / MWh.

It should be noted that that SCC considers the costs of carbon at a global level (as suggested by IWG guidance) while this analysis captures local or region-level characteristics to determine economic potential for specific sites. This discrepancy is not addressed in the model but should be taken into account for interpretation of the model results.

\section{Value of Avoided Health Costs}

The value of avoided $\mathrm{NO}_{\mathrm{X}}, \mathrm{SO}_{\mathrm{X}}$, and particulate matter from reduced fossil generation is included in a sensitivity case as an addition to the avoided cost. The method is a simplified version of what was described in DOE (2015a). This approach takes the estimation of pollutant emissions from a given power plant based on application of results from modeling the atmospheric dispersion and secondary reaction of those pollutants (EPA 2014) and then combines that with the estimation of population exposure to primary and secondary pollutants and the exposure-response relationship for specific outcomes (i.e., morbidity or premature mortality) (EPA 2014). The assessment of the monetary value of reducing each pollutant is assigned by region (East, West, and California) (EPA low case). The analysis assumes existing 
cap-and-trade programs are not binding (e.g., increased wind generation reduces pollution) and presumes existence of MATS and CSAPR. The majority of value is derived from reductions in $\mathrm{SO}_{2}$. It should be noted that that health costs consider the costs of emissions at a macro region level while this analysis captures more local characteristics to determine economic potential for specific sites.

\subsection{Method Caveats}

There are several caveats that are important to keep in mind when considering the methodology:

- The methodology does not attempt to project the level of renewable generation that might actually be deployed in the future. While some market factors are considered in the net value framework, it does not comprehensively consider market conditions and other factors that could affect potential deployment.

- The method described is not intended to replace engineering, project-based, or site analysis, which are necessary to fully assess the economic viability of a technology system by accounting for project-specific issues. The economic potential metric is also not a substitute for capacity expansion or production cost modeling, which takes electricity demand and system operations constraints, including the availability of transmission capacity, and market factors into account, such as economic competition among different renewable or conventional resources.

- While the methodology does consider the cost of the cost of tying potential generation into the grid (intra-regional transmission costs), the potential costs and impact of inter-regional transmission on economic potential are not considered. In particular, the approach compares cost of energy and avoided cost to arrive at net value only at the same location, implying that renewable generation would be used to satisfy load at that location or within the balancing area in which the location resides. The method does not consider either export or import situations for a particular location that long-distance transmission could enable (i.e., the cost of energy at one location, including inter-regional transmission cost, is not compared to the avoided cost in another location that could be served by that transmission. As such, the economic potential estimates based on this method will not identify all the economically viable potential for specific technologies, like land-based wind, that may have low-cost resources at locations remote from load. That is, in some cases site-specific generation may be economically attractive when delivered to another load center, even when transmission and other integration costs are included in the calculation. ${ }^{27}$

- The framework described is static and considers economic potential only at a particular point in time based on the vintage of underlying data and assumptions, including electricity price projections, technical potential, cost of energy, and avoided cost. As resource data, technology cost and performance, actual renewable technology deployment, transmission infrastructure, fuel prices, wholesale electricity prices, and other factors change, estimates of economic potential will change. Further, the framework does not consider potential dynamic feedbacks that increasing renewable deployment may have on wholesale electricity prices.

\footnotetext{
${ }^{27}$ This issue is generally addressed in capacity expansion models that include a representation of inter-regional transmission (e.g., NREL's ReEDS model) and has been considered in market -based assessments of renewable generation in recent "vision" studies (e.g., DOE 2012; DOE 2015a).
} 
- As with other methods that employ renewable resource data, the technical annual generation potential estimates for renewable generation technologies, upon which the net value framework is based, generally rely on typical meteorological year (TMY) statistical profiles. While this underlying data is meant to represent the hourly variability of an average year, significant annual variation in generation can occur based on local/regional weather patterns and storm events.

- The declining value method is an initial broad application of published modeled results for California (Mills and Wiser 2012) that assessed the decline of both energy and capacity value of wind and PV up to $40 \%$ penetration. There is uncertainty associated with the application of these modeled results beyond California and at penetration levels beyond $40 \%$. The incremental value of $\mathrm{PV}$ to the system is reduced by nearly $\$ 55 / \mathrm{MWh}$ at penetration levels of and beyond $40 \%$, effectively reducing economic potential to zero at these penetrations. However, wind's value is only reduced by nearly $\$ 18 / \mathrm{MWh}$ at penetration levels of and beyond $40 \%$. In some locations with high quality wind resource - Texas, for example - wind generation cost may remain less than LACE even after taking this declining value into account. Since this initial method does not reduce the value of wind further as its potential share of generation exceeds $40 \%$, wind potential may be overstated for scenarios where its share of generation in a region exceeds $40 \%$.

- Wholesale prices rely on a range of sources due to varying reporting requirements. More accurate wholesale price estimates for regions without locational marginal prices (LMPs) or market marginal costs (MMCs or system lambdas) reported, such as the Pacific Northwest region, are needed. 


\section{Technology-Specific Inputs}

The technologies included in this analysis are each characterized by their specific technical potential (as reflected in net capacity factors $[\mathrm{CF}]$ ), O\&M costs, and OCCs. This section features these input assumptions for each technology considered in this analysis (see Table 5 for an overview of technology cost assumptions under assumptions used in the Primary Cases). The majority of technology cost assumptions were derived from NREL's ATB database and Standard Scenarios Annual Report (NREL 2015).

Table 5. Overview of Renewable Technology Cost Assumptions Used in Primary Cases

\begin{tabular}{|c|c|c|c|c|c|c|c|}
\hline & TRG & Description & $\begin{array}{l}\text { Resource } \\
\text { Class }\end{array}$ & $\begin{array}{l}\text { Net } \\
\text { Capacity } \\
\text { Factor (CF) }\end{array}$ & $\begin{array}{l}\text { O\&M } \\
\text { (\$/MW) }\end{array}$ & $\begin{array}{l}\text { Overnight } \\
\text { Capital } \\
\text { Cost (\$/MW) }\end{array}$ & $\begin{array}{l}\text { Variable } \\
\text { O\&M } \\
\text { (\$/MWh) }\end{array}$ \\
\hline \multirow{5}{*}{$\stackrel{0}{\frac{0}{5}}$} & 1 & Land-based 1 & ons 1 & $53.8 \%$ & 49,000 & $1,571,000$ & $\mathrm{~N} / \mathrm{A}$ \\
\hline & 2 & Land-based 2 & ons2 & $49.2 \%$ & 49,000 & $1,571,000$ & $\mathrm{~N} / \mathrm{A}$ \\
\hline & 3 & Land-based 3 & ons3 & $46.8 \%$ & 49,000 & $1,673,000$ & $\mathrm{~N} / \mathrm{A}$ \\
\hline & 4 & Land-based 4 & ons4 & $41.2 \%$ & 49,000 & $1,738,000$ & $\mathrm{~N} / \mathrm{A}$ \\
\hline & 5 & Land-based 5 & ons5 & $34.8 \%$ & 49,000 & $1,738,000$ & $\mathrm{~N} / \mathrm{A}$ \\
\hline \multirow{9}{*}{ 方 } & $\mathrm{N} / \mathrm{A}$ & $3-3.5$ & 1 & $14 \%$ & 8,000 & $1,603,000$ & $\mathrm{~N} / \mathrm{A}$ \\
\hline & $N / A$ & $3.5-4$ & 2 & $16 \%$ & 8,000 & $1,603,000$ & $N / A$ \\
\hline & $\mathrm{N} / \mathrm{A}$ & $4-4.5$ & 3 & $18 \%$ & 8,000 & $1,603,000$ & $\mathrm{~N} / \mathrm{A}$ \\
\hline & $\mathrm{N} / \mathrm{A}$ & $4.5-5$ & 4 & $19 \%$ & 8,000 & $1,603,000$ & $\mathrm{~N} / \mathrm{A}$ \\
\hline & $\mathrm{N} / \mathrm{A}$ & $5-5.5$ & 5 & $21 \%$ & 8,000 & $1,603,000$ & $\mathrm{~N} / \mathrm{A}$ \\
\hline & $\mathrm{N} / \mathrm{A}$ & $5.5-6$ & 6 & $23 \%$ & 8,000 & $1,603,000$ & $\mathrm{~N} / \mathrm{A}$ \\
\hline & $\mathrm{N} / \mathrm{A}$ & $6-6.5$ & 7 & $26 \%$ & 8,000 & $1,603,000$ & $\mathrm{~N} / \mathrm{A}$ \\
\hline & $\mathrm{N} / \mathrm{A}$ & $6.5-7$ & 8 & $27 \%$ & 8,000 & $1,603,000$ & $\mathrm{~N} / \mathrm{A}$ \\
\hline & $\mathrm{N} / \mathrm{A}$ & $7-7.5$ & 9 & $29 \%$ & 8,000 & $1,603,000$ & $\mathrm{~N} / \mathrm{A}$ \\
\hline \multirow{10}{*}{ 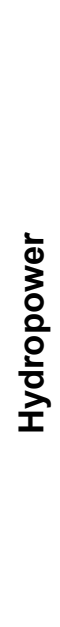 } & $\mathrm{N} / \mathrm{A}$ & NPD & hydclass 1 & Site-specific & 15,000 & Site-specific & 3 \\
\hline & $\mathrm{N} / \mathrm{A}$ & NPD & hydclass2 & Site-specific & 15,000 & Site-specific & 3 \\
\hline & N/A & NPD & hydclass3 & Site-specific & 15,000 & Site-specific & 3 \\
\hline & N/A & NPD & hydclass 4 & Site-specific & 15,000 & Site-specific & 3 \\
\hline & $\mathrm{N} / \mathrm{A}$ & NPD & hydclass5 & Site-specific & 15,000 & Site-specific & 3 \\
\hline & N/A & NSD & hydclass 1 & Site-specific & 15,000 & Site-specific & 3 \\
\hline & $\mathrm{N} / \mathrm{A}$ & NSD & hydclass2 & Site-specific & 15,000 & Site-specific & 3 \\
\hline & $\mathrm{N} / \mathrm{A}$ & NSD & hydclass3 & Site-specific & 15,000 & Site-specific & 3 \\
\hline & N/A & NSD & hydclass 4 & Site-specific & 15,000 & Site-specific & 3 \\
\hline & N/A & NSD & hydclass 5 & Site-specific & 15,000 & Site-specific & 3 \\
\hline
\end{tabular}




\begin{tabular}{|c|c|c|c|c|c|c|c|}
\hline & TRG & Description & $\begin{array}{l}\text { Resource } \\
\text { Class }\end{array}$ & $\begin{array}{l}\text { Net } \\
\text { Capacity } \\
\text { Factor (CF) }\end{array}$ & $\begin{array}{l}\text { O\&M } \\
\text { (\$/MW) }\end{array}$ & $\begin{array}{l}\text { Overnight } \\
\text { Capital } \\
\text { Cost (\$/MW) }\end{array}$ & $\begin{array}{l}\text { Variable } \\
\text { O\&M } \\
\text { (\$/MWh) }\end{array}$ \\
\hline \multirow{4}{*}{ 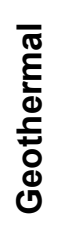 } & $\mathrm{N} / \mathrm{A}$ & $\mathrm{N} / \mathrm{A}$ & geoclass1 & $85 \%$ & 115,000 & Site-specific & $\mathrm{N} / \mathrm{A}$ \\
\hline & N/A & $\mathrm{N} / \mathrm{A}$ & geoclass2 & $85 \%$ & 115,000 & Site-specific & $\mathrm{N} / \mathrm{A}$ \\
\hline & $\mathrm{N} / \mathrm{A}$ & N/A & geoclass3 & $85 \%$ & 115,000 & Site-specific & $\mathrm{N} / \mathrm{A}$ \\
\hline & $\mathrm{N} / \mathrm{A}$ & $\mathrm{N} / \mathrm{A}$ & geoclass 4 & $85 \%$ & 115,000 & Site-specific & $\mathrm{N} / \mathrm{A}$ \\
\hline \multirow{5}{*}{ 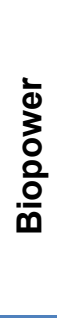 } & $\mathrm{N} / \mathrm{A}$ & $\mathrm{N} / \mathrm{A}$ & bioclass 1 & $51 \%$ & 107,000 & $3,651,000$ & 5 \\
\hline & $\mathrm{N} / \mathrm{A}$ & $\mathrm{N} / \mathrm{A}$ & bioclass2 & $51 \%$ & 107,000 & $3,651,000$ & 5 \\
\hline & $\mathrm{N} / \mathrm{A}$ & $\mathrm{N} / \mathrm{A}$ & bioclass 3 & $51 \%$ & 107,000 & $3,651,000$ & 5 \\
\hline & N/A & $\mathrm{N} / \mathrm{A}$ & bioclass 4 & $51 \%$ & 107,000 & $3,651,000$ & 5 \\
\hline & $\mathrm{N} / \mathrm{A}$ & $\mathrm{N} / \mathrm{A}$ & bioclass 5 & $51 \%$ & 107,000 & $3,651,000$ & 5 \\
\hline \multirow{2}{*}{ 方 } & $\mathrm{N} / \mathrm{A}$ & $\mathrm{N} / \mathrm{A}$ & residential & Site-specific & $\mathrm{N} / \mathrm{A}$ & $2,400,000$ & $\mathrm{~N} / \mathrm{A}$ \\
\hline & $N / A$ & $N / A$ & commercial & Site-specific & $\mathrm{N} / \mathrm{A}$ & $2,000,000$ & $N / A$ \\
\hline
\end{tabular}

Note: All values in $2013 \$$ or $\%$.

\subsection{Centralized Generation}

\section{Wind}

\section{LCOE Input Assumptions}

Values for net CF, fixed O\&M costs, and OCC for the different technology cost years considered in this analysis were derived from the recently published Wind Vision Report (2015). There are five land-based techno-resource groups (TRGs). Net CF and OCC vary by TRG and technology cost year. 2010 and 2014 historical values and future year values for technology costs were derived from the ATB database (NREL 2015) values for onshore resource classes. Net CF is generally assumed to increase and capital costs to decrease in future technology cost year scenarios.

The installation density of wind is assumed to be $3 \mathrm{MW} / \mathrm{sq}$. $\mathrm{km}$. Intra-regional transmission costs are calculated by multiplying the baseline intra-regional transmission cost by regional Transmission Cost Multipliers, which range from 0.90 to 13.65 for wind. Regional Capital Cost multipliers range from 0.91 to 1.34 .

\section{LACE Input Assumptions}

The initial capacity credit for wind was assumed to be 25\% (Milligan and Porter 2008) for all sites and regardless of the time of generation. When the declining value method is applied, this base level is reduced with increasing wind penetration. Capacity payment is based on the overnight capital cost of a new advanced NGCT plant (AEO 2015 Table 8.2). 
UPV

\section{LCOE Input Assumptions}

Values for net CF were derived from a resource analysis using PVWatts5 for nine resource classes, and is consistent with the range of net CF reported in the ATB database (2015). OCC and O\&M costs were taken from the ATB database (2015) and refer to the ATB "Mid Case" projection.Net CFs are assumed to remain flat across all technology cost year scenarios. Cost improvements in future years are only achieved through a reduction in OCC and O\&M costs.

The installation density of UPV is assumed to be $39 \mathrm{MW} / \mathrm{sq}$. km. (Ong et al. 2013). Intraregional transmission costs are calculated by multiplying the baseline intra-regional transmission cost by regional Transmission Cost Multipliers, which range from 0.90 to 13.65 for UPV. Regional Capital cost multipliers range from 0.90 to 1.16 .

\section{LACE Input Assumptions}

The initial capacity credit for UPV was assumed to be 50\% (Sigrin et al. 2014) for all sites and regardless of the time of generation. When the declining value method is applied, this base level is reduced with increasing UPV penetration. Capacity payment is based on the overnight capital cost of a new advanced NGCT plant (AEO 2015 Table 8.2).

\section{Hydropower}

\section{LCOE Input Assumptions}

Net CFs were derived from Oakridge National Laboratory's National Hydropower Asset Assessment program (Hadjerioua et al. 2012; Kao et al. 2014) and aggregated into five hydropower resource classes for two different categories (non-powered dams and new streamreach development) in ReEDS PCAs. Site-specific capacity factors were matched with PCAspecific OCC and average values for fixed and variable O\&M costs from the ATB database (2015) for each hydropower resource class and category. In accordance with the ATB database (NREL 2015), 2014 OCC, O\&M, and CFs were assumed for future technology year cases (i.e., flat over time). s. Intra-regional transmission costs are not taken into consideration for this resource.

\section{LACE Input Assumptions}

The capacity credit for hydropower was assumed to be $62.5 \%$ for all sites and regardless of the time of generation. ${ }^{28}$ The declining value method is not applied, so this capacity credit does not decrease with increased penetration level. Capacity payment is based on the overnight capital cost of a new advanced NGCT plant (AEO 2015 Table 8.2).

\section{Geothermal}

\section{LCOE Input Assumptions}

The geothermal resource is limited to conventional hydrothermal applications, and is characterized by four resource classes by ReEDS power control area. A net CF of $85 \%$ is assumed for all geothermal sites, which is not varied across the various technology cost year scenarios. OCC is calculated for specific sites on the basis of costs generated with Idaho

\footnotetext{
${ }^{28}$ This capacity credit is based on the capacity-weighted average capacity factor across the ReEDS PCAs.
} 
National Laboratory's Geothermal Energy Technology Evaluation Model (GETEM). ${ }^{29}$ In accordance with the ATB database (NREL 2015), 2014 OCC, O\&M, and CF values were assumed for future technology year cases (i.e., flat over time). Intra-regional transmission costs are not taken into consideration for this resource.

\section{LACE Input Assumptions}

The capacity credit for geothermal was assumed to be $99 \%$ for all sites and regardless of the time of generation. The declining value method is not applied, so this capacity credit does not decrease with increased penetration. Capacity payment is based on the overnight capital cost of a new advanced NGCT plant (AEO 2015 Table 8.2).

\section{Biopower}

\section{LCOE Input Assumptions}

Input assumptions for biopower net CF, OCC, and O\&M refer to the ATB database "Dedicated mid" cost scenario. Net CF is assumed to remain flat at $51 \%$ across all scenarios. In accordance with the ATB database (NREL 2015), 2014 OCC, O\&M, and CF values were assumed for future technology year cases (i.e., flat over time). Intra-regional transmission costs are not taken into consideration for this resource.

\section{LACE Input Assumptions}

Capacity credits for biopower were assumed to be $91 \%$ for all sites and regardless of the time of generation. The declining value method is not applied, so this capacity credit does not decrease with increased penetration level.

\section{Future Data Needs}

Future work could improve both LCOE and LACE components for utility-scale technologies. In general, resource classes are discrete and feature averages. By developing continuous cost assumptions, "tails" of the distribution could better be captured. LCOE estimates could be improved for Hydropower, Geothermal, and Biopower by including consideration of intraregional transmission costs, including the use of intra-regional transmission multipliers. In addition, future improvements could capture the possibility of exports and integrate an interregional transmission cost factor as part of location LCOE estimates.

The current analysis does also not consider temporal production profile of generation technologies, and consequently, the market prices captured by production. Additional analysis could develop price estimates that are weighted by the times of generation.

\section{Distributed Generation}

\section{Distributed Solar PV}

\section{Cost Input Assumptions}

We assume the same 2020 capital cost nationwide for the Central Case: $\$ 2.40 / \mathrm{W}$ and $\$ 2.00 / \mathrm{W}$ for the residential and commercial cases, respectively. Capital cost is then reduced to account for the permanent 10\% ITC-additional benefits accruing from Modified Accelerated Cost Recovery

\footnotetext{
${ }^{29} \mathrm{See}$ http://energy.gov/eere/geothermal/geothermal-electricity-technology-evaluation-model for a description of this model, and NREL, 2011 for a description of the process used.
} 
(MACRS) are included. Fuel cost is not applicable; the analysis does not factor in O\&M costs, which are assumed to be small. Cost assumptions are derived from UPV cost projections, increasing the projections by $25 \%$ and $50 \%$ for commercial and residential, respectively.

\section{Avoided Cost Input Assumptions}

When possible, the analysis relied on the standard residential or commercial retail rate schedules - including tier schedules, seasonal schedules, and demand or time-of-use components, when relevant. In order to provide the greatest coverage of retail rates, we collected current (as of August 2014) retail rates for largest utilities in each state by number of customers served. Many utilities offer more than one rate schedule for residential and commercial customers. For residential customers, we relied on EIA data to select the rate with the most customers. For commercial, we considered only rates applicable to the energy and demand profile for a particular building. When more than one remained, we selected the rate that was the most costeffective for PV. For the detailed rate schedules for remaining small utilities, we relied on EIA average utility rates (total revenue by sector divided by total energy sold). EIA average rates are applied as volumetric rates and will not account for fixed charges or any quantity, time, or seasonal variation in the volumetric rate-which do critically affect the utility bill savings derived from a PV system. We assumed full net metering, where any excess hourly generation is credited at the applicable retail rate.

\section{Future Data Needs}

Future work could improve estimates of technical potential and avoided cost components. More robust counts on commercial building types and available roof space are needed, along with an improved understanding of building load profiles, particularly for excluded categories (e.g., public order and safety, religious). More complete coverage of both residential and commercial retail rates is needed, as well an improved ability to match retail commercial rates to specific building types. 


\section{Initial Results}

The methodology described above is applied to several renewable generation technologies, including land-based wind, UPV, DPV, hydropower, geothermal (hydrothermal resource only), and biopower under various assumptions. As described above, the application of the methodology to specific technologies is based on readily available data and relies on simplifying assumptions.

\subsection{Primary Cases Formulations}

Rather than generating a single estimate of economic potential, the analysis assesses three Primary Cases (assumption sets) with the intent of exploring the effects of method and assumption selection on the magnitude of estimates. The three Primary Cases are reported based on the following distinct formulations of economic potential:

- $\quad$ Primary Case 1 - LACE Only: This case is meant to represent the LACE methodology identified in Namovicz (2013) as closely as possible, with little consideration of market factors that could affect the actual deployment of renewable generation. This formulation includes the cost of intra-regional transmission for variable generation technologies (Wind and UPV).

- $\quad$ Primary Case 2 - LACE including Value of Avoided External Costs: This case extends LACE to consider the value of avoided external costs associated with conventional generation, in particular $\mathrm{CO}_{2}$ emissions.

- Primary Case 3-LACE including Value of Avoided External Costs and Declining Value of Variable Generation: This case further extends LACE to also consider the potential impact of increasing amounts of variable generation on its value.

The latter two formulations move beyond a strict formulation of economic potential that considers only technology costs and required revenues for project development to one that considers some market factors. These market extensions are considered in this analysis to offer additional possible perspectives, in recognition that the demarcation between economic and market potential is subject to interpretation, and to demonstrate that the specific factors considered can have a significant impact on estimates.

For each of the above Primary Cases, an economic potential estimate range is established through varying assumptions of the applied capacity value of renewable generation. A major determinant of the capacity value is the extent to which additional generation capacity is required for the electricity system. In each of the Primary Cases, the low end of the estimated range of economic potential assumes that no additional capacity is required and reflects no credit for the capacity value of renewable generation in the avoided cost calculation $(0 \% \mathrm{CV})$. Conversely, the high end of each range assumes that additional capacity is needed on the system and reflects full credit for the capacity value of renewable generation in the avoided cost calculation $(100 \% \mathrm{CV})$.

Collectively, these Primary Cases rely on the following major assumptions: 
- Construction Date: 2014 - Both the LCOE and LACE components of net value are calculated assuming a renewable generation project is constructed in 2014 (cost and value time streams that make up these components begin in 2014 and are discounted back to 2014). This approach enables a "current" view of economic potential based on existing 2014 marginal generation prices and existing forward projections of those prices. In contrast, as noted below, renewable technology costs for the Primary Cases are referenced to 2020. The combination of these two assumptions provides a blended view of economic potential illustrative of both the current environment and the near-term future. A sensitivity analysis explores a case with 2014 renewable costs and a 2014 construction date, as well as a case with 2020 renewable costs and a 2020 construction date.

- Renewable Technology Cost: 2020 mid-projection - The 2020 timeframe reflects additional technology improvement for most technologies assessed. The mid-case projected cost from NREL Annual Technology Baseline (ATB) (NREL 2015) is a central estimate.

- Renewable Technology Incentives: Permanent 10\% ITC for UPV, DPV; Accelerated Depreciation (MACRS) - The inclusion of this level of ITC is intended to reflect a representation of existing federal law. As the current 30\% ITC for solar technologies is scheduled to revert to the $10 \%$ level at the end of 2016 , the "permanent" $10 \%$ level is used. The PTC is not included for wind as it required plant construction to begin by the end of 2013. Accelerated depreciation (MACRS) is assumed for all applicable technologies.

- Project Life: 20 years - Renewable generation plants are assumed to have a financial life of 20 years for the purposes of calculating LCOEs. LACE is estimated from marginal generation prices over this assumed 20-year asset life.

- $\quad$ Avoided Cost Method for Central Generation: MP - The MP method, based on a synthesis of locational marginal price data, is applied as a proxy for the revenue a centralized renewable project might receive in a given market. The capacity value component of avoided cost assumes a NGCT capital cost of $\$ 682 / \mathrm{kW}$ (consistent with AEO 2015). ${ }^{30}$ For DPV, local retail rates, together with full net metering where the customer is credited for any excess hourly generation at the applicable retail rate, are used as a basis for comparison to generation cost.

- Value of Avoided Health Costs: Not Included - Estimates of this type of external cost are not included in the primary cases as this impact of avoided cost was deemed secondary to consideration of the value of avoided $\mathrm{CO}_{2}$ emissions. Avoided heath costs are considered in sensitivity case.

The following variables differentially applied among the three Primary Cases:

- $\quad$ Value of Avoided $\mathrm{CO}_{2}$ Emissions (SCC): IWG (2013) Average SCC using a 3\% discount rate - The value of avoided $\mathrm{CO}_{2}$ emissions is included in Primary Cases 2 and 3.

- Declining Value of Variable Generation: Included for Wind, UPV - Declining value is applied in the net value framework in Primary Case 3 that was designed to more broadly consider market effects. The application is made only to estimates for wind and UPV potential to reflect the possible impact of high levels of variable generation on project

\footnotetext{
${ }^{30}$ See AEO 2015 Table 8.2: http://www.eia.gov/forecasts/aeo/assumptions/pdf/table_8.2.pdf.
} 
economics. This adjustment is not included for any DPV cases (no assumed change in value of solar with increasing DPV generation), given that the topic is an active area of research.

Table D-1 in Appendix D identifies the specific assumptions associated with each Primary Case.

\section{Summary Results by Technology}

For each technology, we provide a brief summary of observations for Primary Cases results followed by estimated economic potential maps for selected Primary Cases, along with pointers to figures in the Appendix E below that document calculation component maps (LCOE, LACE, and Net Value) and related aggregated U.S. supply curves for LCOE and Net Value. State-level estimates for the Primary Cases can be found in Appendices F.

\section{Land-Based Wind (Wind)}

The economic potential estimates for land-based wind for the Primary Cases are shown in Table 6, ranging from 135 to nearly 7,900 TWh in excess of 2013 generation for the continental United States. This range represents from less than one to over 40 times total U.S. wind generation in 2013. The high end of the range and is over one-third of wind annual technical generation potential of 22,000 TWh. For Primary Case 1, wind economic potential is concentrated in Texas, Nevada, and Maine. For Primary Case 3, wind economic potential is concentrated in the central part of the country (West South Central Census division) and appears lowest in the Southeast (East South Central Census division); while Texas garners nearly half of the estimated national annual potential, four other states have potential of at least $50 \mathrm{TWh}$, with twenty-four states in total having potential of at least $1 \mathrm{TWh}$. For Primary Case 2, where no declining value is applied, Texas garners over $40 \%$ of the potential, while 11 other mid-continent states have potential of at least 100 TWh. Figures E-1 through E-3 in Appendix E present LCOE, LACE, and Net Value maps and aggregated national supply curves. Figure 11 below presents economic potential maps by state, both in terms of annual generation and as a percentage of 2010 total generation. 
Table 6. Wind Estimated U.S. Economic Potential - Primary Cases

\begin{tabular}{|c|c|c|c|c|}
\hline & & Annual Generati & n (TWh) & \\
\hline Case & $\begin{array}{l}\text { No Capacity } \\
\text { Value }(0 \% \mathrm{CV})\end{array}$ & $\begin{array}{l}\text { Full Capacity } \\
\text { Value }(100 \% \mathrm{CV})\end{array}$ & $\begin{array}{l}2013 \\
\text { Generation }^{1}\end{array}$ & $\begin{array}{l}\text { Technical } \\
\text { Potential }^{2}\end{array}$ \\
\hline Primary Case 1 - LACE Only ${ }^{3}$ & 135 & 319 & \multirow{3}{*}{168} & \multirow{3}{*}{22,195} \\
\hline $\begin{array}{l}\text { Primary Case 2 - LACE including Value of } \\
\text { Avoided External Costs }{ }^{3}\end{array}$ & 4,590 & 7,870 & & \\
\hline $\begin{array}{l}\text { Primary Case } 3 \text { - LACE including Value of } \\
\text { Avoided External Costs and Declining } \\
\text { Value of Variable Generation }{ }^{4}\end{array}$ & 548 & 869 & & \\
\hline
\end{tabular}

Notes

1 As reported in 2013 Renewable Energy Data Book (2014); including Alaska and Hawaii. Total generaton from all sources in 2013 was $~ 4100$ Twh.

2 As updated in this report; excluding Alaska and Hawaii. Estimates may differ from prior assessments including Lopez et al. (2012) due to differences in the classification of resources advancements in technology (e.g., the availability of higher productivity wind turbines), or other factors.

3 Does not include Alaska and Hawaii; in addition to existing generation.

4 Does not include Alaska and Hawaii; in addition to existing generation. Declining value applied to Wind and UPV only. Wind generation potential exceeds $40 \%$ of 2013 total generation in some regions and may be overstated as the declining value method applied does not reduce the value of wind further as its potential share of generation exceeds $40 \%$.

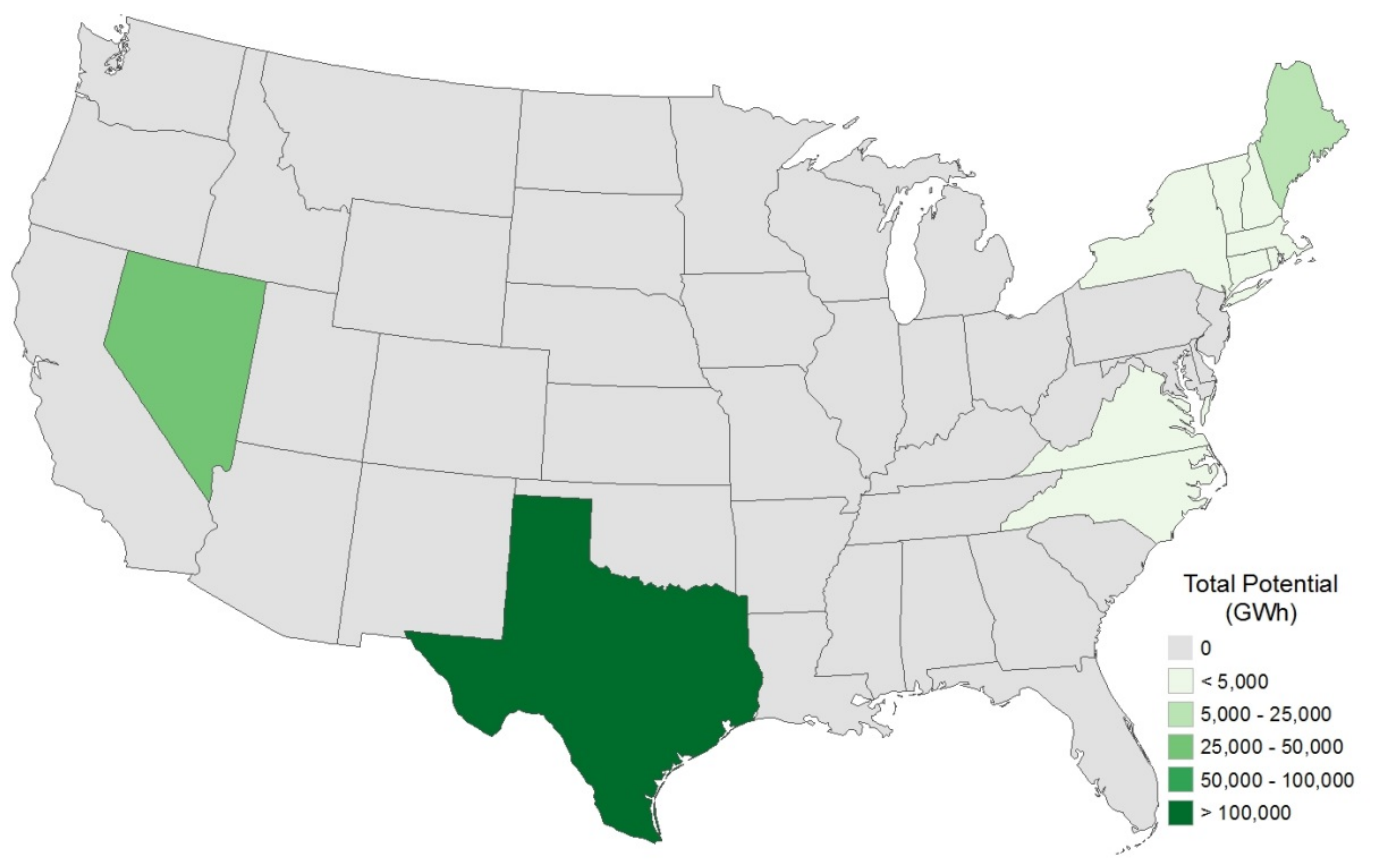

Figure 11a. Wind economic potential - annual generation (Primary Case 1 with full capacity value) 


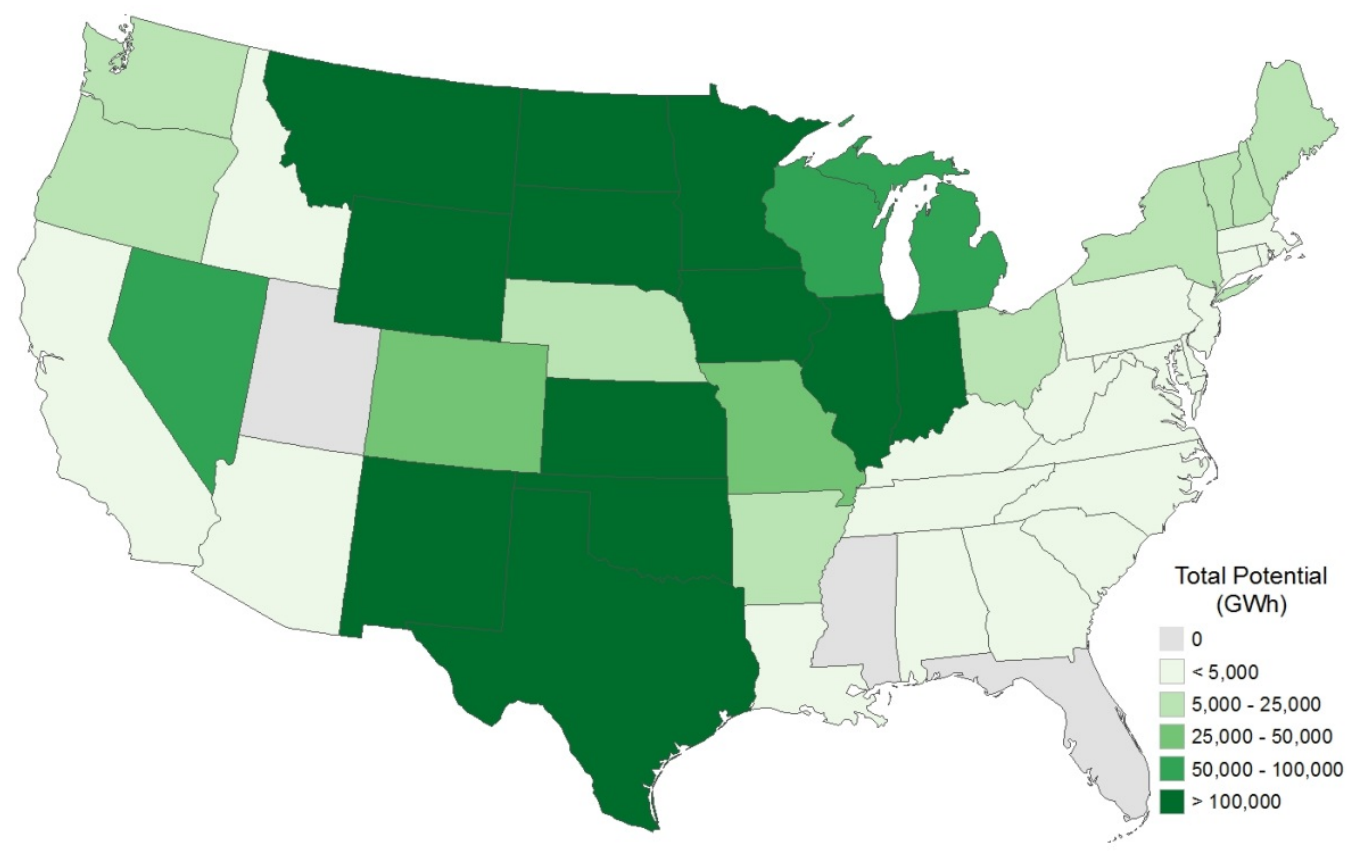

Figure 11b. Wind economic potential - annual generation (Primary Case 2 with full capacity value)

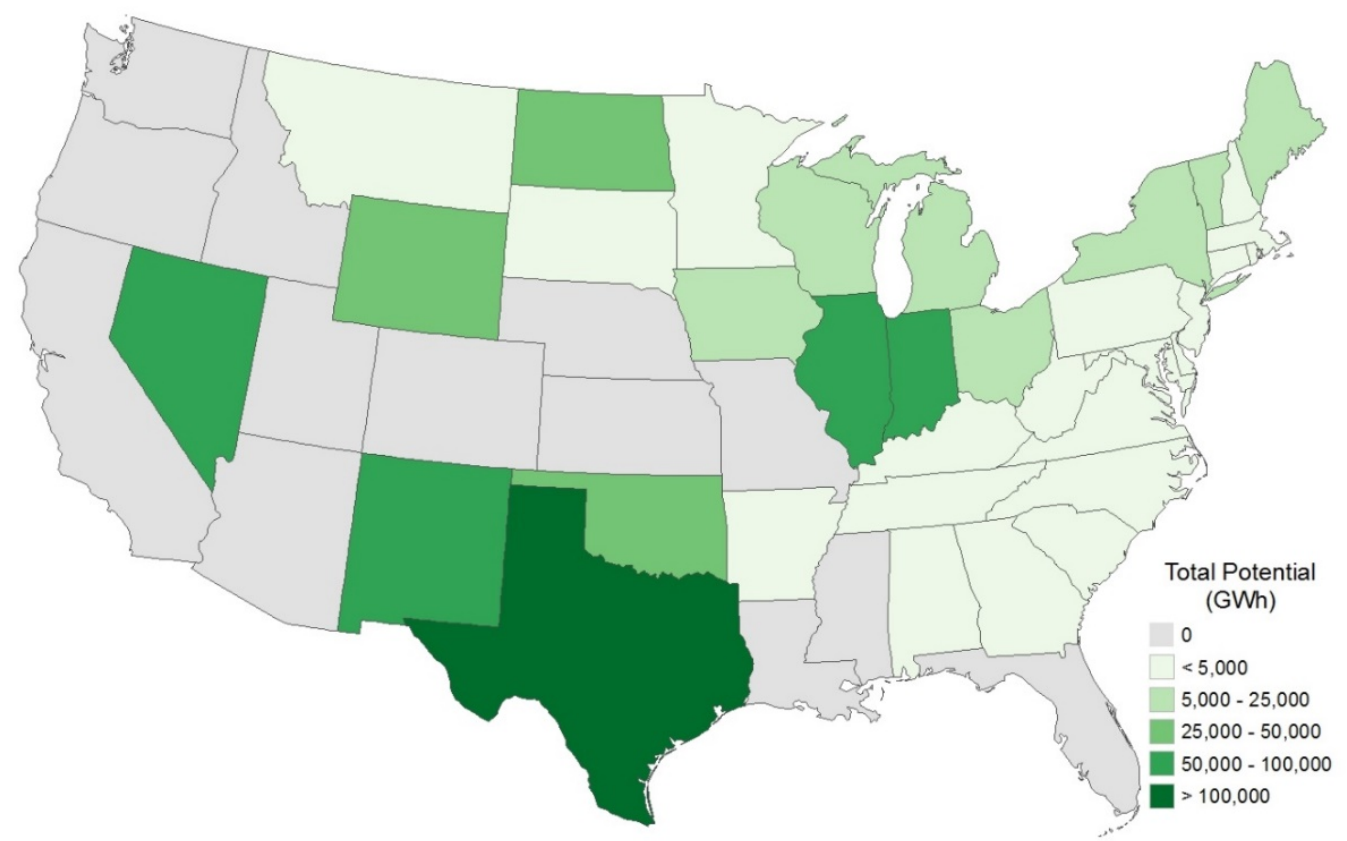

Figure 11c. Wind economic potential - annual generation (Primary Case 3 with full capacity value) 


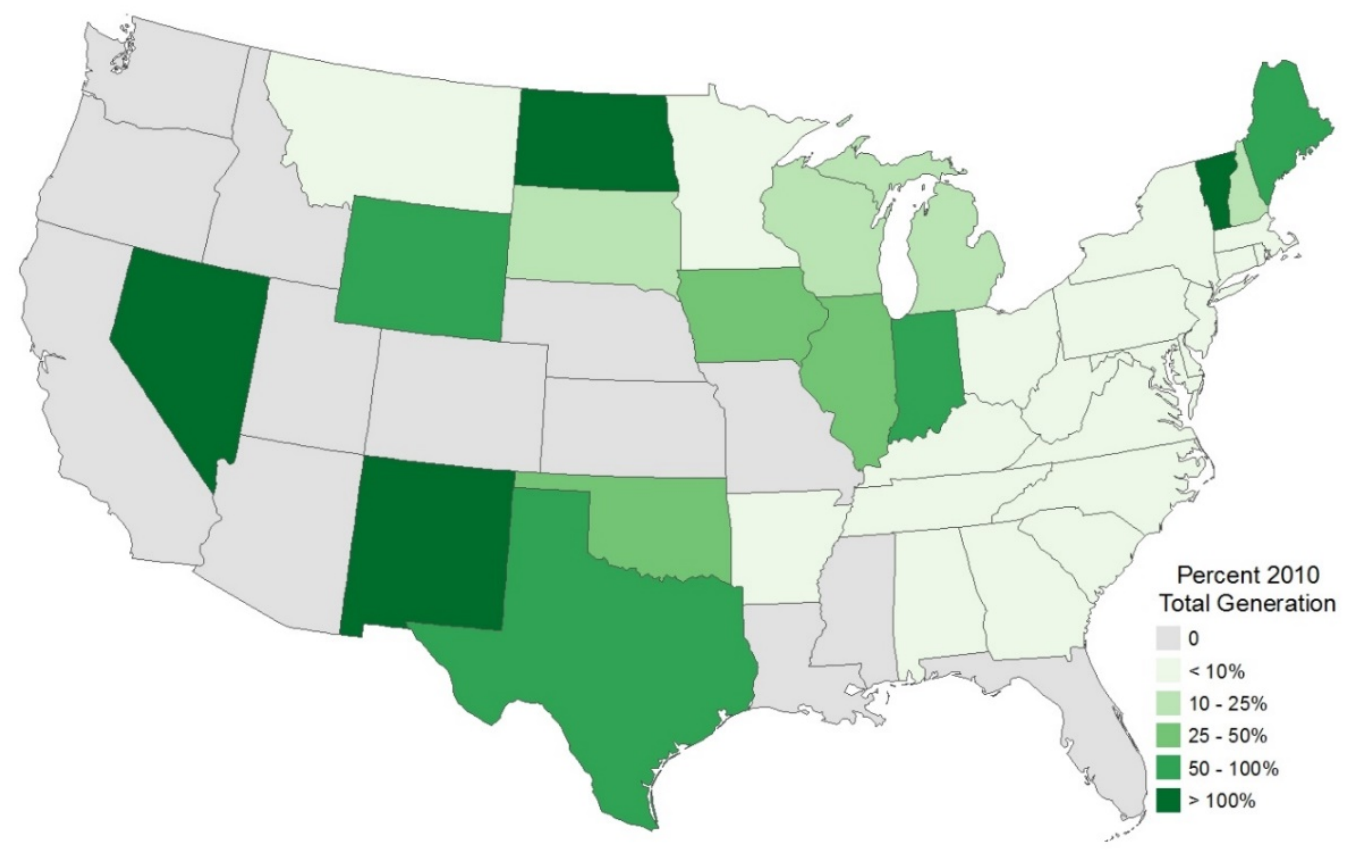

Figure 11d. Wind economic potential - annual generation (Primary Case 3 with full capacity value) as a \% of 2010 total generation

Note: Annual generation shown is incremental to 2013 level.

UPV

The economic potential estimates for UPV for the Primary Cases are shown in Table 7, ranging from 430 to nearly 33,000 TWh in excess of 2013 generation for the continental United States. This range represents from nearly 40 to over 3,000 times total U.S. UPV generation in 2013 . The high end of the range and is one-tenth of UPV annual technical generation potential of 297,000 TWh. In Primary Case 1, economic potential appears in ten states: Nevada shows the bulk of this potential, with South Carolina exceeding $100 \mathrm{TWh}$, and Texas and Virginia exceeding $50 \mathrm{TWh}$. For Primary Case 3, potential appears in a total of 14 states, including in the South Atlantic, West South Central, Mountain, and New England Census divisions; 9 of these states have an estimated potential of at least $10 \mathrm{TWh}$. For Primary Case 2, where no declining value is applied, potential of at least $100 \mathrm{TWh}$ appears more consistently in states across these same regions. Figures E-4 through E-6 in Appendix E present LCOE, LACE, and Net Value maps and aggregated national supply curves. Figure 12 below presents economic potential maps by state. 
Table 7. UPV Estimated U.S. Economic Potential - Primary Cases

\begin{tabular}{|c|c|c|c|c|}
\hline \multirow[b]{2}{*}{ Case } & \multicolumn{4}{|c|}{ Annual Generation (TWh) } \\
\hline & $\begin{array}{l}\text { No Capacity } \\
\text { Value }(0 \% \mathrm{CV})\end{array}$ & $\begin{array}{l}\text { Full Capacity } \\
\text { Value }(100 \% \text { CV })\end{array}$ & $\begin{array}{l}2013 \\
\text { Generation }\end{array}$ & $\begin{array}{l}\text { Technical } \\
\text { Potential }^{2}\end{array}$ \\
\hline Primary Case 1 - LACE Only ${ }^{3}$ & 2,789 & 6,468 & \multirow{3}{*}{11} & \multirow{3}{*}{297,475} \\
\hline $\begin{array}{l}\text { Primary Case 2 - LACE including Value of } \\
\text { Avoided External Costs }^{3}\end{array}$ & 7,713 & 33,523 & & \\
\hline $\begin{array}{l}\text { Primary Case } 3 \text { - LACE including Value of } \\
\text { Avoided External Costs and Declining } \\
\text { Value of Variable Generation }{ }^{4}\end{array}$ & 430 & 606 & & \\
\hline
\end{tabular}

Notes

1 As reported in 2013 Renewable Energy Data Book (2014); including Alaska and Hawaii. Total generaton from all sources in 2013 was $\sim 4100$ Twh.

2 As updated in this report; excluding Alaska and Hawaii. Estimates may differ from prior assessments including Lopez et al. (2012) due to differences in the classification of resources advancements in technology (e.g., the availability of higher productivity wind turbines), or other factors.

3 Does not include Alaska and Hawaii; in addition to existing generation.

4 Does not include Alaska and Hawaii; in addition to existing generation. Declining value applied to Wind and UPV only.

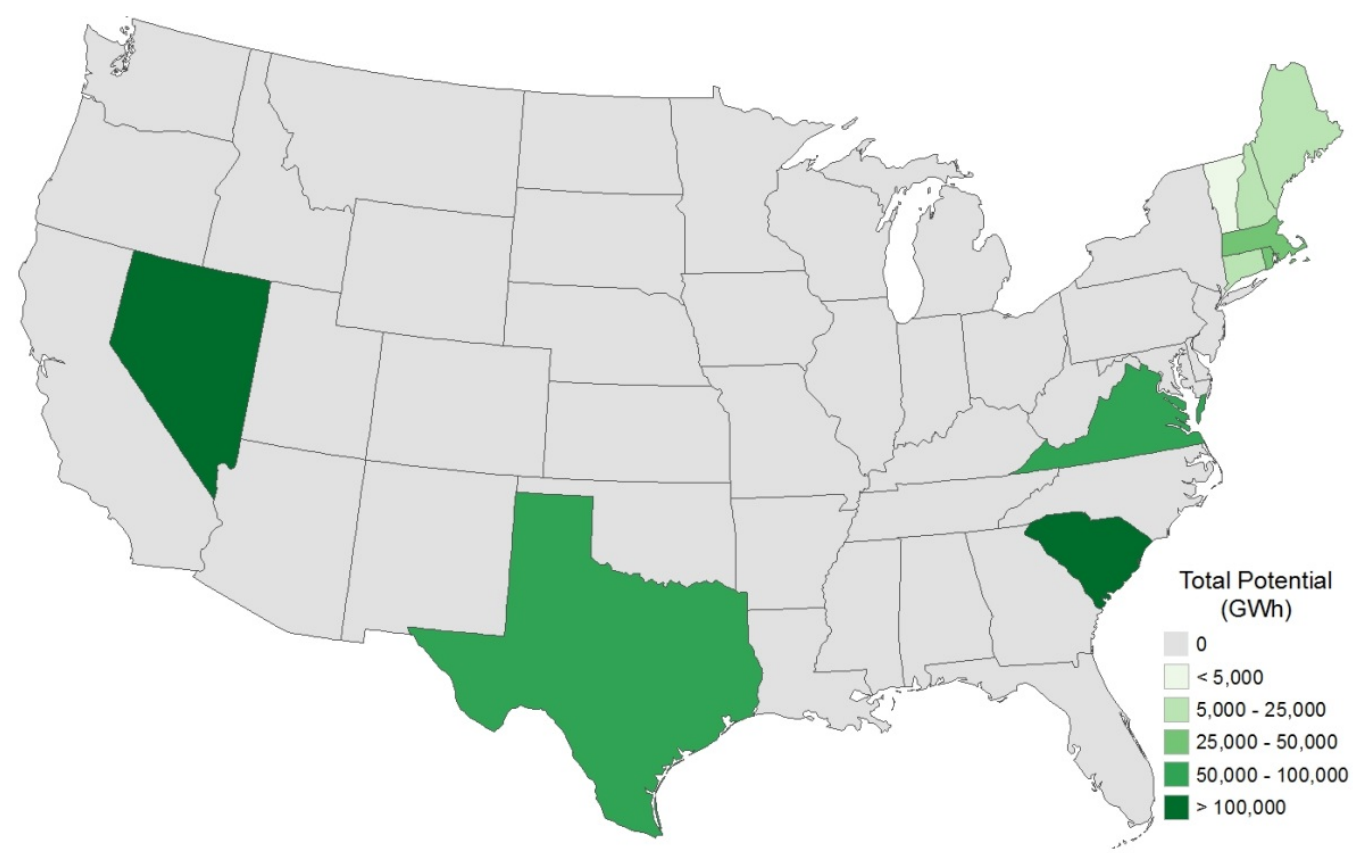

Figure 12a. UPV economic potential - annual generation (Primary Case 1 with full capacity value) 


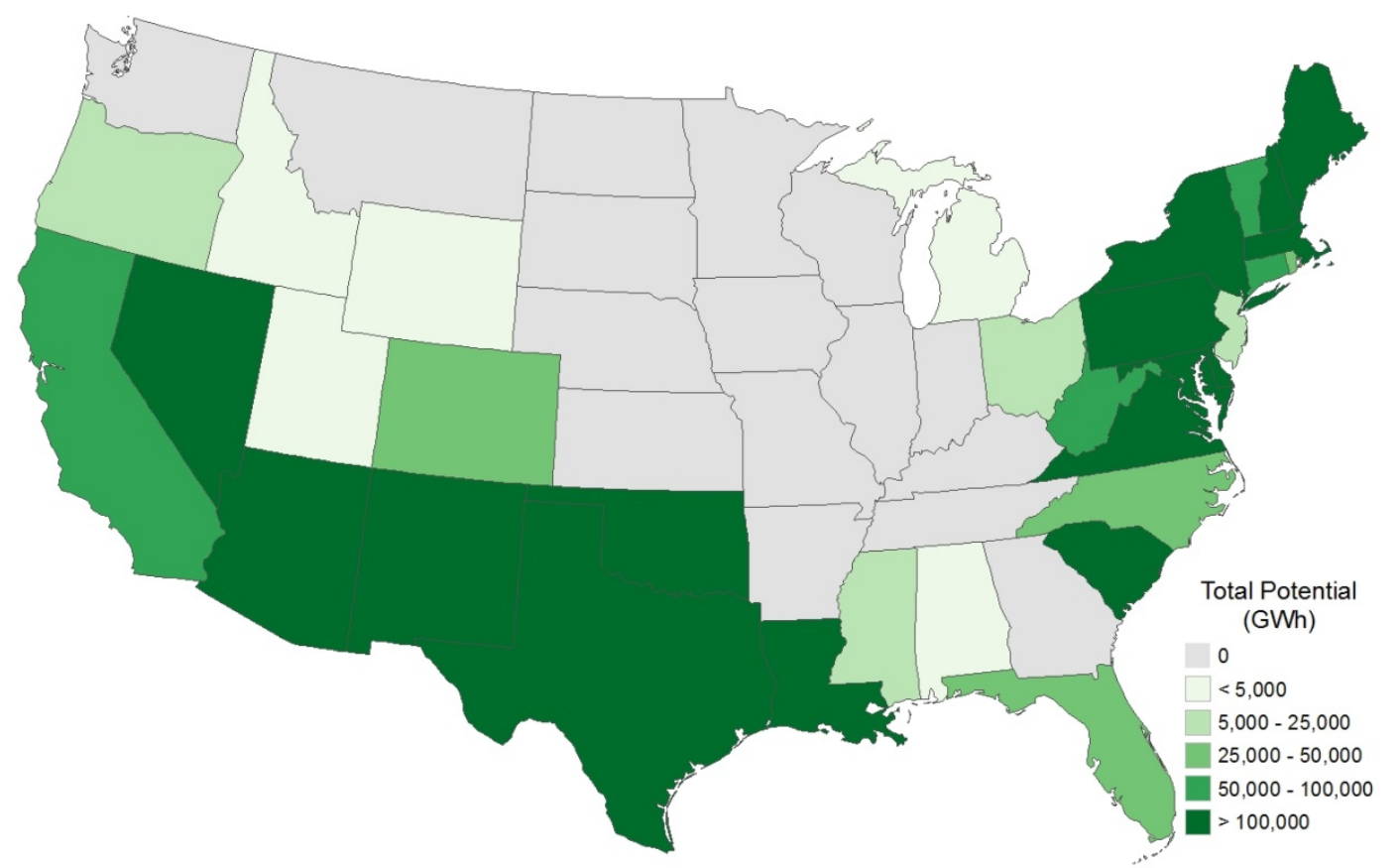

Figure 12b. UPV economic potential - annual generation (Primary Case 2 with full capacity value)

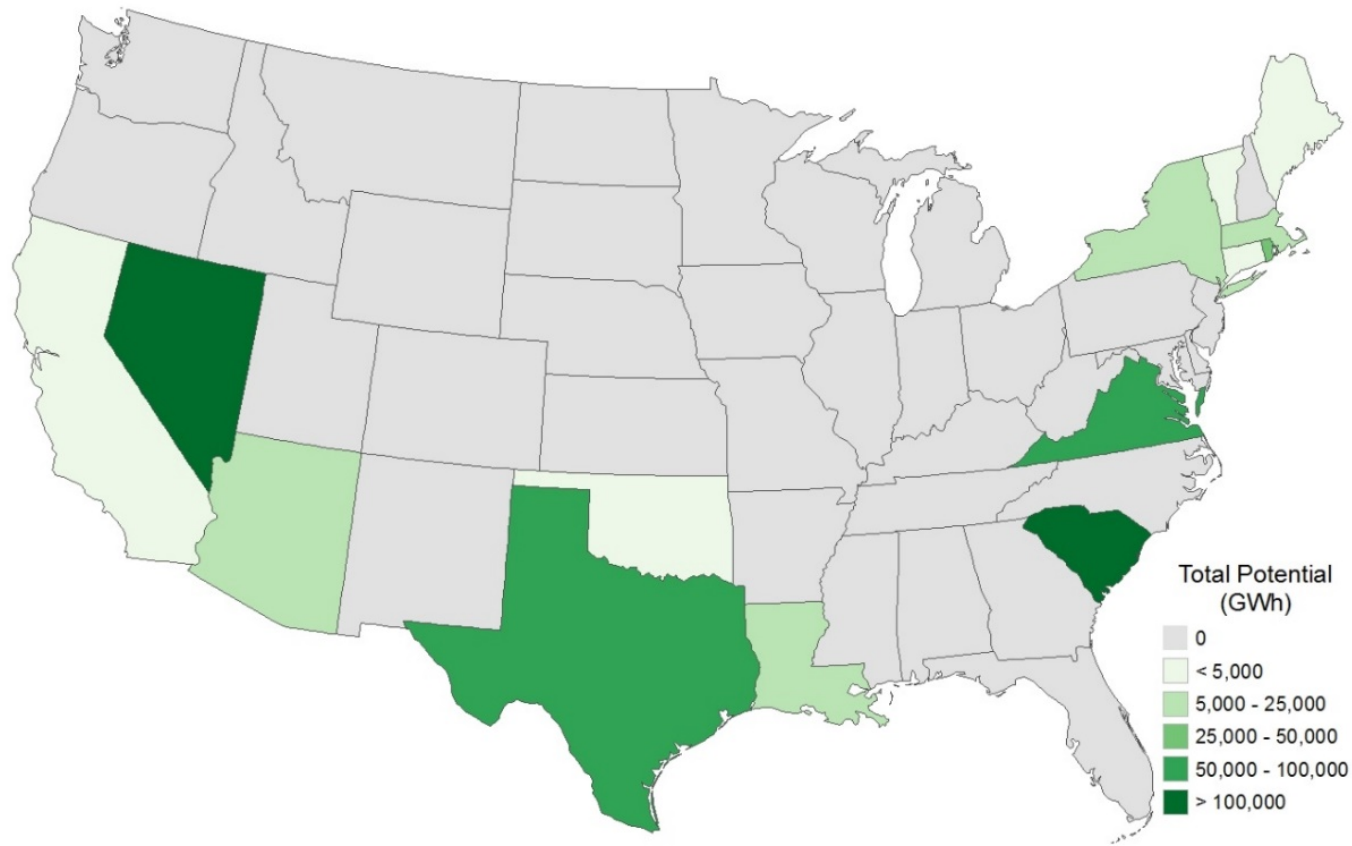

Figure 12c. UPV economic potential - annual generation (Primary Case 3 with full capacity value) 


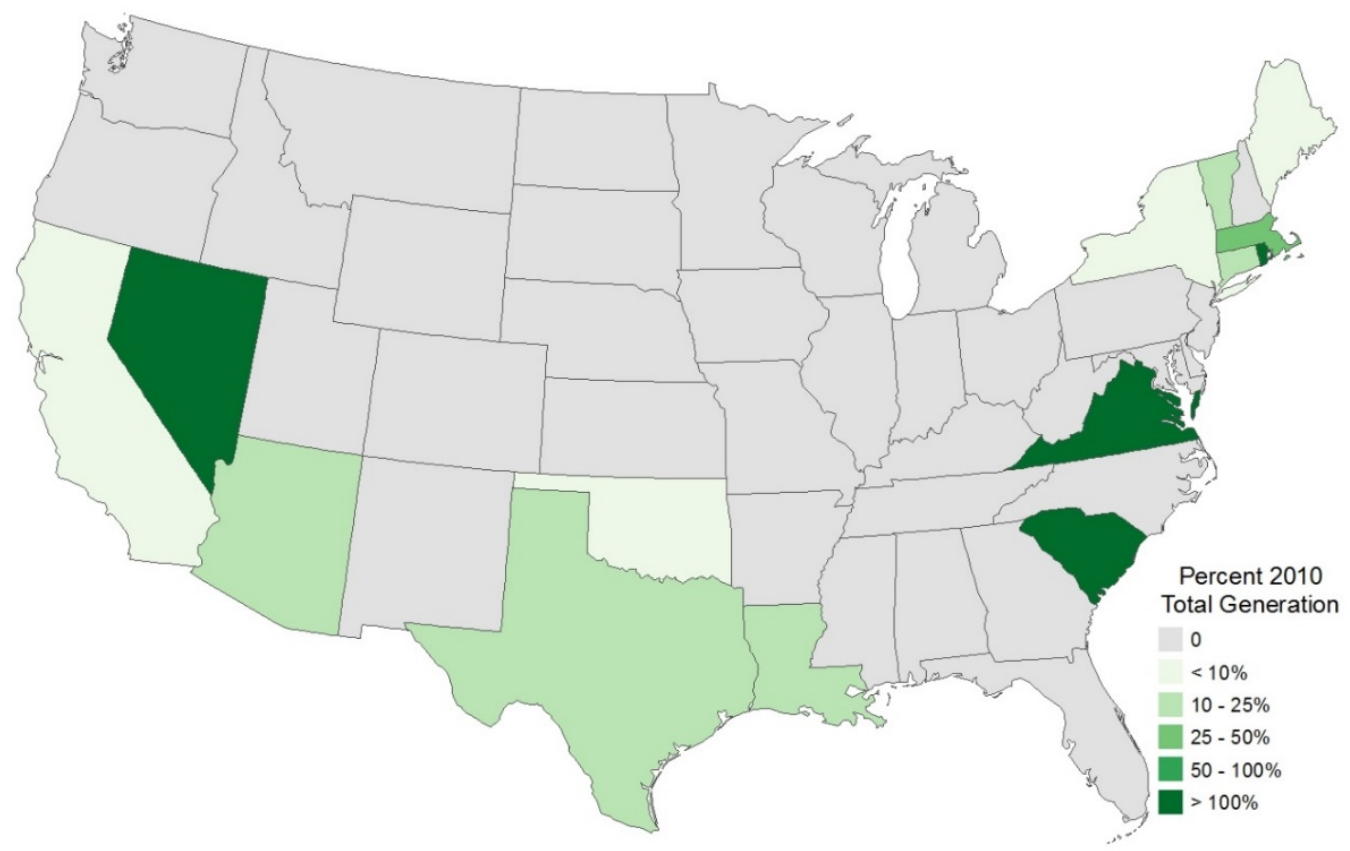

Figure 12d. UPV economic potential - annual generation (Primary Case 3 with full capacity value) as a \% of 2010 total generation

Note: Annual generation shown is incremental to 2013 level.

DPV

The economic potential estimates for DPV (residential and commercial sectors) for the Primary Cases are shown in Table 8, ranging from 190 to nearly 290 TWh in excess of 2013 generation for the continental United States. This range represents from 20 to nearly 30 times total U.S. DPV generation in 2013. The high end of the range and is nearly one-fifth of DPV annual technical generation potential of 1,560 TWh. For Primary Cases 2 and 3, potential appears in the Southwest (Pacific and Mountain Census divisions) and along the Eastern seaboard, consistent with existing generation. While California garners half of the estimated national annual potential, 19 states have potential of least 1 TWh, compared to 13 states in Primary Case 1. Figures E-7 through E-9 in Appendix E present LACE and Net Value maps and aggregated national supply curves. Figure 13 below presents economic potential maps by state. 
Table 8. DPV Estimated U.S. Economic Potential - Primary Cases

\begin{tabular}{|c|c|c|c|c|}
\hline & \multicolumn{4}{|c|}{ Annual Generation (TWh) } \\
\hline Case & \begin{tabular}{|l} 
No Capacity \\
Value $(0 \% \mathrm{CV})$ \\
\end{tabular} & \begin{tabular}{|l|} 
Full Capacity \\
Value $(100 \% \mathrm{CV})$ \\
\end{tabular} & $\begin{array}{l}2013 \\
\text { Generation }^{1} \\
\end{array}$ & $\begin{array}{l}\text { Technical } \\
\text { Potential }^{2} \\
\end{array}$ \\
\hline Primary Case 1 - LACE Only ${ }^{3}$ & 194 & 194 & \multirow{3}{*}{10} & \multirow{3}{*}{1,560} \\
\hline $\begin{array}{l}\text { Primary Case } 2 \text { - LACE including Value of } \\
\text { Avoided External Costs }{ }^{3}\end{array}$ & 287 & 287 & & \\
\hline $\begin{array}{l}\text { Primary Case } 3 \text { - LACE including Value of } \\
\text { Avoided External Costs and Declining } \\
\text { Value of Variable Generation }{ }^{4}\end{array}$ & 287 & 287 & & \\
\hline
\end{tabular}

Notes

1 As reported in 2013 Renewable Energy Data Book (2014); including Alaska and Hawaii. Total generaton from all sources in 2013 was $\sim 4100$ Twh.

2 As updated in this report; excluding Alaska and Hawaii. Estimates may differ from prior assessments including Lopez et al. (2012) due to differences in the classification of resources advancements in technology (e.g., the availability of higher productivity wind turbines), or other factors.

3 Does not include Alaska and Hawaii; in addition to existing generation.

4 Does not include Alaska and Hawaii; in addition to existing generation. Declining value applied to Wind and UPV only. Primary Case 2 results used as substitute.

Not all cases run; gray-shaded cells indicate that another case is used as a substitute.

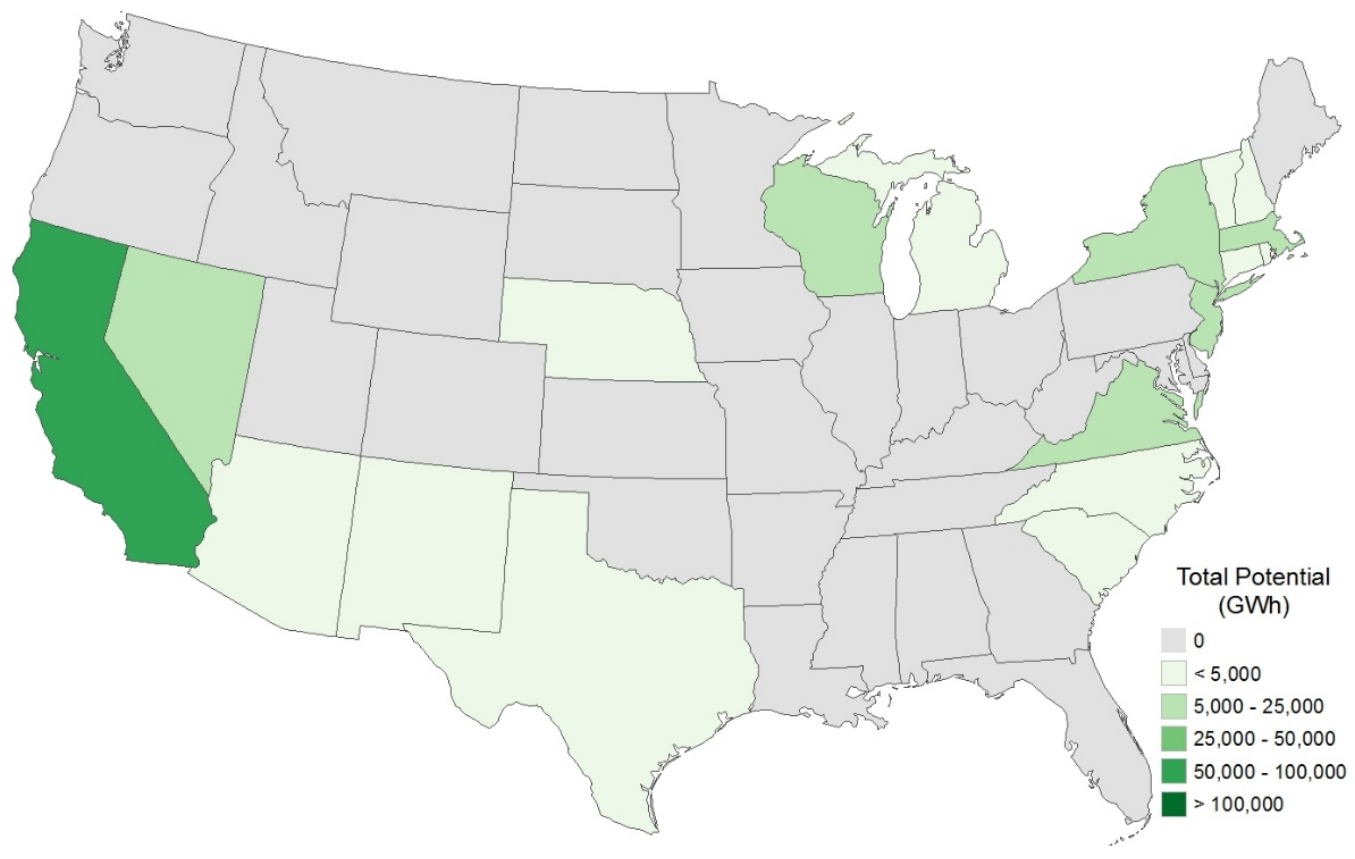

Figure 13a. DPV economic potential: Residential - annual generation (Primary Cases 2 and 3) 


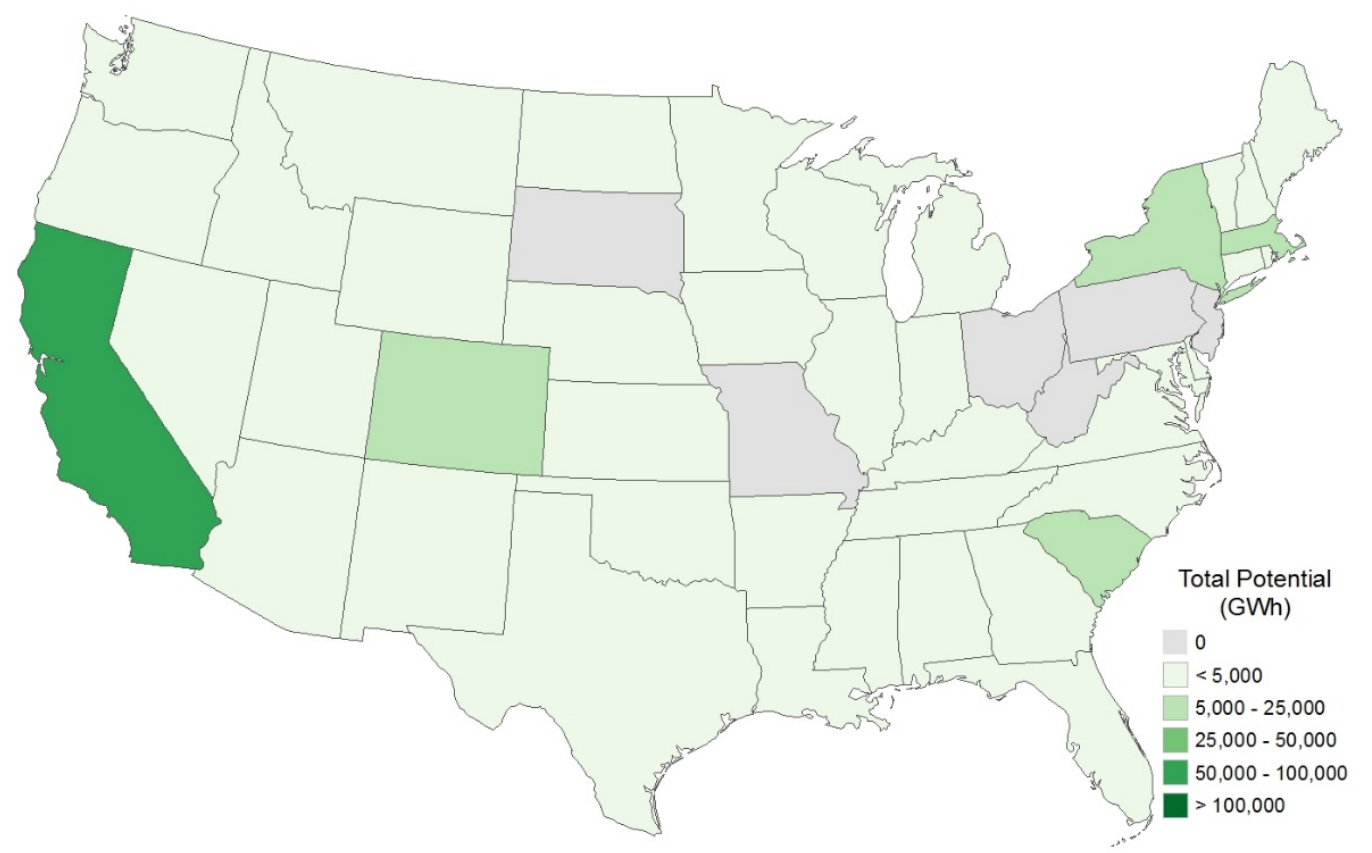

Figure 13b. DPV economic potential: Commercial - annual generation (Primary Cases 2 and 3)

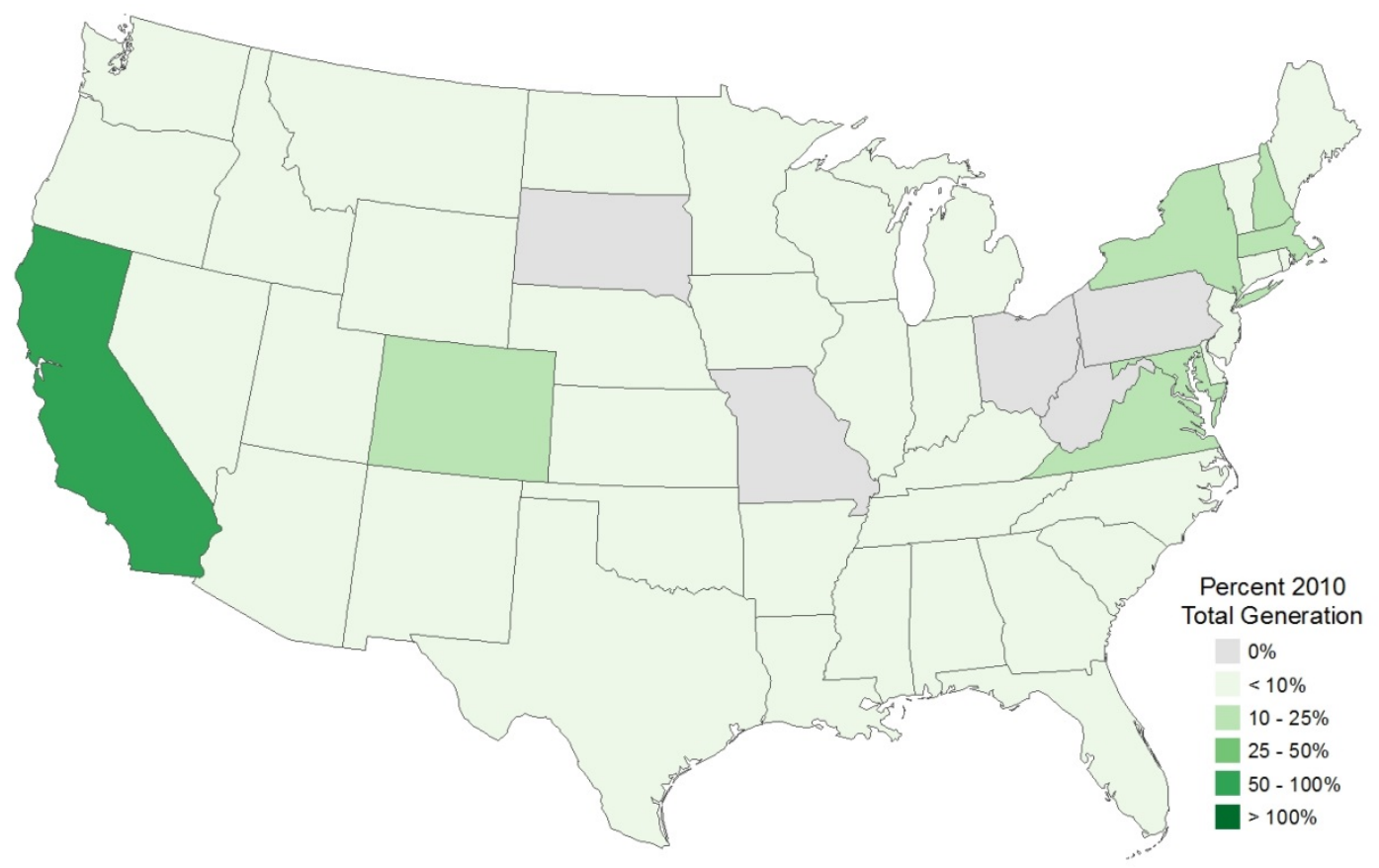

Figure 13c. DPV economic potential: Residential and Commercial - annual generation (Primary Cases 2 and 3 ) as a \% of 2010 total generation

Note: Annual generation shown is incremental to 2013 level. 


\section{Hydropower}

The economic potential estimates for hydropower for the Primary Cases are shown in Table 9, ranging from 38 to $76 \mathrm{TWh}$ in excess of 2013 generation for the continental United States. This range represents from 14 to 28 percent of total U.S. hydropower generation in 2013. The high end of the range is over one-quarter of hydropower annual technical generation potential of 278 TWh. For Primary Cases 2 and 3, potential appears in every Census division. While Kentucky and Pennsylvania collectively garner a quarter of the estimated national annual potential, 18 states in total have potential of least $1 \mathrm{TWh}$, compared to 13 states in Primary Case 1. Figures E10 through E-12 in Appendix E present LCOE, LACE, and Net Value maps and aggregated national supply curves. Figure 14 below presents economic potential maps by state.

Table 9. Hydropower Estimated U.S. Economic Potential - Primary Cases

\begin{tabular}{|c|c|c|c|c|}
\hline \multirow[b]{2}{*}{ Case } & \multicolumn{4}{|c|}{ Annual Generation (TWh) } \\
\hline & $\begin{array}{l}\text { No Capacity } \\
\text { Value }(0 \% \text { CV })\end{array}$ & \begin{tabular}{|l|} 
Full Capacity \\
Value $(100 \% \mathrm{CV})$
\end{tabular} & $\begin{array}{l}2013 \\
\text { Generation }\end{array}$ & $\begin{array}{l}\text { Technical } \\
\text { Potential }^{2}\end{array}$ \\
\hline Primary Case 1 - LACE Only ${ }^{3}$ & 38 & 50 & & \\
\hline $\begin{array}{l}\text { Primary Case 2 - LACE including Value of } \\
\text { Avoided External Costs }{ }^{3}\end{array}$ & 64 & 76 & & \\
\hline $\begin{array}{l}\text { Primary Case } 3 \text { - LACE including Value of } \\
\text { Avoided External Costs and Declining } \\
\text { Value of Variable Generation }{ }^{4}\end{array}$ & 64 & 76 & 209 & 210 \\
\hline
\end{tabular}

Notes

1 As reported in 2013 Renewable Energy Data Book (2014); including Alaska and Hawaii. Total generaton from all sources in 2013 was $\sim 4100$ Twh.

2 As updated in this report; excluding Alaska and Hawaii. Estimates may differ from prior assessments including Lopez et al. (2012) due to differences in the classification of resources advancements in technology (e.g., the availability of higher productivity wind turbines), or other factors.

3 Does not include Alaska and Hawaii; in addition to existing generation.

4 Does not include Alaska and Hawaii; in addition to existing generation. Declining value applied to Wind and UPV only.

Not all cases run; gray-shaded cells indicate that another case is used as a substitute. 


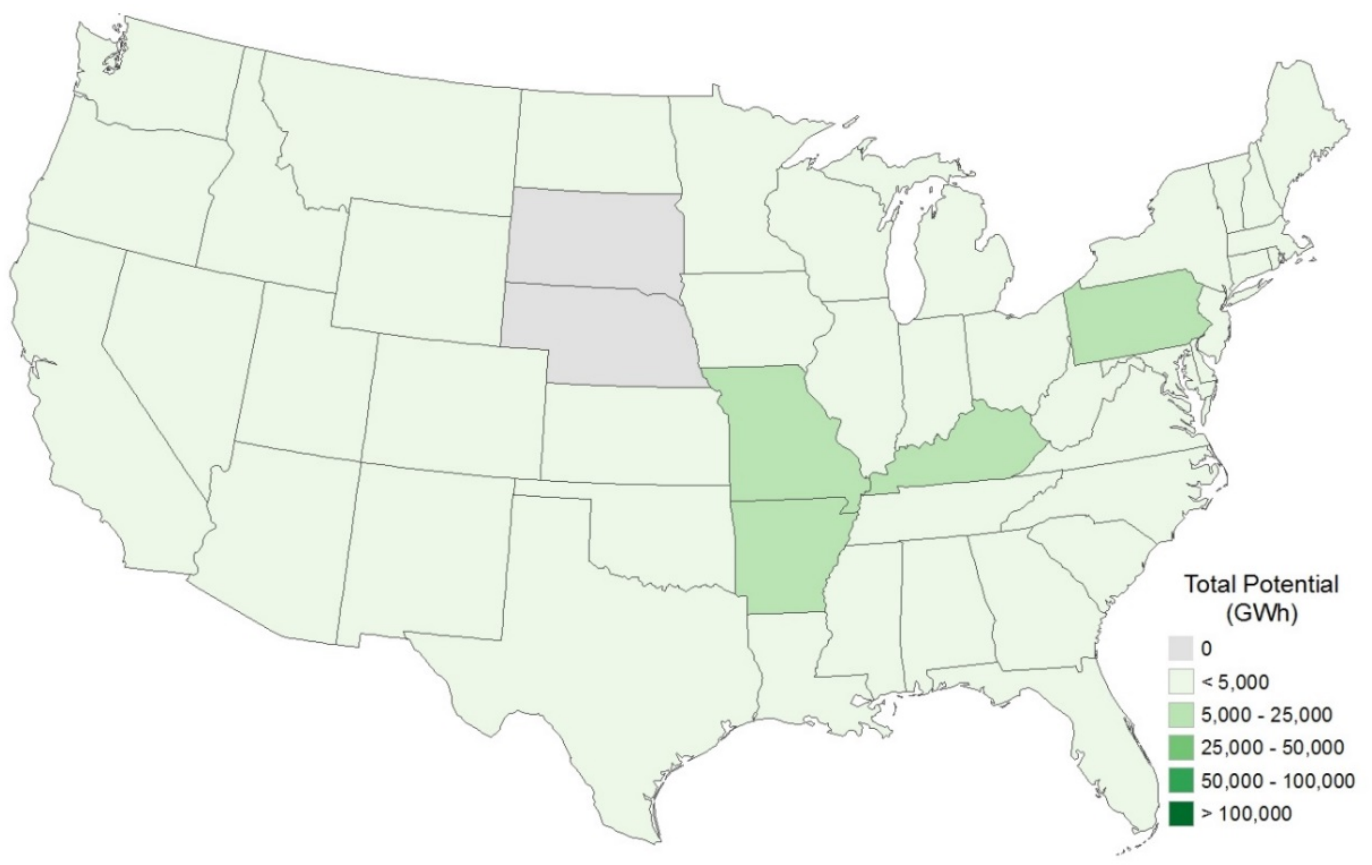

Figure 14a. Hydropower economic potential: annual generation (Primary Cases 2 and 3 with full capacity value) 


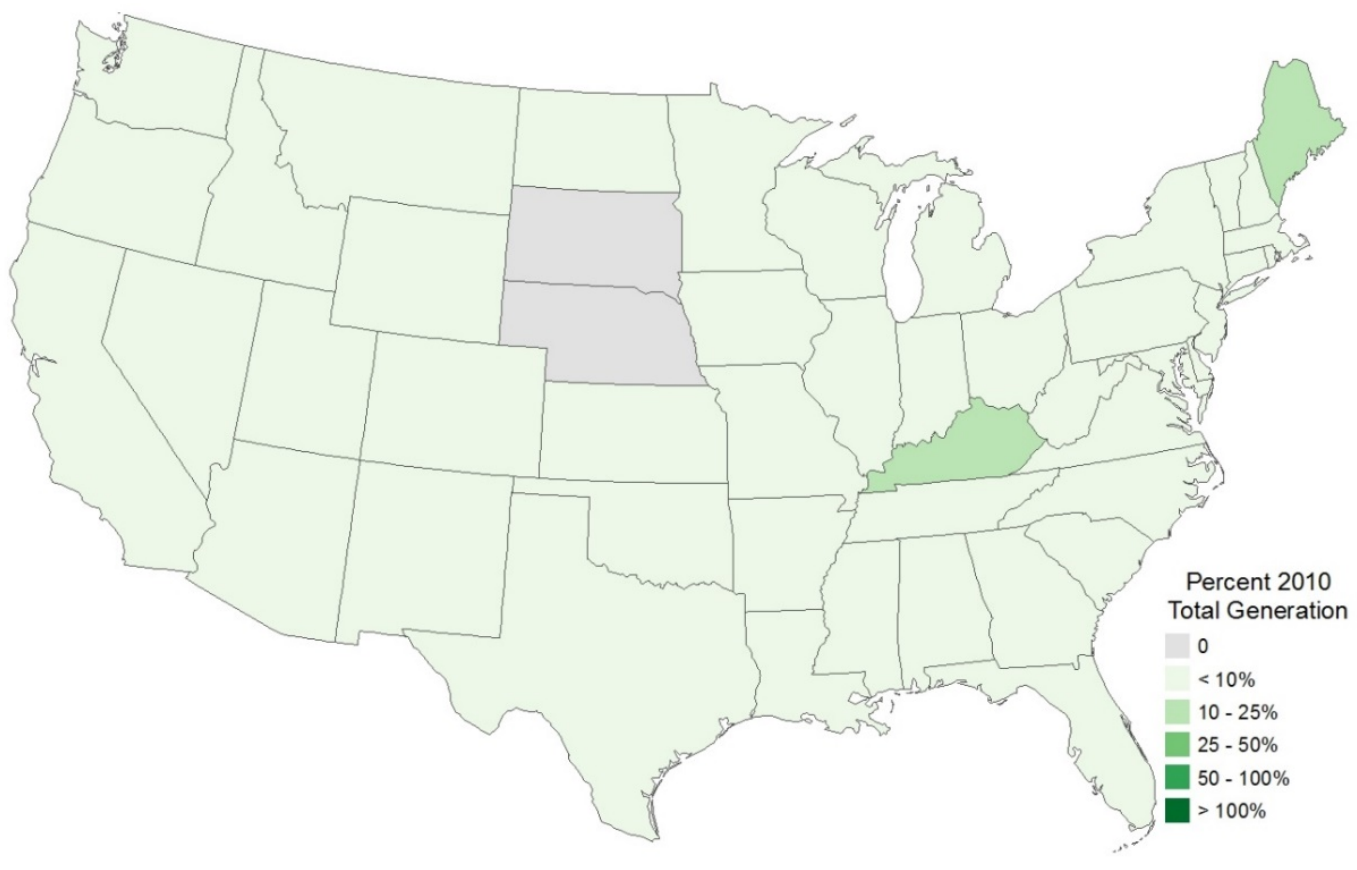

Figure 14b. Hydropower economic potential: annual generation (Primary Cases 2 and 3 with full capacity value as a $\%$ of 2010 total generation

Note: Annual generation shown is incremental to 2013 level.

\section{Geothermal (Hydrothermal Resources Only)}

The economic potential estimates for geothermal for the Primary Cases are shown in Table 10 ranging from 29 to $153 \mathrm{TWh}$ in excess of 2013 generation for the continental United States. This range represents from 1.6 to nine times total U.S. geothermal generation in 2013. The high end of the range is two-thirds of geothermal (hydrothermal resources only) annual technical generation potential of 278 TWh. For Primary Cases 2 and 3, potential appears only in the West (Pacific and Mountain Census divisions), consistent with the location of existing generation. California garners two-thirds of the estimated national annual potential, with three other states having potential of at least 8 TWh, compared to 2 states in Primary Case 1. Figures E-13 through E-15 in Appendix E present LCOE, LACE, and Net Value maps and aggregated national supply curves. Figure 15 below presents economic potential maps by state. 
Table 10. Geothermal Estimated U.S. Economic Potential - Primary Cases

\begin{tabular}{|c|c|c|c|c|}
\hline \multirow[b]{2}{*}{ Case } & \multicolumn{4}{|c|}{ Annual Generation (TWh) } \\
\hline & \begin{tabular}{|l} 
No Capacity \\
Value (0\% CV)
\end{tabular} & \begin{tabular}{|l} 
Full Capacity \\
Value $(100 \% \mathrm{CV})$
\end{tabular} & $\begin{array}{l}2013 \\
\text { Generation }\end{array}$ & $\begin{array}{l}\text { Technical } \\
\text { Potential }^{2}\end{array}$ \\
\hline Primary Case 1 - LACE Only ${ }^{3}$ & 29 & 109 & & \\
\hline $\begin{array}{l}\text { Primary Case 2 - LACE including Value of } \\
\text { Avoided External Costs }{ }^{3}\end{array}$ & 131 & 153 & & \\
\hline $\begin{array}{l}\text { Primary Case } 3 \text { - LACE including Value of } \\
\text { Avoided External Costs and Declining } \\
\text { Value of Variable Generation }{ }^{4}\end{array}$ & 131 & 153 & 17 & 234 \\
\hline
\end{tabular}

Notes

1 As reported in 2013 Renewable Energy Data Book (2014); including Alaska and Hawaii. Total generaton from all sources in 2013 was $\sim 4100$ Twh.

2 As updated in this report; excluding Alaska and Hawaii. Estimates may differ from prior assessments including Lopez et al. (2012) due to differences in the classification of resources advancements in technology (e.g., the availability of higher productivity wind turbines), or other factors.

3 Does not include Alaska and Hawaii; in addition to existing generation.

4 Does not include Alaska and Hawaii; in addition to existing generation. Declining value applied to Wind and UPV only.

Not all cases run; gray-shaded cells indicate that another case is used as a substitute.

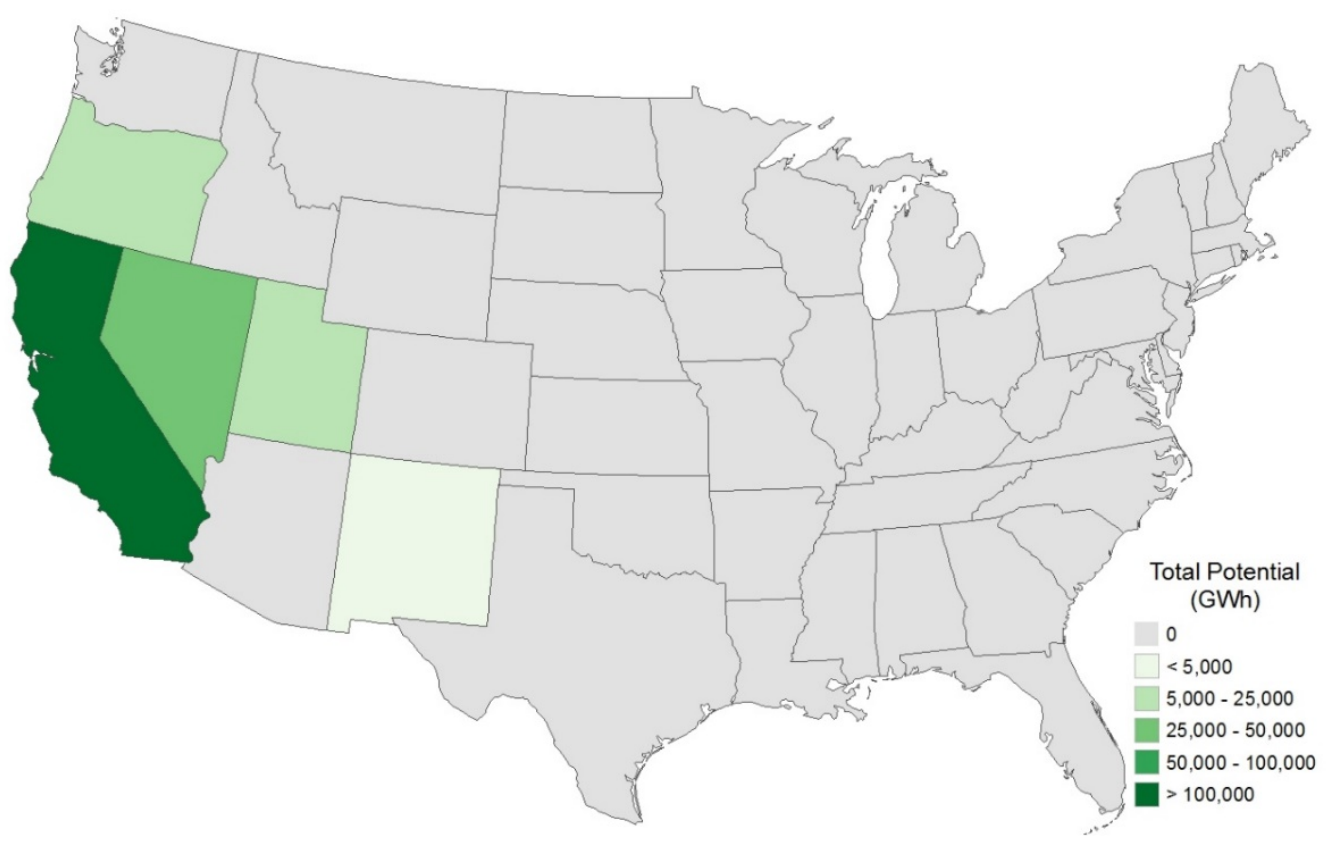

Figure 15a. Geothermal economic potential: annual generation (Primary Cases 2 and $\mathbf{3}$ with full capacity value) 


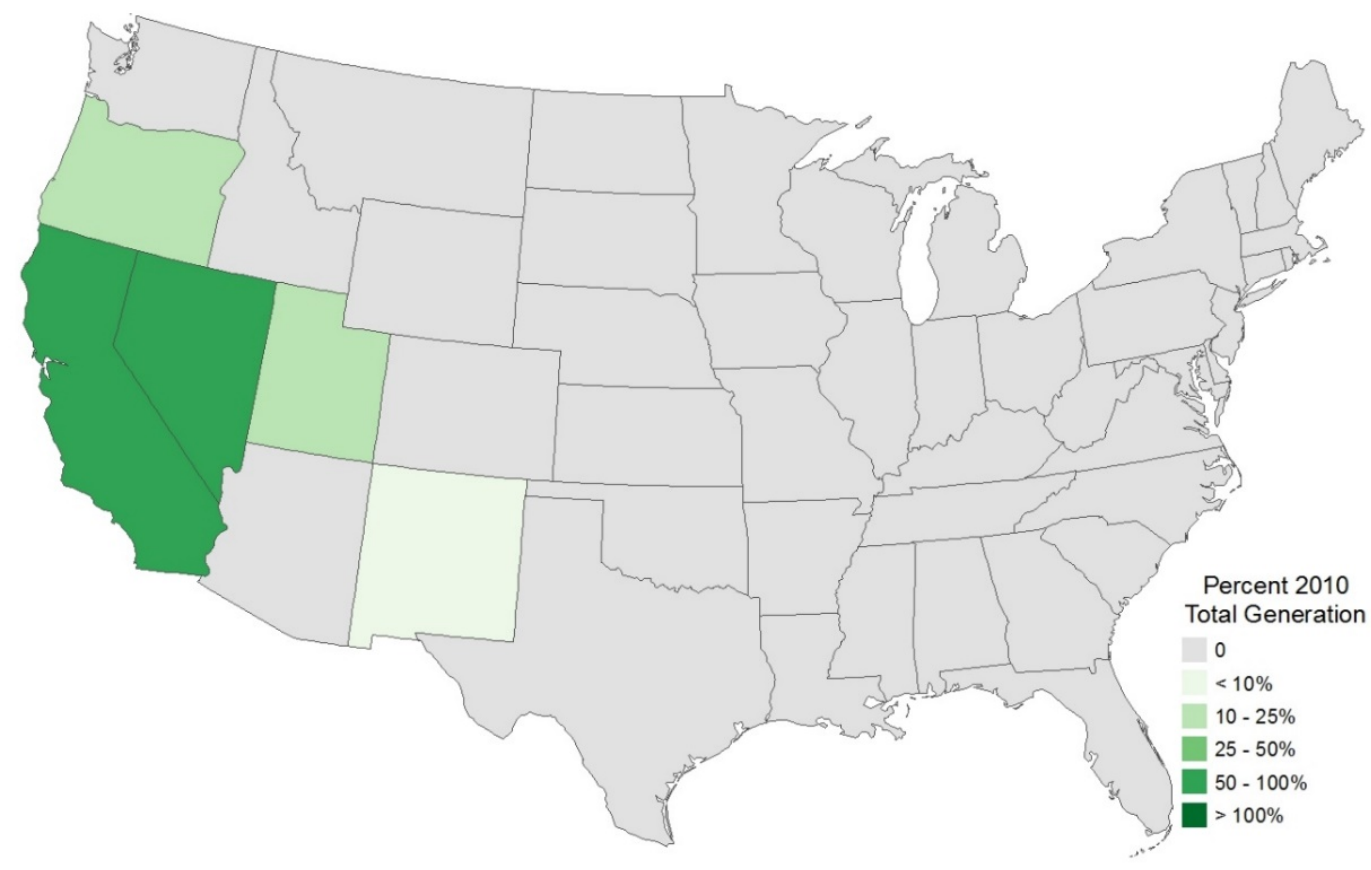

Figure 15b. Geothermal economic potential: annual generation (Primary Cases 2 and 3 with full capacity value) as a \% of 2010 total generation

Note: Annual generation shown is incremental to 2013 level.

\section{Biopower (Dedicated Combustion Plants Only, Not Including Co-firing)}

The economic potential estimates for biopower for the Primary Cases are shown in Table 11. Biopower generated from solid biomass (e.g., crop residues) shows no economic potential for the continental United States in the Primary Cases, despite having 60 TWh of generation in 2013 and a technical potential of 445 TWh. Figures E-16 through E-18 in Appendix E present LCOE, LACE, and Net Value maps and aggregated national supply curves. 
Table 11. Biopower Estimated U.S. Economic Potential - Primary Cases

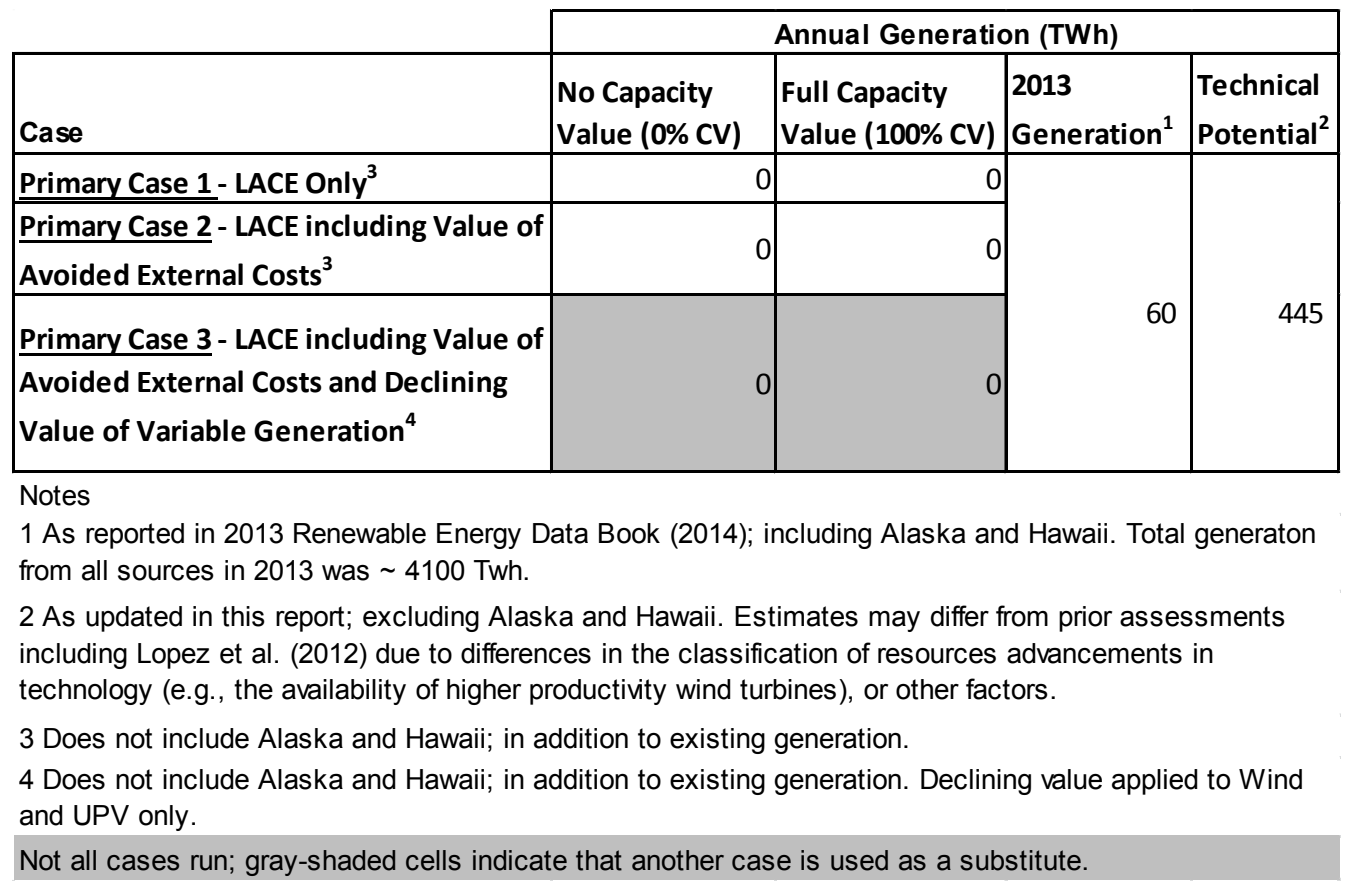

\section{Summary Results - Sum of Assessed Technologies}

Across the Primary Cases, the sum of U.S. economic annual generation potential (excluding Alaska and Hawaii) for the six technologies assessed ranges from nearly 1,500 to 42,000 TWh in excess of 2013 generation. This range of potential represents from nearly three to nearly 80 times total U.S. renewable generation in 2013, or one-third to over ten times 2013 total U.S. generation from all sources, and is a small fraction of the sum of the annual technical generation potential of over 320,000 TWh for these technologies. These estimates simply sum the potentials of the individual technologies. As such, they do not consider any potential competition among the technologies for available land or in economic terms. Further, they do not reflect any impact of the interaction of variable wind and PV generation upon the value of either technology.

More specifically, the following are ranges of aggregate annual generation potential for each the Primary Cases (see Table 12 and Figure 16):

- Primary Case 1 - LACE Only: 3,200 - 7,100 TWh. UPV contributes the bulk of the economic potential under this formulation. The potential shown represents $75-175 \%$ of total U.S. generation from all sources in 2013. Economic potential is estimated to occur in over three quarters of the contiguous states and the District of Columbia for at least one of six renewable generation technologies assessed.

- Primary Case 2 - LACE including Value of Avoided External Costs (related to $\mathrm{CO}_{2}$ emissions): $13,000-42,000 \mathrm{TWh}$. Under this formulation, UPV contributes the bulk of the economic potential, particularly at the high end of the range. Wind economic potential is also significant, representing at least the equivalent of total U.S. generation from all sources in 2013. The potential shown represents three to ten times total U.S. generation from all sources in 2013. Economic potential is estimated to occur in all contiguous states and the District of Columbia for at least one of six renewable generation technologies assessed. 
- Primary Case 3 - LACE including Value of Avoided External Costs and Declining Value of Variable Generation: 1,500-2,000 TWh. While the total economic potential in this formulation is much lower than in Primary Case 2, all of the technologies except biomass contribute significant potential. The potential shown represents $35-50 \%$ of total U.S. generation from all sources in 2013. Economic potential is estimated to occur in all contiguous states and the District of Columbia for at least one of six renewable generation technologies assessed. Figure 17 illustrates this economic potential is additive to existing (2013) generation and displays potential by Census division for the upper estimate of this case.

Appendix F shows estimated annual generation by technology for each state for each of the Primary Cases.

Table 12. Estimated Aggregated U.S. Economic Potential for Primary Cases

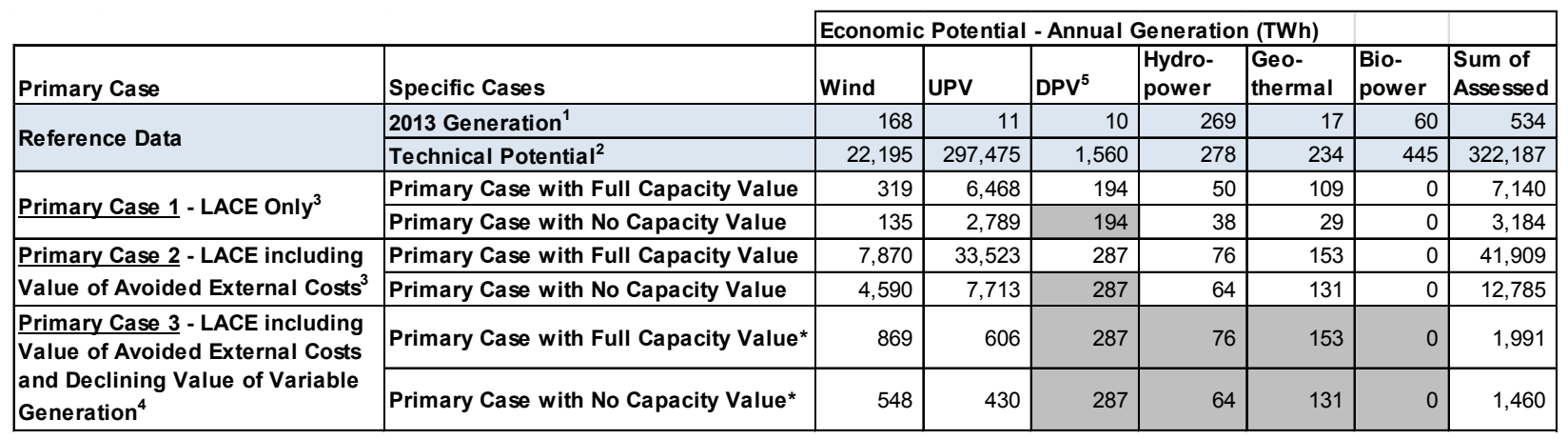

Notes

1 As reported in 2013 Renewable Energy Data Book (2014); including Alaska and Hawaii. Total generaton from all sources in 2013 was $~ 4100$ Twh.

2 As updated in this report; excluding Alaska and Hawaii. Estimates may differ from prior assessments including Lopez et al. (2012) due to differences in the classification of resources (e.g., in some cases hydropower upgrades are not considered as new technical potential), advancements in technology (e.g., the availability of higher productivity wind turbines), or other factors.

3 Does not include Alaska and Hawaii; in addition to existing generation.

4 Does not include Alaska and Hawaii; in addition to existing generation. Declining value applied to Wind and UPV only. An asterisk symbol $\left({ }^{*}\right)$ to the right of a case name indicates that wind generation potential exceeds $40 \%$ of 2013 total generation in some regions and may be overstated as the declining value method applied does not reduce the value of wind further as its potential share of generation exceeds $40 \%$.

5 Not all cases run for DPV, hydropower, geothermal, and biopower; gray-shaded cells indicate that another case is used as a substitute. 

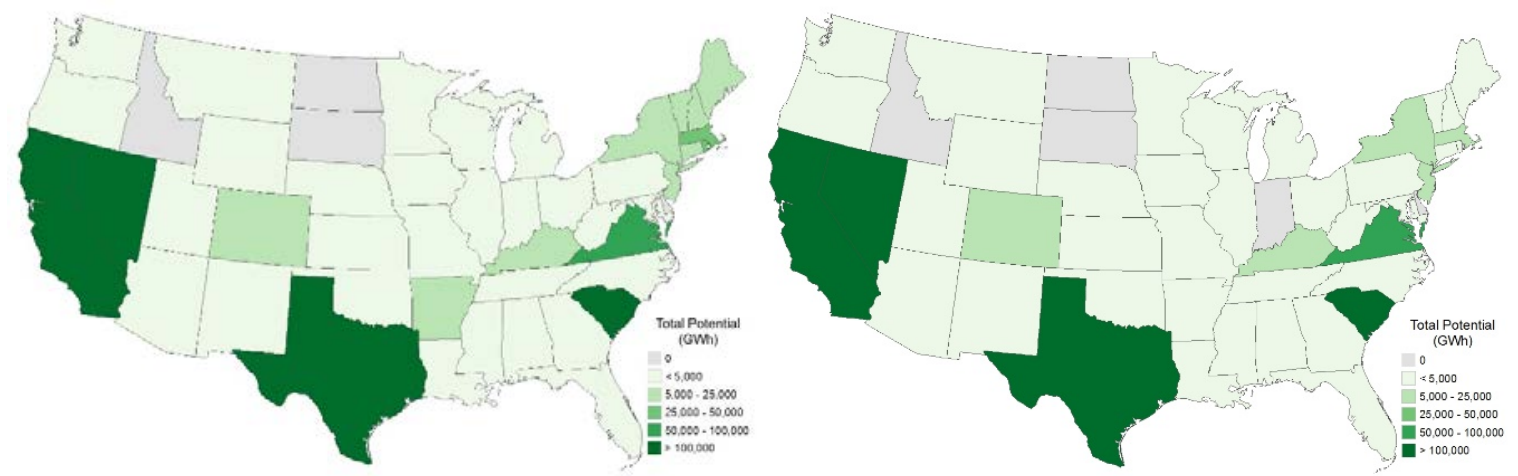

Figure 16a. Sum of assessed technologies: economic potential - annual generation (Primary Case 1) with full (left) and no (right) capacity value
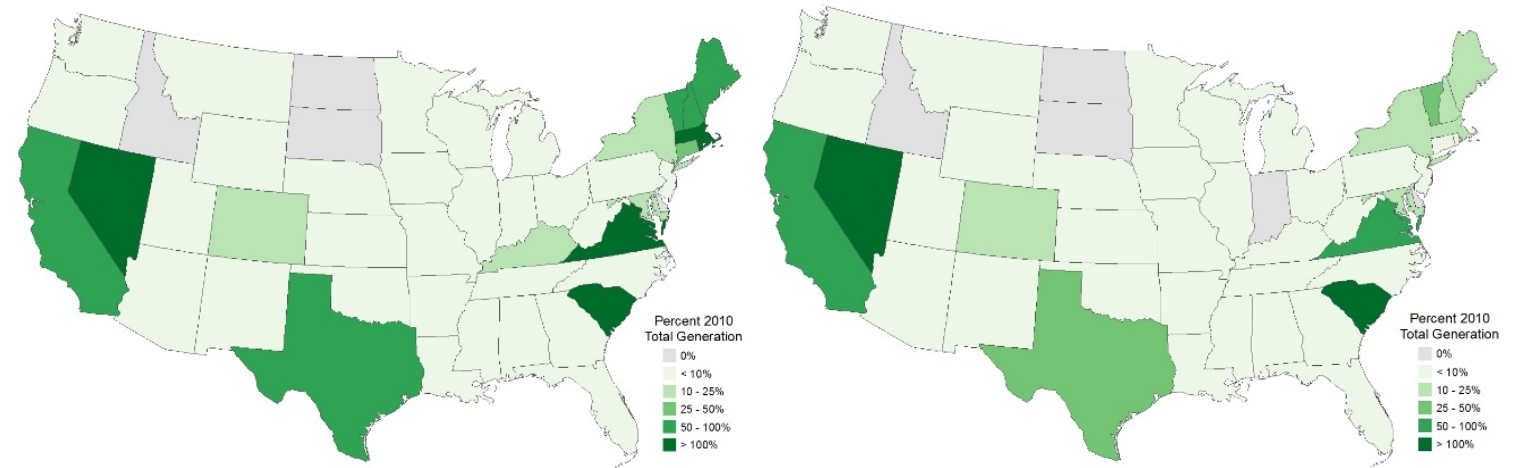

Figure 16b. Sum of assessed technologies: economic potential (Primary Case 1) Annual generation as \% of 2010 total generation with full (left) and no (right) capacity value
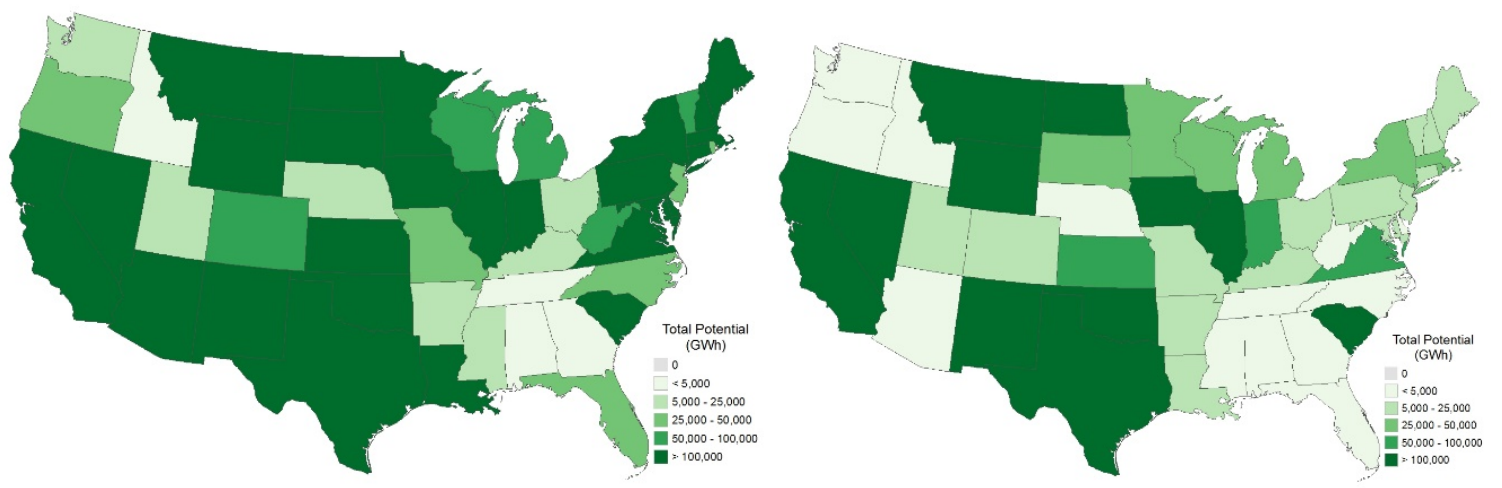

Figure 16c. Sum of assessed technologies: economic potential - annual generation (Primary Case 2) with full (left) and no (right) capacity value 

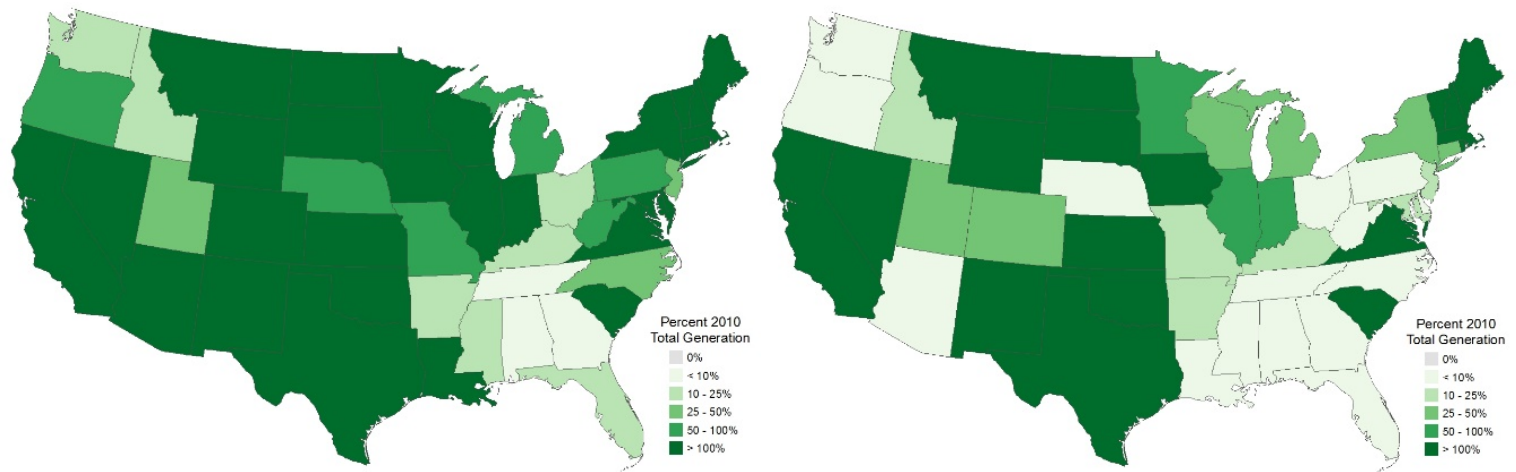

Figure 16d. Sum of assessed technologies: economic potential (Primary Case 2) Annual generation as \% of 2010 total generation with full (left) and no (right) capacity value
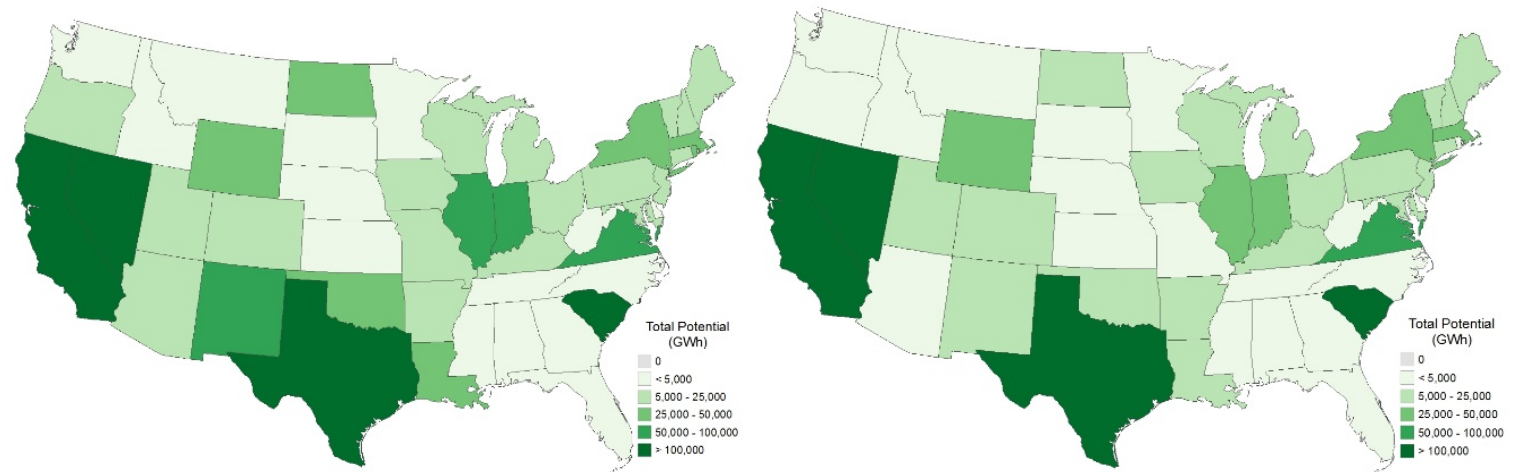

Figure 16e. Sum of assessed technologies: economic potential - annual generation (Primary Case 3) with full (left) and no (right) capacity value
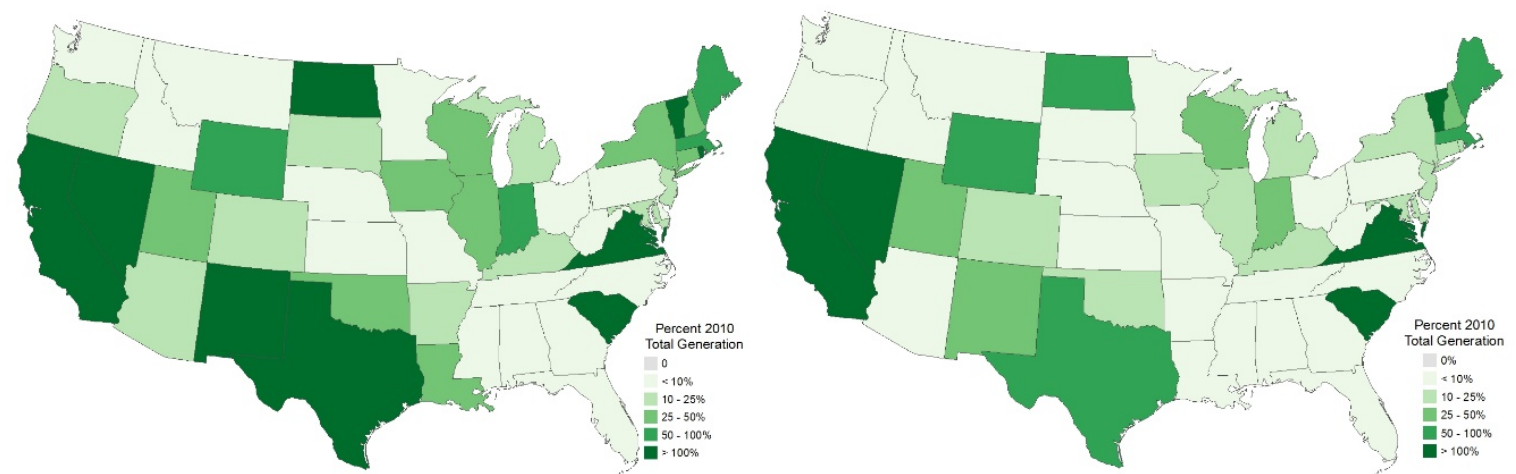

Figure 16f. Sum of assessed technologies: economic potential (Primary Case 3) Annual generation as \% of 2010 total generation with full (left) and no (right) capacity value

Note: Annual generation shown is incremental to 2013 levels. These maps sum the potential estimated independently for the assessed technologies. As such, the estimates do not consider any potential competition among the technologies for available land or in economic terms. Further, the estimate does not reflect any impact of the interaction of variable wind and UPV generation upon the value of either technology. Wind generation potential exceeds $40 \%$ of 2013 total generation in Texas for both Primary Case 3 cases; as a consequence, wind potential for that state may be overstated as the declining value method applied does not reduce the value of wind further as its potential share of generation exceeds $40 \%$. 


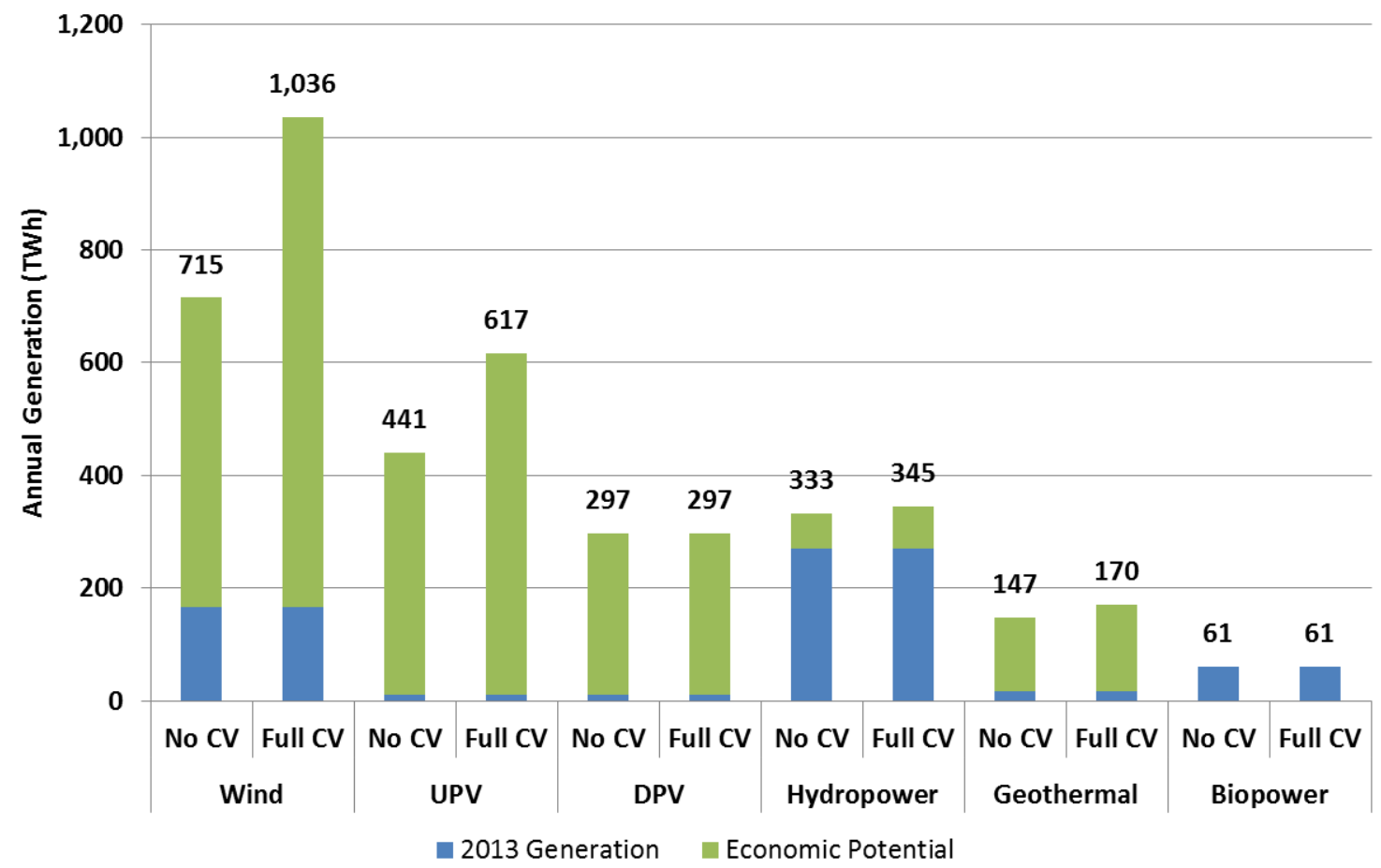

Figure 17a. Aggregated Estimated U.S. Economic Potential (Primary Case 3)

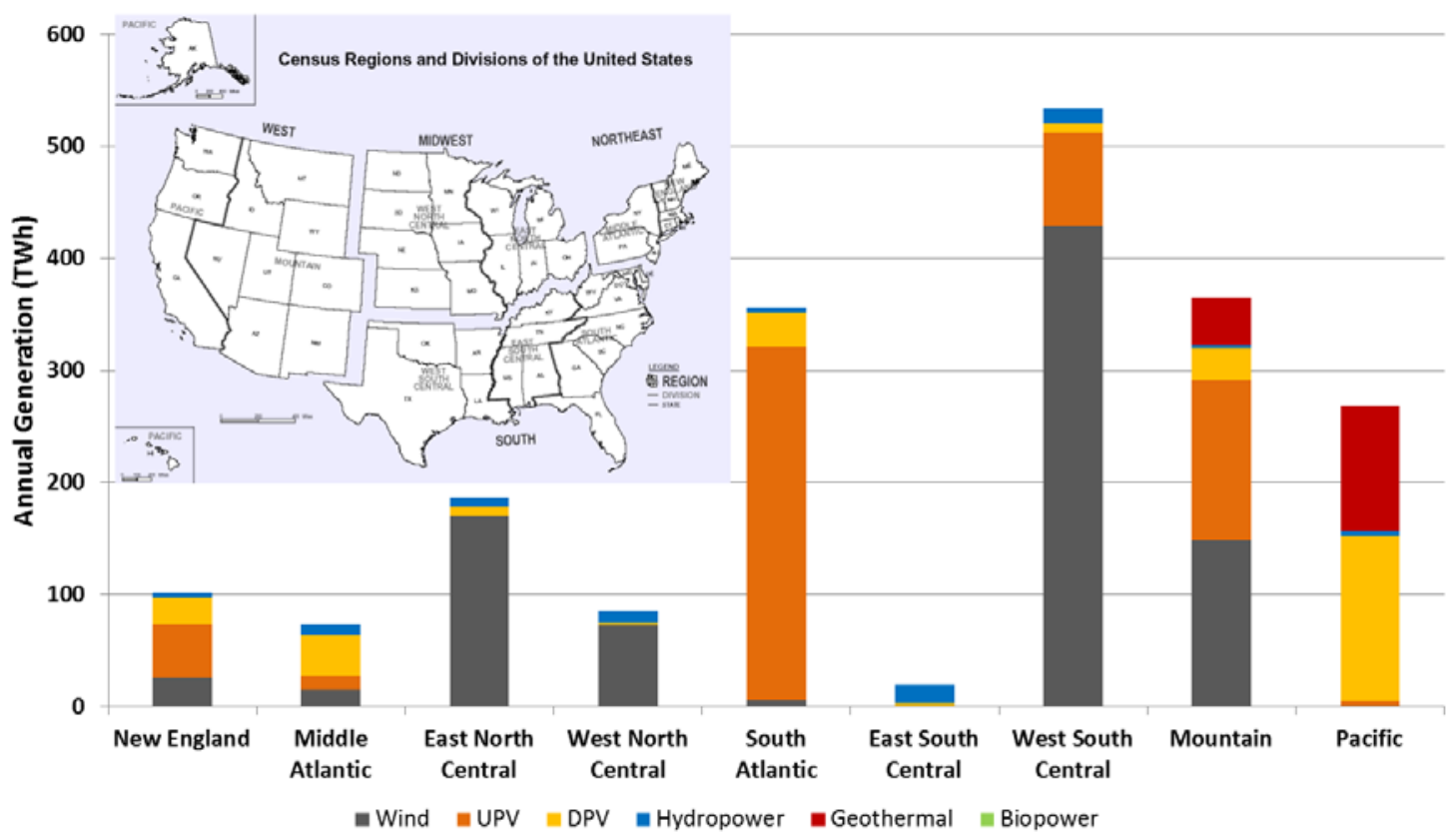

Figure 17b. Economic potential - annual generation (Primary Case 3 with full capacity value) by Census division

Note: Numerical values above each column in (a) are the sum of 2013 generation and the estimated economic potential. As in Table 12 and all tables and graphs of estimates in this report, economic potential is additive to existing generation. Wind generation potential in (b) exceeds $40 \%$ of 2013 total generation in some regions (primarily West South Central) and may be overstated as the declining value method applied does not reduce the value of wind further as its potential share of generation exceeds $40 \%$. UPV potential estimated in the South Atlantic and Mountain divisions reflects higher than average marginal generation prices in South Carolina and Nevada, respectively, as reported in the data sources used. 
These estimates of economic potential can be put into context by comparing existing generation (2013) for the assessed technologies to the estimated economic potential and the remaining technical potential that is not yet found to be economic in this analysis. Figure 18 shows the percentage of each of the assessed technology's technical potential that is already developed, economic, or remaining, based on Primary Case 3 assuming full capacity value. In spite of recent growth, the total renewable generation deployed to date remains small compared to the total technical potential, except for the relatively developed technologies of hydropower and biopower. More specifically, for hydropower and geothermal, a significant portion of technical potential has already been developed, but additional economic potential exists. For wind and DPV, a small amount of technical potential has been developed, and economic potential is significantly more than what has been deployed thus far. For UPV, technical potential is extremely large (greater than all other renewables put together), so deployed and economic potential as a percentage are small.
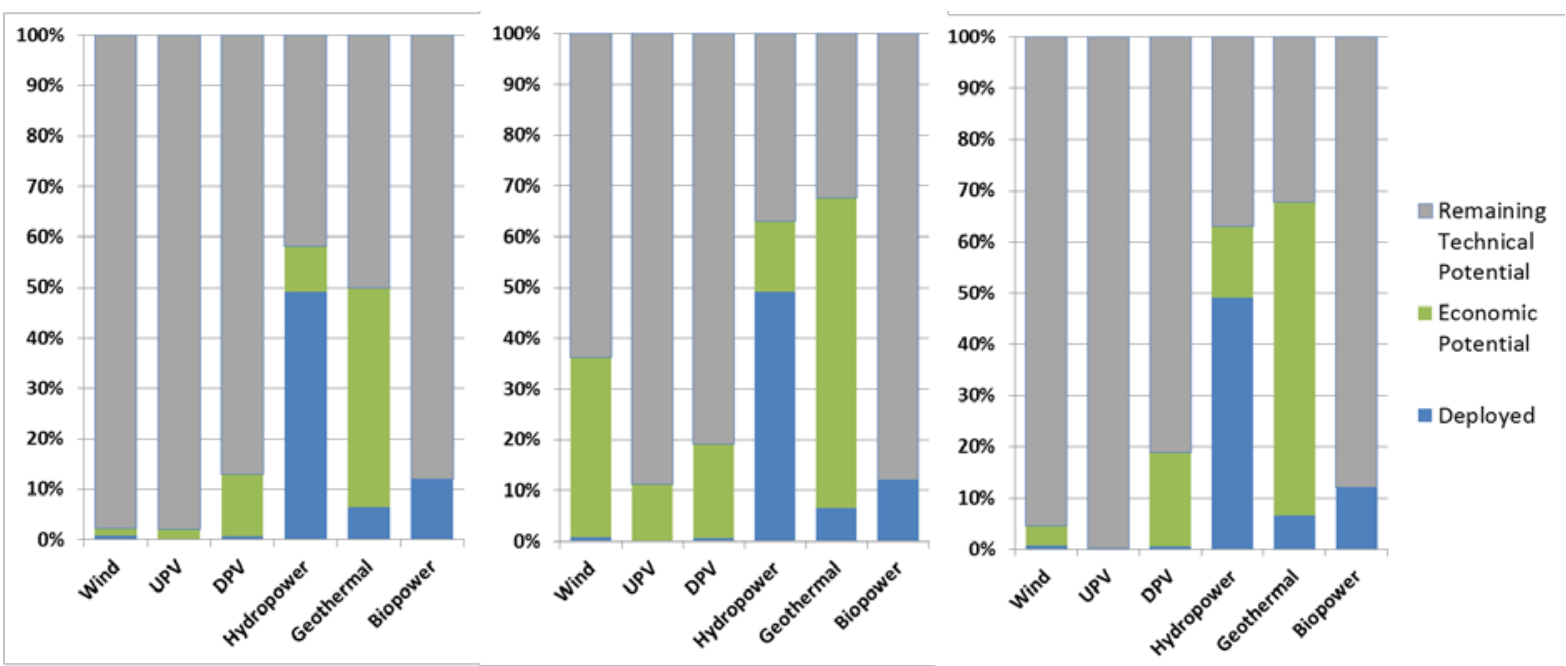

Figure 18: Comparison of deployed, economic, and remaining technical potential in Primary Case 1 (left), 2 (center), and 3 (right) with full capacity value)

Note: For each technology, 2013 generation and economic potential (annual generation) are shown as a share of the total technical potential. Total technical potential varies widely among the technologies.

\subsection{Sensitivity Cases}

One of the uses of economic potential as a metric is to explore how the potential is affected by a range of factors that could affect the economic viability of renewables. While the absolute value of potential in a given scenario does not predict deployment, the magnitude and direction of the change between different scenarios can provide a guide for the relative importance of different economic factors.

\section{Specific Cases Examined}

In addition to the Primary Cases described above, sensitivity cases for Primary Case 3 were also assessed. In all sensitivity cases, full capacity value is assumed unless noted. In most sensitivity cases, a single parameter value was modified; all other parameters were held consistent with the Primary Cases assumptions. The sensitivity cases explored were designed in the following four categories: 
- Framework - These sensitivities provide alternate perspectives on the year snapshot in which both the LCOE and LACE components of the net value framework are considered. A 2020 Construction case considers both net value components from a 2020 perspective. In contrast, an RE Cost - 2014 case considers net value from a fully consistent 2014 perspective. Two variation on the this RE Cost - 2014 case consider the impact of incentives effective in 2014 for Wind (PTC) and UPV/DPV (30\% ITC), both in addition to and in place of the value of avoided $\mathrm{CO}_{2}$ emissions. Finally, an alternate declining value approach that ensures that the incremental value of wind to the system is reduced to zero by $100 \%$ wind penetration is also considered.

- Renewable Technology Cost - Explored costs are intended to reflect a range of plausible future renewable technology costs. In addition to the 2014 costs explored in the Framework sensitivities, 2010 and 2030 Mid cases are explored in this category. Past and present costs are derived from relevant market reports. Future year costs are drawn from the 2015 ATB (NREL, 2015).

- Avoided Generation Cost - Two cases are examined for avoided costs, in addition to the two different assumptions concerning crediting of renewable generation capacity value included in the Primary Cases. One case assumes a higher NGCT capital cost $(\$ 1000 / \mathrm{kW})$ used in the MP method, consistent with an average cost derived from reported costs of recently deployed NGCT plants in several regions (for example, as documented in Energy and Environmental Economics, 2014) . The other case applies an alternate Average Avoided Generator (AAG) method that calculates the value of a renewable generation project in displacing a blended mix of typical "marginal" generators (natural gas combined cycle, combustion turbines, and coal plants), where a single mix is applied nationally.

- Avoided External Cost - Three sensitivity cases that vary the calculation of SCC in the determination of the value of avoided $\mathrm{CO}_{2}$ emissions, as defined in IWG (2013), are considered: Average SCC using a $5 \%$ discount rate, $95^{\text {th }}$ percentile SCC using a discount rate of $3 \%$, and SCC excluded. A single sensitivity exploring the additional impact of avoided health costs in also considered.

Table D-1 in Appendix D identifies the specific assumptions associated with each sensitivity case.

\subsection{Summary Results by Technology \\ Wind}

Aggregate U.S. economic annual generation potential for wind varies from the estimate of nearly 970 TWh for Primary Case 3 with full credit for wind capacity value depending on the specific sensitivities explored (Figure 19). On the low end of the range, annual generation potential is estimated to be less than $200 \mathrm{TWh}$ when the value of avoided $\mathrm{CO}_{2}$ emissions is not included or is discounted with a 5\% rate, or when technology costs in 2010 are assumed. Annual generation potential is $370 \mathrm{TWh}$ when technology costs in 2014 are assumed. On the high end of the range, annual generation potential exceeds: $1,000 \mathrm{TWh}$ when a 30 -year project life is assumed, when 2030 mid-case projection technology costs are assumed, when technology costs for 2014 are assumed with the addition of the PTC to the value of avoided $\mathrm{CO}_{2}$ emissions, or when avoided health costs are included; 2,000 TWh when 2020 is the assumed construction date or when the value of avoided $\mathrm{CO}_{2}$ emissions is based on the $95^{\text {th }}$ percentile SCC with $3 \%$ discount rate. 
As discussed in Section 2.2, these results do not include sites with wind resource below a technoeconomic threshold based on resource intensity and regional capital costs. Recent research suggests that taller towers and other innovations can potentially make these resources (such as in the Southeast) technically and potentially economically viable. Future versions of this analysis can include these resources.

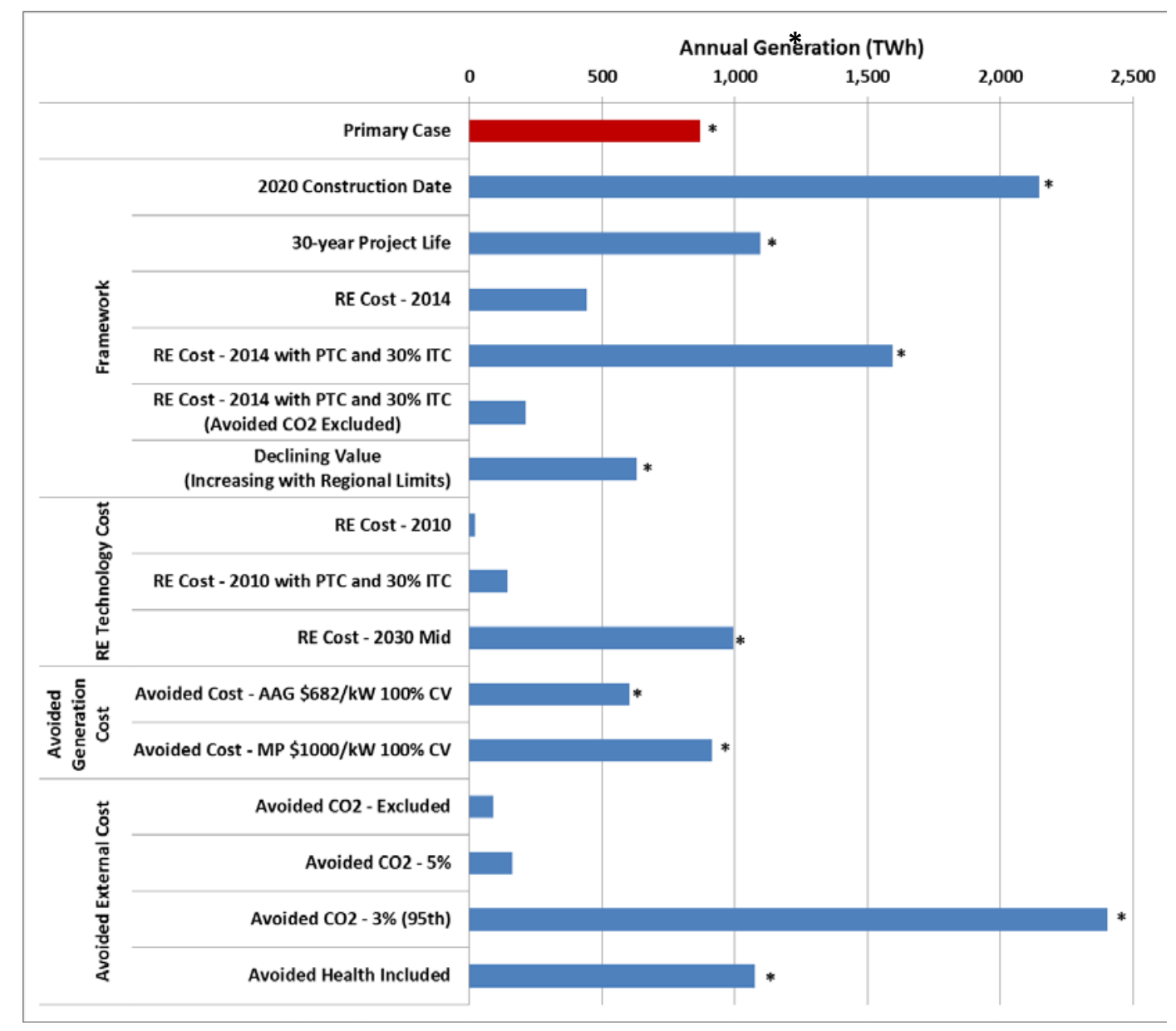

Figure 19. Wind aggregated U.S. economic potential by sensitivity - annual generation

Note: Each sensitivity case assumes full capacity value unless noted. Annual generation shown is incremental to 2013 level. All technology cost assumptions refer to the ATB (NREL, 2015) unless noted otherwise. For reference, total U.S. annual generation from all sources in 2013 was approximately 4,100 TWh. An asterisk symbol (*) to the right of a bar indicates that wind generation potential exceeds $40 \%$ of 2013 total generation and may be overstated.

\section{UPV}

Aggregate U.S. economic annual generation potential for UPV varies from the estimate of 600 TWh for Primary Case 3 with full credit for UPV capacity value depending on the specific sensitivities explored (Figure 20). On the low end of the range, annual generation potential is estimated to be at or close to zero when technology costs in 2010 are assumed. Annual generation potential is estimated be 20-50 TWh when 2014 technology costs are assumed, or the AAG avoided costs method is applied. On the high end of the range, estimated annual generation potential exceeds: 1,000 TWh when 2020 is the assumed construction date, or when 2030 mid- 
projection technology costs are assumed; 2,000 TWh when a 30-year project life is assumed or the value of avoided $\mathrm{CO}_{2}$ emissions is based on the $95^{\text {th }}$ percentile SCC with $3 \%$ discount rate.

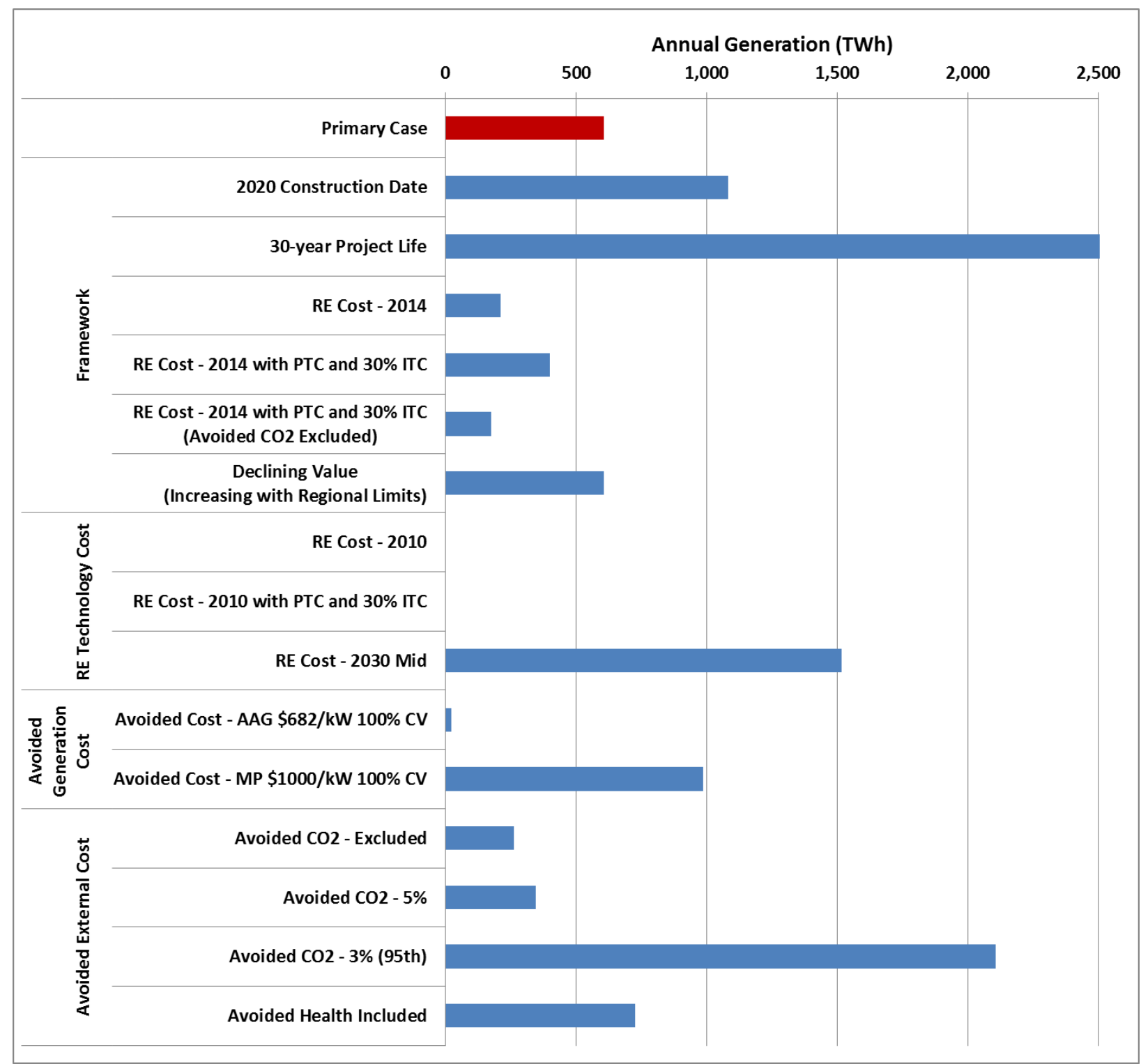

Figure 20. UPV aggregated U.S. economic potential by sensitivity - annual generation

Note: Each sensitivity case assumes full capacity value unless noted. Annual generation shown is incremental to 2013 level. All technology cost assumptions refer to the ATB (NREL 2015) unless noted otherwise.

DPV

Aggregate U.S. economic annual generation potential for DPV (residential and commercial combined) varies from the estimate of 287 TWh for Primary Case 3 depending on the specific sensitivities explored (Figure 21). On the low end of the range, no annual generation potential is estimated when technology cost in 2010 is assumed. Annual generation potential estimates exceed $200 \mathrm{TWh}$ when technology cost in 2014 is assumed, or the value of avoided $\mathrm{CO}_{2}$ emissions is not included or is discounted with a 5\% rate. On the high end of the range, estimated 
annual generation potential exceeds: $400 \mathrm{TWh}$ when a 30-year project life is assumed; $700 \mathrm{TWh}$ when 2030 mid-projection technology costs are assumed or when the value of avoided $\mathrm{CO}_{2}$ emissions is based on the $95^{\text {th }}$ percentile SCC with $3 \%$ discount rate.

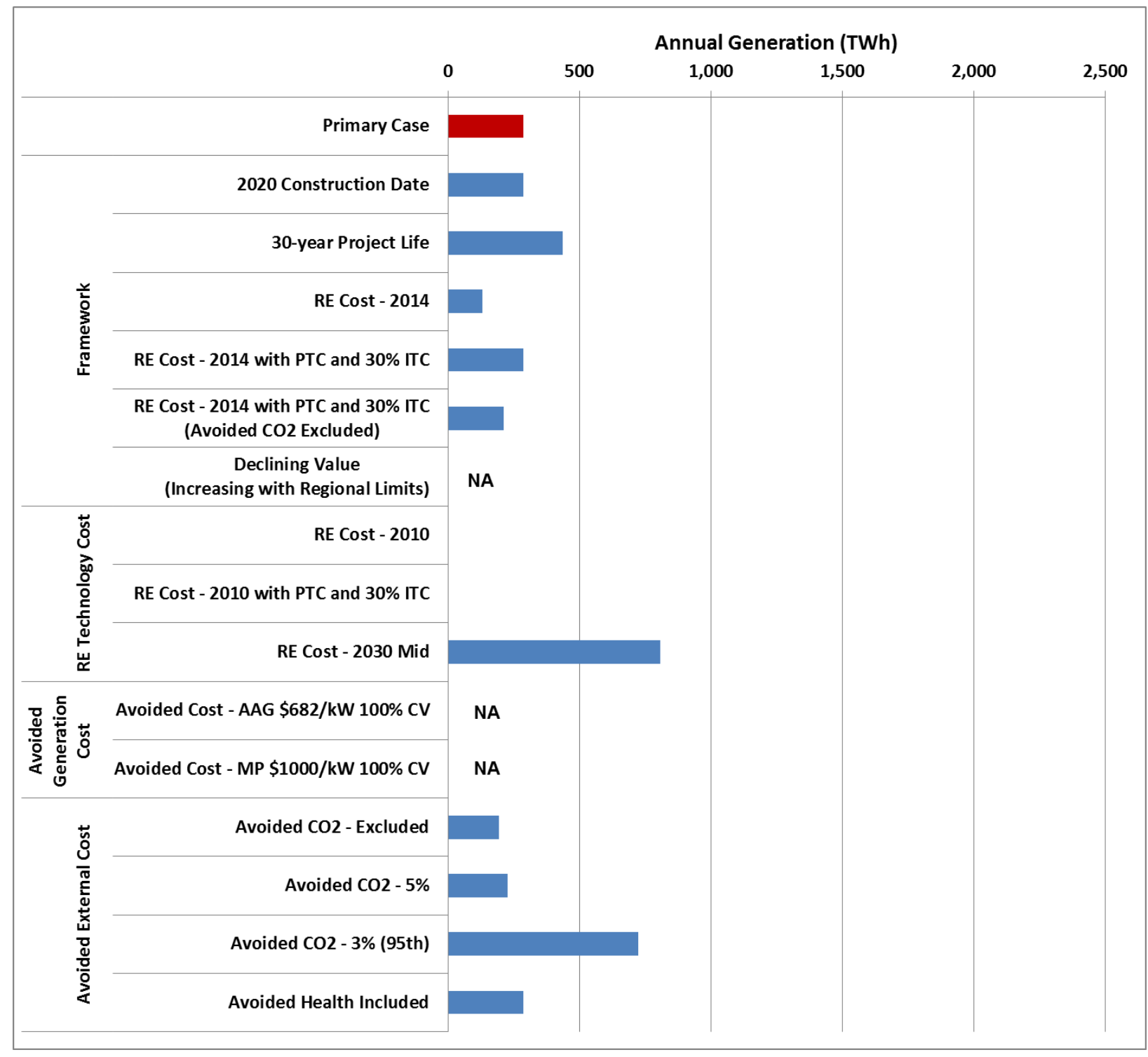

Figure 21. DPV aggregated U.S. economic potential by sensitivity - annual generation

Note: DPV estimates were not made explicitly for the following sensitivities (another case was used as a substitute): 2020 Construction Date, Declining Value, Avoided Costs (all), and Avoided Health Costs. Annual generation shown is incremental to 2013 level. All technology cost assumptions refer to the ATB (NREL, 2015) unless noted otherwise.

\section{Hydropower}

Aggregate U.S. economic annual generation potential for hydropower varies from the estimate of 76 TWh for Primary Case 3 with full credit for wind capacity value depending on the specific sensitivities explored (Figure 22). On the low end of the range, annual generation potential is estimated to be close to zero when capacity value is excluded from the avoided cost estimate. 
Annual generation potential is estimated be $50-60 \mathrm{TWh}$ when the value of avoided $\mathrm{CO}_{2}$ emissions is not included or is discounted with a $5 \%$ rate. On the high end of the range, estimated annual generation potential: exceeds $100 \mathrm{TWh}$ when a 30 -year project life or a 2020 construction date is assumed; and exceeds $200 \mathrm{TWh}$ when the value of avoided $\mathrm{CO}_{2}$ emissions is based on the $95^{\text {th }}$ percentile SCC with 3\% discount rate. Economic potential estimates are unchanged in most technology cost scenarios as the associated cost projections are assumed to be flat.

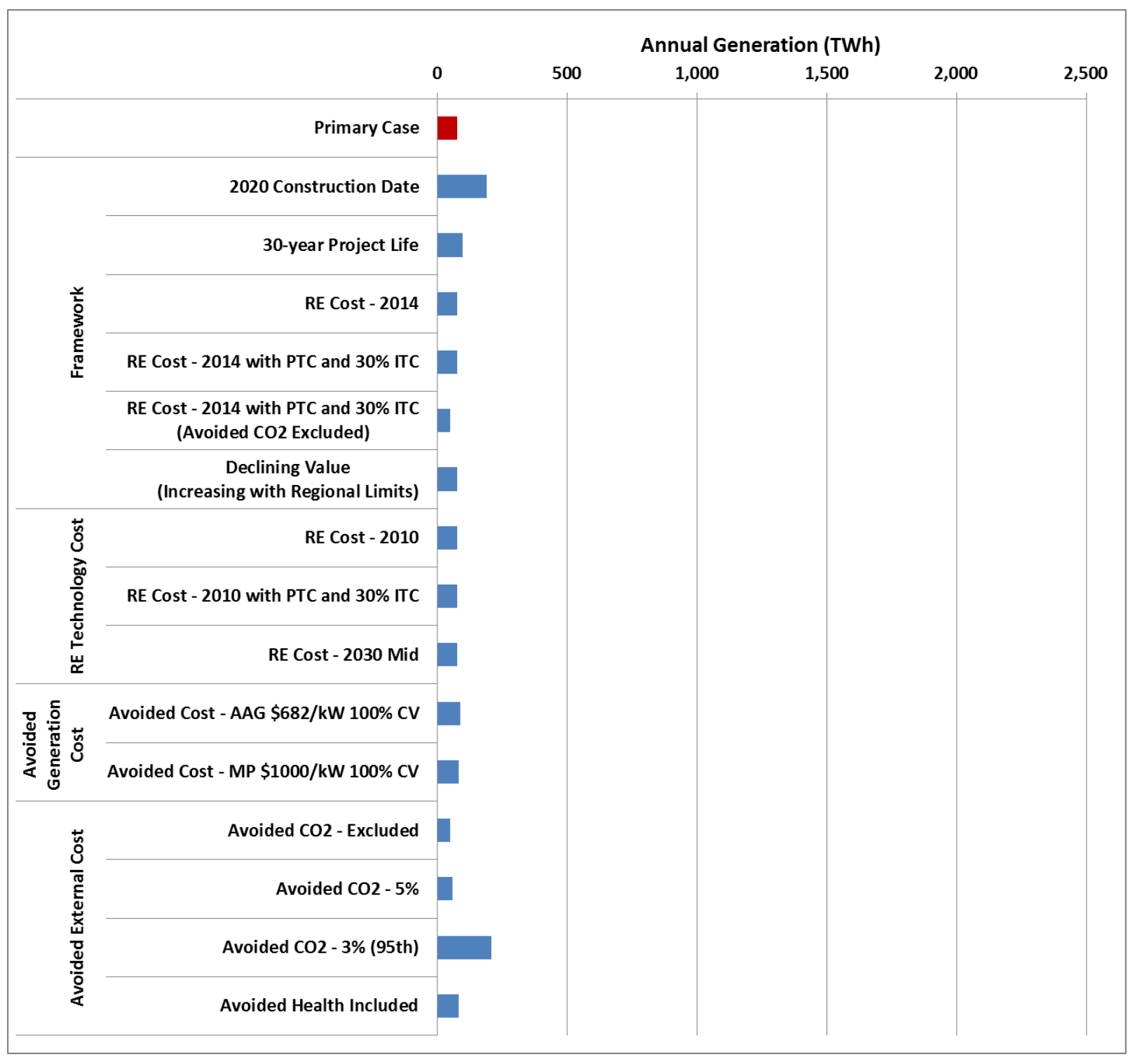

Figure 22. Hydropower aggregated U.S. economic potential by sensitivity - annual generation

Note: Each sensitivity case assumes full capacity value unless noted. Annual generation shown is incremental to 2013 level. All technology cost assumptions refer to the ATB (NREL 2015) unless noted otherwise.

\section{Geothermal}

Aggregate U.S. economic annual generation potential for geothermal (hydrothermal resources only) varies from the estimate of 150 TWh for Primary Case 3 with full credit for geothermal capacity value depending on the specific sensitivities explored (Figure 23). On the low end of the 
range, annual generation potential is estimated be $50 \mathrm{TWh}$ when the value of avoided $\mathrm{CO}_{2}$ emissions is not included. On the high end of the range, estimated annual generation potential exceeds $170 \mathrm{TWh}$ when a 2020 construction date is assumed or when the value of avoided $\mathrm{CO}_{2}$ emissions is based on the $95^{\text {th }}$ percentile SCC with $3 \%$ discount rate. Economic potential estimates are unchanged in most technology cost scenarios as the associated cost projections are assumed to be flat.

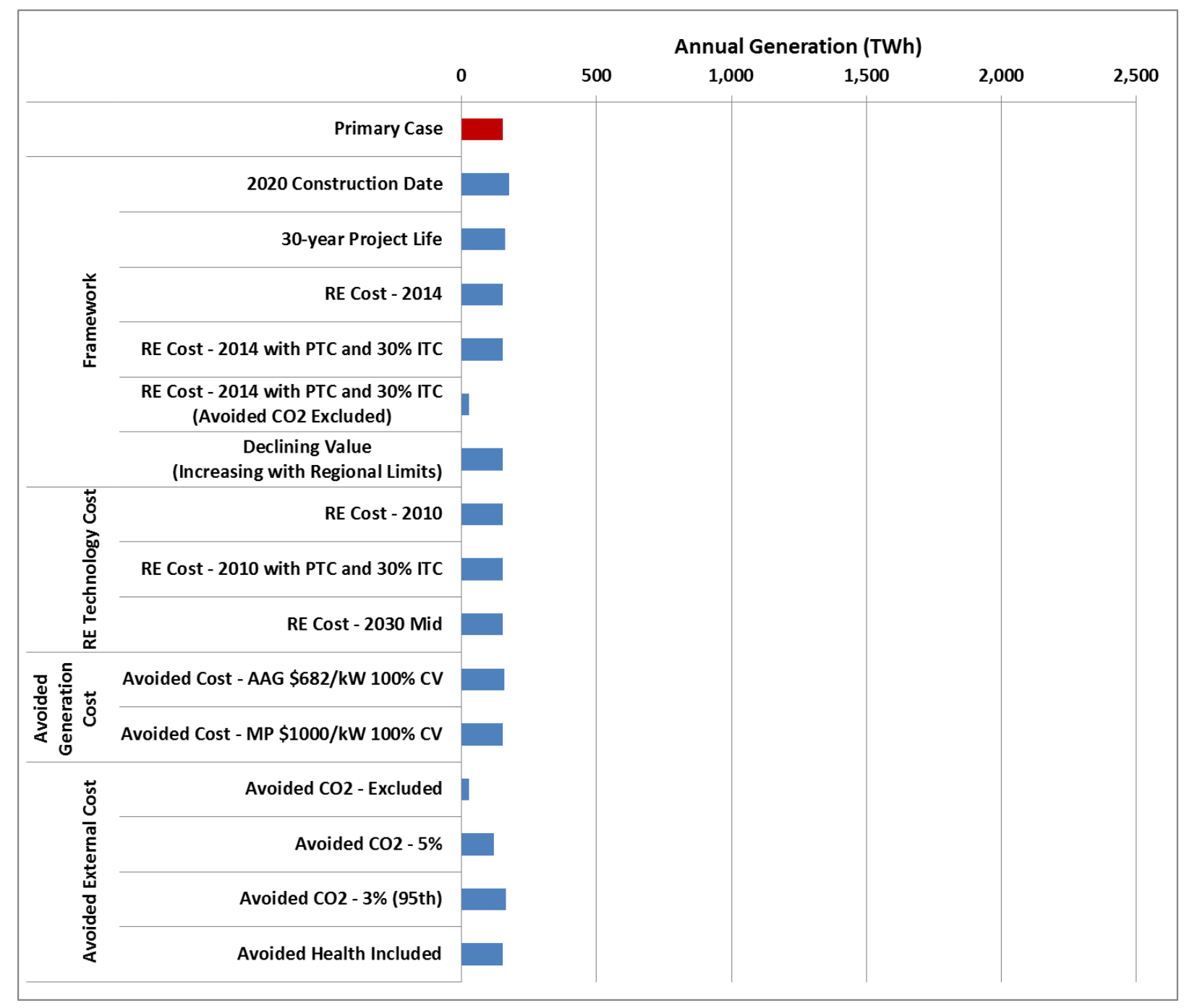

Figure 23. Geothermal aggregated U.S. economic potential by sensitivity - annual generation

Note: Each sensitivity case assumes full capacity value unless noted. Annual generation shown is incremental to 2013 level. All technology cost assumptions refer to the ATB (NREL2015) unless noted otherwise.

\section{Biopower}

Biopower is estimated to have no aggregate U.S. economic potential for almost every sensitivity explored. Annual generation potential is estimated be over 5 TWh when a 2020 construction date is assumed, and the value of avoided $\mathrm{CO}_{2}$ emissions is based on the $95^{\text {th }}$ percentile $\mathrm{SCC}$ with $3 \%$ discount rate. Economic potential estimates are unchanged in most technology cost scenarios as the associated cost projections are assumed to be flat. 


\subsection{Summary Results - Sum of Assessed Technologies}

Estimates of economic potential are highly sensitive to the specific assumptions made for both renewable supply and avoided cost, varying from 250 - 5,600 TWh for Primary Case 3, assuming full credit for the capacity value for renewable generation (see Figure 24). On the low end of this range, annual generation potential is $600 \mathrm{TWh}$ or less when: the value of avoided $\mathrm{CO}_{2}$ emissions is not included or when technology costs in 2010 are assumed. On the high end of the range, annual generation potential exceeds: 2,000 TWh when 2014 technology costs are assumed with PTC and ITC incentives available at that time, 2030 mid-case projection technology costs are assumed, or avoided health costs are included; 3,800 TWh when a 30-year project life or a construction date of 2020 is assumed; and 5,000 TWh when the value of avoided $\mathrm{CO}_{2}$ emissions is based on the $95^{\text {th }}$ percentile SCC with $3 \%$ discount rate.

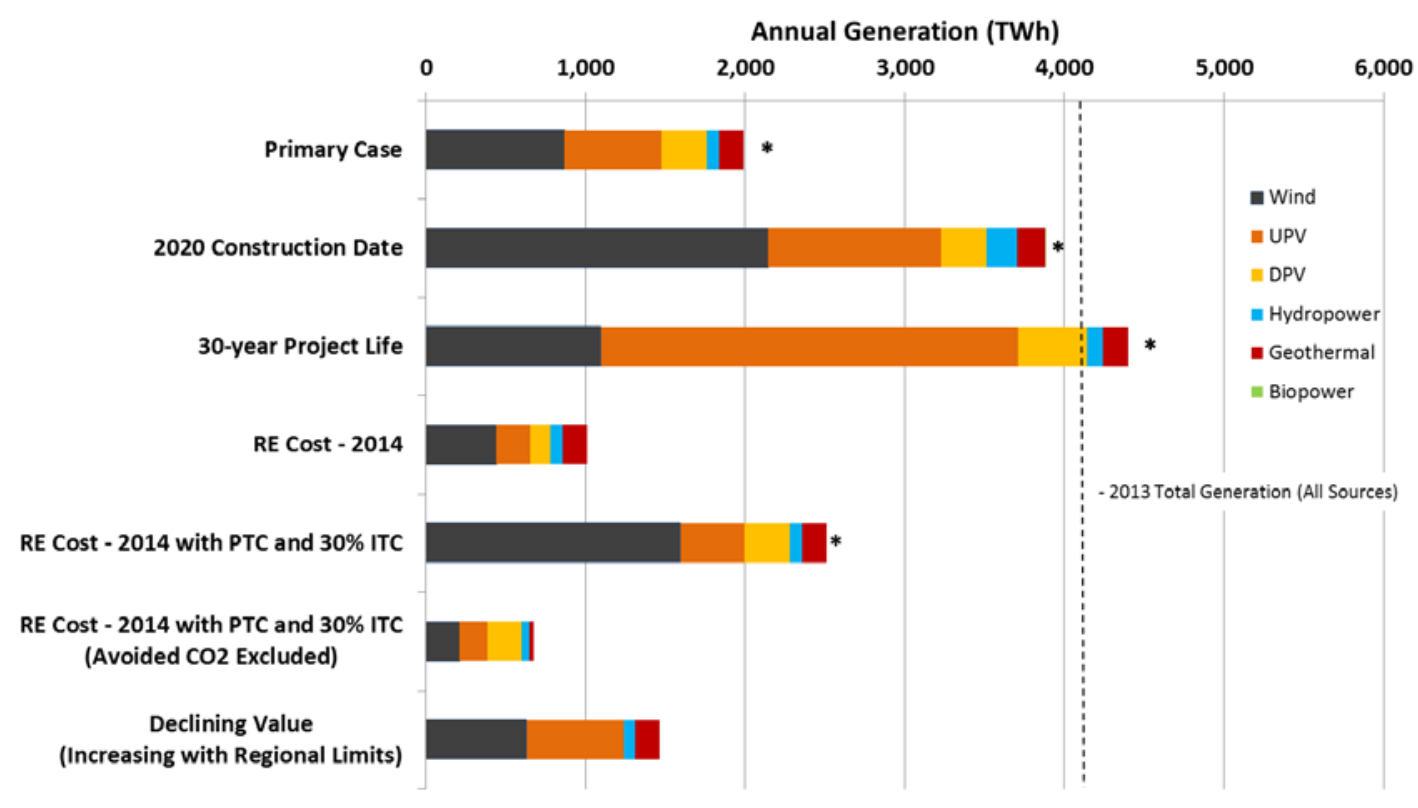

Figure 24a. Sum of estimated U.S. economic potential for assessed technologies - Framework Sensitivities

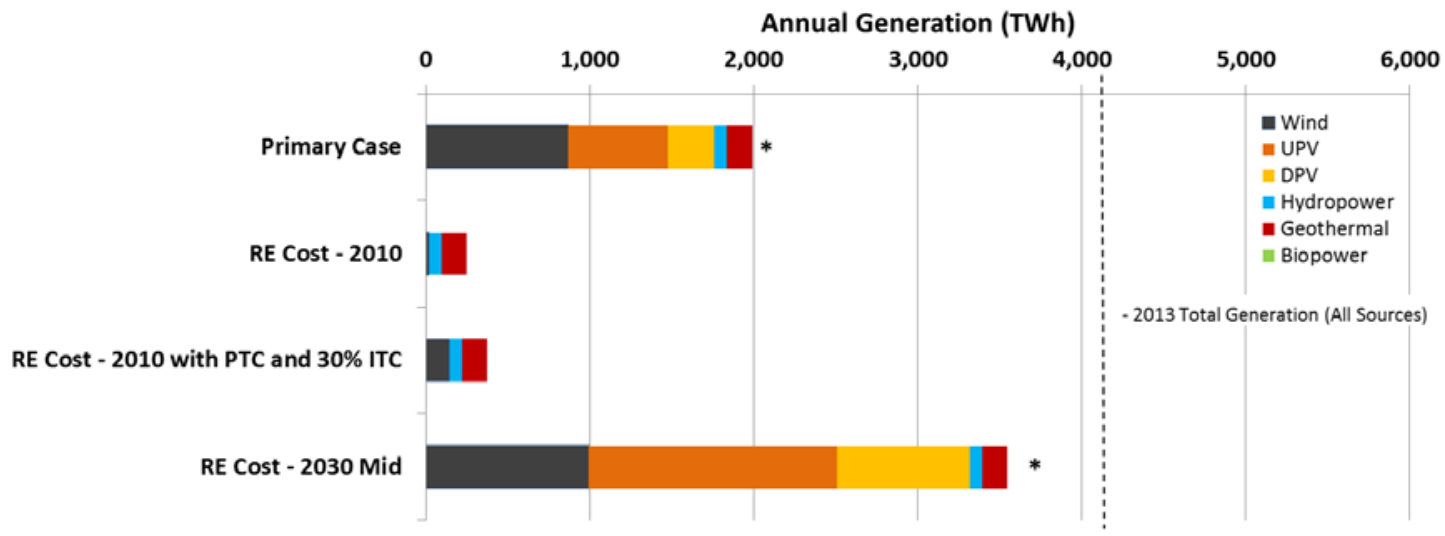

Figure 24b. Sum of estimated U.S. economic potential for assessed technologies - Renewable Technology Cost Sensitivities 


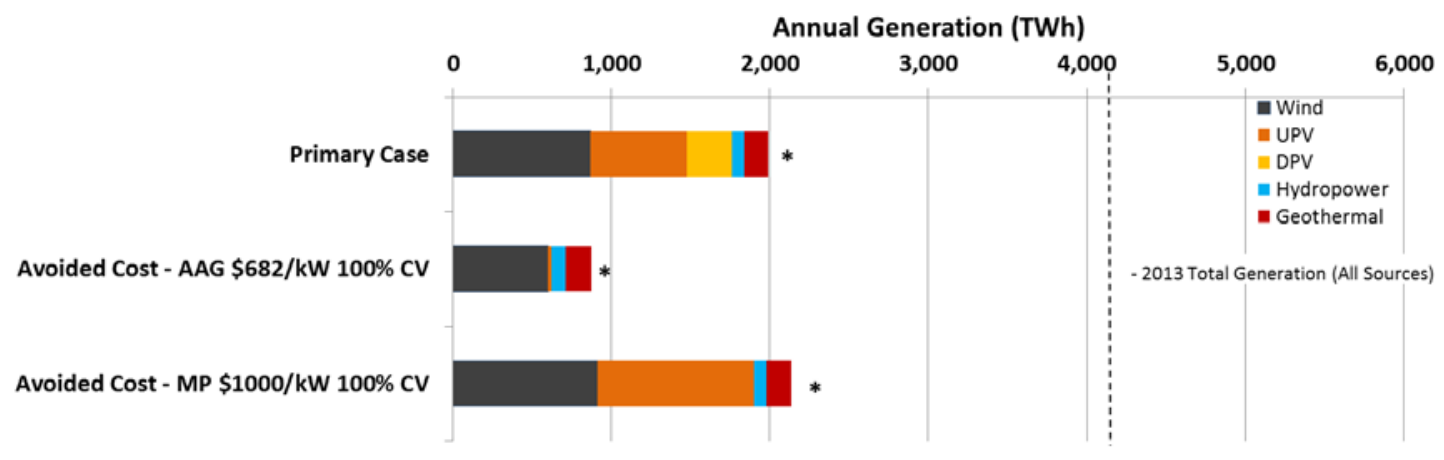

Figure 24c. Sum of estimated U.S. economic potential for assessed technologies - Avoided Generation Cost Sensitivities

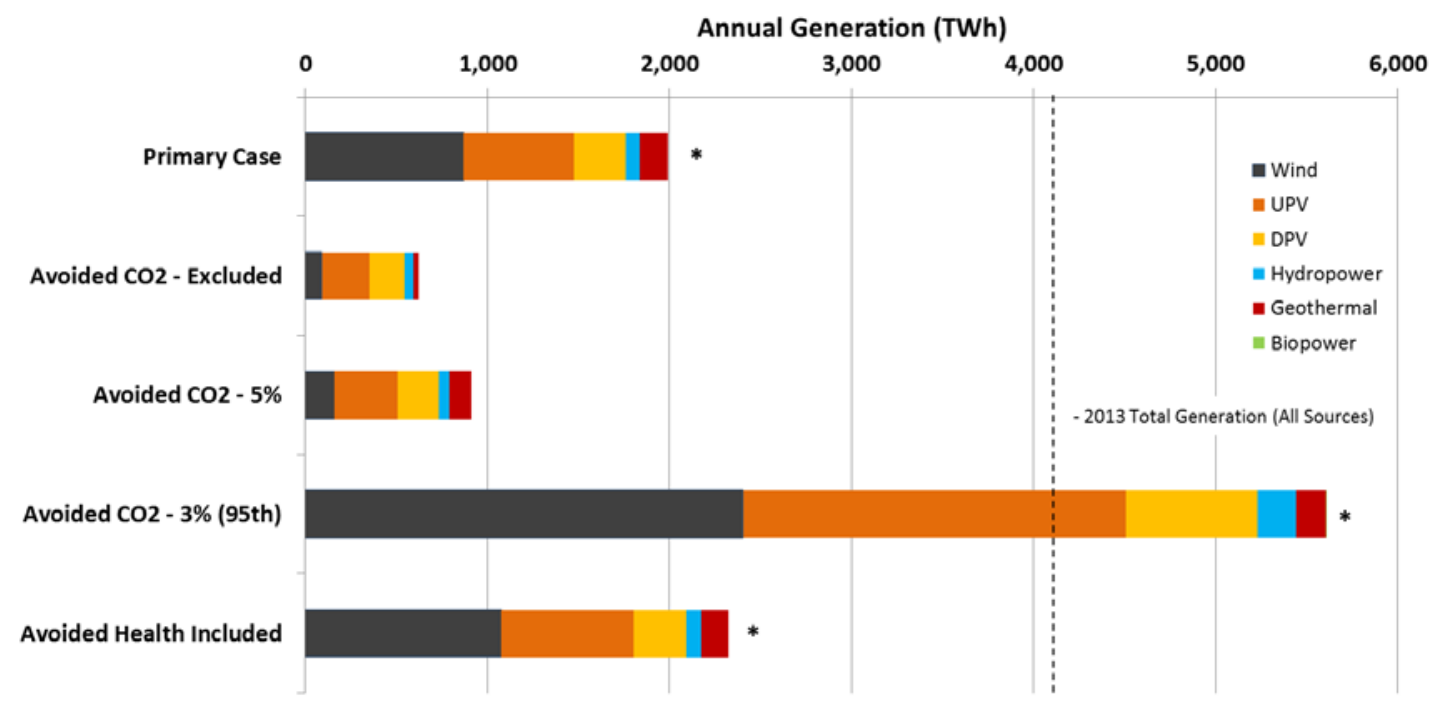

Figure 24d. Sum of estimated U.S. economic potential for assessed technologies - Avoided External Cost Sensitivities

Note: Each sensitivity case assumes capacity value unless noted. DPV estimates were not made explicitly for the following sensitivities (another case was used as a substitute): 2020 Construction Date, Declining Value, Avoided Costs (all), and Avoided Health Costs. Annual generation shown is incremental to 2013 levels. For reference, total U.S. annual generation from all sources in 2013 was approximately 4,100 TWh. An asterisk symbol (*) to the right of a bar indicates that wind generation potential exceeds $40 \%$ of 2013 total generation in some regions and may be overstated as the declining value method applied does not reduce the value of wind further as its potential share of generation exceeds $40 \%$.

Estimates of economic potential are highly sensitive to the specific assumptions used related to both renewable generation supply and avoided cost. Consideration of the capacity value of renewable generation, external costs and associated discount rates, and the declining value of variable generation (wind and solar PV) with increased penetration have a major impact on estimates. The reference year for project construction, renewable technology costs, and the method and assumptions associated with the avoided cost of generation are other variables that have a significant effect on estimates. 
Changes in assumption that affect the year snapshot in which both the LCOE and LACE components of the net value framework are considered have a significant effect on economic potential estimates for Primary Case 3 (Figure 24a). When the net value framework is assessed from a fully consistent 2014 perspective (RE Cost - 2014 case), assuming full credit for the capacity value for renewable generation, annual generation is estimated to be $800 \mathrm{TWh}$, compared to nearly 2,000 TWh for the mixed perspective Primary Case. In contrast, when a 2020 perspective is applied (2020 Construction Date), annual generation potential is estimated to be nearly 3,900 TWh. Extending the assumed project life of generation assets to 30 years also results in a significantly higher estimate (over 4,000 TWh). Finally, when an alternate method for declining value is applied that reduces the incremental value of wind to zero by $100 \%$ penetration level, estimated annual generation is 1,500 .

Renewable technology costs are a significant driver for economic potential in Primary Case 3 (Figures 24a and 24b). Estimated annual generation potential is the following, assuming full credit for the capacity value for renewable generation, for the corresponding assumed costs (highest to lowest costs): 250 TWh (2010), 990 TWh (2014), 2,000 TWh (2020 mid), and 3,500 TWh $(2030 \mathrm{mid})$. Cost reductions already realized for renewable generation technologies between 2010 and 2014, particularly for wind and solar PV technologies, increase the combined potential under this formulation by nearly $300 \%$. Finally, the magnitude of technology tax incentives for wind and solar PV also impacts estimates. When an extension of federal incentives available to renewable generation projects in 2014 is considered (30\% ITC for UPV and DPV, PTC for wind), estimated annual generation is 2,500 TWh when applied in addition to the value of avoided $\mathrm{CO}_{2}$ emissions compared to $990 \mathrm{TWh}$ when only the value of avoided emissions is considered. When these incentive levels are considered in absence of the value of avoided emissions, estimated annual generation is $550 \mathrm{TWh}$.

Changes in assumptions in the calculation of avoided generation cost (Figure 24c), assuming full credit for the capacity value for renewable generation, result in the following annual generation estimates: $870 \mathrm{TWh}$ (alternate AAG method with $\$ 862 / \mathrm{kW}$ capacity payment), 2,000 TWh (MP method with $\$ 862 / \mathrm{kW}$ capacity payment), and $2,100 \mathrm{TWh}$ (MP method with $\$ 1000 / \mathrm{kW}$ capacity payment).

Finally, assumptions related to the treatment of external costs (Figure 24d), have a significant impact on estimates. Estimated annual generation potential is the following, assuming full credit for the capacity value for renewable generation, for the corresponding cases: $620 \mathrm{TWh}$ (SCC not included), $900 \mathrm{TWh}$ (average SCC with 5\% discount rate), 2,000 TWh (average SCC with 3\% discount rate), and 5,600 TWh ( $95^{\text {th }}$ percentile SCC with $3 \%$ discount rate). When avoided health costs are considered, in addition to the value of avoided $\mathrm{CO}_{2}$ emissions, estimated annual generation is estimated to be $2,300 \mathrm{TWh}$,

Maps of aggregated U.S. economic potential are included in Appendix G for selected Framework and Renewable Technology Cost Sensitivities.

There are several caveats that are important to keep in mind when considering the above initial estimates: 
- The framework described is static and considers economic potential only at a particular point in time based on the vintage of underlying data and assumptions, including electricity price projections, technical potential, cost of energy, and avoided cost. As resource data, technology cost and performance, actual renewable technology deployment, transmission infrastructure, fuel prices, wholesale electricity prices, and other factors change, estimates of economic potential will change. Further, the framework does not consider potential dynamic feedbacks that increasing renewable deployment may have on wholesale electricity prices.

- The range of estimates shown is based on readily available data sets and simplifying assumptions. Supporting data assumptions for both cost of energy and avoided cost components of the methodology, especially those in the form of electricity price projections, are inherently uncertain.

- The framework relies on some assumptions related to technology incentives that can have a significant effect on resulting estimates. The continued existence of existing "permanent" incentives is inherently uncertain. Further, simplifying assumptions on state-level policies, primarily in adopting single national approach to distributed PV net metering, were made to make the analysis more tractable.

- In the Primary Case 3 analysis, including many of the assessed sensitivities, wind generation potential exceeds $40 \%$ of 2013 total generation in some regions and may be overstated as the declining value method applied does not reduce the value of wind further as its potential share of generation exceeds $40 \%$. This situation is primarily limited to the ERCOT region for cases where wind potential is less than $1000 \mathrm{TWh}$, but extends to other regions for cases that exceed that level of potential. The applied method does not allow wind potential to exceed $100 \%$ of total generation in any region.

- Total estimates of economic potential simply sum the potentials of the individual technologies. As such, they do not consider any potential competition among the technologies for available land or in economic terms. Further, they do not reflect any impact of the interaction of variable wind and PV generation upon the value of either technology.

- Sensitivity cases were assessed for only one of the Primary Cases (3) assuming full capacity value. 


\section{Summary and Observations}

\subsection{Observations Based on Initial Estimates}

We have developed a methodology to estimate the economic potential of renewable generation, based on a specific definition of the term. Further, we explored three different formulations of this definition, based on inclusion of additional factors beyond LCOE and LACE. The methodology is applied to several renewable generation technologies, including wind, UPV, DPV, hydropower, geothermal (hydrothermal resource only), and biopower under various assumptions.

The specific definition and related formulations of the metric is extremely important, as well as its sensitivity to key input data and assumptions. As with all metrics, care should be applied in in the interpretation of results to avoid misleading conclusions.

Three Primary Cases are reported based on the following distinct formulations of economic potential:

- Primary Case 1 - LACE Only: This case is meant to represent the LACE methodology identified in Namovicz (2013) as closely as possible, with little consideration of market factors that could affect the actual deployment of renewable generation. This formulation includes the cost of intra-regional transmission for variable generation technologies (Wind and UPV).

- $\quad$ Primary Case 2 - LACE including Value of Avoided External Costs: This case extends LACE to consider the value of avoided external costs associated with conventional generation, in particular $\mathrm{CO}_{2}$ emissions.

- $\quad$ Primary Case 2 - LACE including Value of Avoided External Costs and Declining Value of

Variable Generation: This case further extends LACE to also consider the potential impact of increasing amounts of variable generation on its value.

The latter two formulations move beyond a strict formulation of economic potential that considers only technology costs and required revenues for project development to one that considers some market factors. These market extensions are considered in this analysis to offer additional possible perspectives, in recognition that the demarcation between economic and market potential is subject to interpretation, and to demonstrate that the specific factors considered can have a significant impact on estimates.

For each of the above Primary Cases, an economic potential estimate range is established through varying assumptions of the applied capacity value of renewable generation. A major determinant of the capacity value is the extent to which additional generation capacity is required for the electricity system. In each of the Primary Cases, the low end of the estimated range of economic potential assumes that no additional capacity is required and reflects no credit for the capacity value of renewable generation in the avoided cost calculation. Conversely, the high end of each range assumes that additional capacity is needed on the system and reflects full credit for the capacity value of renewable generation in the avoided cost calculation.

The sum of U.S. economic annual generation potential (excluding Alaska and Hawaii) for the six technologies assessed ranges from nearly 1,500 to 42,000 TWh in excess of 2013 generation for 
the Primary Cases. This range of potential represents from over two to nearly 80 times total U.S. renewable generation in 2013 and is a small fraction of the aggregate annual technical generation potential of over 320,000 TWh for these technologies.

More specifically, the following are ranges of aggregate annual generation potential for each the Primary Cases (see Table 13 for a summary of all cases assessed):

- Primary Case 1-LACE Only: 3,200 - 7,100 TWh. UPV contributes the bulk of the economic potential under this formulation.

- $\quad$ Primary Case 2 - LACE including Value of Avoided External Costs (related to $\mathrm{CO}_{2}$ emissions): $13,000-42,000 \mathrm{TWh}$. Under this formulation, UPV contributes the bulk of the economic potential, particularly at the high end of the range. Wind economic potential is also significant, representing at least the equivalent of total U.S. generation from all sources in 2013.

- $\quad$ Primary Case 3 - LACE including Value of Avoided External Costs and Declining Value of Variable Generation: 1,500-2,000 TWh. While the total economic potential in this formulation is much lower than in Primary Case 2, all of the technologies except biomass contribute significant potential. The potential shown represents $35-50 \%$ of total U.S. generation from all sources in 2013. 
Table 13. Estimated Aggregated U.S. Economic Potential for All Cases Assessed

\begin{tabular}{|c|c|c|c|c|c|c|c|c|c|}
\hline & \multirow{2}{*}{\multicolumn{5}{|c|}{ Economic Potential - Annual Generation (TWh) }} & \multirow[b]{3}{*}{$\begin{array}{l}\text { Bio- } \\
\text { power }\end{array}$} & \multirow[b]{3}{*}{$\begin{array}{l}\text { Sum of } \\
\text { Assessed }\end{array}$} \\
\hline & & & & & & & & & \\
\hline \multicolumn{2}{|c|}{ Case Group } & Specific Cases & Wind & UPV & DPV $^{6}$ & $\begin{array}{l}\text { Hydro- } \\
\text { power }\end{array}$ & $\begin{array}{l}\text { Geo- } \\
\text { thermal }\end{array}$ & & \\
\hline \multirow{2}{*}{\multicolumn{2}{|c|}{ Reference }} & 2013 Generation $^{1}$ & 168 & 11 & 10 & 269 & 17 & 60 & 534 \\
\hline & & Technical Potential $^{2}$ & 22,195 & 297,475 & 1,560 & 278 & 234 & 445 & 322,187 \\
\hline \multirow{2}{*}{\multicolumn{2}{|c|}{ Group 1: LACE Only ${ }^{3}$}} & Primary Case with Full Capacity Value & 319 & 6,468 & 194 & 50 & 109 & 0 & 7,140 \\
\hline & & Primary Case with No Capacity Value & 135 & 2,789 & 194 & 38 & 29 & 0 & 3,184 \\
\hline \multirow{2}{*}{\multicolumn{2}{|c|}{$\begin{array}{l}\text { Group 2: LACE including } \\
\text { Value of Avoided External } \\
\text { Costs }^{3}\end{array}$}} & Primary Case with Full Capacity Value & 7,870 & 33,523 & 287 & 76 & 153 & 0 & 41,909 \\
\hline & & Primary Case with No Capacity Value & 4,590 & 7,713 & 287 & 64 & 131 & 0 & 12,785 \\
\hline \multirow{17}{*}{ 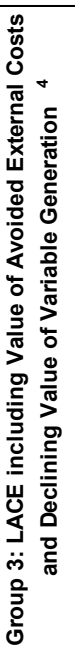 } & \multirow{2}{*}{ Primary Cases } & Primary Case with Full Capacity Value* & 869 & 606 & 287 & 76 & 153 & 0 & 1,991 \\
\hline & & Primary Case with No Capacity Value* & 548 & 430 & 287 & 64 & 131 & 0 & 1,460 \\
\hline & \multirow{6}{*}{$\begin{array}{l}\text { Framework } \\
\text { Sensitivities }\end{array}$} & 2020 Construction Date* & 2,146 & 1,081 & 287 & 189 & 176 & 8 & 3,887 \\
\hline & & 30-year Project Life* & 1,095 & 2,614 & 435 & 97 & 162 & 0 & 4,403 \\
\hline & & RE Cost - 2014 & 441 & 211 & 111 & 76 & 153 & 0 & 992 \\
\hline & & RE Cost - 2014 with PTC and $30 \%$ ITC $^{*}$ & 1,594 & 399 & 287 & 76 & 153 & 0 & 2,509 \\
\hline & & $\begin{array}{l}\text { RE Cost }-2014 \text { with PTC and 30\% ITC (Avoided } \\
\text { CO2 Excluded)* }\end{array}$ & 212 & 175 & 210 & 50 & 29 & 0 & 676 \\
\hline & & Declining Value (Increasing with Regional Limits) ${ }^{5}$ & 631 & 606 & NA & 76 & 153 & 0 & 1,467 \\
\hline & \multirow{3}{*}{$\begin{array}{l}\text { RE Technology } \\
\text { Cost Sensitivities }\end{array}$} & RE Cost -2010 & 20 & 0 & 0 & 76 & 153 & 0 & 249 \\
\hline & & RE Cost - 2010 with PTC and $30 \%$ ITC & 145 & 0 & 0 & 76 & 153 & 0 & 374 \\
\hline & & RE Cost - 2030 Mid* $^{*}$ & 994 & 1,517 & 805 & 76 & 153 & 0 & 3,546 \\
\hline & \multirow{2}{*}{$\begin{array}{l}\text { Avoided } \\
\text { Generation Cost } \\
\text { Sensitivities } \\
\end{array}$} & Avoided Cost - AAG $\$ 682 / \mathrm{kW} 100 \% \mathrm{CV}^{*}$ & 602 & 23 & NA & 87 & 159 & 0 & 871 \\
\hline & & Avoided Cost - MP $\$ 1000 / \mathrm{kW} 100 \% \mathrm{CV}^{*}$ & 913 & 987 & NA & 81 & 153 & 0 & 2,134 \\
\hline & \multirow{4}{*}{$\begin{array}{l}\text { Avoided External } \\
\text { Cost Sensitivities }\end{array}$} & Avoided $\mathrm{CO}_{2}-$ Excluded & 90 & 261 & 194 & 50 & 29 & 0 & 624 \\
\hline & & Avoided $\mathrm{CO}_{2}-5 \%$ & 161 & 345 & 227 & 57 & 121 & 0 & 911 \\
\hline & & Avoided $\mathrm{CO}_{2}-3 \%(95 \text { th })^{*}$ & 2,404 & 2,104 & 724 & 209 & 166 & 6 & 5,613 \\
\hline & & Avoided Health Included* & 1,076 & 727 & 287 & 82 & 153 & 0 & 2,325 \\
\hline
\end{tabular}

Notes

1 As reported in 2013 Renewable Energy Data Book (2014); including Alaska and Hawaii. Total generaton from all sources in 2013 was 4100 Twh.

2 As updated in this report; excluding Alaska and Hawaii. Estimates may differ from prior assessments including Lopez et al. (2012) due to differences in the classification of resources (e.g., in some cases hydropower upgrades are not considered as new technical potential), advancements in technology (e.g., the availability of higher productivity wind turbines), or other factors.

3 Does not include Alaska and Hawaii; in addition to existing generation.

4 Does not include Alaska and Hawaii; in addition to existing generation. All Group 3 sensitivity cases assume 100\% Capacity Value; all Group 3 cases for Wind and UPV apply declining value with "flat"extension beyond $40 \%$ and $100 \%$ regional limits unless noted. As a consequence, wind generation potential exceeds $40 \%$ of 2013 total generation in some regions for scenarios marked with * and may be overstated. Declining value is not applied to DPV, Hydropower,

5 Applies declining value with decreasing value beyond $40 \%$ and regional limits

6 Not all cases run for DPV, hydropower, geothermal, and biopower; gray-shaded cells indicate that another case is used as a substitute.

Estimates of economic potential are highly sensitive to the specific assumptions made for both renewable supply and avoided cost, varying from $250-5,600 \mathrm{TWh}$ for the sensitivities to Primary Case 3, assuming full credit for the capacity value for renewable generation. On the low end of this range, annual generation potential is $600 \mathrm{TWh}$ or less when the value of avoided $\mathrm{CO}_{2}$ emissions is not included or when technology costs in 2010 are assumed. On the high end of the range, annual generation potential exceeds: 2,000 TWh when 2014 technology costs are assumed with PTC and ITC incentives available at that time, 2030 mid-case projection technology costs are assumed, or avoided health costs are included; 3,800 TWh when a 30-year project life or a construction date of 2020 is assumed; and 5,000 TWh when the value of avoided $\mathrm{CO}_{2}$ emissions is based on the $95^{\text {th }}$ percentile SCC with $3 \%$ discount rate.

The following general findings and trends are observed based on the above initial estimates:

- The specific formulation of the economic potential metric is extremely important. Across the three distinct formulations of the definition used in this analysis, economic potential 
estimates varied by almost 30 -fold. As with all metrics, care should be applied in definition and supporting details to avoid misleading conclusions.

- Estimates of economic potential are highly sensitive to the specific assumptions used related to both renewable generation supply and avoided cost. The capacity value of renewable generation, external costs and associated discount rates, and the declining value of variable generation with increased penetration have a major impact on estimates. The reference year for project construction, renewable technology costs, and the method and assumptions associated with the avoided cost of generation are other variables that have a significant effect on estimates.

- Economic potential appears in all states for at least one of the renewable generation technologies assessed, depending on the specific formulation of economic potential considered.

- Technology costs are a significant driver for economic potential, as seen in the sensitivity cases in Primary Case 3. Annual generation potential, assuming full credit for the capacity value for renewable generation, is the following for the corresponding assumed costs (highest to lowest costs): 250 TWh (2010), 990 TWh (2014), 2,000 TWh (2020 mid), and 3,500 TWh (2030 mid). Cost reductions already realized for renewable generation technologies between 2010 and 2014, particularly for wind and solar PV technologies, increase aggregate potential under this formulation by nearly $300 \%$.

- Despite recent growth, total renewable energy deployed overall remains small compared to the total technical potential, except for the relatively developed technologies of hydropower, geothermal, and biopower. For wind and distributed solar photovoltaics (DPV), a small amount of technical potential has been developed, and economic potential is significantly more than what has been deployed to date. For utility-scale photovoltaics UPV, technical potential is extremely large (greater than all other renewables together), and deployed and economic potential are small in comparison.

- The net value supply curves of wind and solar PV (both UPV and DPV) are characterized by extensive flat (low slope) sections at higher levels of generation. Changes in assumptions that drive renewable generation costs significantly lower (e.g., achievement of technology improvement) or avoided costs significantly higher (e.g., lower discount rates applied in the determination of the value of avoided $\mathrm{CO}_{2}$ emissions) tend to shift the net value curve higher, and into positive territory in the flat sections of the curves. In these instances, estimates of potential may be sensitive to small changes in assumptions. 


\section{Next Steps and Future Work}

The spreadsheet-based model used to conduct this analysis is under active development and is expected to be refined further. It may be updated to reflect improved understanding of any of the various factors affecting economic potential. In particular, the use of wholesale market price data as a basis for a geospatial representation of avoided costs is an emerging area of analysis.

The following method improvement opportunities have been identified:

- Consider the impact of changes in technical potential resulting from technology innovation (e.g., as a result of taller wind turbine towers).

- Further evolve and apply consistently among the centralized technologies the calculation of technical potential and intra-regional transmission cost for centralized technologies.

- Extend the method to consider electricity export situations and associated estimated interregional transmission costs.

- Further evolve the declining value method by considering sensitivities for the energy value component with natural gas prices, considering alternate extrapolations beyond the penetration levels modeled in California, and incorporating any new modeling results from other regions of the country.

- Extend consideration of declining value to technologies beyond Wind and UPV, including allowing capacity credit values to vary with penetration levels.

- Represent the potential impact of mitigation options that may reduce the declining value of high levels of variable generation.

The following improvement opportunities in underlying data have also been identified:

- Develop improved proxies for marginal costs/market prices (particularly in Pacific Northwest) for the Market Price (MP) avoided cost method.

- Consider the temporal production profile of each generation technology, and similarly, the market prices captured by production.

- Use actual high-resolution generation data to account for wind and UPV existing generation (currently applied at the state level).

- Represent other renewable technologies, including concentrating solar power (CSP) and offshore wind.

- Complete, up-to-date coverage of residential and commercial utility retail rates applicable to each building type.

- Move beyond current discrete resource classes to a more continuous representation of resource supply.

Finally, the following opportunities for additional scenario analysis have also been identified:

- Refine financing assumptions and explore the effect of different financing models on economic potential. 
- Assess appropriate sensitivities on the other two Primary Cases to confirm the effects seen in the cases assessed for Primary Case 3.

- Compare results to other studies of market potential (such as with the ReEDS model) under parallel scenarios. 


\section{References}

Argonne National Laboratory. (2014). "Greenhouse Gases, Regulated Emissions, and Energy Use in Transportation Model (GREET).” Accessed May 2015: https:/greet.es.anl.gov/.

Black \& Veatch. (2012). Cost and Performance Data for Power Generation Technologies. Report prepared for the National Renewable Energy Laboratory. Accessed May 2015: http://bv.com/docs/reports-studies/nrel-cost-report.pdf.

Bolinger, M. (2014). An Analysis of the Costs, Benefits, and Implications of Different Approaches to Capturing the Value of Renewable Energy Tax Incentives. Berkeley, CA: Lawrence Berkeley National Laboratory.

Denholm, P.; Margolis, R. (2008). Supply Curves for Rooftop Solar PV-Generated Electricity for the United States. NREL/TP-6A0-44073. Golden, CO: National Renewable Energy Laboratory.

Denholm, P.; Margolis, R.; Ong, S.; Roberts, B. (2009). Break-Even Cost for Residential Photovoltaics in the United States: Key Drivers and Sensitivities. NREL/TP-6A20-46909. Golden, CO: NREL. Accessed May 2015: http://www.nrel.gov/docs/fy10osti/46909.pdf.

Energy and Environmental Economics (E3). (2014). Capital Cost Review of Power Generation Technologies: Recommendations for WECC's 10- and 20-Year Studies. San Francisco, CA. Accessed June 2015:

https://www.wecc.biz/Reliability/2014_TEPPC_Generation_CapCost_Report_E3.pdf

U.S. Department of Energy (DOE). (2012). Sunshot Vision Study. DOE/GO-102012-3037.

Washington, D.C.: DOE. Accessed June 2015:

http://energy.gov/sites/prod/files/2014/01/f7/47927.pdf

DOE. (2013). 2012 Wind Technologies Market Report. DOE/GO-102013-3948. Washington, D.C.: DOE. Accessed May 2015: http://emp.lbl.gov/sites/all/files/lbnl-6356e.pdf.

DOE. (2015a). Wind Vision: A New Era for Wind Power in the United States Report. DOE/GO102015-4557. Washington, D.C.: DOE. Accessed May 2015:

http://www.energy.gov/sites/prod/files/WindVision Report final.pdf

DOE. (2015b). Enabling Wind Power Nationwide. DOE/EE-1218 . Washington, D.C.: DOE. Accessed June 2015:

http://www.energy.gov/sites/prod/files/2015/05/f22/Enabling\%20Wind\%20Power\%20Nationwid e_18MAY2015_FINAL.pdf

U.S. Energy Information Administration (EIA). (2015). EIA Annual Energy Outlook 2015.

Washington, D.C.: EIA. Accessed July 2015:

http://www.eia.gov/forecasts/aeo/pdf/0383(2015).pdf

EIA. (2014a). EIA Annual Energy Outlook 2014. Washington, D.C.: EIA. Accessed May 2015: http://www.eia.gov/forecasts/aeo/pdf/0383(2014).pdf. 
EIA. (2014b). Assumptions to the Annual Energy Outlook. Washington, D.C.: EIA. Accessed May 2015: http:/www.eia.gov/forecasts/aeo/assumptions/pdf/electricity.pdf.

EIA. (2014c). "U.S. Crude Oil and Natural Gas Proved Reserves.” Washington, D.C.: EIA. Accessed April 2015: http:/www.eia.gov/naturalgas/crudeoilreserves/.

EIA. (2013a). "Levelized Cost of Electricity and Levelized Avoided Cost of Electricity Methodology Supplement"

EIA. (2013b). "Assessing the Economic Value of New Utility-Scale Renewable Generation Projects" Presentation to EIA Energy Conference, June 17, 2013.

Environmental Protection Agency (EPA). (2013). "The Social Cost of Carbon." Washington, D.C.: EPA. Accessed March 2015:

http://www.epa.gov/climatechange/EPAactivities/economics/scc.html.

EPA. (2014). Regulatory Impact Analysis for the Proposed Carbon Pollution Guidelines for Existing Power Plants and Emission Standards for Modified and Reconstructed Power Plants. EPA-542/R-14-002. Washington, D.C.: EPA.

FERC. (2010). "ISO/RTO Performance Metrics”, Commission Staff Report AD10-5-000, Available at: http://www.ferc.gov/legal/staff-reports/10-21-10-rto-metrics.pdf (Accessed 05/29/2015).

Hadjerioua, B.Y; Wei, Y.; Kao, S-C. (2012). "An Assessment Of Energy Potential At NonPowered Dams In The United States.” Washington, D.C.: Wind and Water Power Program, DOE. Accessed March 2015:

http://nhaap.ornl.gov/sites/default/files/NHAAP_NPD_FY11_Final_Report.pdf.

Interagency Working Group (IWG) on Social Cost of Carbon, United States Government. (2013). Technical Support Document: Technical Update of the Social Cost of Carbon for Regulatory Impact Analysis Under Executive Order 12866. Accessed May 2015:

http://www.whitehouse.gov/sites/default/files/omb/inforeg/social cost of carbon for ria 2013 update.pdf.

ISO New England. (2015). "Locational Marginal Pricing (FAQ)" Available at: http://www.isone.com/participate/support/faq/lmp (Accessed 05/29/2015).

Kao, S.-C.; McManamay, R.A.; Stewart, K.M.; Samu, N.M.; Hadjerioua, B.Y.; DeNeale, S.T.; Yeasmin, D.; Pasha, M.F.K.; Oubeidillah, A.A.; Smith, B.T. (2014). New Stream-Reach Development: A Comprehensive Assessment Of Hydropower Energy Potential In The United States. Accessed March 2015:

http://nhaap.ornl.gov/sites/default/files/ORNL_NSD_FY14_Final_Report.pdf.

Lopez, A.; Roberts, B.; Heimiller, D.; Blair, N.; Porro, G. (2012). U.S. Renewable Energy Technical Potentials: A GIS-Based Analysis. NREL/TP-6A20-51946. Golden, CO: NREL. Accessed May 2015: http://www.nrel.gov/docs/fy12osti/51946.pdf. 
Mills, A.; Wiser, R. (2012). Changes in the Economic Value of Variable Generation at High Penetration Levels: A Pilot Case. Berkeley, CA: Lawrence Berkeley National Laboratory. Accessed May 2015: http://emp.lbl.gov/sites/all/files/lbnl-5445e.pdf.

Milligan, M.; Porter, K. (2008). Determining the Capacity Value of Wind: An Updated Survey of Methods and Implementation. Golden, CO: NREL. Accessed July 2014:

http://www.nrel.gov/docs/fy08osti/43433.pdf

Namovicz, C. (2013). Assessing the Economic Value of New Utility-Scale Renewable Generation Projects. Washington, D.C.: EIA. Accessed May 2015:

http://www.eia.gov/conference/2013/pdf/presentations/namovicz.pdf.

National Renewable Energy Laboratory (NREL). (2015). Annual Technology Baseline and Standard Scenarios. Golden, CO: NREL. Accessed March 1, 2015:

http://www.nrel.gov/analysis/data tech_baseline.html.

NREL. (2012). Renewable Electricity Futures Study. Hand, M.M.; Baldwin, S.; DeMeo, E.; Reilly, J.M.; Mai, T.; Arent, D.; Porro, G.; Meshek, M.; Sandor, D. eds. 4 vols. NREL/TP-6A2052409. Golden, CO: National Renewable Energy Laboratory.

http://www.nrel.gov/analysis/re futures/.

Ong, S.; Campbell, C.; Denholm, P.; Margolis, R.; Heath, G. (2013). Land-Use Requirements for Solar Power Plants in the United States. Golden, CO: NREL. Accessed July, 2015: http://www.nrel.gov/docs/fy13osti/56290.pdf

PJM. (2015). “Day-Ahead Energy Market.” Audubon, PA: PJM. Accessed March 2015: http://www.pjm.com/markets-and-operations/energy/day-ahead.aspx.

Short, W.; Packey, D.J.; Holt, T. (1995). A Manual for the Economic Evaluation of Energy Efficiency and Renewable Energy Technologies. NREL/TP-462-5173. Golden, CO: NREL. Accessed May 2015: http://www.nrel.gov/docs/legosti/old/5173.pdf.

Short, W.; Sullivan, P.; Mai, T.; Mowers, M.; Uriarte, C.; Blair, N.; Heimiller, D.; Martinez, A. (2011). Regional Energy Deployment System (ReEDS). NREL/TP-6A20-46534. Golden, CO: NREL. Accessed May 2015: http://www.nrel.gov/analysis/reeds/pdfs/reeds documentation.pdf.

Sigrin, B.; Sullivan, P.; Ibanez, E.; Margolis, R. (2014) Representation of the Solar Capacity Value in the ReEDS Capacity Expansion Model. Golden, CO: NREL. Accessed July 2015: http://www.nrel.gov/docs/fy14osti/62015.pdf

SPE International (SPE). (2007). Petroleum Resources Management System. Richardson, TX: SPE. Accessed March 2015:

http://www.spe.org/industry/docs/Petroleum_Resources_Management_System_2007.pdf.

“Transparent Cost Database." (undated).

Ventyx (2015). Velocity Suite Database. Atlanta, GA: Ventyx/ABB. Accessed December 2014. 
Wiser, R. (2014). Presentation at DOE WIND Exchange Summit, May 5, 2014.

Wiser, R.; Lantz, E.; Bolinger, M.; Hand, M. (2012). "Recent Developments in the Levelized Cost of Energy from U.S. Wind Power Projects.” Berkeley, CA: Lawrence Berkeley National Laboratory. Accessed April 2015: http://emp.lbl.gov/sites/all/files/wind-energy-costs-22012 0.pdf. 


\section{Appendix A. Updated Technical Potential for Assessed Technologies}

This appendix presents state-level results of a spatial analysis calculating renewable energy technical potential, reporting available land area (square kilometers), installed capacity (gigawatts), and electric generation (gigawatt-hours) for the following renewable electricity generation technologies: land-based wind, UPV, DPV, hydropower, geothermal (hydrothermal resources only), and biopower. Each technology's system-specific power density (or equivalent), capacity factor, and land-use constraints were identified using published research, subject matter experts, and analysis by the National Renewable Energy Laboratory (NREL). System performance estimates rely heavily on NREL's System Advisor Model (SAM) ${ }^{31}$ and Regional Energy Deployment System (ReEDS), ${ }^{32}$ a multiregional, multi-time period, geographic information system (GIS) and linear programming model.

These results are an updated version of technical potential estimates first presented in Lopez et al. (2012), which applied unifying assumptions and methods to generate comparable estimates across technologies, where possible, to enable cross-technology comparison. A number of changes to the technical potential estimates have occurred since the publication of Lopez et al. (2012), reflecting changes in the underlying resource data, changes in technology characteristics, and improved information from industry on renewable energy development considerations. For some technologies, only portions of the potential described in the earlier report are used, based on the focus of this current analysis on electricity production. Specific changes are noted below.

As a technical potential, rather than economic or market potential, these estimates do not consider availability of transmission infrastructure, costs, reliability or time-of-dispatch, current or future electricity loads, or relevant policies. Further, as this analysis does not allocate land for use by a particular technology, the same land area may be the basis for estimates of multiple technologies (i.e., non-excluded land is assumed to be available to support development of more than one technology). As in the 2012 analysis, while the majority of the exclusions applied for this updated technical potential assessment focus on assessing technical potential, we include some economic exclusion criteria in this step of the process based on current commercial configuration standards to provide a more reasonable and conservative estimation of renewable resource technical potential.

\section{Land-Based Wind}

A number of changes to the underlying wind resource technical potential have occurred since 2012, driven by the detailed resource analysis developed for the 2015 WindVision analysis (DOE 2015a):

- New wind resource data has been compiled and re-categorized (TRG definitions) in DOE (2015a). The land-based high-resolution wind resource data annual gross capacity factor was re-computed using modern wind turbine technology power curves, chosen to best fit a site based on annual average wind speed and hourly Typical Meteorological Year (TMY) profiles. This approach allows the impact of low wind speed turbine technology to be

\footnotetext{
${ }^{31}$ For more information, see http://sam.nrel.gov/.

${ }^{32}$ For more information, see http:/www.nrel.gov/analysis/reeds/.
} 
reflected in the wind resource data. However, the current TRG definitions do not include windy areas that may have significant potential with changes in wind turbine technology that can utilize lower wind speed resources or extend to higher hub heights.

- Installation density has changed to reflect current industry practices-from $5 \mathrm{MW} / \mathrm{sq}$. $\mathrm{km}$ in the 2012 analysis to $3 \mathrm{MW} / \mathrm{sq}$. $\mathrm{km}$ in DOE (2015a).

- The types of exclusions considered in DOE (2015a) are unchanged, but source data was updated to exclusion data reflect the impact of higher resolution land cover and population data sets, better capturing urbanized areas in particular.

- As in the 2012 analysis, sites with resource below a techno-economic threshold based on resource intensity and regional capital costs are also excluded from the updated analysis. These excluded sites include those that might have technical potential as a result of ongoing or new innovations, as highlighted in the recent DOE report Enabling Wind Power Nationwide (DOE 2015b).

- The total land-based wind resource potential estimate has reduced from 31,402 TWh in Lopez et al. (2012) to 22,195 TWh.

\section{Utility-Scale Photovoltaics (UPV)}

Several changes to the underlying resource data and technical potential analysis assumptions have occurred since the 2012 analysis, reflecting ongoing solar resource analysis at NREL.

- The capacity factors used in Lopez et al. (2012) were applied at the state level, and ranged in the 48 contiguous states from 17.2\% (West Virginia) to 26.3\% (Arizona and New Mexico). The updated analysis uses SAM-modeled capacity factor based on $0.5 \mathrm{kWh} / \mathrm{m}^{2} /$ day annual average solar resource intervals, with values ranging from $14 \%\left(3-3.5 \mathrm{kWh} / \mathrm{m}^{2} /\right.$ day) to $29 \%$ $\left(7-7.5 \mathrm{kWh} / \mathrm{m}^{2} /\right.$ day). This change better reflects the geographic variability of the resource intensity within the state.

- The slope exclusion was reduced to a 5\% slope threshold based on feedback received on standard industry practice after publication of the 2012 study.

- The installation density changed from $48 \mathrm{MW} / \mathrm{km}^{2}$ to $39 \mathrm{MW} / \mathrm{km}^{2}$, based on analysis reported in Ong et al. (2013).

\section{Distributed-Scale Photovoltaics (DPV)}

DPV includes residential and commercial installations of photovoltaic panels. Several changes to the underlying resource data and technical potential analysis assumptions have occurred since the 2012 analysis of DPV technical potential, which was originally reported by Denholm and Margolis (2008).

- A LIDAR-based analysis of residential rooftop suitability found that on average $80 \%$ of single-family detached home rooftops are suitable for DPV installations (defined as having at least 10 square meters of available roofspace). This is much higher than the Denholm and Margolis values of $22 \%$ in cool climates and $27 \%$ in warm climates.

- The earlier approach estimated total rooftop area and applied an installation density of 110 $\mathrm{W} / \mathrm{m} 2$ to flat roofs, and $135 \mathrm{~W} / \mathrm{m} 2$ to tilted roofs (commercial and residential). The current 
approach identified typical DPV installation sizes for residential and different types of commercial buildings based on technically -available roof space, and uses estimates of the number of buildings in each category to calculate the technical potential. The number of buildings were taken from the U.S. Census Bureau's 2011 American Community Housing Survey for residential, and EIA's Commercial Building Energy Consumption Survey (CBECS) for commercial.

- Solar panel efficiency was estimated at $13.5 \%$ in the earlier study, and $15 \%$ in the current analysis.

- The total combined DPV resource potential estimate (residential and commercial) has grown from $818 \mathrm{TWh}$ in Lopez et al. (2012) to 1,561 TWh.

\section{Hydropower}

Hydropower resource data has been updated by Oak Ridge National Laboratory since Lopez et al. (2012). This data represents the potential of generating electricity at existing non-power dams and from new stream reaches. The combined hydropower potential estimate has increased slightly from 259 TWh in the 2012 analysis to $278 \mathrm{TWh}$.

\section{Geothermal}

This study utilizes the Lopez et al. (2012) data for identified and undiscovered hydrothermal power systems, but does not include enhanced Geothermal Systems (EGS) potential. The hydrothermal potential estimate has reduced slightly from $272 \mathrm{TWh}$ to $234 \mathrm{TWh}$.

\section{Biopower}

This study utilizes data developed for the ReEDS model representing estimates of biopower residues for electricity production, and does not include the potential from gaseous biomass residues such as animal waste, municipal solid waste or landfill gas. The data used in this updated analysis also incorporate updated modeled results from the Billion Ton Study Update (2011). The solid biopower potential estimate has increased slightly from $399 \mathrm{TWh}$ to $445 \mathrm{TWh}$. 
Tables A-1 through A-7 provide state-level estimates of available land area (square kilometers), installed capacity (gigawatts), and annual electric generation (terawatt-hours/year) for each technology. Table A-8 shows aggregated totals for the continental United States for each technology.

Table A-1. Land-based Wind Technical Potential

\begin{tabular}{|c|c|c|c|}
\hline State & Area $\left(\mathrm{km}^{2}\right)$ & $\begin{array}{l}\text { Capacity } \\
\text { (GW) }\end{array}$ & $\begin{array}{c}\text { Generation } \\
\text { (TWh/yr) }\end{array}$ \\
\hline Alabama & 388.2 & 1.2 & 3 \\
\hline Arizona & $12,286.0$ & 36.9 & 106 \\
\hline Arkansas & $14,105.1$ & 42.3 & 123 \\
\hline California & $10,924.6$ & 32.8 & 102 \\
\hline Colorado & $75,476.5$ & 226.4 & 784 \\
\hline Connecticut & 63.4 & 0.2 & 1 \\
\hline Delaware & 1.9 & 0.0 & $<1$ \\
\hline Florida & 0.9 & 0.0 & $<1$ \\
\hline Georgia & 129.9 & 0.4 & 1 \\
\hline Idaho & $15,542.9$ & 46.6 & 135 \\
\hline Illinois & $48,892.6$ & 146.7 & 480 \\
\hline Indiana & $28,331.4$ & 85.0 & 274 \\
\hline lowa & $92,010.3$ & 276.0 & 1,045 \\
\hline Kansas & $157,890.4$ & 473.7 & 1,877 \\
\hline Kentucky & $1,061.6$ & 3.2 & 9 \\
\hline Louisiana & $1,698.7$ & 5.1 & 14 \\
\hline Maine & $7,219.9$ & 21.7 & 65 \\
\hline Maryland & 298.4 & 0.9 & 3 \\
\hline Massachusetts & 445.5 & 1.3 & 4 \\
\hline Michigan & $16,810.0$ & 50.4 & 151 \\
\hline Minnesota & $56,789.0$ & 170.4 & 630 \\
\hline Mississippi & 218.0 & 0.7 & 2 \\
\hline Missouri & $67,471.4$ & 202.4 & 645 \\
\hline Montana & $192,032.7$ & 576.1 & 2,063 \\
\hline
\end{tabular}

\begin{tabular}{|l|r|r|r|}
\hline \multicolumn{1}{|c|}{ State } & Area $\left(\mathbf{k m}^{2}\right)$ & $\begin{array}{c}\text { Capacity } \\
\text { (GW) }\end{array}$ & $\begin{array}{c}\text { Generation } \\
\text { (TWh/yr) }\end{array}$ \\
\hline Nebraska & $153,284.2$ & 459.9 & 1,822 \\
\hline Nevada & $8,171.5$ & 24.5 & 72 \\
\hline New Hampshire & $1,094.7$ & 3.3 & 10 \\
\hline New Jersey & 15.3 & 0.0 & $<1$ \\
\hline New Mexico & $127,987.0$ & 384.0 & 1,313 \\
\hline New York & $11,739.2$ & 35.2 & 105 \\
\hline North Carolina & 304.7 & 0.9 & 3 \\
\hline North Dakota & $98,047.0$ & 294.1 & 1,164 \\
\hline Ohio & $19,048.4$ & 57.1 & 165 \\
\hline Oklahoma & $106,287.5$ & 318.9 & 1,153 \\
\hline Oregon & $14,913.9$ & 44.7 & 134 \\
\hline Pennsylvania & $4,000.2$ & 12.0 & 35 \\
\hline Rhode Island & 18.3 & 0.1 & $<1$ \\
\hline South Carolina & 16.5 & 0.0 & $<1$ \\
\hline South Dakota & $137,173.8$ & 411.5 & 1,609 \\
\hline Tennessee & 760.8 & 2.3 & 7 \\
\hline Texas & $404,212.9$ & $1,212.6$ & 4,353 \\
\hline Utah & $10,352.5$ & 31.1 & 90 \\
\hline Vermont & $1,483.8$ & 4.5 & 14 \\
\hline Virginia & 570.2 & 1.7 & 5 \\
\hline Washington & $10,414.6$ & 31.2 & 93 \\
\hline West Virginia & $1,070.9$ & 3.2 & 10 \\
\hline Wisconsin & $26,336.5$ & 79.0 & 240 \\
\hline Wyoming & $118,864.6$ & 356.6 & $\mathbf{2 2 , 1 9 5}$ \\
\hline L 48 Total & $\mathbf{2 , 0 5 6 , 2 5 8}$ & $\mathbf{6 , 1 6 9}$ & \\
\hline
\end{tabular}


Table A-2. Utility-scale Photovoltaics (UPV) Technical Potential

\begin{tabular}{|c|c|c|c|}
\hline State & Area $\left(\mathrm{km}^{2}\right)$ & $\begin{array}{c}\text { Capacity } \\
\text { (GW) }\end{array}$ & $\begin{array}{c}\text { Generation } \\
\text { (TWh/yr) }\end{array}$ \\
\hline Alabama & $77,159.2$ & $3,009.2$ & 5,500 \\
\hline Arizona & $147,621.0$ & $5,757.2$ & 13,580 \\
\hline Arkansas & $73,842.2$ & $2,879.8$ & 5,198 \\
\hline California & $107,201.0$ & $4,180.8$ & 9,192 \\
\hline Colorado & $121,119.6$ & $4,723.7$ & 9,998 \\
\hline Connecticut & $1,686.7$ & 65.8 & 111 \\
\hline Delaware & $3,643.8$ & 142.1 & 242 \\
\hline Florida & $63,804.7$ & $2,488.4$ & 4,697 \\
\hline Georgia & $91,755.5$ & $3,578.5$ & 6,615 \\
\hline Idaho & $56,640.2$ & $2,209.0$ & 4,119 \\
\hline Illinois & $116,009.3$ & $4,524.4$ & 7,641 \\
\hline Indiana & $71,468.3$ & $2,787.3$ & 4,612 \\
\hline lowa & $114,201.4$ & $4,453.9$ & 7,532 \\
\hline Kansas & $181,121.0$ & $7,063.7$ & 13,637 \\
\hline Kentucky & $42,240.8$ & $1,647.4$ & 2,806 \\
\hline Louisiana & $59,837.4$ & $2,333.7$ & 4,315 \\
\hline Maine & $31,889.5$ & $1,243.7$ & 2,005 \\
\hline Maryland & $11,964.7$ & 466.6 & 796 \\
\hline Massachusetts & $3,094.3$ & 120.7 & 202 \\
\hline Michigan & $87,248.5$ & $3,402.7$ & 5,395 \\
\hline Minnesota & $150,607.3$ & $5,873.7$ & 9,565 \\
\hline Mississippi & $84,969.8$ & $3,313.8$ & 6,107 \\
\hline Missouri & $109,469.6$ & $4,269.3$ & 7,287 \\
\hline Montana & $152,377.9$ & $5,942.7$ & 10,174 \\
\hline
\end{tabular}

\begin{tabular}{|l|r|r|r|}
\hline \multicolumn{1}{|c|}{ State } & Area $\left(\mathbf{k m}^{2}\right)$ & \multicolumn{1}{c|}{$\begin{array}{c}\text { Capacity } \\
\text { (GW) }\end{array}$} & \multicolumn{1}{c|}{$\begin{array}{c}\text { Generation } \\
\text { (TWh/yr) }\end{array}$} \\
\hline Nebraska & $146,853.6$ & $5,727.3$ & 10,614 \\
\hline Nevada & $111,478.9$ & $4,347.7$ & 9,494 \\
\hline New Hampshire & $2,820.9$ & 110.0 & 183 \\
\hline New Jersey & $6,597.6$ & 257.3 & 438 \\
\hline New Mexico & $195,631.9$ & $7,629.6$ & 17,561 \\
\hline New York & $34,618.3$ & $1,350.1$ & 2,147 \\
\hline North Carolina & $67,168.0$ & $2,619.6$ & 4,851 \\
\hline North Dakota & $138,069.5$ & $5,384.7$ & 8,854 \\
\hline Ohio & $60,306.5$ & $2,352.0$ & 3,796 \\
\hline Oklahoma & $136,001.3$ & $5,304.1$ & 10,280 \\
\hline Oregon & $58,626.1$ & $2,286.4$ & 4,294 \\
\hline Pennsylvania & $21,579.9$ & 841.6 & 1,367 \\
\hline Rhode Island & 715.9 & 27.9 & 48 \\
\hline South Carolina & $46,545.4$ & $1,815.3$ & 3,364 \\
\hline South Dakota & $145,981.8$ & $5,693.3$ & 10,001 \\
\hline Tennessee & $46,730.4$ & $1,822.5$ & 3,107 \\
\hline Texas & $523,444.7$ & $20,414.3$ & 41,309 \\
\hline Utah & $71,792.3$ & $2,799.9$ & 5,956 \\
\hline Vermont & $1,915.1$ & 74.7 & 118 \\
\hline Virginia & $43,330.3$ & $1,689.9$ & 3,022 \\
\hline Washington & $29,296.1$ & $1,142.5$ & 2,035 \\
\hline West Virginia & $2,371.4$ & 92.5 & 156 \\
\hline Wisconsin & $88,014.1$ & $3,432.6$ & 5,491 \\
\hline Wyoming & $104,242.2$ & $4,065.4$ & 7,663 \\
\hline L 48 Total & $\mathbf{4 , 0 4 5 , 1 0 6}$ & $\mathbf{1 5 7 , 7 5 9}$ & $\mathbf{2 9 7 , 4 7 5}$ \\
\hline
\end{tabular}


Table A-3. Distributed-scale Residential Photovoltaics (DPV - Residential) Technical Potential

\begin{tabular}{|l|r|r|}
\hline \multicolumn{1}{|c|}{ State } & $\begin{array}{c}\text { Capacity } \\
\text { (GW) }\end{array}$ & $\begin{array}{c}\text { Generation } \\
\text { (TWh/yr) }\end{array}$ \\
\hline Alabama & 9.4 & 13.2 \\
\hline Arizona & 11.3 & 20.0 \\
\hline Arkansas & 5.9 & 8.3 \\
\hline California & 50.7 & 82.8 \\
\hline Colorado & 8.8 & 14.3 \\
\hline Connecticut & 5.6 & 7.0 \\
\hline Delaware & 1.5 & 2.0 \\
\hline District of Columbia & 0.2 & 0.3 \\
\hline Florida & 31.0 & 44.9 \\
\hline Georgia & 17.2 & 24.5 \\
\hline Idaho & 3.1 & 4.4 \\
\hline Illinois & 19.8 & 26.0 \\
\hline Indiana & 13.0 & 16.8 \\
\hline lowa & 6.3 & 8.1 \\
\hline Kansas & 5.7 & 8.5 \\
\hline Kentucky & 8.3 & 10.8 \\
\hline Louisiana & 8.1 & 11.4 \\
\hline Maine & 3.2 & 4.1 \\
\hline Maryland & 7.8 & 10.6 \\
\hline Massachusetts & 10.1 & 11.9 \\
\hline Michigan & 5.7 & 25.9 \\
\hline Minnesota & & 12.7 \\
\hline Mississippi & 2.1 & 16.8 \\
\hline Missouri & 12.9 \\
\hline Montana & & \\
\hline
\end{tabular}

\begin{tabular}{|c|c|c|}
\hline State & $\begin{array}{c}\text { Capacity } \\
\text { (GW) }\end{array}$ & $\begin{array}{c}\text { Generation } \\
\text { (TWh/yr) }\end{array}$ \\
\hline Nebraska & 3.7 & 5.4 \\
\hline Nevada & 4.4 & 7.4 \\
\hline New Hampshire & 2.5 & 3.2 \\
\hline New Jersey & 12.2 & 16.1 \\
\hline New Mexico & 3.7 & 6.5 \\
\hline New York & 21.8 & 27.6 \\
\hline North Carolina & 17.9 & 25.5 \\
\hline North Dakota & 1.2 & 1.6 \\
\hline Ohio & 22.4 & 28.0 \\
\hline Oklahoma & 7.8 & 11.7 \\
\hline Oregon & 6.8 & 9.1 \\
\hline Pennsylvania & 20.2 & 25.0 \\
\hline Rhode Island & 1.6 & 2.1 \\
\hline South Carolina & 8.4 & 12.2 \\
\hline South Dakota & 1.6 & 2.2 \\
\hline Tennessee & 12.3 & 16.8 \\
\hline Texas & 41.4 & 62.3 \\
\hline Utah & 4.3 & 7.0 \\
\hline Vermont & 1.4 & 1.6 \\
\hline Virginia & 13.4 & 18.6 \\
\hline Washington & 11.6 & 14.6 \\
\hline West Virginia & 4.0 & 5.1 \\
\hline Wisconsin & 11.1 & 14.1 \\
\hline Wyoming & 1.1 & 1.7 \\
\hline L 48 Total & 514 & 722 \\
\hline
\end{tabular}


Table A-4. Distributed-scale Commercial Photovoltaics (DPV - Commercial) Technical Potential

\begin{tabular}{|l|r|r|}
\hline \multicolumn{1}{|c|}{ State } & $\begin{array}{r}\text { Capacity } \\
\text { (GW) }\end{array}$ & $\begin{array}{c}\text { Generation } \\
\text { (TWh/yr) }\end{array}$ \\
\hline Alabama & 10.7 & 14.8 \\
\hline Arizona & 6.5 & 9.2 \\
\hline Arkansas & 9.2 & 16.3 \\
\hline California & 52.5 & 85.7 \\
\hline Colorado & 10.2 & 16.5 \\
\hline Connecticut & 4.7 & 5.9 \\
\hline Delaware & 1.8 & 2.5 \\
\hline District of Columbia & 0.9 & 1.3 \\
\hline Florida & 41.3 & 59.9 \\
\hline Georgia & 19.5 & 27.8 \\
\hline Idaho & 3.1 & 4.5 \\
\hline Illinois & 19.6 & 25.7 \\
\hline Indiana & 15.6 & 20.1 \\
\hline lowa & 11.7 & 15.1 \\
\hline Kansas & 11.9 & 17.6 \\
\hline Kentucky & 8.9 & 11.6 \\
\hline Louisiana & 10.6 & 14.9 \\
\hline Maine & 2.8 & 3.6 \\
\hline Maryland & 12.8 & 11.9 \\
\hline Massachusetts & 23.6 & 15.5 \\
\hline Michigan & 14.8 & 29.2 \\
\hline Minnesota & 6.8 & 18.6 \\
\hline Mississippi & & 9.6 \\
\hline Missouri & 19.8 & \\
\hline Montana & 12.0 & 1.2 \\
\hline
\end{tabular}

\begin{tabular}{|c|c|c|}
\hline State & $\begin{array}{l}\text { Capacity } \\
\text { (GW) }\end{array}$ & $\begin{array}{c}\text { Generation } \\
\text { (TWh/yr) }\end{array}$ \\
\hline Nebraska & 7.8 & 11.4 \\
\hline Nevada & 4.7 & 7.9 \\
\hline New Hampshire & 3.3 & 4.2 \\
\hline New Jersey & 13.3 & 17.5 \\
\hline New Mexico & 4.2 & 7.4 \\
\hline New York & 28.2 & 35.7 \\
\hline North Carolina & 23.3 & 33.1 \\
\hline North Dakota & 3.3 & 4.4 \\
\hline Ohio & 27.7 & 34.6 \\
\hline Oklahoma & 10.2 & 15.3 \\
\hline Oregon & 6.9 & 9.2 \\
\hline Pennsylvania & 18.7 & 23.1 \\
\hline Rhode Island & 1.8 & 2.3 \\
\hline South Carolina & 12.2 & 17.7 \\
\hline South Dakota & 3.7 & 5.0 \\
\hline Tennessee & 13.2 & 18.0 \\
\hline Texas & 36.2 & 54.4 \\
\hline Utah & 3.5 & 5.7 \\
\hline Vermont & 0.4 & 0.5 \\
\hline Virginia & 15.0 & 20.8 \\
\hline Washington & 10.3 & 12.9 \\
\hline West Virginia & 4.3 & 5.6 \\
\hline Wisconsin & 15.5 & 19.7 \\
\hline Wyoming & 1.8 & 2.7 \\
\hline L 48 Total & 600 & 839 \\
\hline
\end{tabular}


Table A-5. Hydropower Technical Potential

\begin{tabular}{|c|c|c|}
\hline State & $\begin{array}{l}\text { Capacity } \\
\text { (GW) }\end{array}$ & $\begin{array}{c}\text { Generation } \\
\text { (TWh/yr) }\end{array}$ \\
\hline Alabama & 1.0 & 5.2 \\
\hline Arizona & 0.4 & 2.5 \\
\hline Arkansas & 1.8 & 9.4 \\
\hline California & 1.4 & 7.9 \\
\hline Colorado & 2.2 & 13.9 \\
\hline Connecticut & 0.1 & 0.7 \\
\hline Delaware & $<0.1$ & $<0.1$ \\
\hline Florida & 0.2 & 1.1 \\
\hline Georgia & 0.4 & 2.4 \\
\hline Idaho & 3.6 & 21.2 \\
\hline Illinois & 1.1 & 6.5 \\
\hline Indiana & 0.5 & 2.9 \\
\hline lowa & 1.1 & 6.3 \\
\hline Kansas & 2.4 & 14.8 \\
\hline Kentucky & 2.5 & 13.3 \\
\hline Louisiana & 1.1 & 5.2 \\
\hline Maine & 0.7 & 4.0 \\
\hline Maryland & 0.2 & 1.1 \\
\hline Massachusetts & 0.1 & 0.6 \\
\hline Michigan & 0.1 & 0.5 \\
\hline Minnesota & 0.3 & 2.0 \\
\hline Mississippi & 0.4 & 2.4 \\
\hline Missouri & 2.3 & 13.2 \\
\hline Montana & 2.8 & 17.0 \\
\hline
\end{tabular}

\begin{tabular}{|c|c|c|}
\hline State & $\begin{array}{l}\text { Capacity } \\
\text { (GW) }\end{array}$ & $\begin{array}{c}\text { Generation } \\
\text { (TWh/yr) }\end{array}$ \\
\hline Nebraska & 1.6 & 9.7 \\
\hline Nevada & 0.1 & 0.5 \\
\hline New Hampshire & 0.3 & 1.7 \\
\hline New Jersey & 0.1 & 0.5 \\
\hline New Mexico & 0.8 & 4.6 \\
\hline New York & 1.0 & 5.7 \\
\hline North Carolina & 0.6 & 3.3 \\
\hline North Dakota & 0.3 & 1.6 \\
\hline Ohio & 0.5 & 2.6 \\
\hline Oklahoma & 1.2 & 6.3 \\
\hline Oregon & 2.9 & 16.8 \\
\hline Pennsylvania & 2.4 & 13.0 \\
\hline Rhode Island & $<0.1$ & 0.1 \\
\hline South Carolina & 0.2 & 1.2 \\
\hline South Dakota & 0.1 & 0.4 \\
\hline Tennessee & 0.6 & 3.3 \\
\hline Texas & 1.5 & 7.4 \\
\hline Utah & 0.6 & 3.4 \\
\hline Vermont & 0.1 & 0.7 \\
\hline Virginia & 0.7 & 3.8 \\
\hline Washington & 3.4 & 20.6 \\
\hline West Virginia & 1.0 & 5.0 \\
\hline Wisconsin & 0.5 & 2.8 \\
\hline Wyoming & 1.6 & 9.3 \\
\hline L 48 Total & 49 & 278 \\
\hline
\end{tabular}


Table A-6. Geothermal (Hydrothermal) Technical Potential

\begin{tabular}{|l|r|r|}
\hline \multicolumn{1}{|c|}{ State } & $\begin{array}{c}\text { Capacity } \\
\text { (GW) }\end{array}$ & $\begin{array}{c}\text { Generation } \\
\text { (TWh/yr) }\end{array}$ \\
\hline Alabama & 0.0 & 0.0 \\
\hline Arizona & 1.1 & 8.0 \\
\hline Arkansas & 0.0 & 0.0 \\
\hline California & 14.8 & 110.3 \\
\hline Colorado & 1.1 & 8.4 \\
\hline Connecticut & 0.0 & 0.0 \\
\hline Delaware & 0.0 & 0.0 \\
\hline Florida & 0.0 & 0.0 \\
\hline Georgia & 0.0 & 0.0 \\
\hline Idaho & 2.1 & 15.4 \\
\hline Illinois & 0.0 & 0.0 \\
\hline Indiana & 0.0 & 0.0 \\
\hline lowa & 0.0 & 0.0 \\
\hline Kansas & 0.0 & 0.0 \\
\hline Kentucky & 0.0 & 0.0 \\
\hline Louisiana & 0.0 & 0.0 \\
\hline Maine & 0.0 & 0.0 \\
\hline Maryland & 0.0 & 0.0 \\
\hline Massachusetts & 0.0 & 0.0 \\
\hline Michigan & 0.0 & 0.0 \\
\hline Minnesota & 0.0 & 0.0 \\
\hline Mississippi & & 0.0 \\
\hline Missouri & 0.0 & 0.0 \\
\hline Montana & 0.0 & 0.0 \\
\hline
\end{tabular}

\begin{tabular}{|l|r|r|}
\hline \multicolumn{1}{|c|}{ State } & $\begin{array}{c}\text { Capacity } \\
\text { (GW) }\end{array}$ & $\begin{array}{c}\text { Generation } \\
\text { (TWh/yr) }\end{array}$ \\
\hline Nebraska & 0.0 & 0.0 \\
\hline Nevada & 5.5 & 41.1 \\
\hline New Hampshire & 0.0 & 0.0 \\
\hline New Jersey & 0.0 & 0.0 \\
\hline New Mexico & 1.6 & 12.1 \\
\hline New York & 0.0 & 0.0 \\
\hline North Carolina & 0.0 & 0.0 \\
\hline North Dakota & 0.0 & 0.0 \\
\hline Ohio & 0.0 & 0.0 \\
\hline Oklahoma & 0.0 & 0.0 \\
\hline Oregon & 2.4 & 17.6 \\
\hline Pennsylvania & 0.0 & 0.0 \\
\hline Rhode Island & 0.0 & 0.0 \\
\hline South Carolina & 0.0 & 0.0 \\
\hline South Dakota & 0.0 & 0.0 \\
\hline Tennessee & 0.0 & 0.0 \\
\hline Texas & 0.0 & 0.0 \\
\hline Utah & 1.5 & 11.5 \\
\hline Vermont & 0.0 & 0.0 \\
\hline Virginia & 0.0 & 0.0 \\
\hline Washington & 0.3 & 2.0 \\
\hline West Virginia & 0.0 & 0.0 \\
\hline Wisconsin & 31 & 0.0 \\
\hline Wyoming & 0.0 & 0.0 \\
\hline L 48 Total & 0.0 & 0.0 \\
\hline
\end{tabular}


Table A-7. Biopower Technical Potential

\begin{tabular}{|l|r|r|}
\hline \multicolumn{1}{|c|}{ State } & \multicolumn{1}{c|}{$\begin{array}{c}\text { Capacity } \\
\text { (GW) }\end{array}$} & $\begin{array}{c}\text { Generation } \\
\text { (TWh/yr) }\end{array}$ \\
\hline Alabama & 3.0 & 24.0 \\
\hline Arizona & 0.2 & 1.5 \\
\hline Arkansas & 2.2 & 17.5 \\
\hline California & 1.2 & 9.3 \\
\hline Colorado & 0.5 & 3.7 \\
\hline Connecticut & $<0.1$ & 0.1 \\
\hline Delaware & 0.1 & 0.5 \\
\hline Florida & 1.5 & 11.7 \\
\hline Georgia & 3.1 & 24.9 \\
\hline Idaho & 0.4 & 3.0 \\
\hline Illinois & 2.0 & 15.9 \\
\hline Indiana & 0.9 & 7.4 \\
\hline lowa & 3.3 & 26.0 \\
\hline Kansas & 1.6 & 12.9 \\
\hline Kentucky & 0.6 & 4.5 \\
\hline Louisiana & 2.1 & 17.1 \\
\hline Maine & 2.4 & 19.1 \\
\hline Maryland & 0.2 & 1.7 \\
\hline Massachusetts & 2.3 & 0.2 \\
\hline Michigan & 0.1 & 18.1 \\
\hline Minnesota & 0.6 & 27.4 \\
\hline Mississippi & & 18.1 \\
\hline Missouri & 2.3 & 5.2 \\
\hline Montana & 0.1 & 0.9 \\
\hline
\end{tabular}

\begin{tabular}{|c|c|c|}
\hline State & $\begin{array}{c}\text { Capacity } \\
\text { (GW) }\end{array}$ & $\begin{array}{c}\text { Generation } \\
\text { (TWh/yr) }\end{array}$ \\
\hline Nebraska & 2.2 & 17.8 \\
\hline Nevada & 0.0 & 0.0 \\
\hline New Hampshire & 0.3 & 2.1 \\
\hline New Jersey & $<0.1$ & 0.1 \\
\hline New Mexico & 0.2 & 1.4 \\
\hline New York & 0.7 & 5.4 \\
\hline North Carolina & 2.0 & 16.1 \\
\hline North Dakota & 0.6 & 4.7 \\
\hline Ohio & 1.2 & 9.4 \\
\hline Oklahoma & 0.4 & 3.2 \\
\hline Oregon & 0.8 & 6.4 \\
\hline Pennsylvania & 0.8 & 6.6 \\
\hline Rhode Island & 0.0 & 0.0 \\
\hline South Carolina & 1.6 & 13.0 \\
\hline South Dakota & 1.6 & 13.0 \\
\hline Tennessee & 1.0 & 7.6 \\
\hline Texas & 2.2 & 17.7 \\
\hline Utah & 0.2 & 1.2 \\
\hline Vermont & 0.2 & 1.8 \\
\hline Virginia & 1.3 & 10.3 \\
\hline Washington & 0.9 & 7.1 \\
\hline West Virginia & 0.5 & 3.9 \\
\hline Wisconsin & 2.6 & 20.5 \\
\hline Wyoming & $<0.1$ & 0.3 \\
\hline L 48 Total & 56 & 445 \\
\hline
\end{tabular}


Table A-8. Estimated Aggregated Technical Potential by Technology (Continental United States)

\begin{tabular}{|l|r|r|}
\hline \multicolumn{1}{|c|}{ Technology } & \multicolumn{1}{c|}{$\begin{array}{c}\text { Capacity } \\
(\mathrm{GW})^{1}\end{array}$} & $\begin{array}{c}\text { Generation } \\
\text { (TWh) }^{1}\end{array}$ \\
\hline Land-based Wind & 6,169 & 22,195 \\
\hline Utility-scale PV (UPV) & 157,759 & 297,475 \\
\hline Distributed-scale PV (DPV) - Residential & 514 & 722 \\
\hline Distributed-scale PV (DPV - Commercial & 600 & 839 \\
\hline Hydropower & 49 & 278 \\
\hline $\begin{array}{l}\text { Geothermal (Hydrothermal Resources } \\
\text { Only) }\end{array}$ & 31 & 234 \\
\hline Biopower & 56 & 445 \\
\hline
\end{tabular}

${ }^{1}$ Non-excluded land was assumed to be available to support development of more than one technology. 


\section{Appendix B. Renewable Generation Potential in the Context of Fossil Energy Resources}

\section{Fossil Energy Resource Definitions}

Analogous characterization of resources and assessment of availability is regularly used to describe fossil resources. Although specific usage may vary, available fossil energy is often discussed in terms of resource, proven reserves, and production. The following discussion employs an aggregated and simplified version of these definitions and considers how such ideas might be potentially applicable to renewable resources.

For fossil energy, resources refers to the total amount of energy in the earth's crust irrespective of whether it can be exploited. Resources may further be divided into recoverable resources and unrecoverable resources (SPE 2007) based on the current technological viability of developing the resource.

Reserves refer to the subset of resources that are or may be economic to produce. Proved reserves are, according to the U.S. Energy Information Administration (EIA) (EIA 2014c), "estimated volumes of hydrocarbon resources that analysis of geologic and engineering data demonstrates with reasonable certainty (assumes a probability of recovery of $90 \%$ or greater) are recoverable under existing economic and operating conditions. There are other sorts of reserves where the probability of recovery is less certain, probable reserves and possible reserves. Together, these quantities are called reserves. Reserves estimates change from year to year as new discoveries are made, existing fields are more thoroughly appraised, existing reserves are produced, and prices and technologies change" ( $\ 13$ ). A recent example of this is the increase in reserves of natural gas and oil in the United States with development of horizontal drilling and hydraulic fracturing that have made the previously unrecoverable resources recoverable.

Notably, reserves can increase or decrease due to technological, informational, or economic changes, even though the resource actually in the ground remains the same. For example, if extraction becomes cheaper, reserves may increase, as in recent years in unconventional U.S. oil and gas. If new information becomes available - for example, if a resource basin is more accurately mapped - reserves will be adjusted accordingly. And, if the price of the commodity to be extracted goes up or down, more or less resource may become economic, and therefore will be added to or subtracted from the reserves.

Production is the amount of fossil energy commodities produced from reserves that have been developed. It is defined over a time period, often monthly or annual. Because fossil resources are finite, production for fossil technologies depletes reserves and the resource over time, though historically more reserves have also been identified as others are produced.

\section{Analogies Between Fossil and Renewable Energy Resource Terms}

Part of the motivation of defining and estimating economic potential for renewable energy is to provide a partial analogy to these fossil energy concepts, summarized in Table B-1. Defining reserves for fossil energy has been a valuable way to assess the current state of availability, and the renewable economic potential metric is intended to serve a similar purpose. Because renewable potentials here are annual, and (unlike fossil resources and reserves) do not generally 
deplete the resource itself, it is inappropriate to quantitatively compare renewable and fossil potentials. This discussion is intended only to build an analogy that illustrates how potentials can be used to assess availability under different conditions.

For renewable energy, total resources refer to the amount of energy that could be captured from that source. For example, the total solar resource of an area is directly related to the total solar irradiance striking that land area, on average, over a year. This means that resources for fossil and renewable energies are broadly analogous terms. Renewable energy technical potential is analogous to fossil recoverable resources because it is the amount of resource that could be recovered after accounting for system performance (such as the efficiency of a solar panel) and land-use restrictions (such as excluding water, national parks, and developed areas), but not accounting for economics of production.

The metric developed in this report, economic potential, is partially analogous to fossil proved reserves, as it represents the amount of energy that could be available at a competitive price. Like fossil reserves, renewable economic potential reflects the current market prices of the commodity produced (in this case, electricity) and so can increase or decrease based on technological, informational, or market factors. For example, energy technology innovation may decrease the cost of future production, and thus increase economic potential or proved reserves.

One significant difference between renewable economic potential and fossil reserves is that fossil reserves represent total lifetime potential reported in primary energy units (e.g., quadrillion Btus, barrels of oil, or million cubic feet of natural gas) while renewables represent annual potential reported in electricity units (TWh per year). Because electricity is a higher quality form of energy than primary energy commodities (in that more of it can be used to produce useful work), these energy units should not be compared directly.

Another key difference between economic potential and proved reserves is that reserves are usually owned or controlled by an entity such as a company or a nation that has explored or measured the resource to the extent that they have high confidence of their ability to develop the resource. In the initial estimation of economic potential in this report, no such assessment is done, so uncertainty may be higher.

Lastly, in general, renewable production does not deplete that resource. Two partial exceptions are geothermal, where development may lead to resource reductions of time, and wind, where wind production can reduce wind speeds.

Because of these fundamental differences, it is not clear if there is any method to quantitatively compare potentials between fossil and renewables. This analogy is therefore intended only to increase understanding of the economic potential metric and provide ideas for how it could be used to assess renewable energy.

In this analysis, we consider all renewable energy potential as calculated to be comparable among renewable technologies (that is, we do not differentiate between different technologies). Future analysis may lead to differentiation of factors governing the potential for different technologies - for example, the ability to repower in the future, or declining production under some conditions. 
Table B-1. Summary of Analogous (Although Not Quantitatively Comparable) Terms

\begin{tabular}{|c|c|c|c|}
\hline $\begin{array}{l}\text { Common Sense } \\
\text { Definition }\end{array}$ & Fossil Term & $\begin{array}{l}\text { Renewable Energy } \\
\text { Term }\end{array}$ & Notes \\
\hline $\begin{array}{l}\text { Total available amount } \\
\text { of energy }\end{array}$ & Total Resource (Total) & Total Resource (Annual) & $\begin{array}{l}\text { Total amount of energy } \\
\text { for fossil, annual for } \\
\text { renewables }\end{array}$ \\
\hline $\begin{array}{l}\text { Total amount of } \\
\text { energy that can be } \\
\text { potentially captured }\end{array}$ & $\begin{array}{l}\text { Recoverable Resource } \\
\text { (Total) }\end{array}$ & $\begin{array}{l}\text { Technical Potential } \\
\text { (Annual) }\end{array}$ & $\begin{array}{l}\text { Accounts for system } \\
\text { performance, land-use } \\
\text { constraints, etc. }\end{array}$ \\
\hline $\begin{array}{l}\text { Total amount of } \\
\text { energy that is likely to } \\
\text { be economic given } \\
\text { current conditions }\end{array}$ & Reserves (Total) & $\begin{array}{l}\text { Economic Potential } \\
\text { (Annual) }\end{array}$ & $\begin{array}{l}\text { Accounts for projected } \\
\text { technology cost, value } \\
\text { of produced resource, } \\
\text { and market prices }\end{array}$ \\
\hline $\begin{array}{l}\text { Amount of energy } \\
\text { actually being } \\
\text { produced }\end{array}$ & Production (Total) & $\begin{array}{l}\text { Developed Resource } \\
\text { (Annual) }\end{array}$ & $\begin{array}{l}\text { Annual production or } \\
\text { electric generation }\end{array}$ \\
\hline
\end{tabular}




\section{Appendix C. Additional Method Detail}

\section{Detailed Formulas}

\section{LCOE}

The calculation of a location-specific LCOE value follows this general form ${ }^{33}$ :

$L C O E($ Delivered Costs $)=\frac{F C R *(\text { Overnight Capital Costs } * R C C M+O f f \text { shore Cable Costs })+\text { Fixed O\&M }}{\text { Capacity Factor } * 8760 \mathrm{~h}}+$ Variable $0 \& \mathrm{M}+$ Fuel costs $+\frac{\text { Onshore Distance } * T C M * B \text { Base Transmission Cost }+ \text { Tie_in_costs }}{\text { Capacity Factor } * 8760 \mathrm{~h}} *$ FCR

Where:

\begin{tabular}{|c|c|c|}
\hline Variable & Description & $\begin{array}{l}\text { Assumption under Primary } \\
\text { Cases }\end{array}$ \\
\hline $\begin{array}{l}\text { Fixed Charge Rate } \\
\text { (FCR) }\end{array}$ & $\begin{array}{l}\text { A financial factor to levelize (annualize) capital costs based } \\
\text { on required rate of return and project lifetime: } \\
\qquad F C R=\frac{C R F *(1-\text { Tax rate } * \text { PV of depreciation })}{(1-\text { Tax rate })}\end{array}$ & $\begin{array}{l}\text { Discount rate: } 7 \% \\
\mathrm{t}=20 \text { years (project lifetime) } \\
\text { For more detail, see DOE } \\
(2015 \mathrm{a})\end{array}$ \\
\hline $\begin{array}{l}\text { Regional Capital } \\
\text { Cost Multiplier } \\
\text { (RCCM) }\end{array}$ & $\begin{array}{l}\text { Capital cost multipliers to account for regional variations } \\
\text { that affect plant construction costs }\end{array}$ & $\begin{array}{l}\text { Range: } 0.9 \text { to } 13.65 \text {. Data } \\
\text { developed for the } 2015 \text { Wind } \\
\text { Vision study (DOE, 2015a) }\end{array}$ \\
\hline Offshore Cable Costs & $\begin{array}{l}\text { Cost for offshore (underwater) export cables from the } \\
\text { offshore turbines to land including incremental } \\
\text { construction-period transit costs }\end{array}$ & $\begin{array}{l}\text { Assumed HVAC for cables } \\
\text { that are less than } 70 \mathrm{~km} \text { and } \\
\text { HVDC otherwise }(\$ 8.10 / \mathrm{kW}- \\
\mathrm{km} \text { for AC cables and } \\
\$ 13.49 / \mathrm{kW}-\mathrm{km} \text { for DC } \\
\text { cables) }\end{array}$ \\
\hline Onshore Distance & Onshore transmission line costs (for spur line) & $\begin{array}{l}\text { Base onshore transmission } \\
\text { line costs }(\$ 3,981 / \mathrm{MW} \text {-mile })\end{array}$ \\
\hline $\begin{array}{l}\text { Transmission Cost } \\
\text { Multiplier (TCM) }\end{array}$ & $\begin{array}{l}\text { Multiplier to account for regional variations that affect } \\
\text { onshore transmission line costs }\end{array}$ & $\begin{array}{l}\text { Range: } 0.19 \text { to } 1.16 . \text { Data } \\
\text { developed for DOE (2015a). }\end{array}$ \\
\hline $\begin{array}{l}\text { Capital Recovery } \\
\text { Factor (CRF) }\end{array}$ & $\begin{array}{l}\text { The ratio of a constant annuity to the present value of } \\
\text { receiving that annuity for a given length of time: } \\
\qquad C R F=\frac{W A C C}{1-\frac{1}{(1+W A C C)^{t}}} \\
\text { Where: } \\
\text { WACC = Weighted Average Cost of Capital } \\
\mathrm{t}=\text { Number of time periods }\end{array}$ & $\begin{array}{l}\mathrm{t}=20 \text { years (project lifetime) } \\
\text { WACC }=8.9 \% \text { (nominal); } \\
6.2 \% \text { (real) } \\
\text { For more detail, see DOE } \\
(2015 \mathrm{a})\end{array}$ \\
\hline Tie-in Costs & $\begin{array}{l}\text { Point of interconnection at the high-voltage transmission } \\
\text { network, including substation, transmission lines, load } \\
\text { center, or balancing area center. }\end{array}$ & $\begin{array}{l}\text { Default in ReEDS is } \$ 0 / \mathrm{kW} \\
\text { for substation and load center } \\
\text { and } \$ 14 / \mathrm{kW} \text { for others }\end{array}$ \\
\hline
\end{tabular}

${ }^{33}$ Formula differs by technology; this formula refers to wind for illustrative purposes. 
LACE

The calculation of a location-specific LACE value follows this general form ${ }^{34}$ :

LACE

$=\frac{\text { Average Marginal Generation Price } * \text { Escalation Factor } * \text { Capacity Factor } * 8760 h+\text { Capacity Payment } * \text { Capacity Credit }}{\text { Capacity Factor } * 8760 h}$

Where:

\begin{tabular}{|c|c|c|}
\hline Variable & Description & $\begin{array}{l}\text { Assumption under } \\
\text { Primary Cases }\end{array}$ \\
\hline $\begin{array}{l}\text { Average Marginal } \\
\text { Generation Price }\end{array}$ & $\begin{array}{l}\text { For each ReEDS region, weighted average marginal generation } \\
\text { price is estimated by: } \\
\qquad \sum_{j=1}^{J=16} \text { Price }_{j} * \frac{n_{j}}{8760 h} \\
\text { Where: } \\
\mathrm{j}=\text { ReEDS time slice } \\
\text { Price }{ }_{\mathrm{j}}=\text { Either } 2014 \text { Average LMP or } 2014 \text { Average Market } \\
\begin{array}{l}\text { Marginal Cost lambda value in ReEDS time slice } \mathrm{j} \\
\mathrm{n}=\text { Number of hours in ReEDS time slice } \mathrm{j}\end{array}\end{array}$ & $\begin{array}{l}\mathrm{j}=16 \text { (Number of } \\
\text { ReEDS time slices) }\end{array}$ \\
\hline Escalation factor & $\begin{array}{l}\text { For each EIA Annual Energy Outlook (2015) market region, } \\
\text { the escalation factor is estimated by: } \\
\qquad \prod_{t=1}^{T=20} 1+\frac{Y_{t}}{Y_{t-1}}-1 \\
(1+i)^{t} \\
\frac{\text { Where: }}{\mathrm{t}=\text { Year }} \\
\text { Y= Generation price (from EIA } 2015 \text { Annual Energy Outlook, } \\
\text { EIA 2015) } \\
\mathrm{i}=\text { Discount rate }\end{array}$ & $\begin{array}{l}\mathrm{t}=20 \text { (Project } \\
\text { lifetime) } \\
\mathrm{i}=7 \%\end{array}$ \\
\hline Capacity payment & $\begin{array}{l}\text { Capacity payments capture the value a generation project can } \\
\text { offer to the system in meeting reliability reserve margins (EIA } \\
2013 \text { ). } \\
\text { The Overnight capital cost of an advanced natural gas-fired } \\
\text { combustion turbine (NGCT) plant, } \$ 682 / \mathrm{kW} \text { (consistent with } \\
\text { AEO } 2015 \text { in EIA } 2015 \text { ), is used as proxy for capacity } \\
\text { payment. }\end{array}$ & \\
\hline Capacity credit & $\begin{array}{l}\text { Capacity credit captures "the ability of a unit to provide system } \\
\text { reliability reserves" (EIA 2013, p. 3) }\end{array}$ & $\begin{array}{l}\text { See Table } 4 \text { in Section } \\
2\end{array}$ \\
\hline
\end{tabular}

${ }^{34}$ Formula differs by technology; this formula refers to wind for illustrative purposes. 


\section{Alternate Average Avoided Generator (AAG) Method for Avoided Generation Cost}

In this method, avoided costs are developed based on the estimate avoided generation and capacity costs in a region. This approach is less granular that the MP method. It may have value as a contrasting method that is not as affected by regional irregularities in wholesale prices, which may or may not persist. It also is intended as a proxy for certain approaches to generation planning, which reflect the fuel, operating, and capacity costs of alternatives over the life of a project.

In this method, avoided costs are the sum of three individual costs associated with existing generation and capacity that are displaced by renewable generation: avoided generation cost, avoided capital cost, and (optionally) avoided SCC emissions. We estimate the avoided emissions resulting from deployed technology and the associated cost based on the SCC method from Interagency Working Group (IWG) for Social Cost of Carbon (2013)—identical to the MP method.

\section{Avoided Generation}

Avoided generation costs are calculated by estimating the existing generation mix that is displaced and the fuel and operating costs associated with that avoided generation. In this analysis, we assume a single avoided generation mix applied nationally. Regional mixes could also be developed. Projected regional fuel price differences are incorporated into the AAG method based on the single national generation mix and EIA projections for natural gas and coal costs over the life of the project (Annual Energy Outlook 2014 in EIA 2014a).

Here, we estimate $65 \%$ NGCC, $5 \%$ NGCT, and 30\% coal for a single generation mix applied nationally. This generation profile is based on an initial survey of the PJM Interconnection through analysis of PJM marginal price curves on the day-ahead market (Figure C-1).

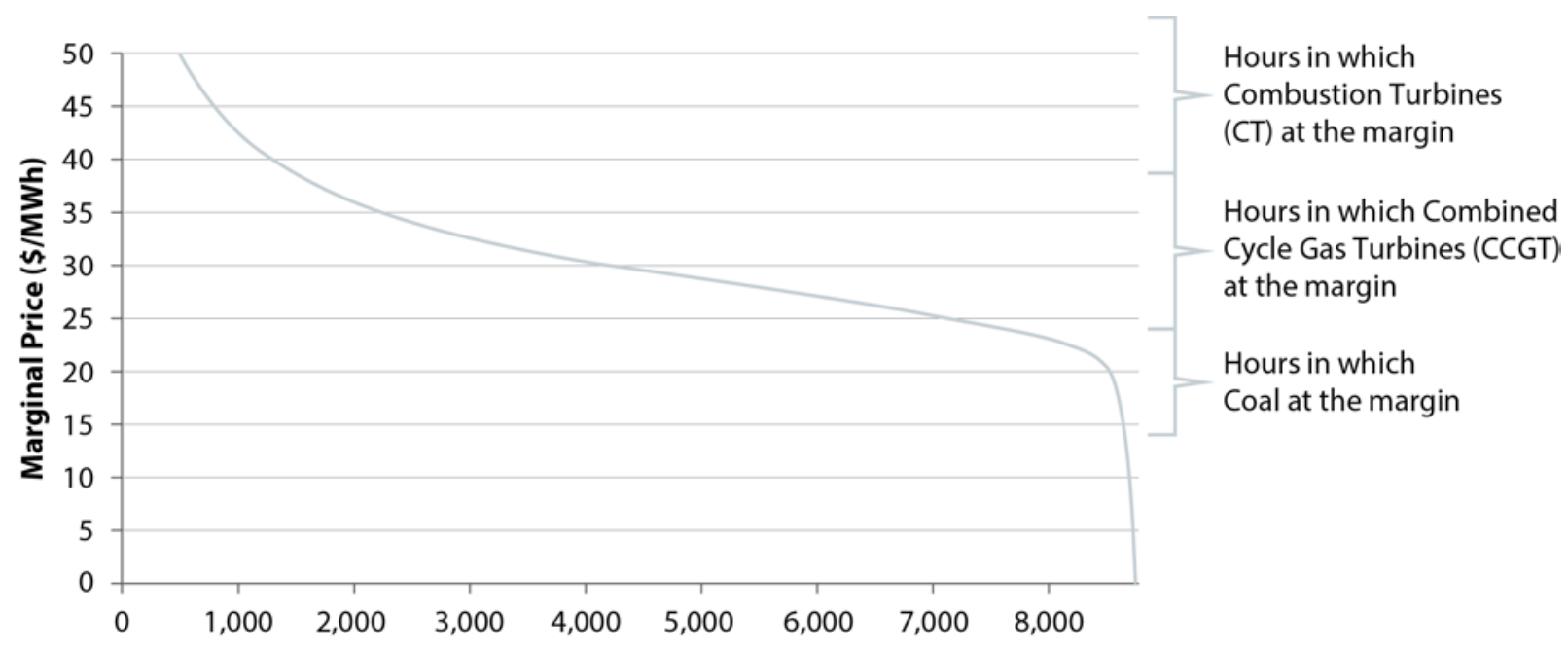

Figure C-1. Marginal price curve for PJM's Day-Ahead Market mapped to marginal unit type

Source: PJM 2015 
Avoided costs are calculated for the nine Census divisions based on EIA (2014a) fuel price projections (AEO 2014), assuming a project was built in 2015. Projected regional fuel price differences are incorporated into the AAG method based on the single national generation mix.

\section{Avoided Capacity}

We estimate the value of additional capacity that would not need to be built based on the capacity value of a given renewable technology and the avoided capital and operating expenditures. Capacity value reflects the availability of a technology to produce electricity when it is needed, and varies between 0 and 1 . A technology that produces electricity when it is most needed will have a capacity value higher than its capacity factor. Avoided capital costs depend on the capacity value of the renewable resource (for example, $1 \mathrm{MW}$ of wind does not generally replace $1 \mathrm{MW}$ of other capacity) relative to the capacity value of natural gas, herein assumed to be $95 \%$. For renewable technologies we assumed capacity values of: wind $10 \%$; solar PV 50\%; hydro 95\%; geothermal $99 \%$; biopower $91 \%$. As technologies enter the market, capacity value may change. In this analysis, the declining value of wind and solar is intended to reflect that change.

We assume that all avoided capacity is natural gas, proportional to the share of avoided generation weighted by capacity factor. This estimates the capacity of these technologies that would supply the natural gas share of the assumed displaced generation mix. This results in the assumption that CCGT represents $82 \%$ of capacity avoided and NGCT represents $18 \%$ of capacity avoided.

The outcome of this avoided cost analysis for wind is shown in Figure C-2.

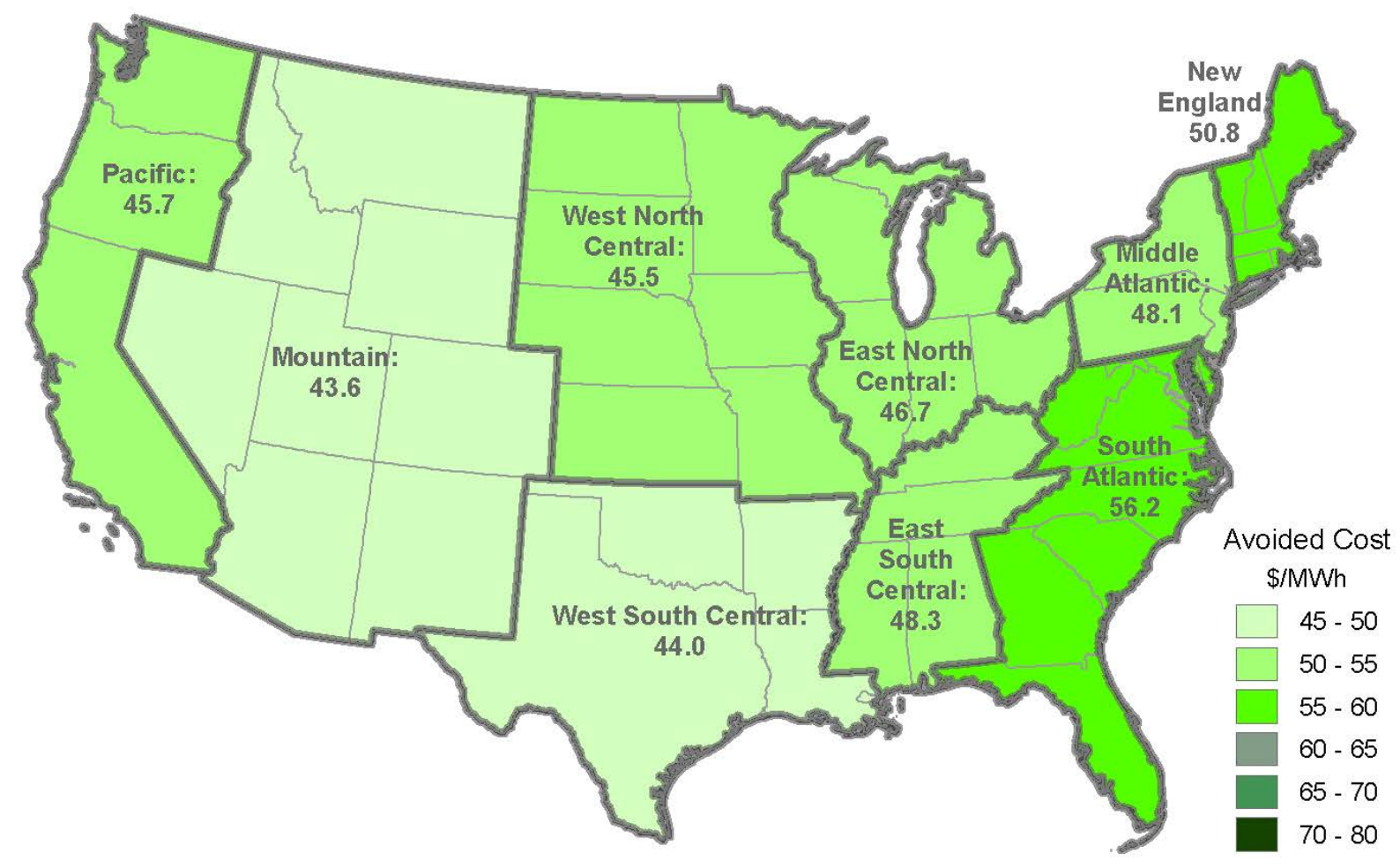

Figure C-2. Example estimated avoided costs for wind, including generation and capacity components, by region 
The MP and AAG methods each use different data sources and different fundamental assumptions. They are also based on different regional scales, with the MP calculated at the highest granularity available for market prices and the AAG method at the census division. Because of this, there are significant regional and technology differences between the two methods. 


\section{Appendix D. Case Structure and Additional Assumptions}

Table D-1. Summary of Cases and Assumptions

\begin{tabular}{|c|c|c|c|}
\hline \multicolumn{2}{|c|}{ Case Group } & Specific Cases & Assumptions \\
\hline \multirow{2}{*}{\multicolumn{2}{|c|}{ Group 1: LACE Only }} & 1a. Primary Case at $100 \%$ Capacity Value & $\begin{array}{l}\text { Construction Date: } 2014 \\
\text { RE Technology Cost: } 2020 \text { Mid } \\
\text { Renewable Technology Incentives: Permanent } \\
10 \% \text { ITC for UPV, DPV; MACRS } \\
\text { Project Life: } 20 \text { years } \\
\text { Avoided Cost Method for Central Generaton: MP } \\
\text { Capacity Value in MP: } 100 \% ; \$ 682 / \mathrm{kW}\end{array}$ \\
\hline & & 1b. Primary Case at $0 \%$ Capacity Value ${ }^{3}$ & $\begin{array}{l}\text { Same as 1a except: } \\
\text { Capacity Value in MP: } 100 \% ; \$ 0 / k W\end{array}$ \\
\hline \multirow{2}{*}{\multicolumn{2}{|c|}{$\begin{array}{l}\text { Group 2: LACE including } \\
\text { Value of Avoided External } \\
\text { Costs }\end{array}$}} & 2a. Primary Case at $100 \%$ Capacity Value & $\begin{array}{l}\text { Same as 1a except: } \\
\text { Value of Avoided CO2: Average SCC with 3\% } \\
\text { discount rate }\end{array}$ \\
\hline & & 2b. Primary Case at $0 \%$ Capacity Value ${ }^{3}$ & $\begin{array}{l}\text { Same as } 1 \mathrm{~b} \text { except: } \\
\text { Value of Avoided CO2: Average SCC with 3\% } \\
\text { discount rate }\end{array}$ \\
\hline \multirow{17}{*}{ 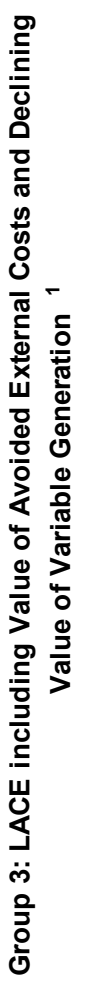 } & \multirow[t]{2}{*}{ Primary Cases } & 3a. Primary Case at $100 \%$ Capacity Value & $\begin{array}{l}\text { Same as } 2 \text { a except: } \\
\text { Declining value with "flat"extension beyond } 40 \% \\
\text { and } 100 \% \text { regional limits applied to Wind, UPV }\end{array}$ \\
\hline & & 3b. Primary Case at $0 \%$ Capacity Value ${ }^{3}$ & $\begin{array}{l}\text { Same as } 2 \text { b except: } \\
\text { Capacity Value in MP: } 100 \% ; \$ 0 / k W\end{array}$ \\
\hline & \multirow{6}{*}{$\begin{array}{l}\text { Framework } \\
\text { Sensitivities }\end{array}$} & 2020 Construction Date ${ }^{3}$ & \multirow{15}{*}{$\begin{array}{l}\text { Same as } 3 a \text { except: } \\
\text { Change to variable in Case Name }\end{array}$} \\
\hline & & 30-year Project Life & \\
\hline & & RE Cost - 2014 & \\
\hline & & RE Cost - 2014 with PTC and $30 \%$ ITC $^{4}$ & \\
\hline & & $\begin{array}{l}\text { RE Cost - } 2014 \text { with PTC and 30\% ITC (Avoided } \\
\text { CO2 Excluded) }\end{array}$ & \\
\hline & & $\begin{array}{l}\text { Declining Value (Increasing with Regional } \\
\text { Limits) }^{3,5}\end{array}$ & \\
\hline & \multirow{3}{*}{$\begin{array}{l}\text { RE Technology } \\
\text { Cost Sensitivities }\end{array}$} & RE Cost - 2010 & \\
\hline & & RE Cost - 2010 with PTC and $30 \%$ ITC $^{4}$ & \\
\hline & & RE Cost - 2030 Mid $^{*}$ & \\
\hline & \multirow{2}{*}{$\begin{array}{l}\text { Avoided } \\
\text { Generation Cost } \\
\text { Sensitivities }^{2}\end{array}$} & Avoided Cost - AAG $\$ 682 / \mathrm{kW} 100 \% \mathrm{CV}^{6}$ & \\
\hline & & Avoided Cost - MP $\$ 1000 / \mathrm{kW} 100 \% \mathrm{CV}^{6}$ & \\
\hline & \multirow{4}{*}{$\begin{array}{l}\text { Avoided External } \\
\text { Cost Sensitivities }\end{array}$} & Avoided $\mathrm{CO}_{2}$ - Excluded & \\
\hline & & Avoided $\mathrm{CO}_{2}-5 \%$ & \\
\hline & & Avoided $\mathrm{CO}_{2}-3 \%$ (95th) & \\
\hline & & Avoided Health Included ${ }^{3}$ & \\
\hline
\end{tabular}

Notes

1 All Group 3 sensitivity cases assume 100\% Capacity Value; all Group 3 cases for Wind and UPV apply declining value with

"flat"extension beyond $40 \%$ and $100 \%$ regional limits unless noted.

$2 \$ / \mathrm{kW}$ value indicates assumed NGCT overnight capital cost

3 Not all cases run for DPV; Primary Case 1 or 2 used as a substitute

4 This sensitivity case changes more than one variable

5 Alternate declining value methods that decreases value of wind beyond $40 \%$ generaton share

6 Not applicable to DPV 


\section{Appendix E. Method Calculation Flow Intermediate Products}

\section{Calculation Component Maps and Supply Curves for Select Primary Cases}

The progression of calculation component maps and supply curves is displayed in the following order for each technology:

- LCOE

- LACE

- Net Value (LACE - LCOE).

Costs (both LCOE and LACE) are expressed in terms of 2014\$/MWh. In all cases, full credit is given for the capacity value of renewable generation). For Wind and UPV, LCOE, net value, and summary results are shown first for Primary Case 2 then for Primary Case 3 (declining value of variable generation applied). For all other technologies, Primary Case 2 is shown (also equivalent to Primary Case 3 as no declining value is applied to these technologies).

\section{Wind}

LCOE

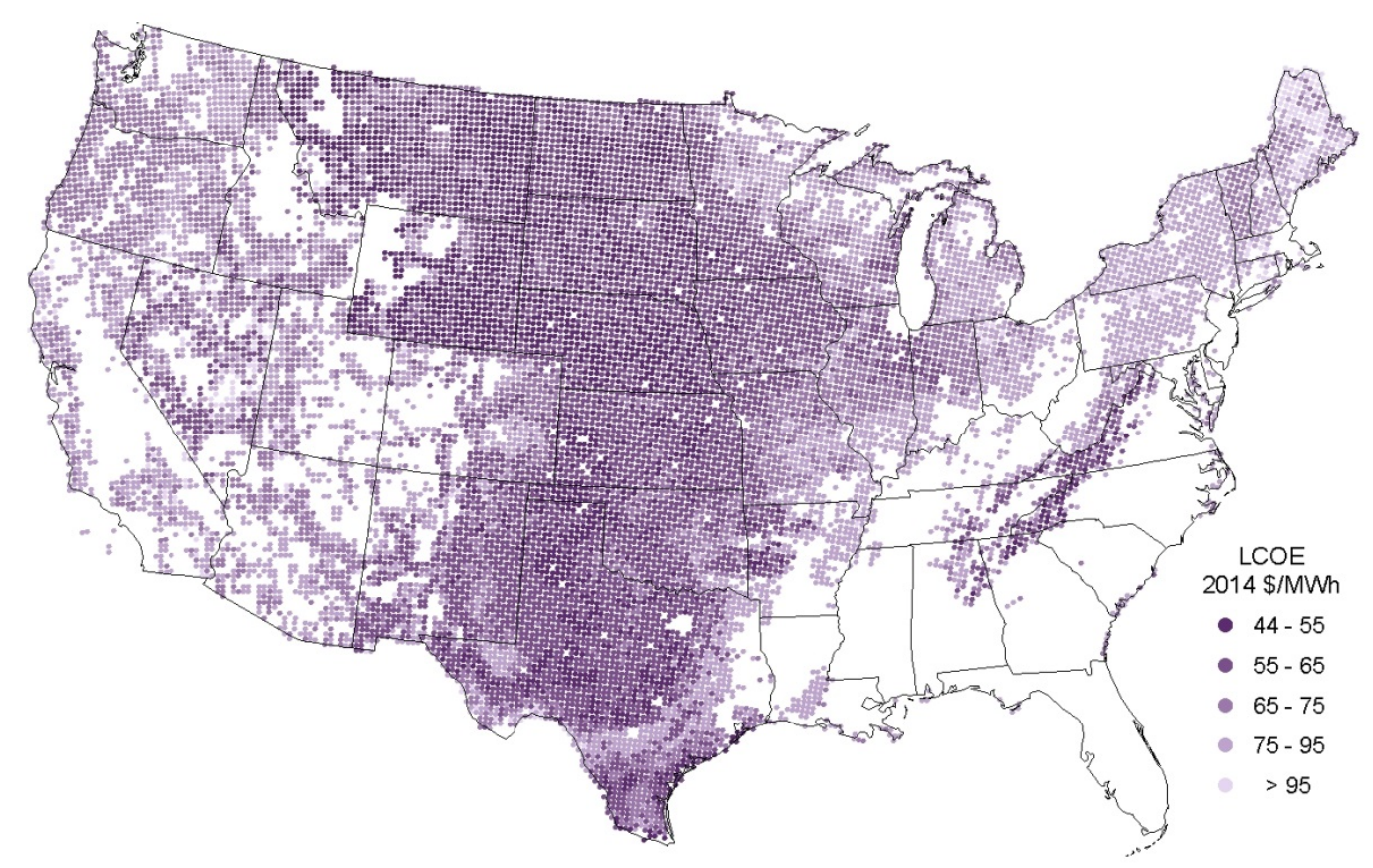

Figure E-1a. Wind LCOE site map (Primary Case 2) 


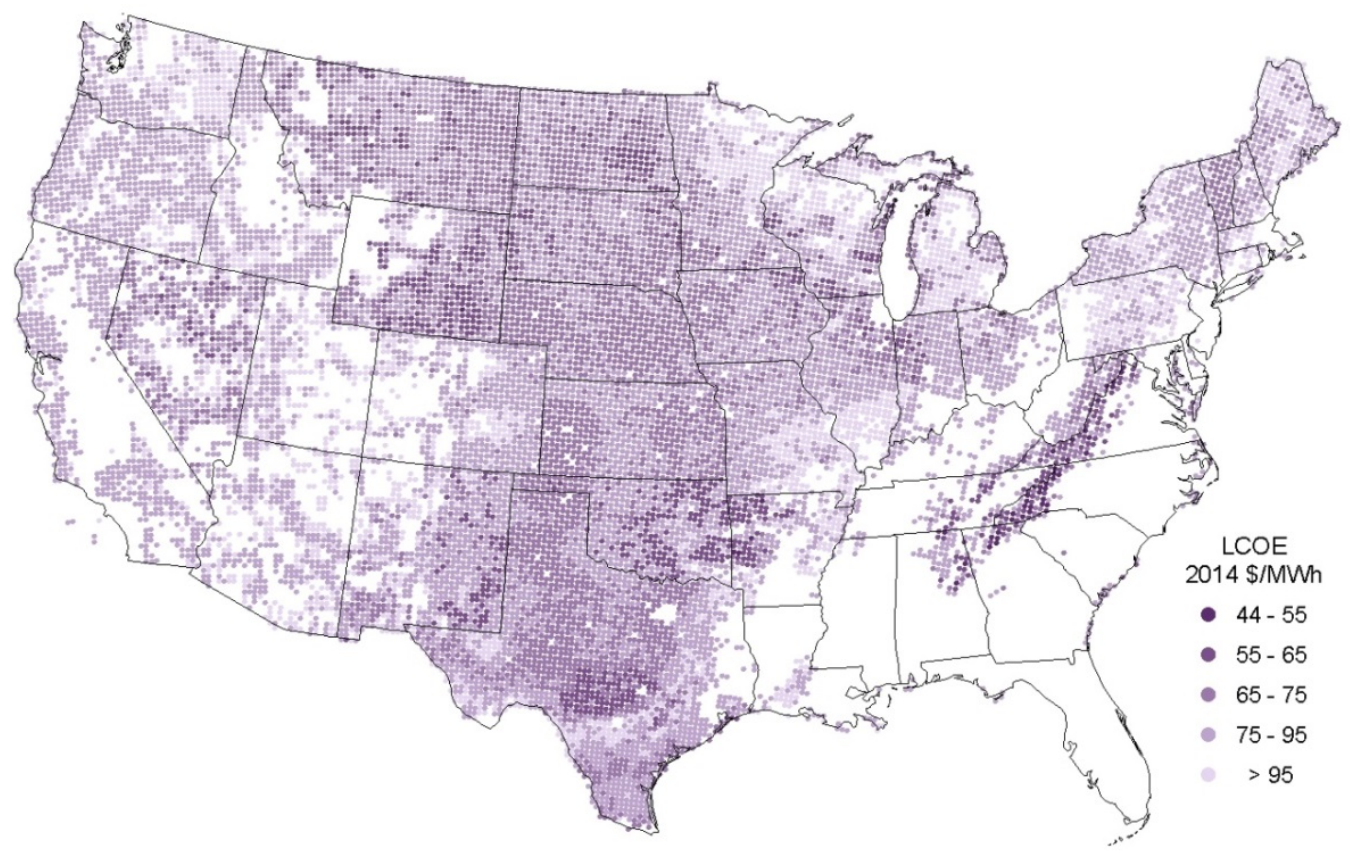

Figure E-1b. Wind LCOE site map (Primary Case 3)

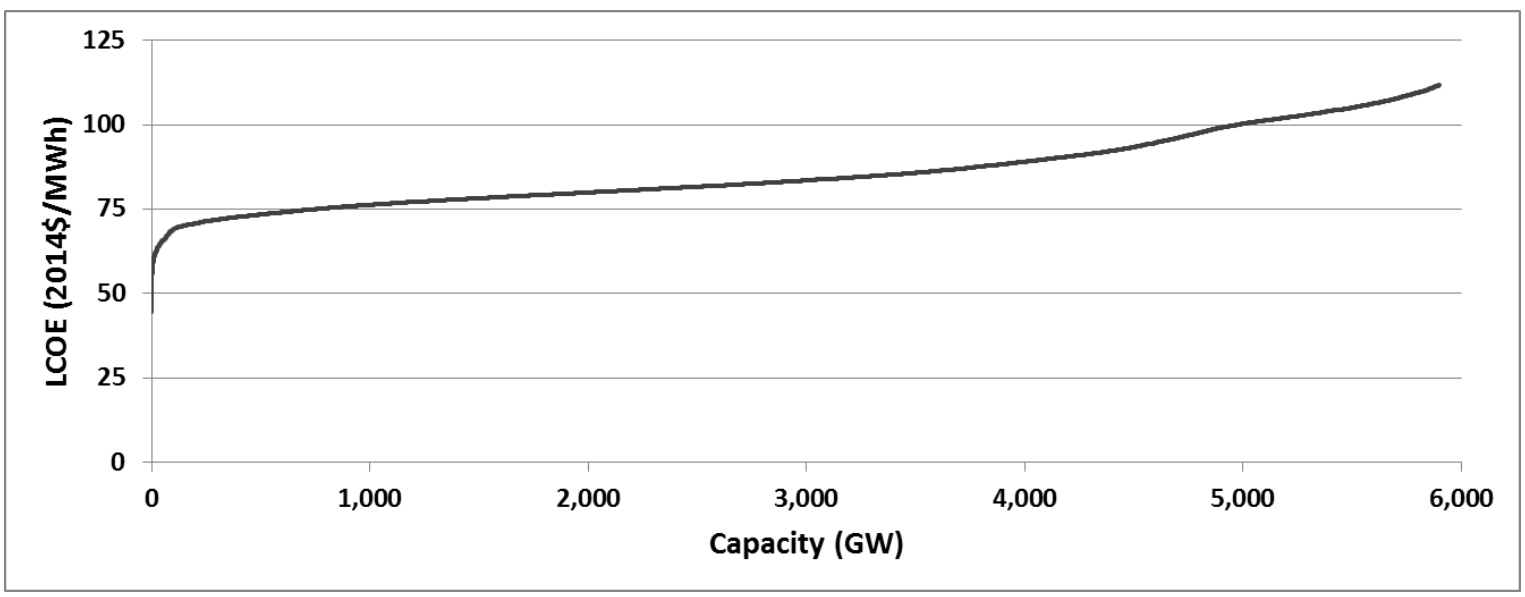

Figure E-1c. Wind aggregated U.S. LCOE supply curve (Primary Case 3) 


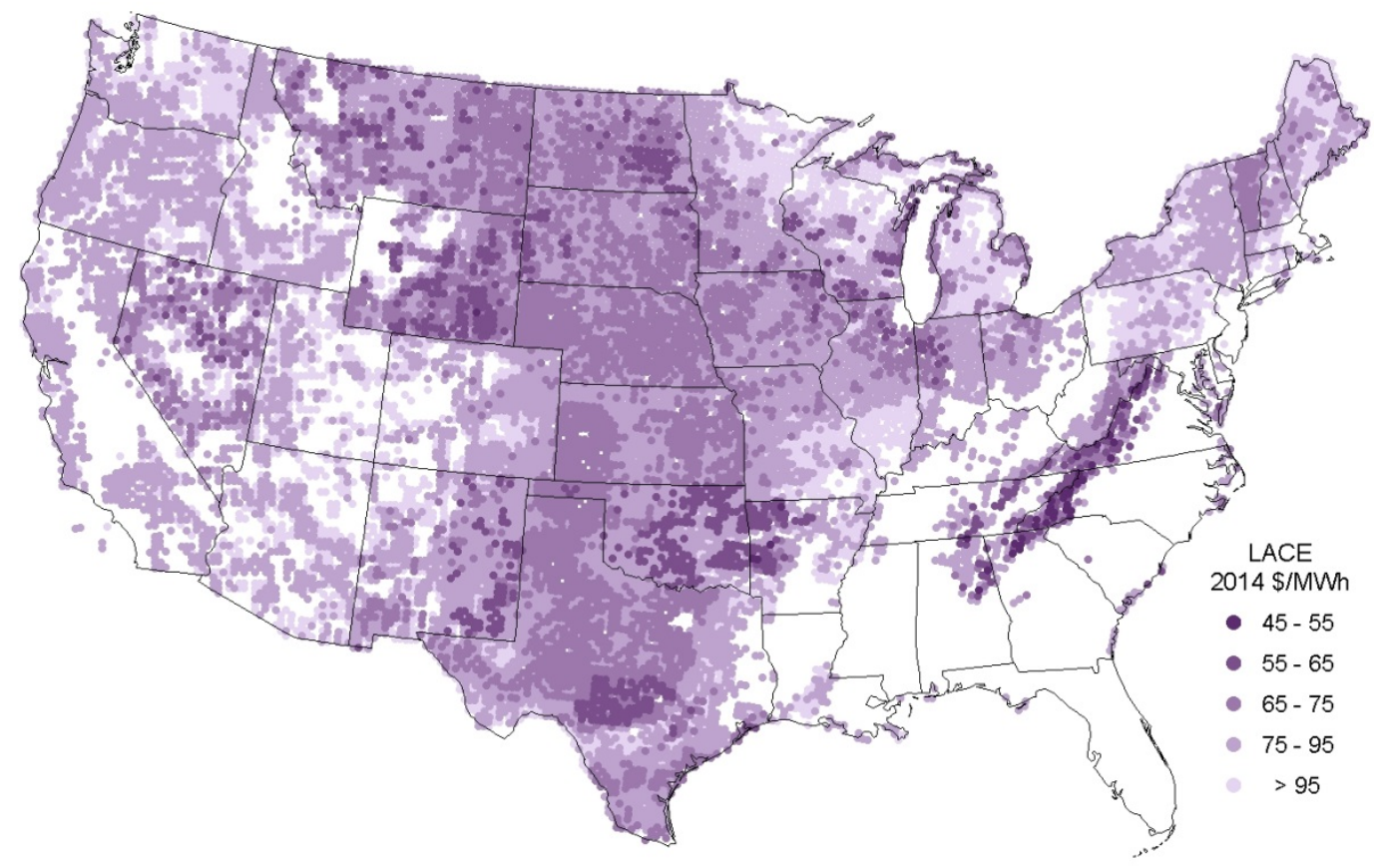

Figure E-2. Wind LACE site map (Primary Cases 2 and 3 with full credit for renewable generation capacity value)

Net Value

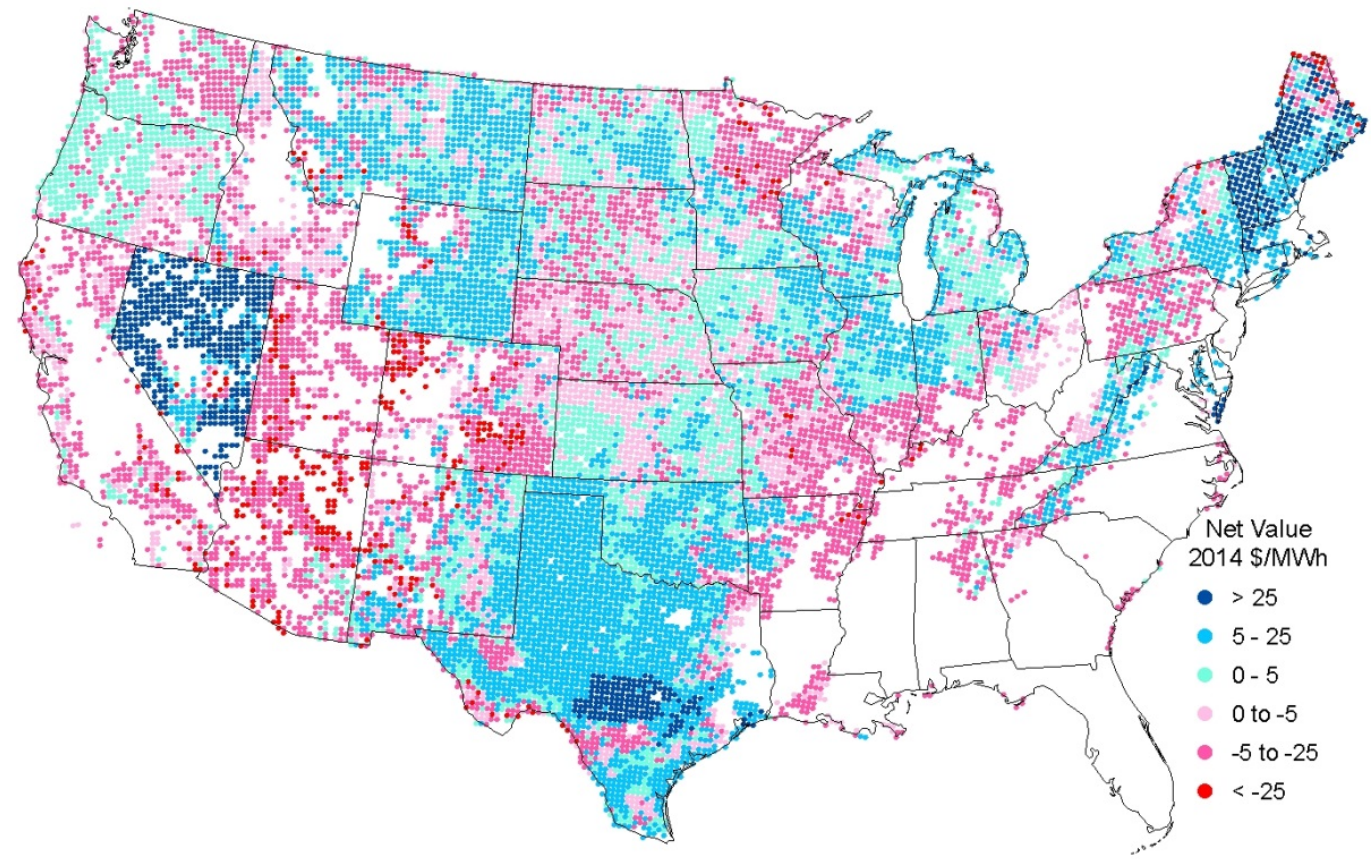

Figure E-3a. Wind net value map (Primary Case 2 with full credit for renewable generation capacity value) 


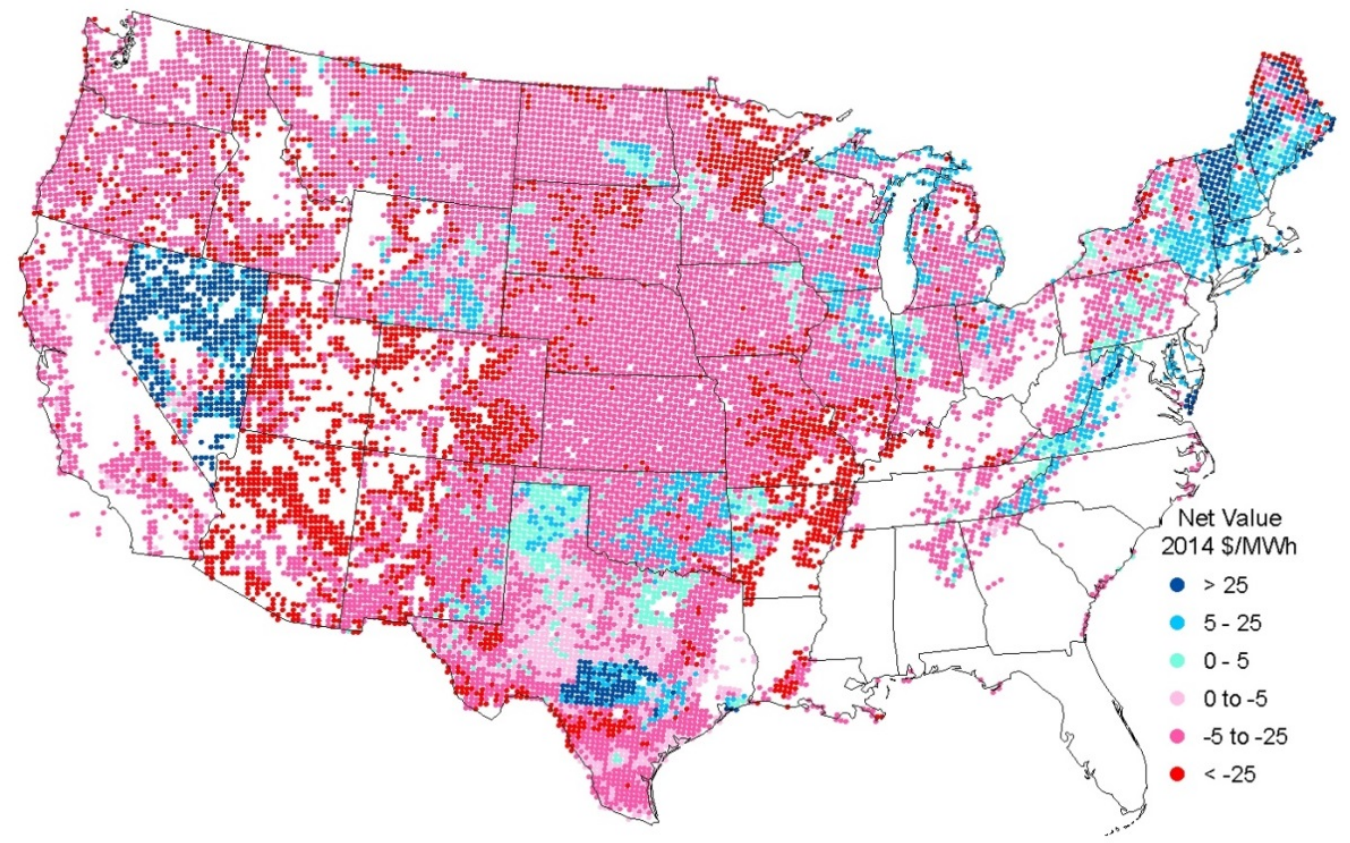

Figure E-3b Wind net value map (Primary Case 3 with full credit for renewable generation capacity value)

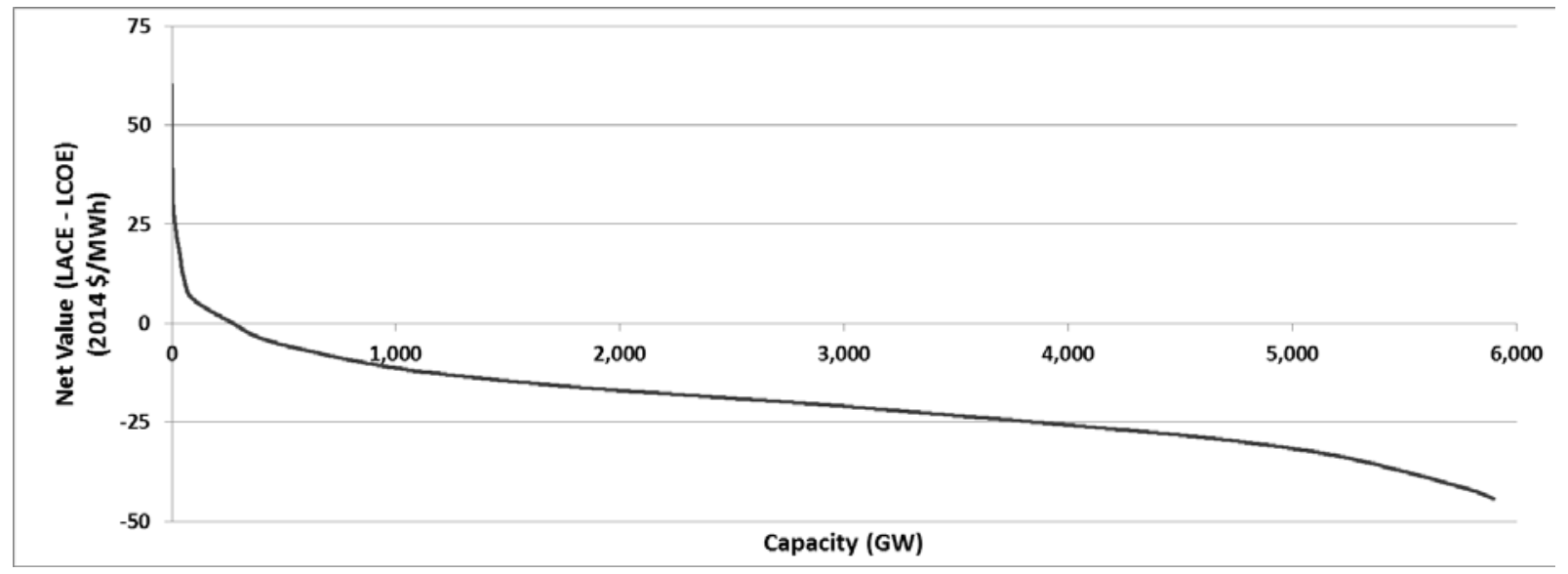

Figure E-3c. Wind aggregated U.S. wind net value supply curve (Primary Case 3 with full credit for renewable generation capacity value)

Note: Capacity shown is incremental to 2013 level. 
UPV

$\angle C O E$

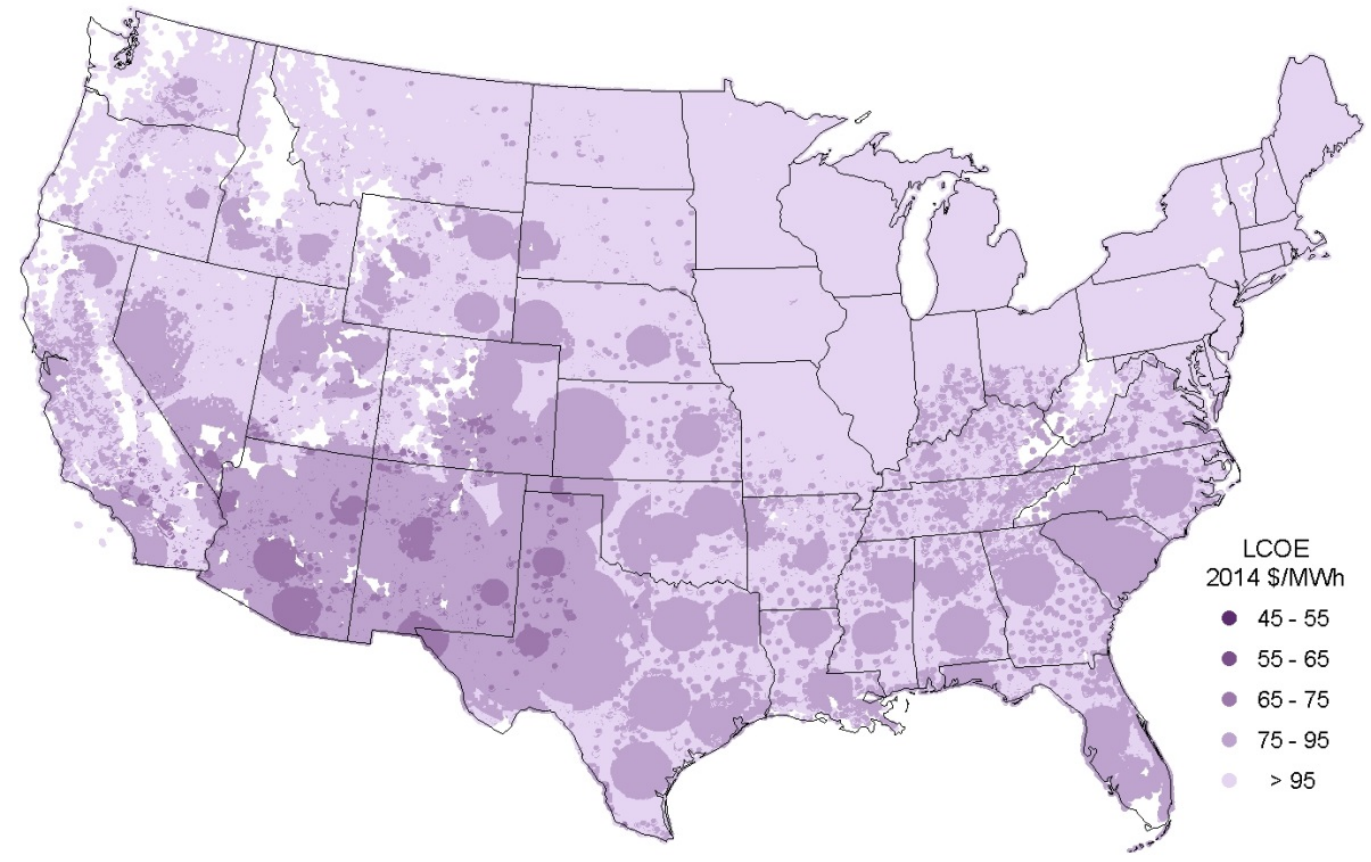

Figure E-4a. UPV LCOE site map (Primary Case 2)

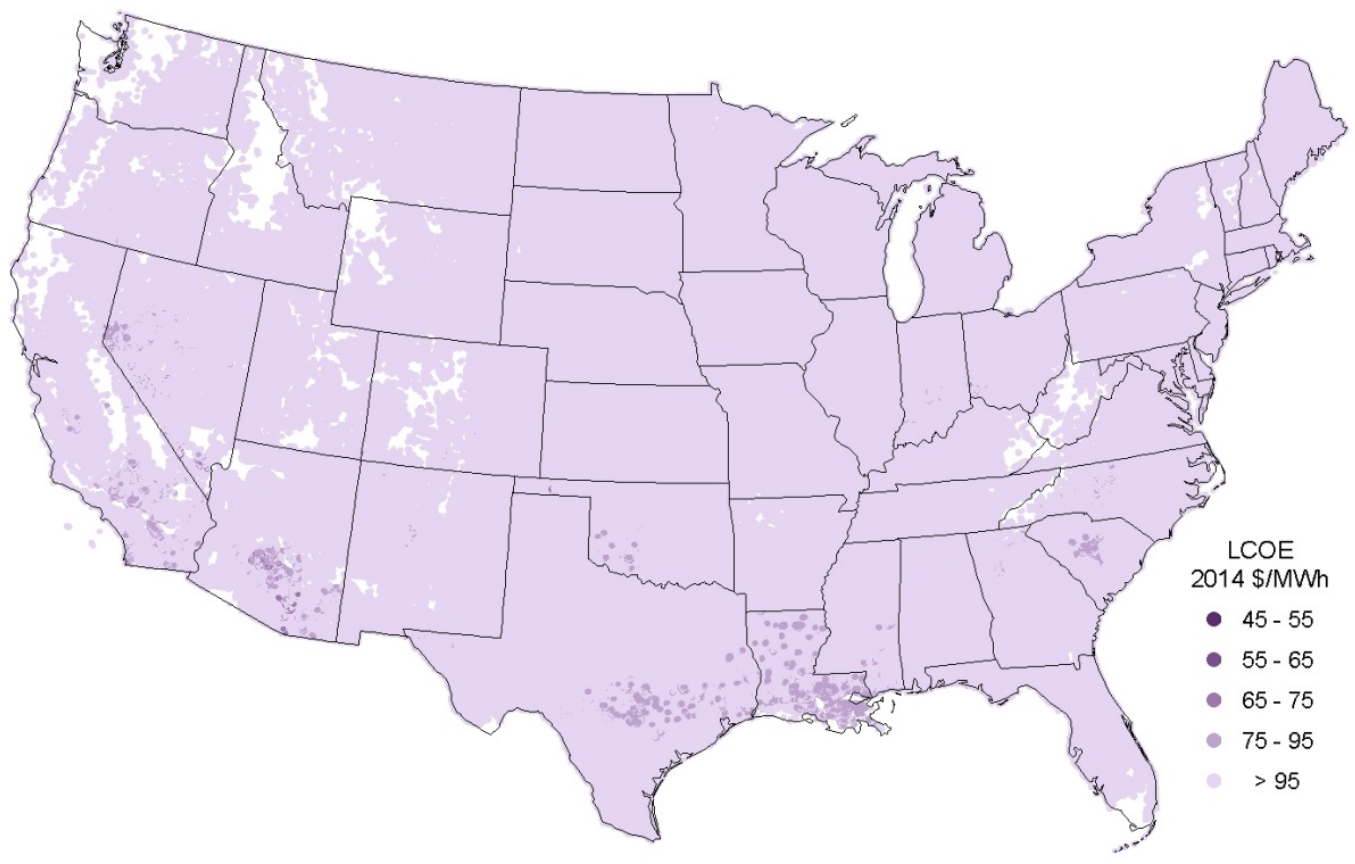

Figure E-4b. UPV LCOE site map (Primary Case 3) 


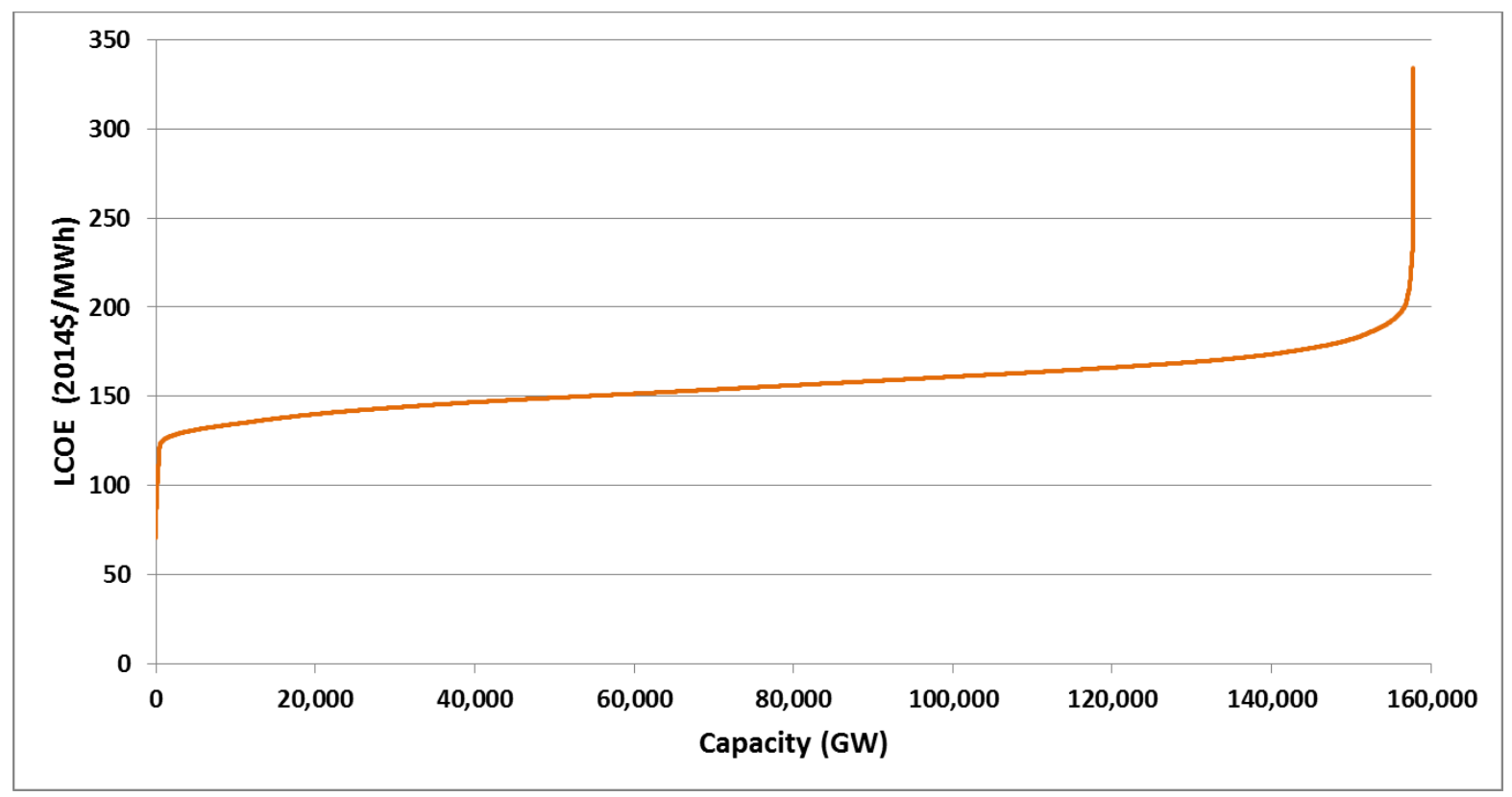

Figure E-4c. UPV aggregated U.S. LCOE supply curve (Primary Case 3)

\section{LACE}

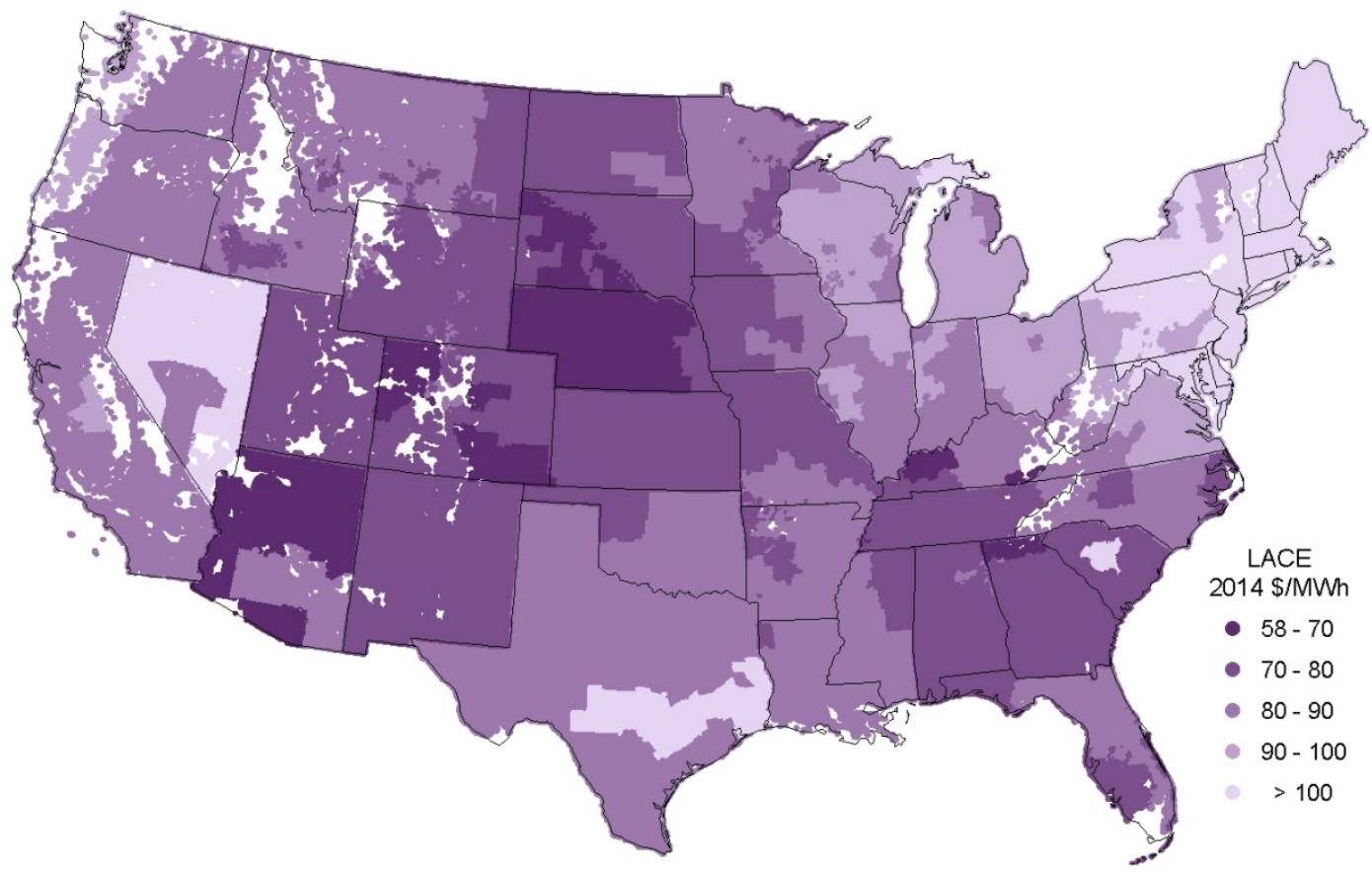

Figure E-5. UPV LACE site map (Primary Cases 2 and 3 with full credit for renewable generation capacity value) 
Net Value

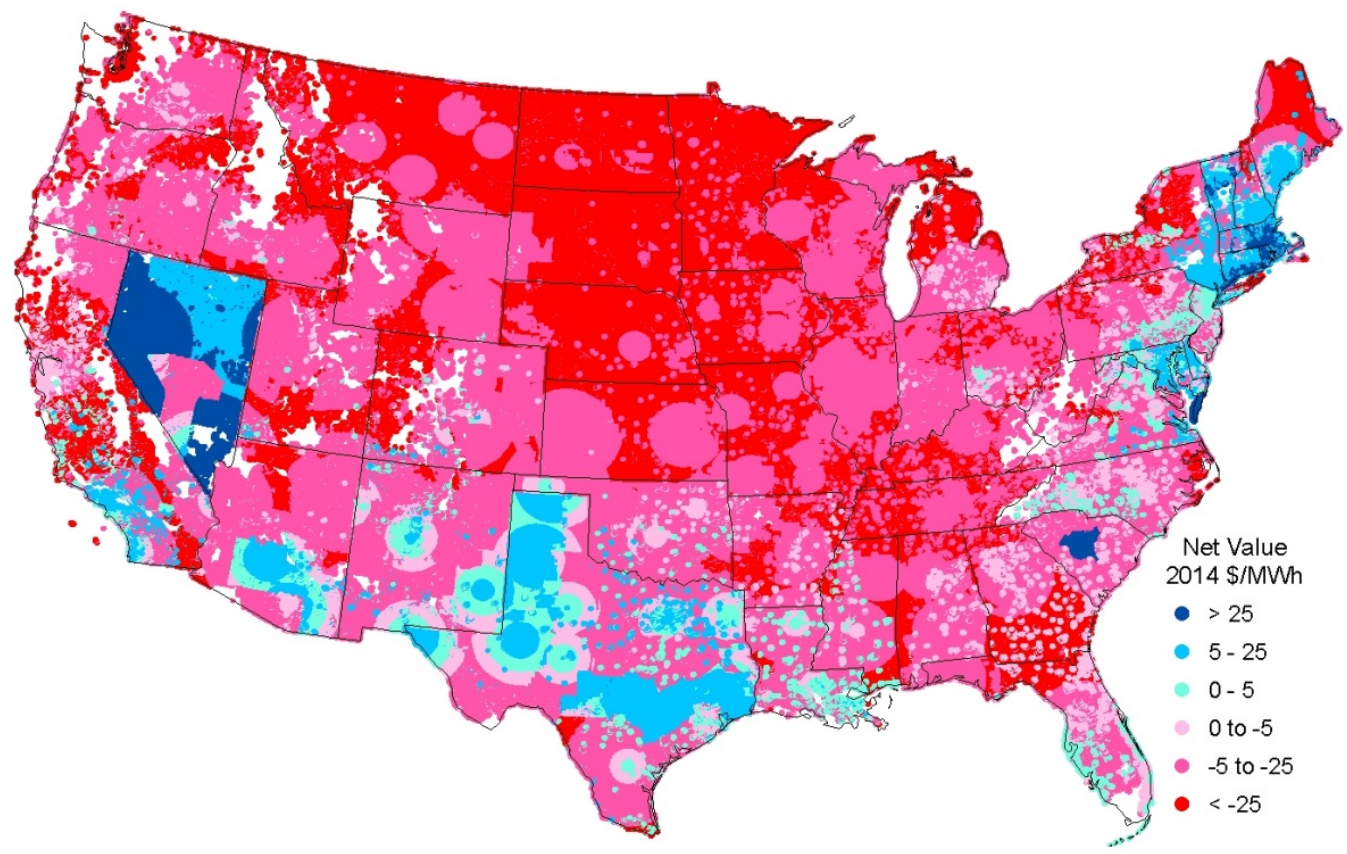

Figure E-6a. UPV net value map (Primary Case 2 with full credit for renewable generation capacity value)

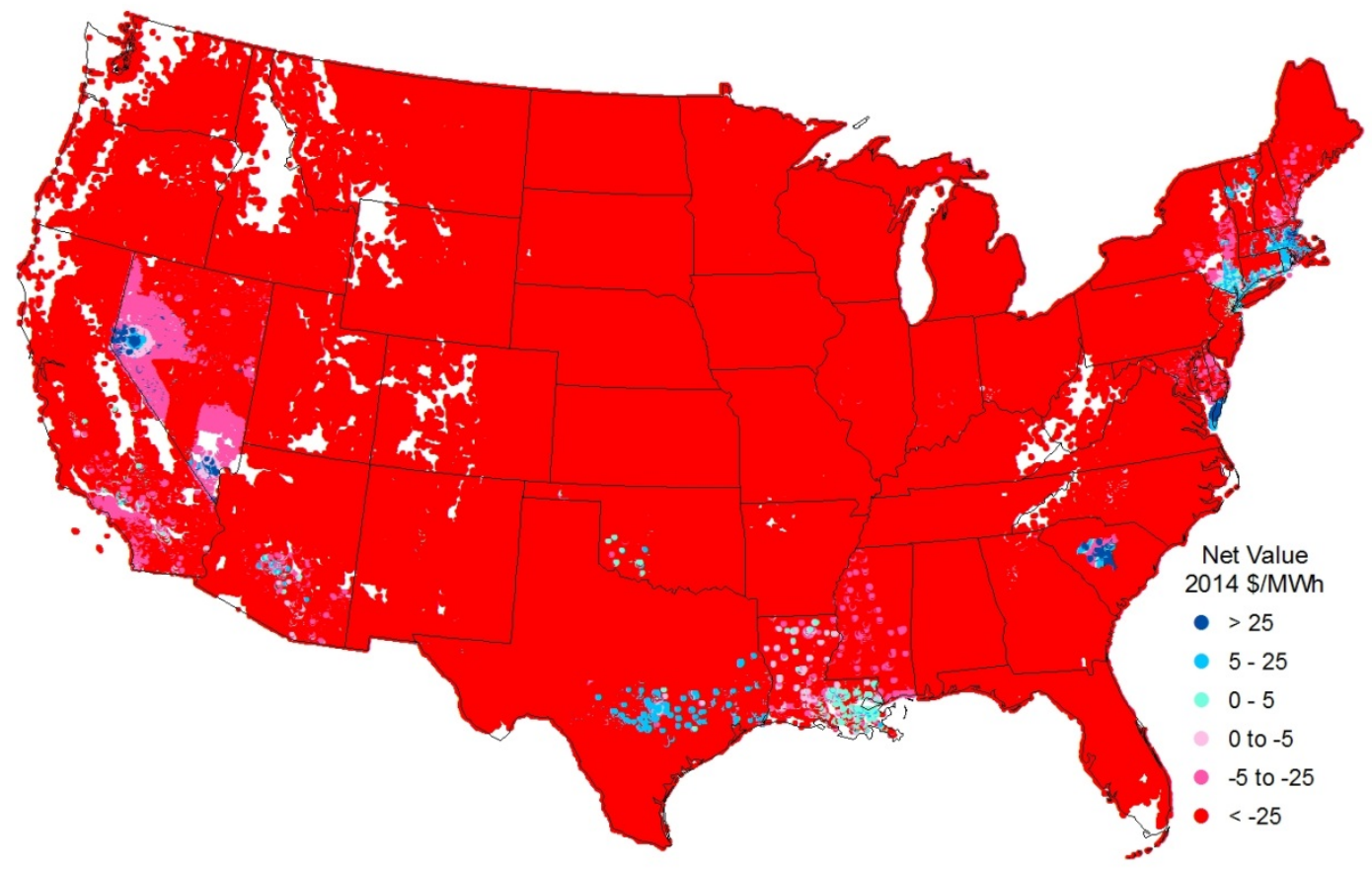

Figure E-6b. UPV net value map (Primary Case 3 with full credit for renewable generation capacity value) 


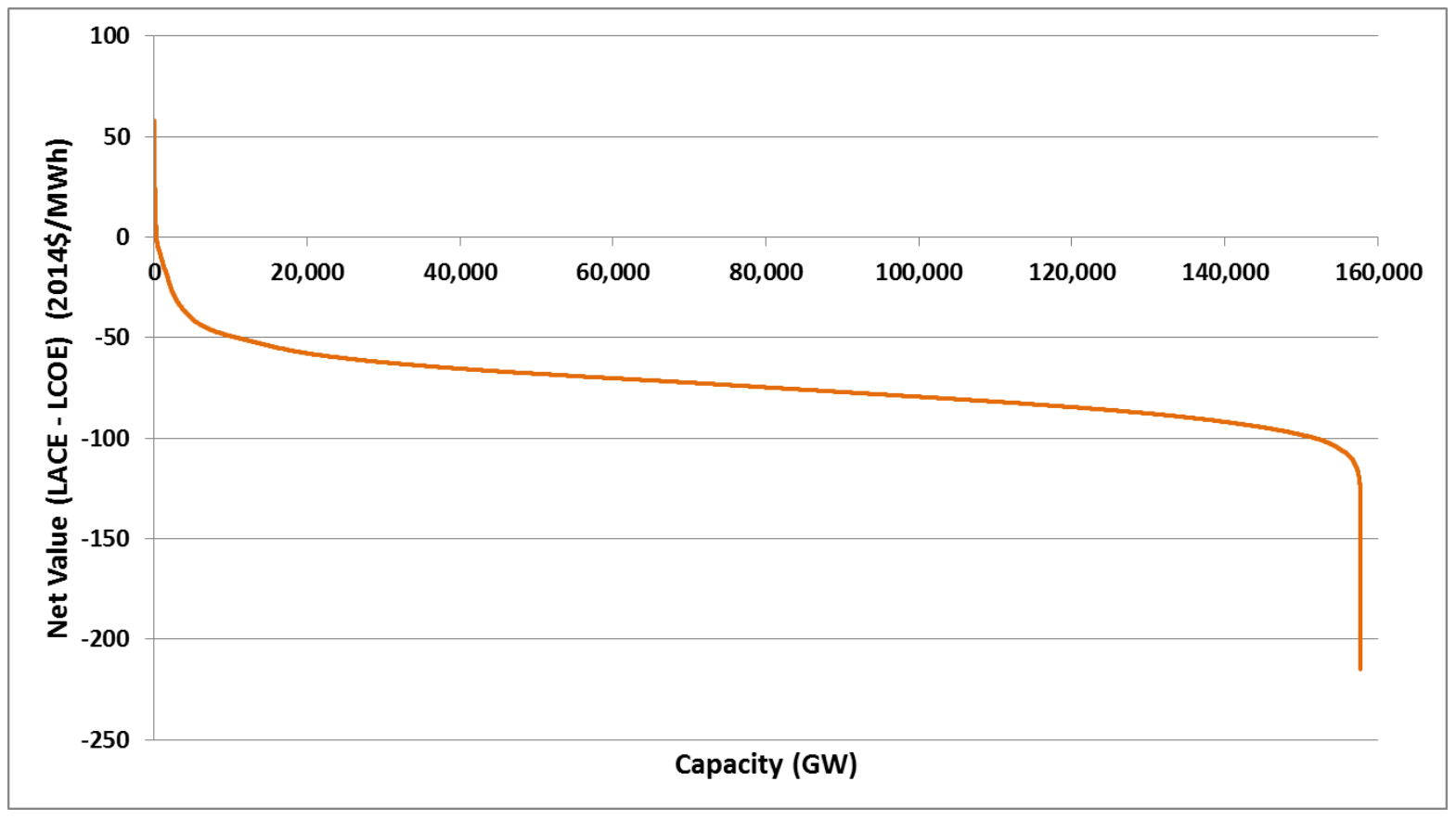

Figure E-6c. UPV aggregated U.S. net value supply curve (Primary Case 3 with full credit for renewable generation capacity value)

Note: Capacity shown is incremental to 2013 level.

\section{DPV}

Avoided Costs (Retail Rates)

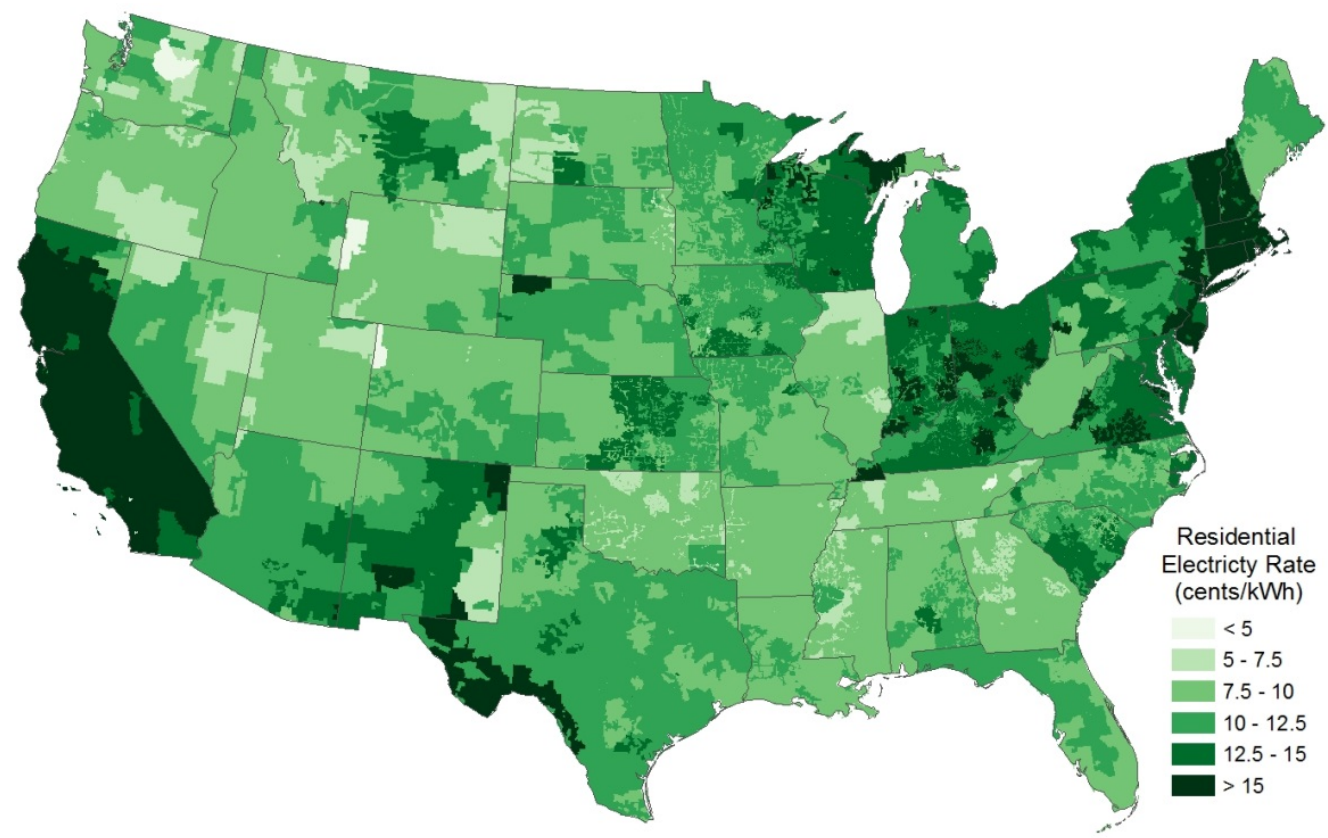

Figure E-7a. DPV - residential retail rate map by utility area (Primary Cases 2 and 3)

Note: The map above displays average residential retail rates by utility (EIA) and do not reflect detailed seasonal, tiered, demand, or time-of-use components that were accounted for in the analysis. 


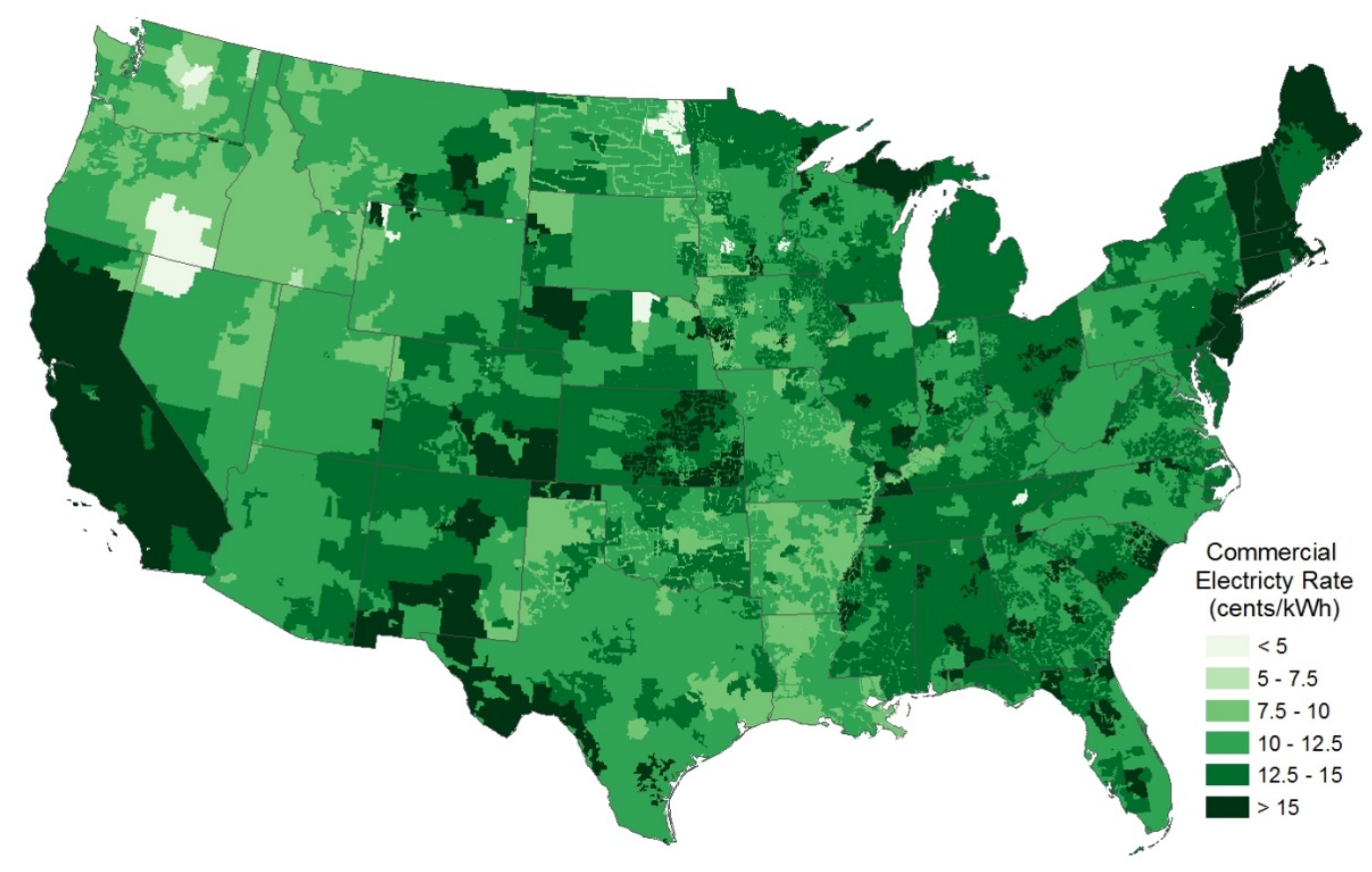

Figure E-7b. DPV - commercial retail rate map by utility area (Primary Cases 2 and 3)

Note: The map above displays average commercial retail rates by utility (EIA) and do not reflect detailed seasonal, tiered, demand, or time-of-use components that were accounted for in the analysis.

Net Value (Breakeven Cost - System Cost)

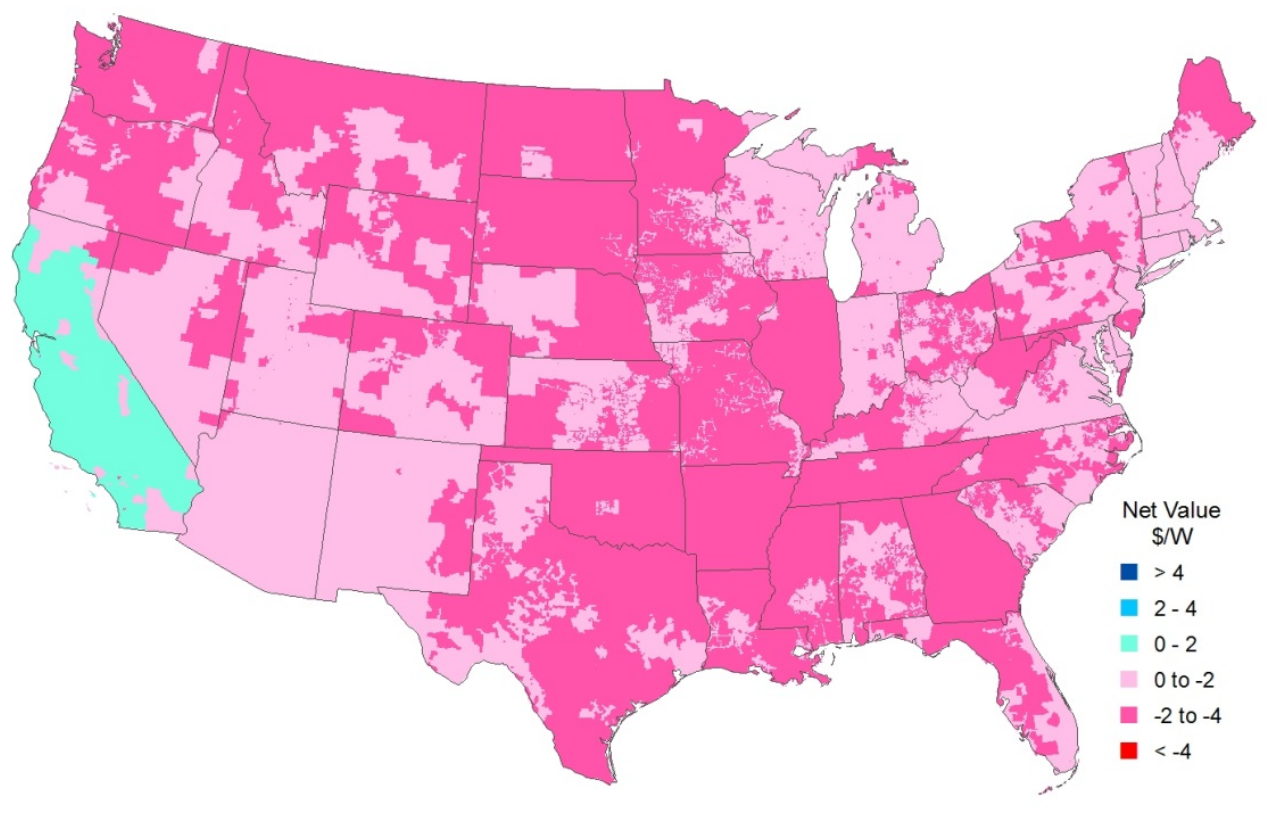

Figure E-8a. DPV - residential net value map by utility area (Primary Cases 2 and 3) 


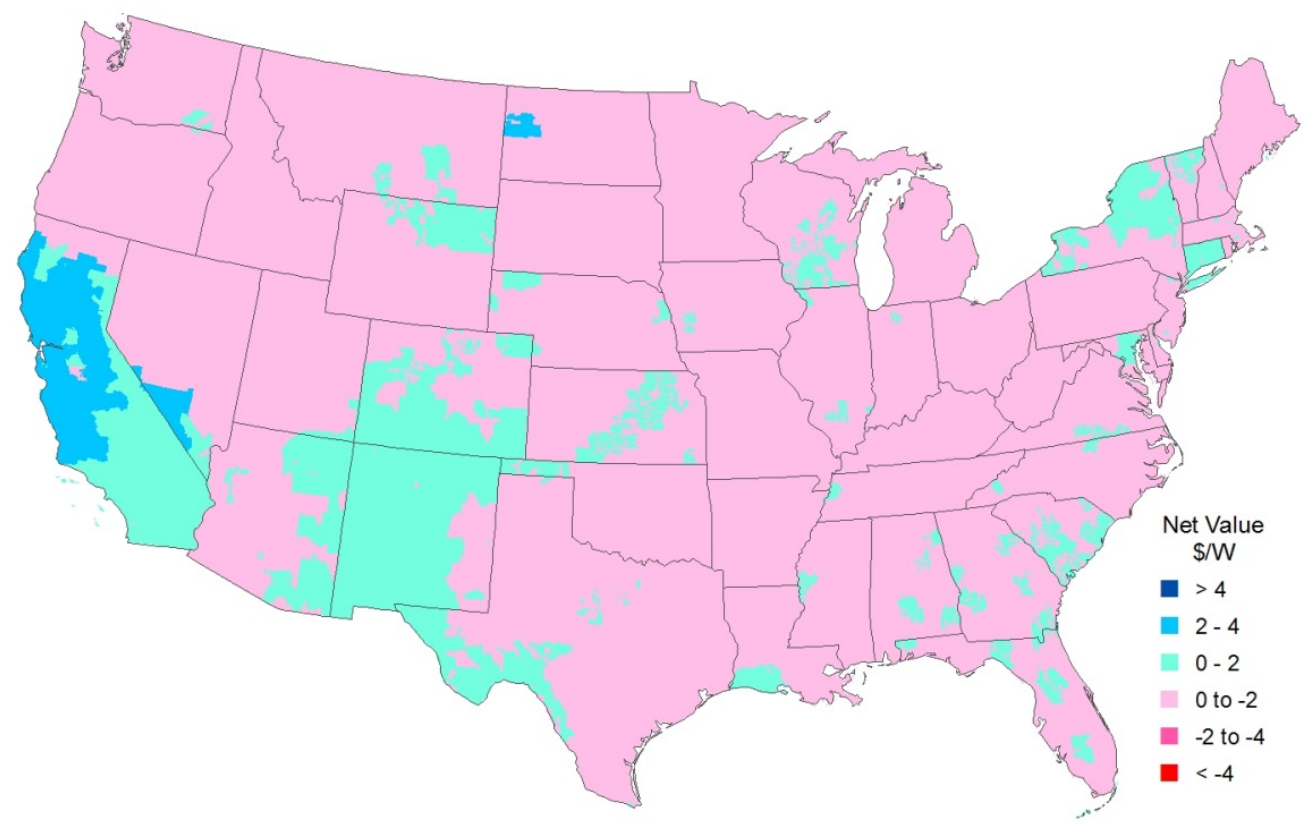

Figure E-8b. DPV - commercial net value map (medium-sized office building) by utility area (Primary Cases $\mathbf{2}$ and 3 )

Note: The commercial sector comprises many building types; net value varies by building type. The map above displays net value for the medium office building type.

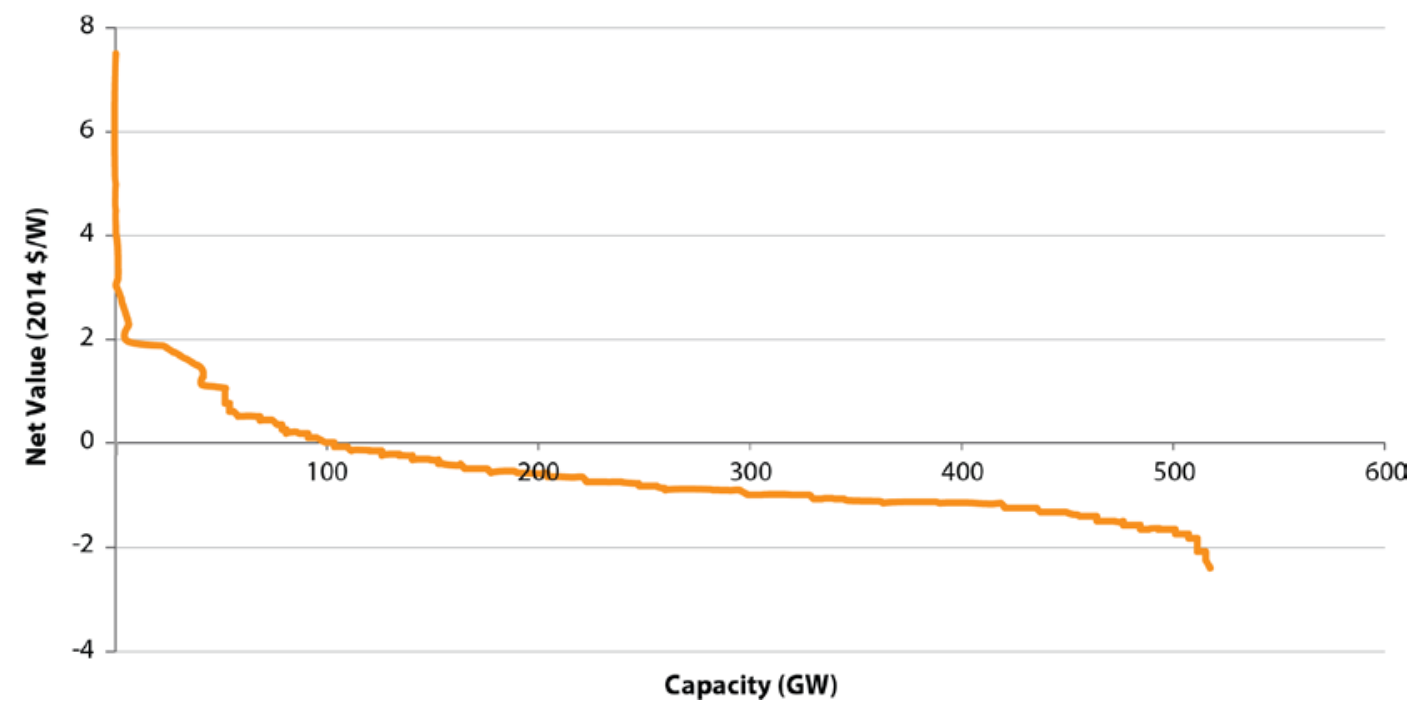

Figure E-9a. DPV - aggregated U.S. residential net value supply curve (Primary Cases 2 and 3)) 


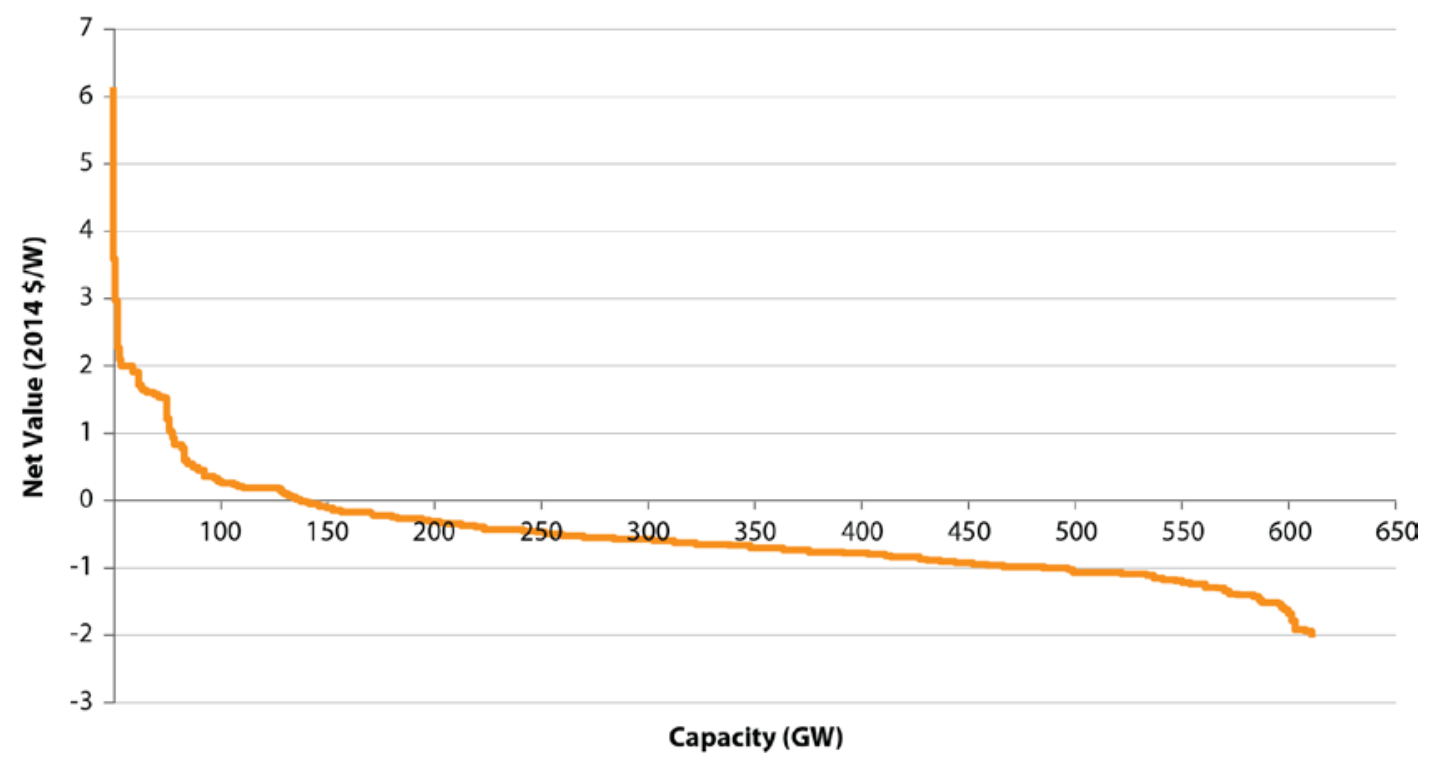

Figure E-9b. DPV aggregated U.S. commercial net value supply curve (Primary Cases 2 and 3)) Note: Capacity shown is incremental to 2013 level.

\section{Hydropower}

$\angle C O E$

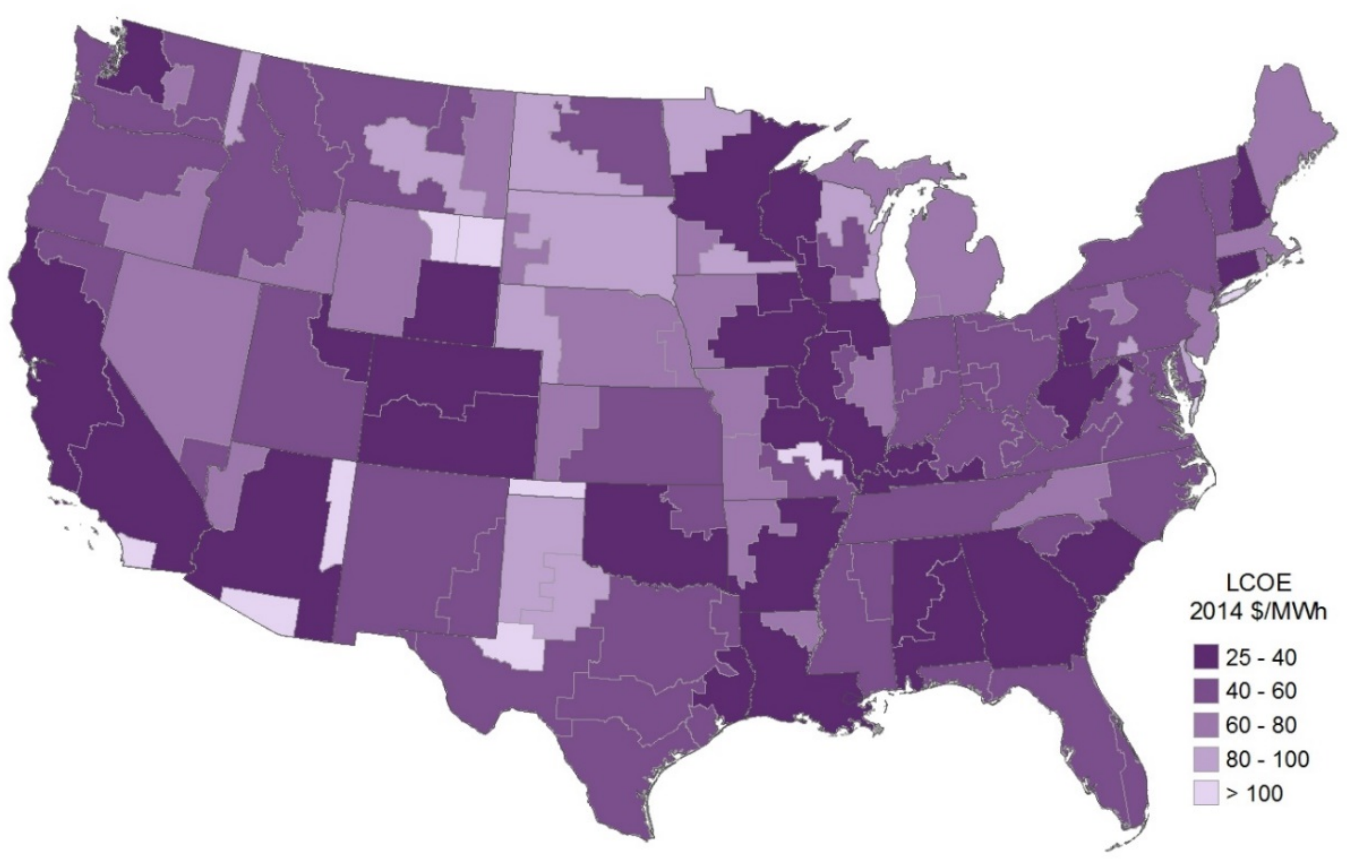

Figure E-10a. Hydropower LCOE map (Primary Cases 2 and 3) 


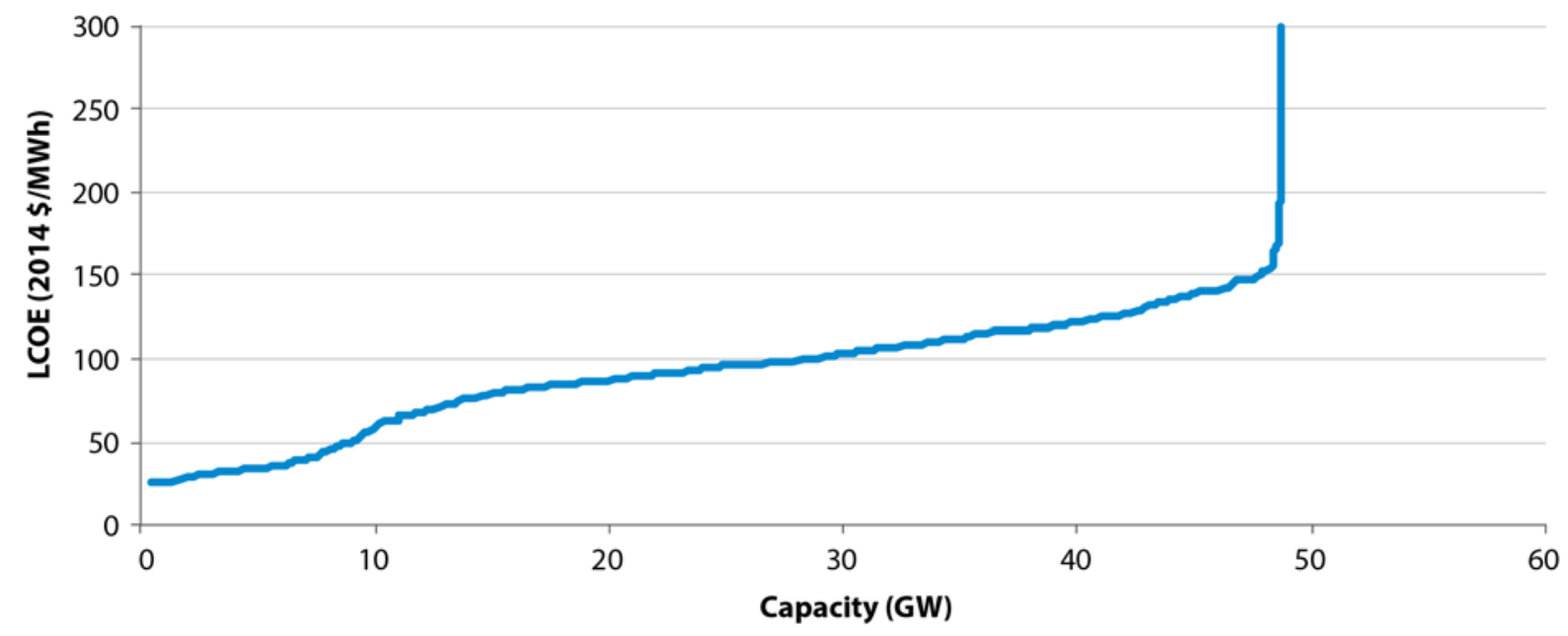

Figure E-10b. Hydropower aggregated U.S. LCOE supply curve (Primary Cases 2 and 3)

\section{LACE}

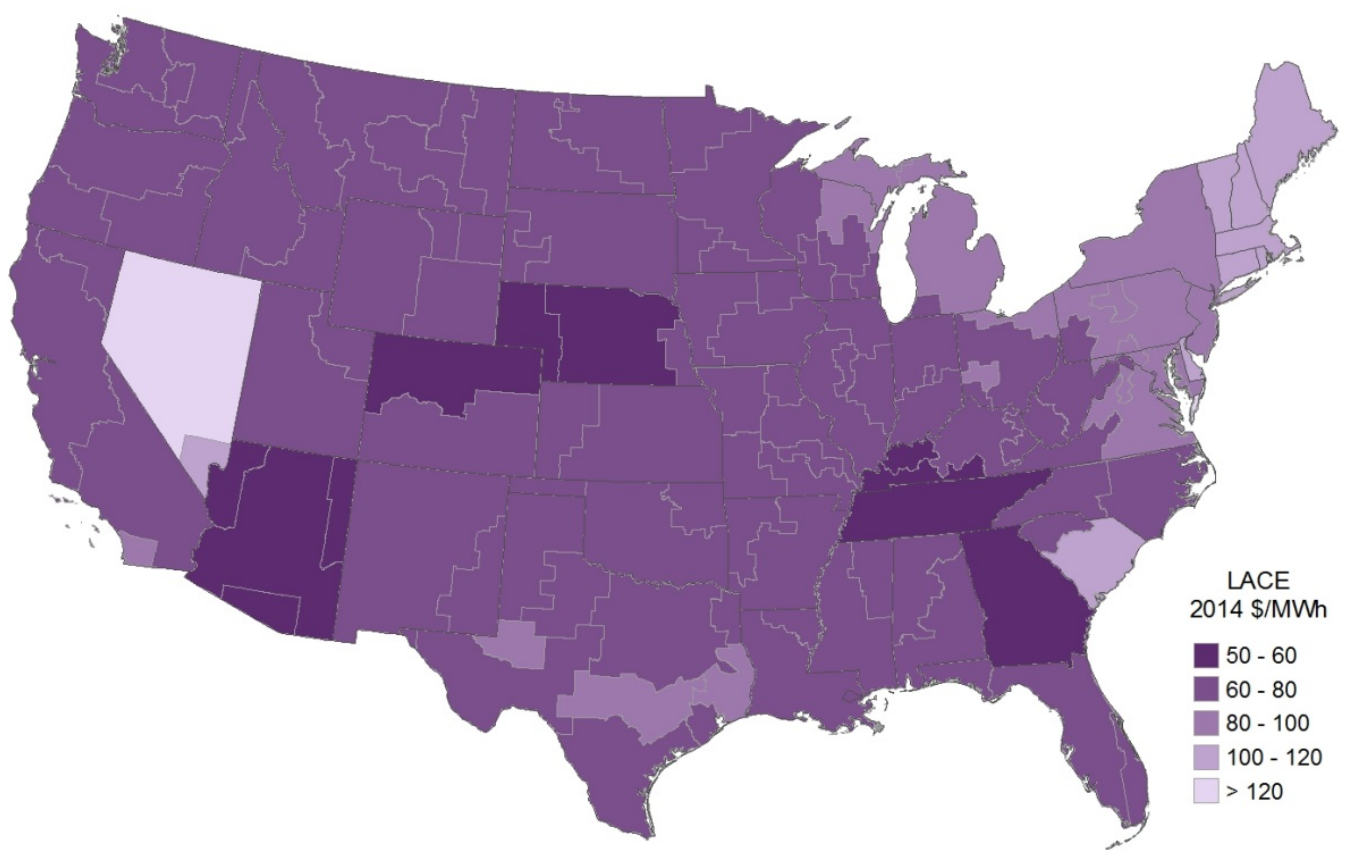

Figure E-11. Hydropower LACE map (Primary Cases 2 and 3 with full credit for renewable generation capacity value) 
Net Value

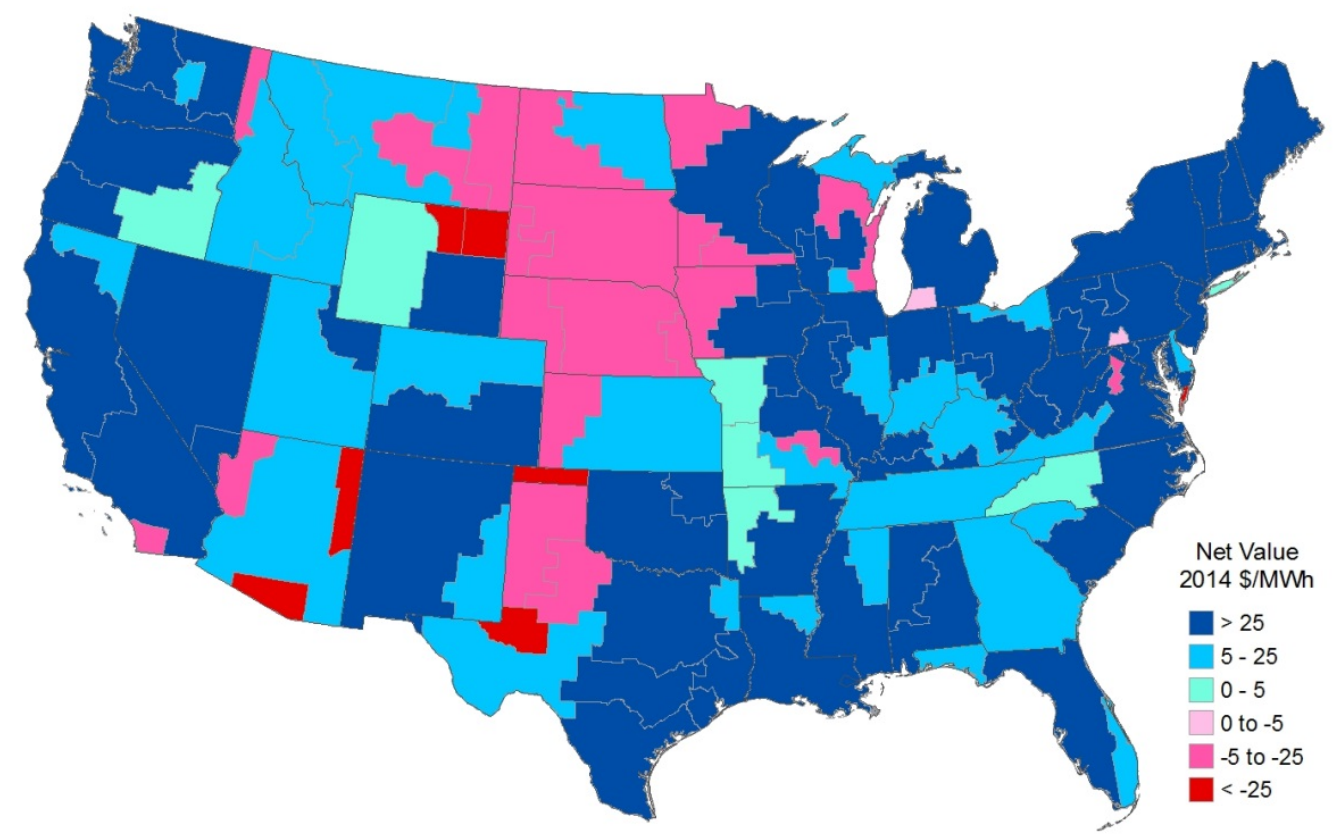

Figure E-12a. Hydropower net value map (Primary Cases 2 and 3 with full credit for renewable generation capacity value)

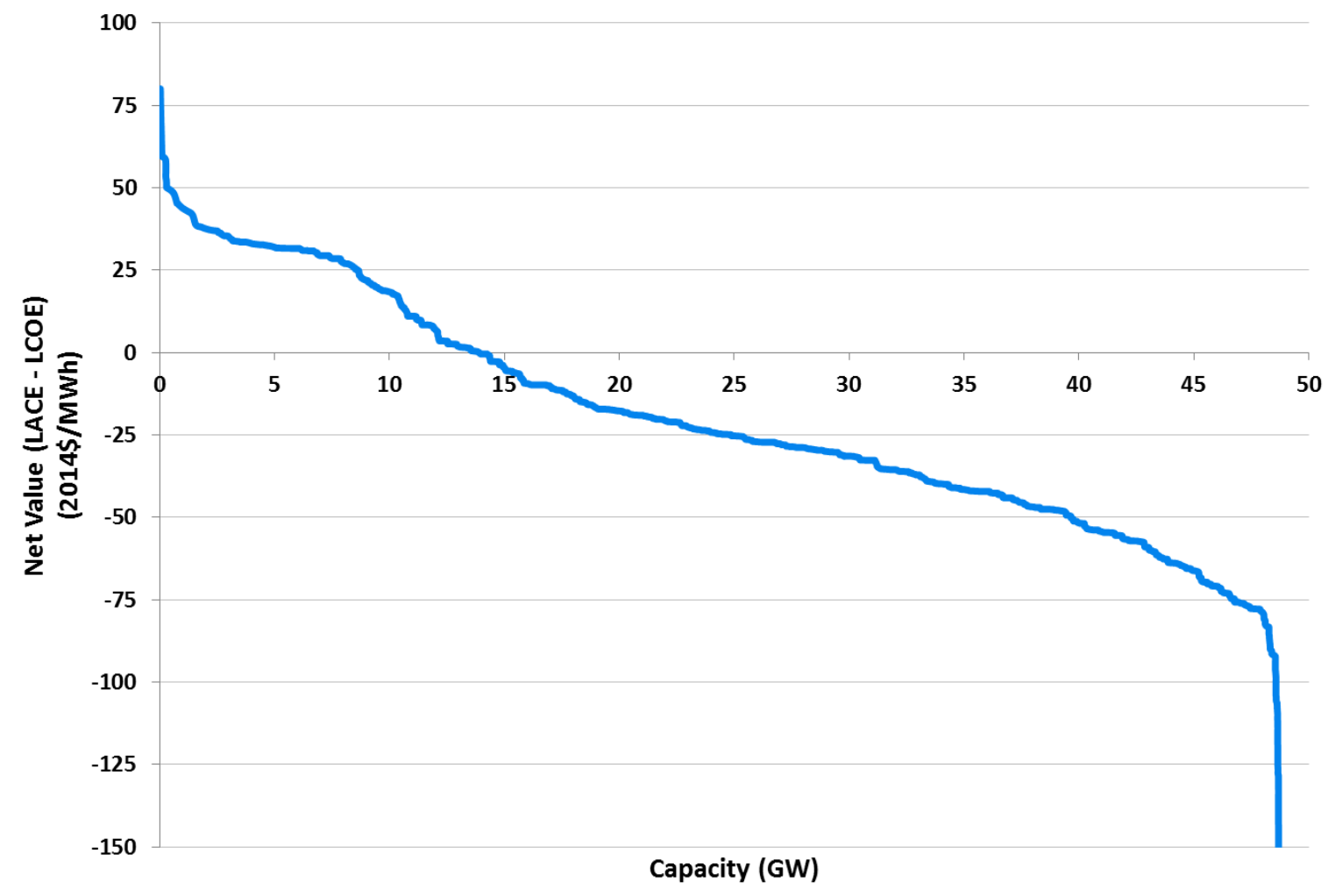

Figure E-12b. Hydropower aggregated U.S. net value supply curve (Primary Cases 2 and 3 with full credit for renewable generation capacity value)

Note: Capacity shown is incremental to 2013 level. 


\section{Geothermal (Hydrothermal Resources Only)}

$\angle C O E$

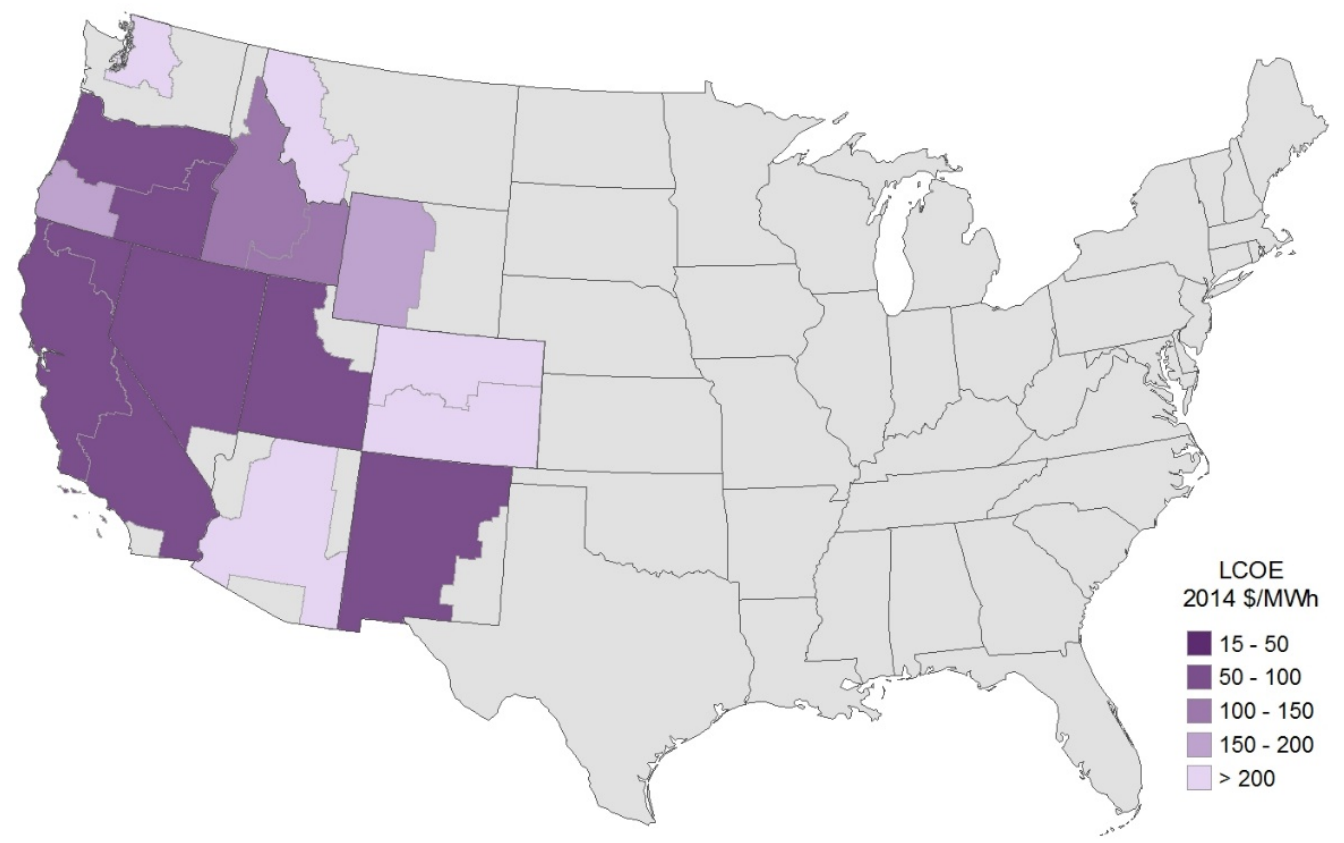

Figure E-13a. Geothermal LCOE map (Primary Cases 2 and 3 )

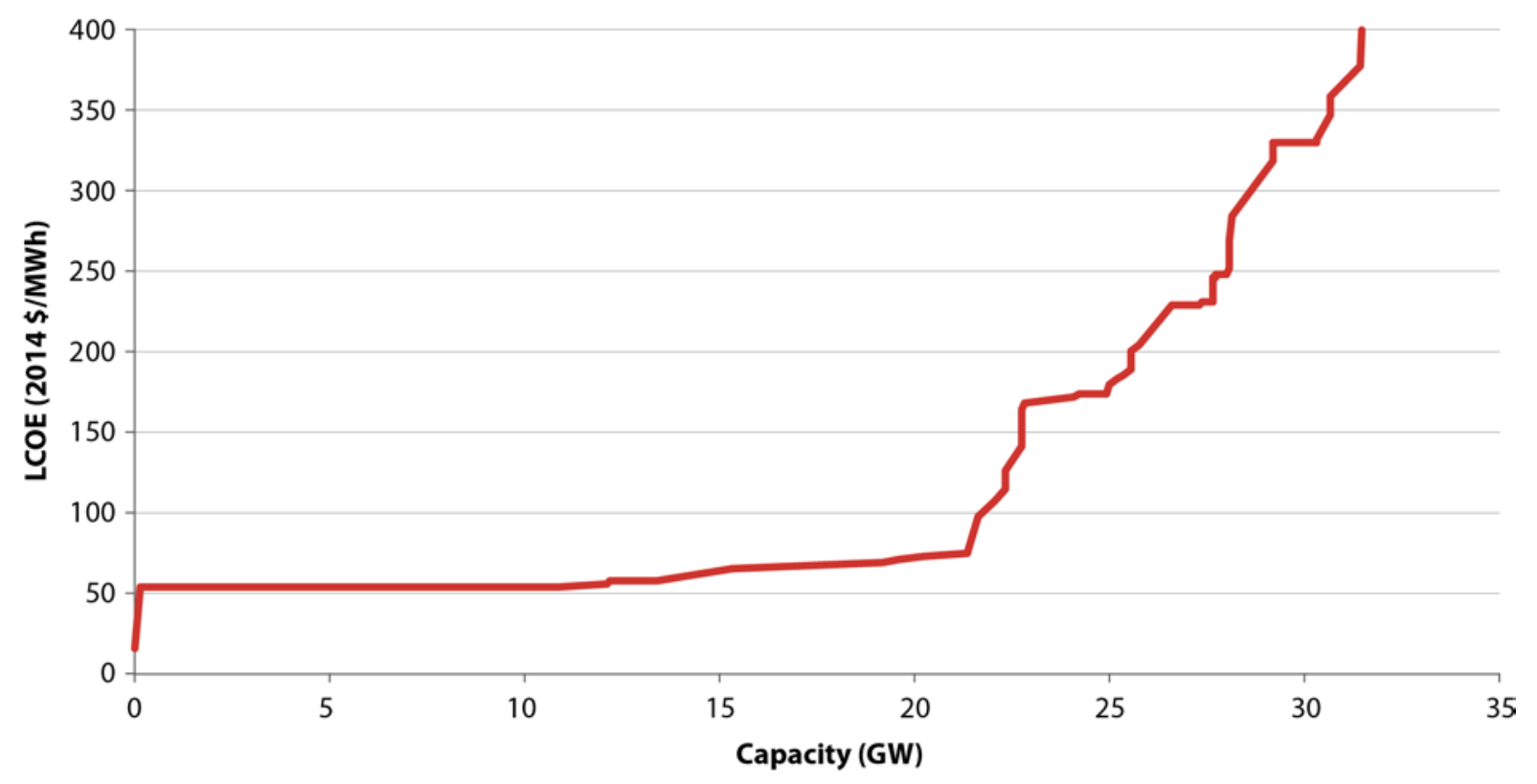

Figure E-13b. Geothermal aggregated U.S. geothermal LCOE supply curve (Primary Cases 2 and 3) 


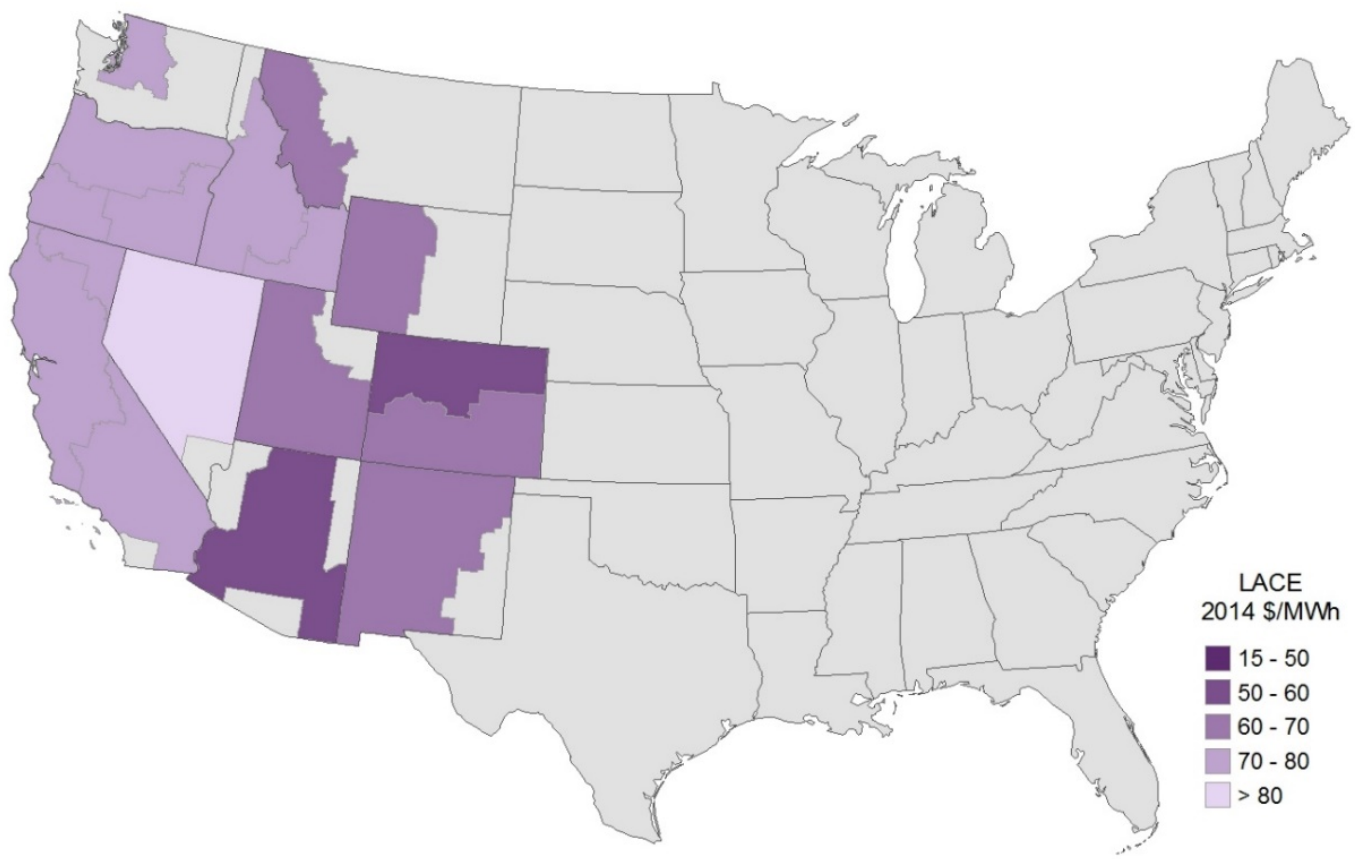

Figure E-14. Geothermal LACE map (Primary Cases 2 and 3 with full credit for renewable generation capacity value)

Net Value

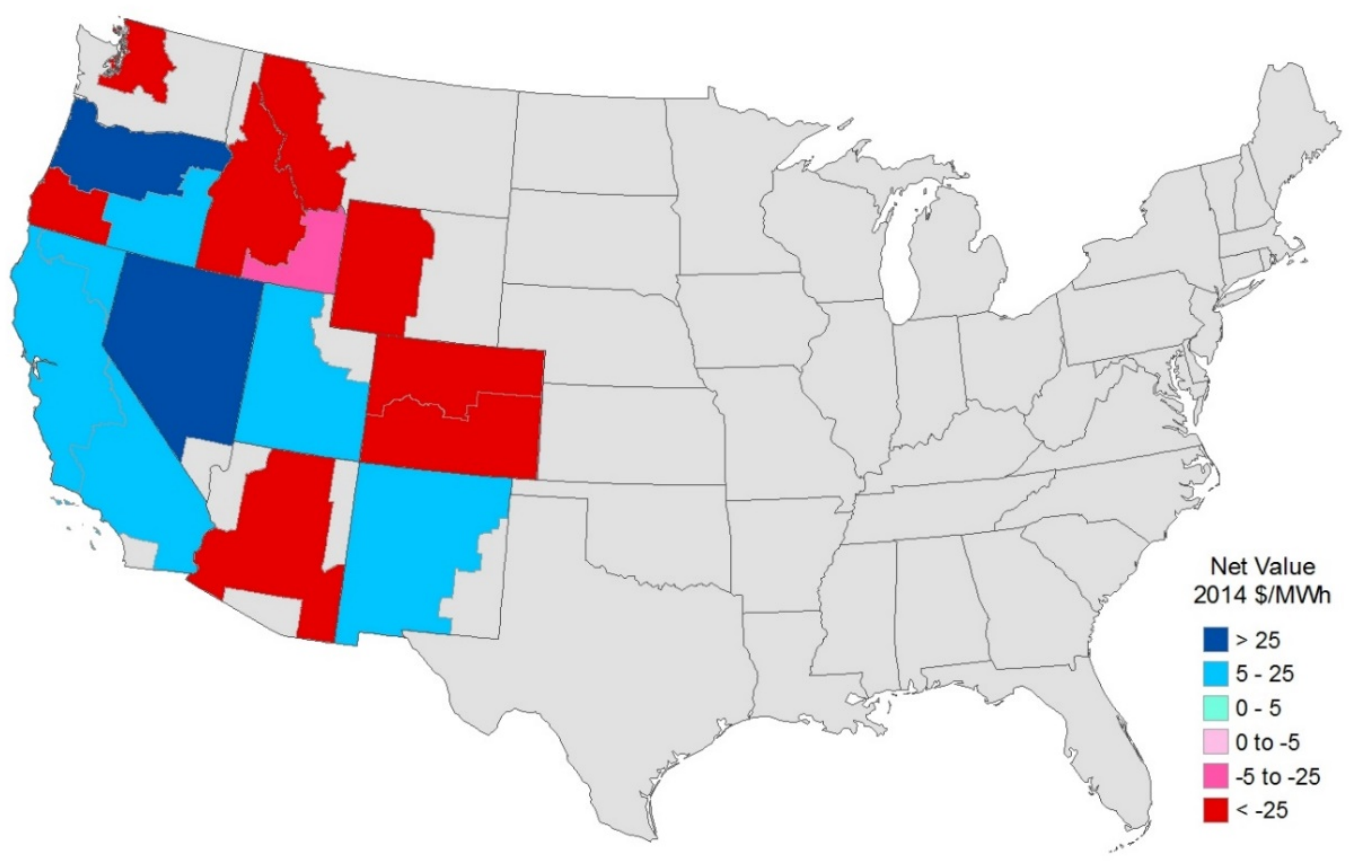

Figure E-15a. Geothermal net value map (Primary Cases 2 and 3 with full credit for renewable generation capacity value) 


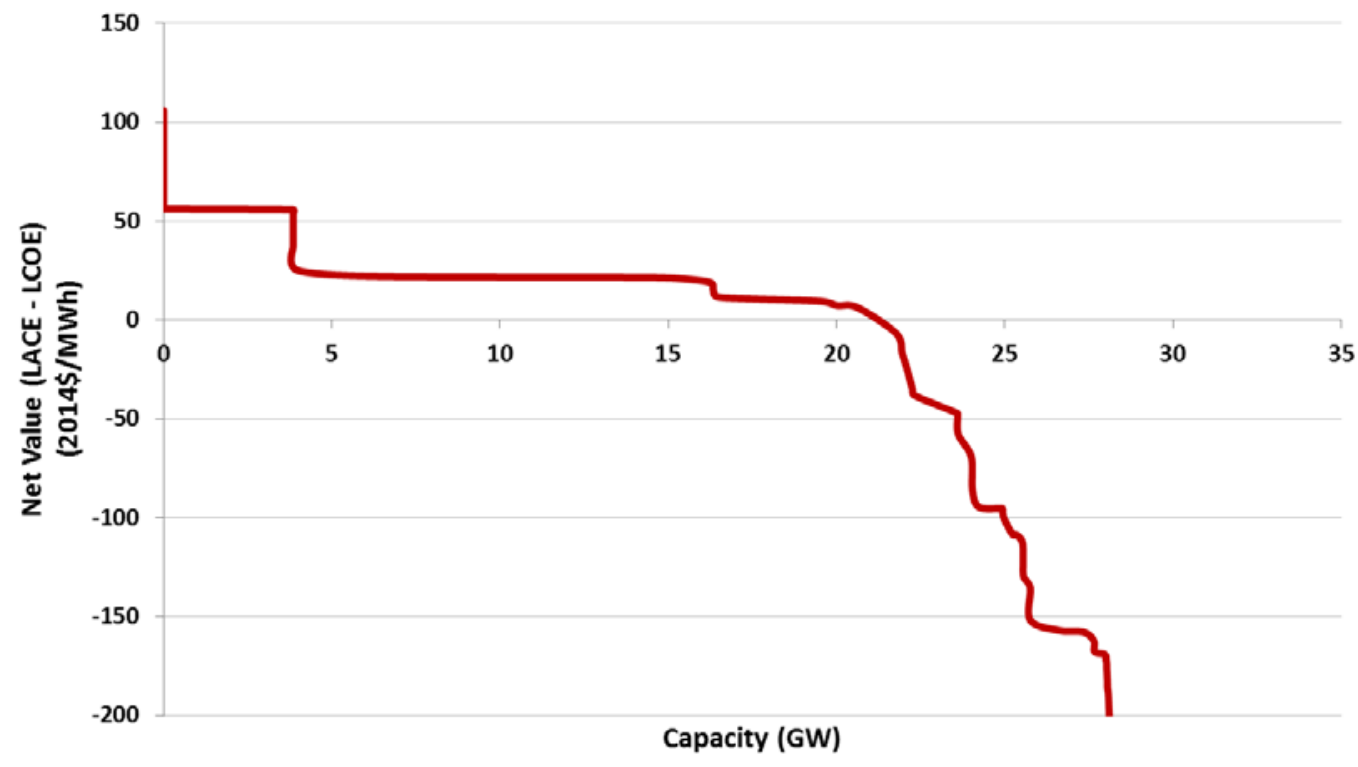

Figure E-15b. Geothermal aggregated U.S. net value supply curve (Primary Cases 2 and 3 with full credit for renewable generation capacity value)

Note: Capacity shown is incremental to 2013 level.

\section{Biopower \\ $\angle C O E$}

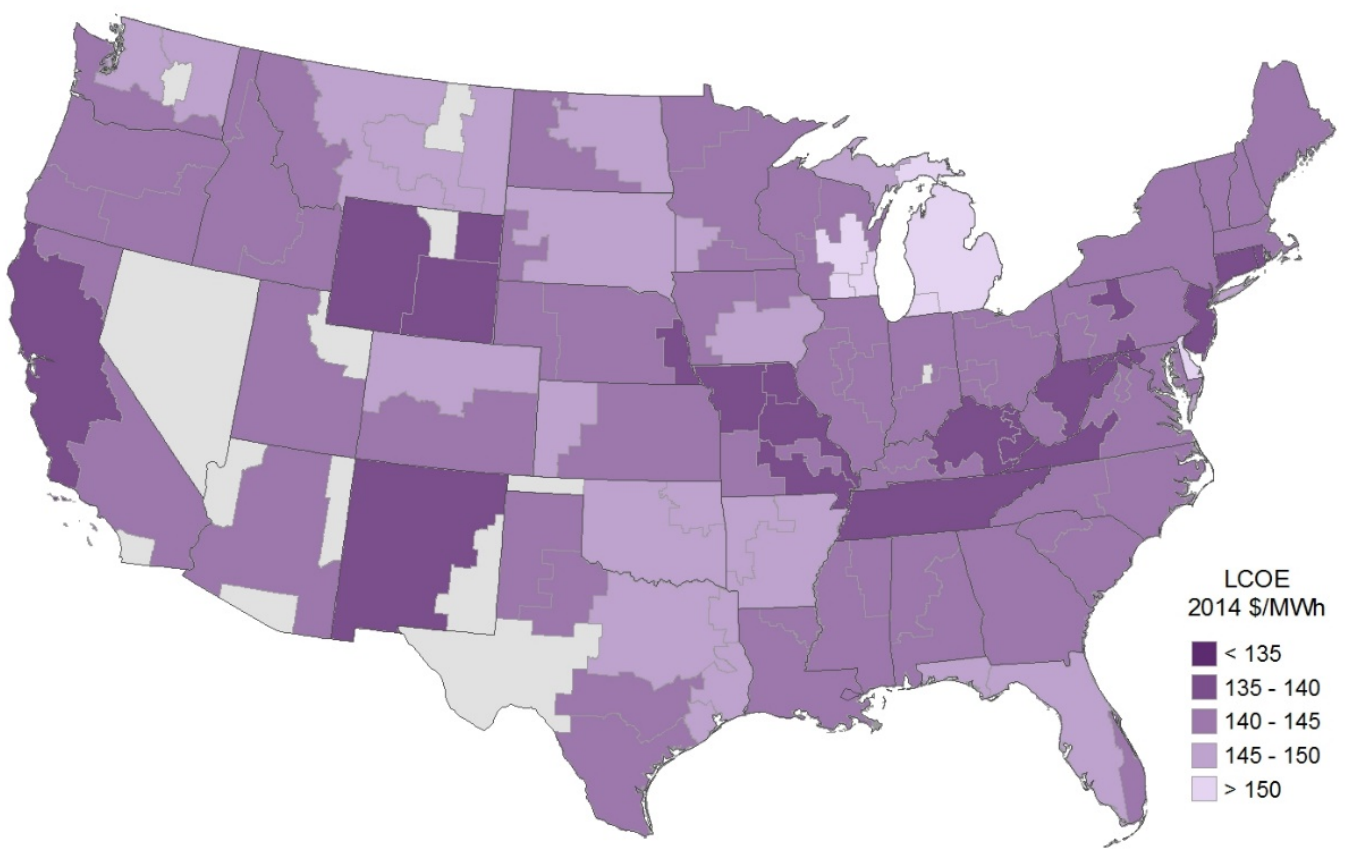

Figure E-16a. Biopower LCOE map (Primary Cases 2 and 3) 


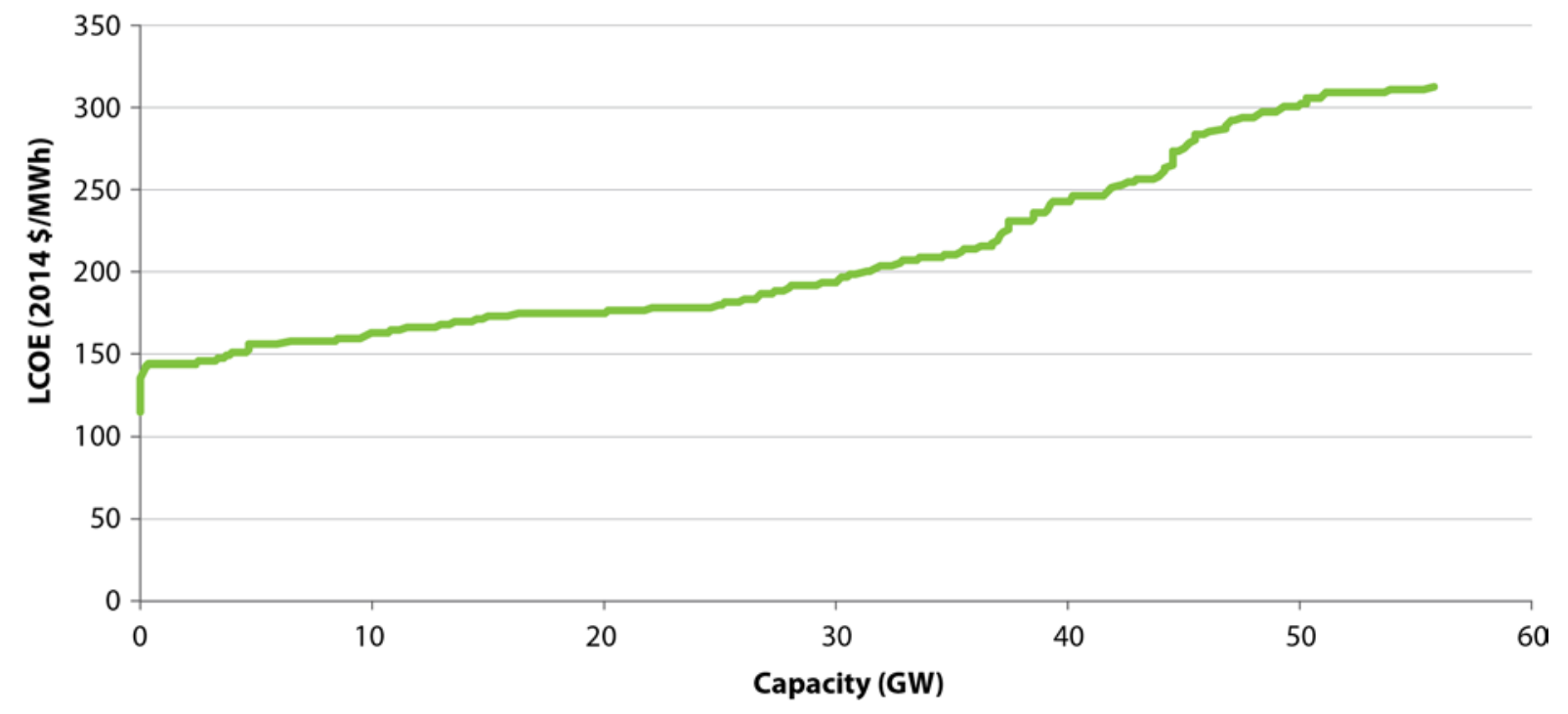

Figure E-16b. Biopower aggregated U.S LCOE supply curve (Primary Cases 2 and 3)

LACE

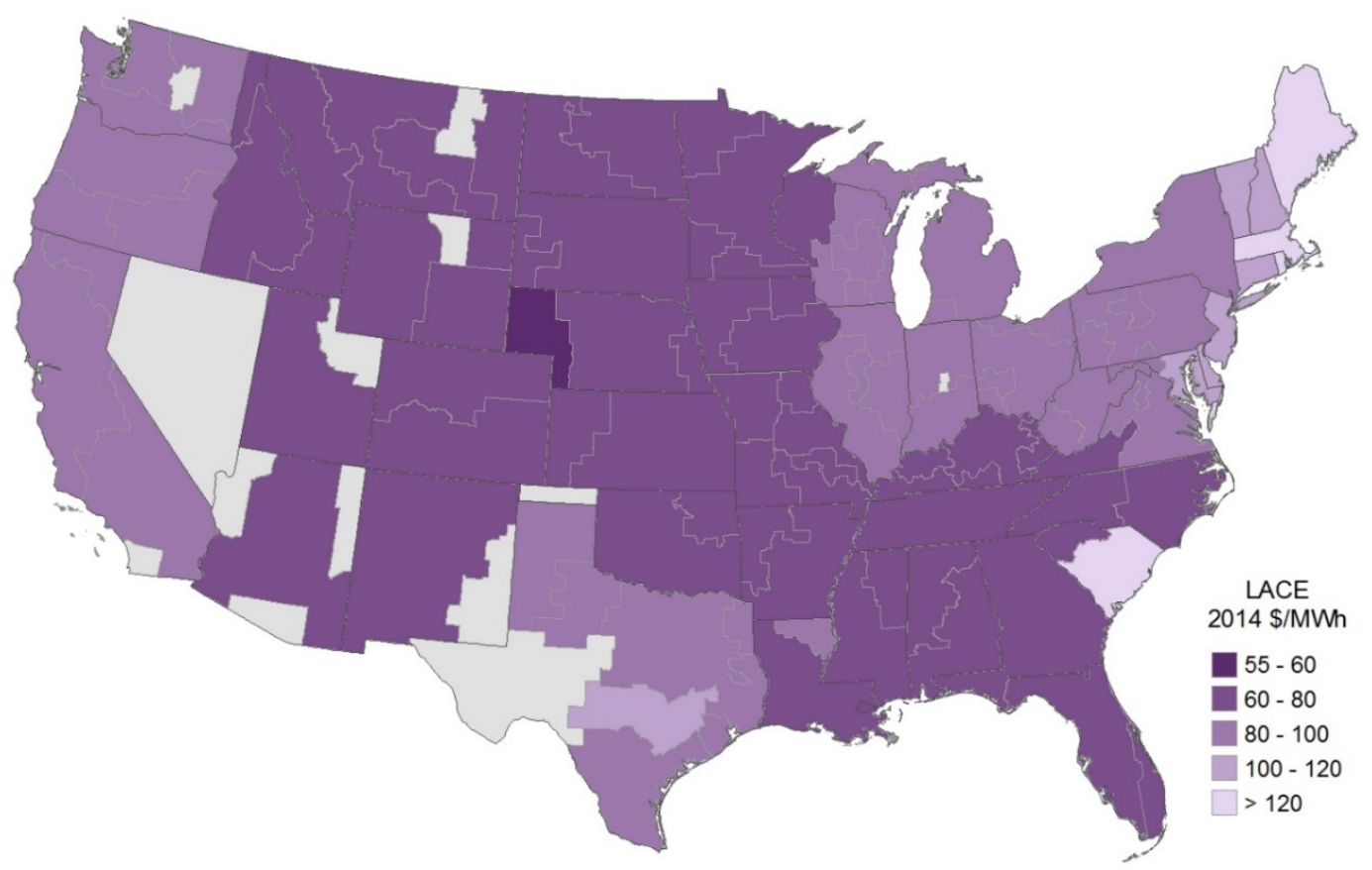

Figure E-17. Biopower LACE map (Primary Cases 2 and 3 with full credit for renewable generation capacity value) 


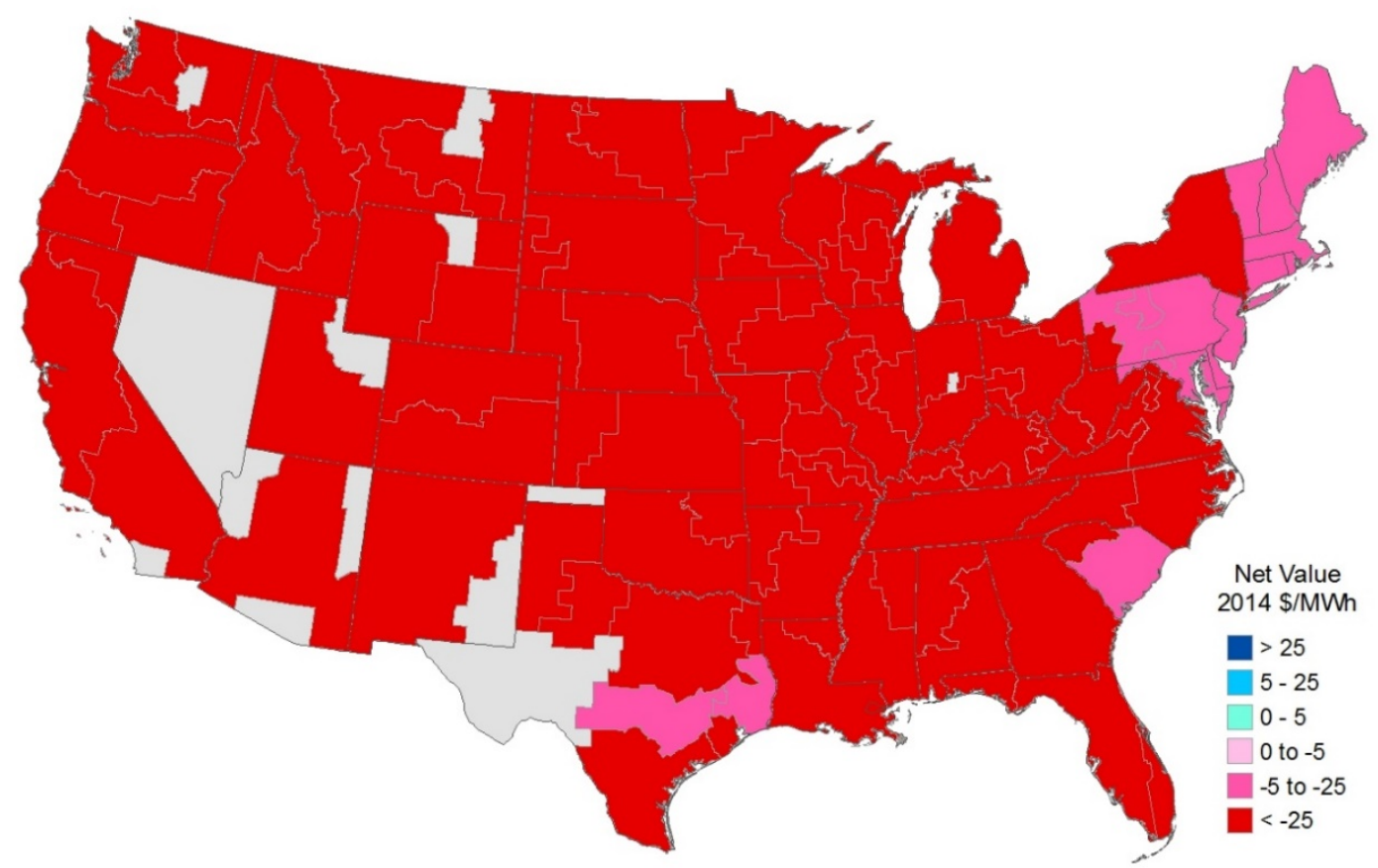

Figure E-18a. Biopower net value map (Primary Cases 2 and 3 with full credit for renewable generation capacity value)

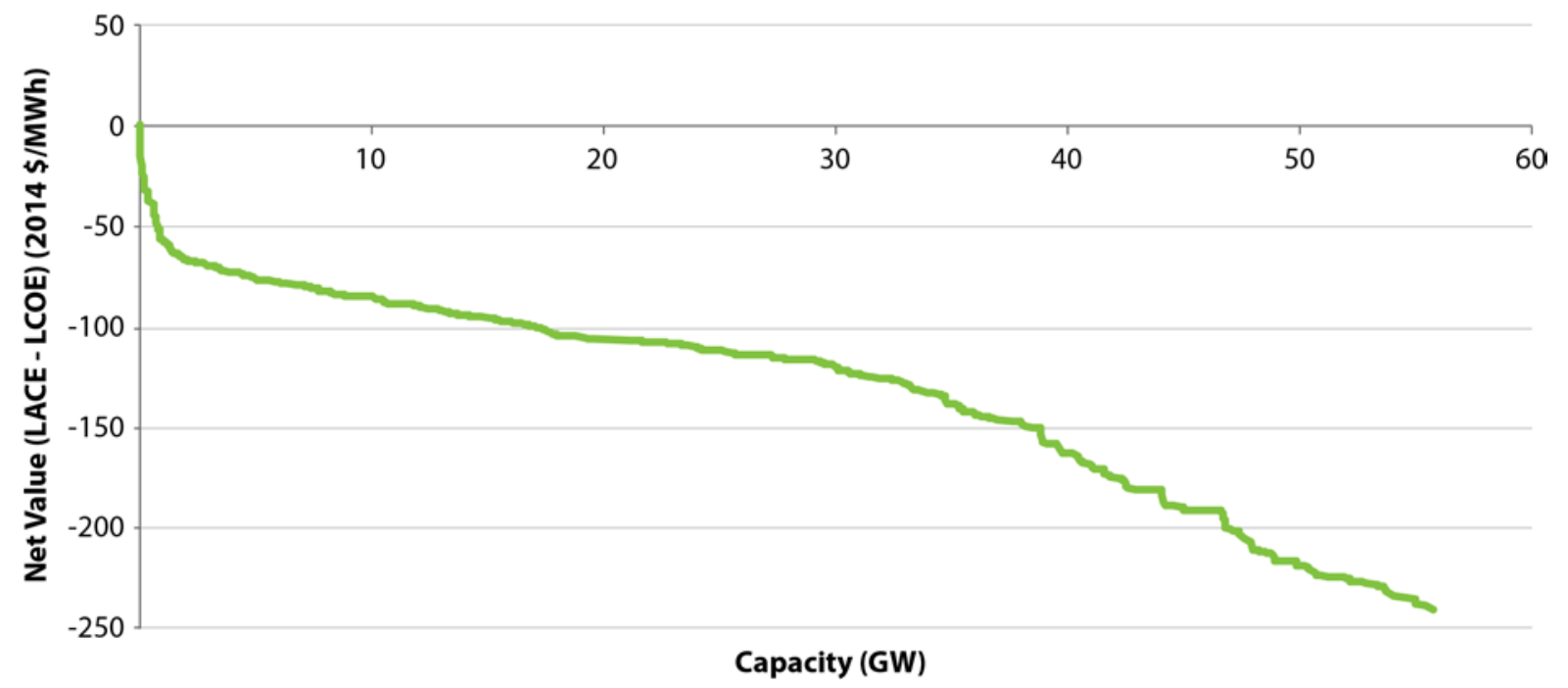

Figure E-18b. Biopower aggregated U.S. net value supply curve (Primary Cases 2 and 3 with full credit for renewable generation capacity value)

Note: Capacity shown is incremental to 2013 level. 


\section{Appendix F. Economic Potential Estimates (Primary Cases) by State}

Table F-1. Economic Potential Estimates (Primary Case 1a) by State

\begin{tabular}{|c|c|c|c|c|c|c|c|}
\hline \multirow[b]{2}{*}{ State } & \multicolumn{7}{|c|}{ Economic Potential - Annual Generation (TWh) } \\
\hline & Wind & UPV & DPV & $\begin{array}{l}\text { Hydro- } \\
\text { power }\end{array}$ & \begin{tabular}{|l|} 
Geo- \\
thermal
\end{tabular} & $\begin{array}{l}\text { Bio- } \\
\text { power }\end{array}$ & $\begin{array}{l}\text { Sum of } \\
\text { Assessed }\end{array}$ \\
\hline Alabama & 0.0 & 0.0 & 0.0 & 4.1 & 0.0 & 0.0 & 4.1 \\
\hline Arizona & 0.0 & 0.0 & 1.9 & 0.0 & 0.0 & 0.0 & 1.9 \\
\hline Arkansas & 0.0 & 0.0 & 0.0 & 5.3 & 0.0 & 0.0 & 5.3 \\
\hline California & 0.0 & 0.0 & 113.1 & 0.7 & 79.5 & 0.0 & 193.3 \\
\hline Colorado & 0.0 & 0.0 & 9.6 & 0.5 & 0.0 & 0.0 & 10.1 \\
\hline Connecticut & 0.1 & 9.3 & 2.3 & 0.3 & 0.0 & 0.0 & 12.0 \\
\hline Delaware & 0.0 & 0.0 & 0.0 & 0.0 & 0.0 & 0.0 & 0.0 \\
\hline $\begin{array}{l}\text { District of } \\
\text { Columbia }\end{array}$ & 0.0 & 0.0 & 0.0 & 0.0 & 0.0 & 0.0 & 0.0 \\
\hline Florida & 0.0 & 0.0 & 1.1 & 0.5 & 0.0 & 0.0 & 1.6 \\
\hline Georgia & 0.0 & 0.0 & 0.2 & 0.3 & 0.0 & 0.0 & 0.5 \\
\hline Idaho & 0.0 & 0.0 & 0.0 & 0.0 & 0.0 & 0.0 & 0.0 \\
\hline Illinois & 0.0 & 0.0 & 0.0 & 4.8 & 0.0 & 0.0 & 4.8 \\
\hline Indiana & 0.0 & 0.0 & 0.0 & 0.2 & 0.0 & 0.0 & 0.2 \\
\hline lowa & 0.0 & 0.0 & 0.0 & 3.2 & 0.0 & 0.0 & 3.2 \\
\hline Kansas & 0.0 & 0.0 & 0.4 & 0.0 & 0.0 & 0.0 & 0.4 \\
\hline Kentucky & 0.0 & 0.0 & 0.0 & 9.8 & 0.0 & 0.0 & 9.8 \\
\hline Louisiana & 0.0 & 0.0 & 0.0 & 3.7 & 0.0 & 0.0 & 3.7 \\
\hline Maine & 5.2 & 5.8 & 0.0 & 0.0 & 0.0 & 0.0 & 11.1 \\
\hline Maryland & 0.0 & 0.0 & 4.7 & 0.2 & 0.0 & 0.0 & 4.9 \\
\hline Massachusetts & 0.9 & 29.9 & 8.1 & 0.2 & 0.0 & 0.0 & 39.1 \\
\hline Michigan & 0.0 & 0.0 & 0.0 & 0.1 & 0.0 & 0.0 & 0.1 \\
\hline Minnesota & 0.0 & 0.0 & 0.0 & 0.6 & 0.0 & 0.0 & 0.6 \\
\hline Mississippi & 0.0 & 0.0 & 0.0 & 0.6 & 0.0 & 0.0 & 0.6 \\
\hline Missouri & 0.0 & 0.0 & 0.0 & 1.5 & 0.0 & 0.0 & 1.5 \\
\hline Montana & 0.0 & 0.0 & 0.0 & 0.1 & 0.0 & 0.0 & 0.1 \\
\hline Nebraska & 0.0 & 0.0 & 0.1 & 0.0 & 0.0 & 0.0 & 0.1 \\
\hline Nevada & 35.5 & 5757.0 & 0.0 & 0.2 & 28.7 & 0.0 & 5821.3 \\
\hline New Hampshire & 1.0 & 10.4 & 2.3 & 0.2 & 0.0 & 0.0 & 13.8 \\
\hline New Jersey & 0.0 & 0.0 & 5.5 & 0.0 & 0.0 & 0.0 & 5.6 \\
\hline New Mexico & 0.0 & 0.0 & 0.7 & 0.4 & 0.0 & 0.0 & 1.1 \\
\hline New York & 1.2 & 0.0 & 20.2 & 1.3 & 0.0 & 0.0 & 22.7 \\
\hline North Carolina & 0.0 & 0.0 & 0.7 & 0.3 & 0.0 & 0.0 & 1.1 \\
\hline North Dakota & 0.0 & 0.0 & 0.0 & 0.0 & 0.0 & 0.0 & 0.0 \\
\hline Ohio & 0.0 & 0.0 & 0.0 & 0.9 & 0.0 & 0.0 & 0.9 \\
\hline Oklahoma & 0.0 & 0.0 & 0.5 & 0.9 & 0.0 & 0.0 & 1.4 \\
\hline Oregon & 0.0 & 0.0 & 0.0 & 0.4 & 0.9 & 0.0 & 1.3 \\
\hline Pennsylvania & 0.0 & 0.0 & 0.0 & 3.1 & 0.0 & 0.0 & 3.1 \\
\hline Rhode Island & 0.1 & 34.0 & 0.0 & 0.0 & 0.0 & 0.0 & 34.2 \\
\hline South Carolina & 0.0 & 466.9 & 8.2 & 0.4 & 0.0 & 0.0 & 475.5 \\
\hline South Dakota & 0.0 & 0.0 & 0.0 & 0.0 & 0.0 & 0.0 & 0.0 \\
\hline Tennessee & 0.0 & 0.0 & 0.0 & 0.0 & 0.0 & 0.0 & 0.0 \\
\hline Texas & 270.4 & 72.8 & 0.9 & 1.6 & 0.0 & 0.0 & 345.6 \\
\hline Utah & 0.0 & 0.0 & 0.0 & 0.1 & 0.0 & 0.0 & 0.1 \\
\hline Vermont & 3.7 & 2.2 & 0.2 & 0.1 & 0.0 & 0.0 & 6.2 \\
\hline Virginia & 0.6 & 80.0 & 11.6 & 0.0 & 0.0 & 0.0 & 92.2 \\
\hline Washington & 0.0 & 0.0 & 0.0 & 0.4 & 0.0 & 0.0 & 0.4 \\
\hline West Virginia & 0.0 & 0.0 & 0.0 & 0.9 & 0.0 & 0.0 & 0.9 \\
\hline Wisconsin & 0.0 & 0.0 & 1.1 & 1.3 & 0.0 & 0.0 & 2.4 \\
\hline Wyoming & 0.0 & 0.0 & 0.0 & 0.2 & 0.0 & 0.0 & 0.2 \\
\hline
\end{tabular}

Note: Annual generation shown is incremental to 2013 level. 
Table F- 2. Economic Potential Estimates (Primary Case 1b) by State

\begin{tabular}{|c|c|c|c|c|c|c|c|}
\hline \multirow[b]{2}{*}{ State } & \multicolumn{7}{|c|}{ Economic Potential - Annual Generation (TWh) } \\
\hline & Wind & UPV & DPV & $\begin{array}{l}\text { Hydro- } \\
\text { power }\end{array}$ & \begin{tabular}{|l|}
$\begin{array}{l}\text { Geo- } \\
\text { thermal }\end{array}$ \\
\end{tabular} & $\begin{array}{l}\text { Bio- } \\
\text { power }\end{array}$ & $\begin{array}{l}\text { Sum of } \\
\text { Assessed }\end{array}$ \\
\hline Alabama & 0.0 & 0.0 & 0.0 & 3.6 & 0.0 & 0.0 & 3.6 \\
\hline Arizona & 0.0 & 0.0 & 1.9 & 0.0 & 0.0 & 0.0 & 1.9 \\
\hline Arkansas & 0.0 & 0.0 & 0.0 & 4.4 & 0.0 & 0.0 & 4.4 \\
\hline California & 0.0 & 0.0 & 113.1 & 0.5 & 0.0 & 0.0 & 113.7 \\
\hline Colorado & 0.0 & 0.0 & 9.6 & 0.5 & 0.0 & 0.0 & 10.1 \\
\hline Connecticut & 0.0 & 0.0 & 2.3 & \begin{tabular}{l|l}
0.3 \\
\end{tabular} & 0.0 & 0.0 & 2.6 \\
\hline Delaware & 0.0 & 0.0 & 0.0 & 0.0 & 0.0 & 0.0 & 0.0 \\
\hline $\begin{array}{l}\text { District of } \\
\text { Columbia }\end{array}$ & 0.0 & 0.0 & 0.0 & 0.0 & 0.0 & 0.0 & 0.0 \\
\hline Florida & 0.0 & 0.0 & 1.1 & 0.0 & 0.0 & 0.0 & 1.1 \\
\hline Georgia & 0.0 & 0.0 & 0.2 & 0.0 & 0.0 & 0.0 & 0.2 \\
\hline Idaho & 0.0 & 0.0 & 0.0 & 0.0 & 0.0 & 0.0 & 0.0 \\
\hline Illinois & 0.0 & 0.0 & 0.0 & 4.7 & 0.0 & 0.0 & 4.7 \\
\hline Indiana & 0.0 & 0.0 & 0.0 & 0.0 & 0.0 & 0.0 & 0.0 \\
\hline Iowa & 0.0 & 0.0 & 0.0 & 2.9 & 0.0 & 0.0 & 2.9 \\
\hline Kansas & 0.0 & 0.0 & 0.4 & 0.0 & 0.0 & 0.0 & 0.4 \\
\hline Kentucky & 0.0 & 0.0 & 0.0 & 5.5 & 0.0 & 0.0 & 5.5 \\
\hline Louisiana & 0.0 & 0.0 & 0.0 & 3.4 & 0.0 & 0.0 & 3.4 \\
\hline Maine & 2.9 & 0.0 & 0.0 & 0.0 & 0.0 & 0.0 & 3.0 \\
\hline Maryland & 0.0 & 0.0 & 4.7 & 0.2 & 0.0 & 0.0 & 4.9 \\
\hline Massachusetts & 0.8 & 0.0 & 8.1 & 0.2 & 0.0 & 0.0 & 9.0 \\
\hline Michigan & 0.0 & 0.0 & 0.0 & 0.0 & 0.0 & 0.0 & 0.0 \\
\hline Minnesota & 0.0 & 0.0 & 0.0 & 0.6 & 0.0 & 0.0 & 0.6 \\
\hline Mississippi & 0.0 & 0.0 & 0.0 & 0.2 & 0.0 & 0.0 & 0.2 \\
\hline Missouri & 0.0 & 0.0 & 0.0 & 1.4 & 0.0 & 0.0 & 1.4 \\
\hline Montana & 0.0 & 0.0 & 0.0 & 0.0 & 0.0 & 0.0 & 0.0 \\
\hline Nebraska & 0.0 & 0.0 & 0.1 & 0.0 & 0.0 & 0.0 & 0.1 \\
\hline Nevada & 18.6 & 2511.9 & 0.0 & 0.1 & 28.7 & 0.0 & 2559.2 \\
\hline New Hampshire & 0.5 & 0.0 & 2.3 & 0.2 & 0.0 & 0.0 & 2.9 \\
\hline New Jersey & 0.0 & 0.0 & 5.5 & 0.0 & 0.0 & 0.0 & 5.6 \\
\hline New Mexico & 0.0 & 0.0 & 0.7 & 0.0 & 0.0 & 0.0 & 0.7 \\
\hline New York & 0.0 & 0.0 & 20.2 & 1.0 & 0.0 & 0.0 & 21.2 \\
\hline North Carolina & 0.0 & 0.0 & 0.7 & 0.0 & 0.0 & 0.0 & 0.7 \\
\hline North Dakota & 0.0 & 0.0 & 0.0 & 0.0 & 0.0 & 0.0 & 0.0 \\
\hline Ohio & 0.0 & 0.0 & 0.0 & 0.5 & 0.0 & 0.0 & 0.5 \\
\hline Oklahoma & 0.0 & 0.0 & 0.5 & 0.7 & 0.0 & 0.0 & 1.2 \\
\hline Oregon & 0.0 & 0.0 & 0.0 & 0.3 & 0.0 & 0.0 & 0.3 \\
\hline Pennsylvania & 0.0 & 0.0 & 0.0 & 3.1 & 0.0 & 0.0 & 3.1 \\
\hline Rhode Island & 0.0 & 0.0 & 0.0 & 0.0 & 0.0 & 0.0 & 0.1 \\
\hline South Carolina & 0.0 & 234.2 & 8.2 & 0.4 & 0.0 & 0.0 & 242.7 \\
\hline South Dakota & 0.0 & 0.0 & 0.0 & 0.0 & 0.0 & 0.0 & 0.0 \\
\hline Tennessee & 0.0 & 0.0 & 0.0 & 0.0 & 0.0 & 0.0 & 0.0 \\
\hline Texas & 108.8 & 0.0 & 0.9 & 1.0 & 0.0 & 0.0 & 110.7 \\
\hline Utah & 0.0 & 0.0 & 0.0 & 0.0 & 0.0 & 0.0 & 0.0 \\
\hline Vermont & 3.0 & 0.0 & 0.2 & 0.1 & 0.0 & 0.0 & 3.2 \\
\hline Virginia & 0.5 & 42.4 & 11.6 & 0.0 & 0.0 & 0.0 & 54.6 \\
\hline Washington & 0.0 & 0.0 & 0.0 & 0.2 & 0.0 & 0.0 & 0.3 \\
\hline West Virginia & 0.0 & 0.0 & 0.0 & 0.7 & 0.0 & 0.0 & 0.7 \\
\hline Wisconsin & 0.0 & 0.0 & 1.1 & 1.1 & 0.0 & 0.0 & 2.2 \\
\hline Wyoming & \begin{tabular}{l|l|}
0.0 \\
\end{tabular} & 0.0 & 0.0 & \begin{tabular}{l|l|}
0.0 \\
\end{tabular} & 0.0 & 0.0 & 0.0 \\
\hline
\end{tabular}

Note: Annual generation shown is incremental to 2013 level. 
Table F- 3. Economic Potential Estimates (Primary Case 2a) by State

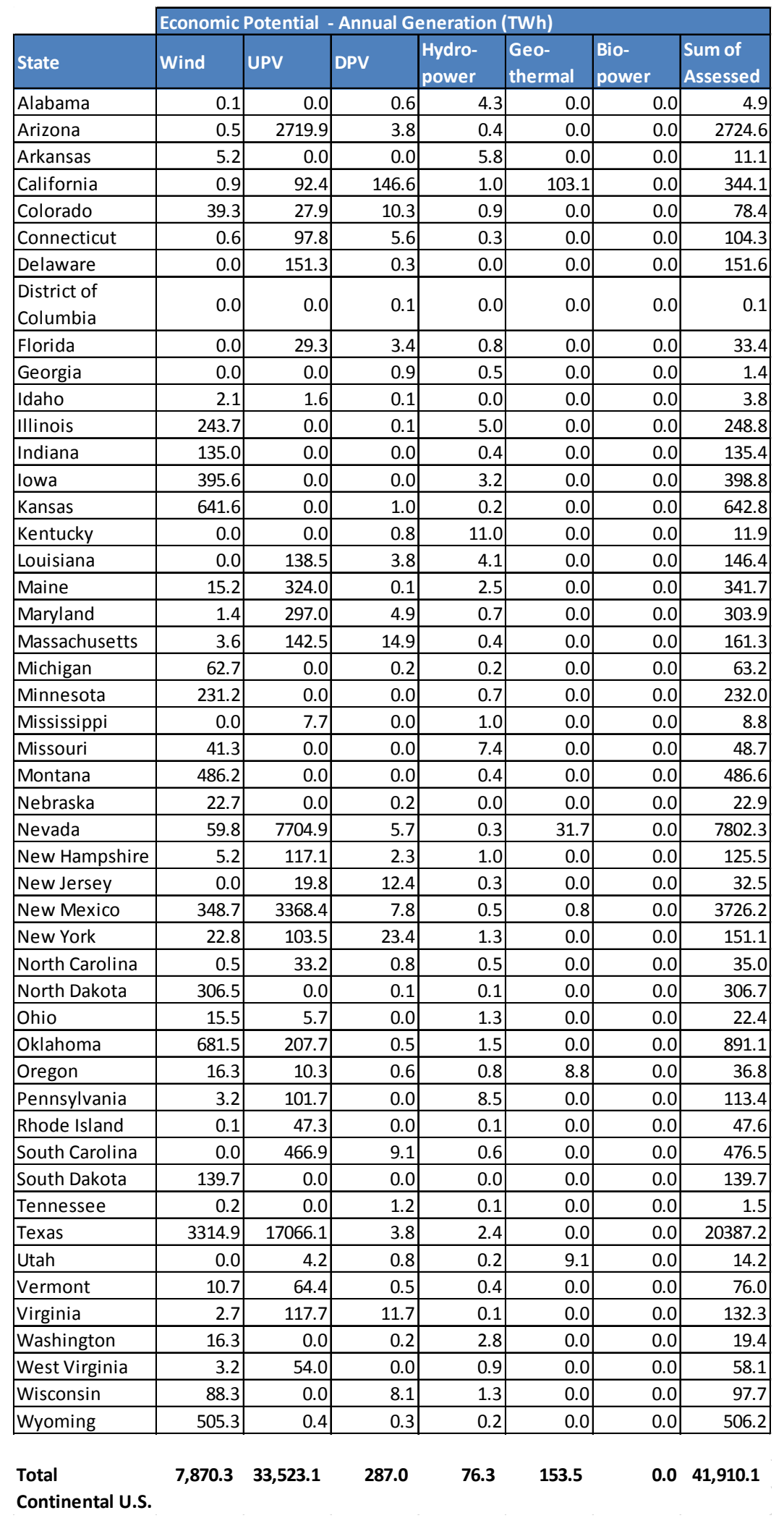

Note: Annual generation shown is incremental to 2013 level. 
Table F- 4. Economic Potential Estimates (Primary Case 2b) by State

\begin{tabular}{|c|c|c|c|c|c|c|c|}
\hline \multirow[b]{2}{*}{ State } & \multicolumn{7}{|c|}{ Economic Potential - Annual Generation (TWh) } \\
\hline & Wind & UPV & DPV & $\begin{array}{l}\text { Hydro- } \\
\text { power }\end{array}$ & \begin{tabular}{|l|l} 
Geo- \\
thermal
\end{tabular} & $\begin{array}{l}\text { Bio- } \\
\text { power }\end{array}$ & \begin{tabular}{|l|} 
Sum of \\
Assessed
\end{tabular} \\
\hline Alabama & 0.0 & 0.0 & 0.6 & \begin{tabular}{|r|}
4.3 \\
\end{tabular} & \begin{tabular}{r|}
0.0 \\
\end{tabular} & 0.0 & 4.8 \\
\hline Arizona & 0.0 & 0.0 & 3.8 & 0.3 & 0.0 & 0.0 & 4.2 \\
\hline Arkansas & 4.3 & 0.0 & 0.0 & 5.3 & 0.0 & 0.0 & 9.6 \\
\hline California & 0.0 & 0.0 & 146.6 & 0.9 & 88.7 & 0.0 & 236.1 \\
\hline Colorado & 5.8 & 0.0 & 10.3 & 0.8 & 0.0 & 0.0 & 16.9 \\
\hline Connecticut & 0.5 & 9.3 & 5.6 & \begin{tabular}{l|l}
0.3 \\
\end{tabular} & 0.0 & 0.0 & 15.8 \\
\hline Delaware & 0.0 & 0.0 & 0.3 & 0.0 & 0.0 & 0.0 & 0.3 \\
\hline $\begin{array}{l}\text { District of } \\
\text { Columbia } \\
\end{array}$ & 0.0 & 0.0 & 0.1 & 0.0 & 0.0 & 0.0 & 0.1 \\
\hline Florida & 0.0 & 0.0 & 3.4 & 0.8 & 0.0 & 0.0 & 4.1 \\
\hline Georgia & 0.0 & 0.0 & 0.9 & 0.5 & 0.0 & 0.0 & 1.4 \\
\hline Idaho & 2.0 & 0.0 & 0.1 & 0.0 & 0.0 & 0.0 & 2.1 \\
\hline Illinois & 120.2 & 0.0 & 0.1 & 4.8 & 0.0 & 0.0 & 125.1 \\
\hline Indiana & 85.1 & 0.0 & 0.0 & 0.3 & 0.0 & 0.0 & 85.4 \\
\hline lowa & 145.8 & 0.0 & 0.0 & 3.2 & 0.0 & 0.0 & 149.0 \\
\hline Kansas & 97.4 & 0.0 & 1.0 & 0.1 & 0.0 & 0.0 & 98.5 \\
\hline Kentucky & 0.0 & 0.0 & 0.8 & 11.0 & 0.0 & 0.0 & 11.8 \\
\hline Louisiana & 0.0 & 0.0 & 3.8 & 3.8 & 0.0 & 0.0 & 7.6 \\
\hline \begin{tabular}{|l|} 
Maine \\
\end{tabular} & 11.5 & 5.8 & 0.1 & 1.7 & 0.0 & 0.0 & 19.1 \\
\hline Maryland & 0.3 & 0.0 & 4.9 & 0.2 & 0.0 & 0.0 & 5.4 \\
\hline Massachusetts & 3.2 & 29.8 & 14.9 & 0.4 & 0.0 & 0.0 & 48.3 \\
\hline \begin{tabular}{|l|} 
Michigan \\
\end{tabular} & 28.1 & 0.0 & 0.2 & 0.2 & 0.0 & 0.0 & 28.5 \\
\hline Minnesota & 35.3 & 0.0 & 0.0 & 0.6 & 0.0 & 0.0 & 36.0 \\
\hline Mississippi & 0.0 & 0.0 & 0.0 & 1.0 & 0.0 & 0.0 & 1.1 \\
\hline Missouri & 9.0 & 0.0 & 0.0 & 1.5 & 0.0 & 0.0 & 10.5 \\
\hline \begin{tabular}{|l} 
Montana \\
\end{tabular} & 147.9 & 0.0 & 0.0 & 0.4 & 0.0 & 0.0 & 148.3 \\
\hline Nebraska & 0.3 & 0.0 & 0.2 & 0.0 & 0.0 & 0.0 & 0.4 \\
\hline Nevada & 59.7 & 6737.9 & 5.7 & 0.2 & 31.7 & 0.0 & 6835.1 \\
\hline New Hampshire & 4.2 & 12.4 & 2.3 & 1.0 & 0.0 & 0.0 & 19.9 \\
\hline New Jersey & 0.0 & 0.0 & 12.4 & 0.1 & 0.0 & 0.0 & 12.5 \\
\hline New Mexico & 187.7 & 0.0 & 7.8 & 0.5 & 0.8 & 0.0 & 196.8 \\
\hline New York & 12.8 & 0.0 & 23.4 & 1.3 & 0.0 & 0.0 & 37.6 \\
\hline North Carolina & 0.3 & 0.0 & 0.8 & 0.5 & 0.0 & 0.0 & 1.6 \\
\hline \begin{tabular}{|l|} 
North Dakota \\
\end{tabular} & 128.7 & 0.0 & 0.1 & 0.0 & 0.0 & 0.0 & 128.8 \\
\hline \begin{tabular}{|l|} 
Ohio \\
\end{tabular} & 7.2 & 0.0 & 0.0 & 1.2 & 0.0 & 0.0 & 8.5 \\
\hline Oklahoma & 386.8 & 0.0 & 0.5 & \begin{tabular}{l|l}
1.3 \\
\end{tabular} & 0.0 & 0.0 & 388.6 \\
\hline Oregon & 0.3 & 0.0 & 0.6 & 0.5 & 0.9 & 0.0 & 2.3 \\
\hline \begin{tabular}{|l|} 
Pennsylvania \\
\end{tabular} & 0.9 & 0.0 & 0.0 & 7.0 & 0.0 & 0.0 & 7.8 \\
\hline Rhode Island & 0.1 & 34.1 & 0.0 & 0.1 & 0.0 & 0.0 & 34.4 \\
\hline South Carolina & 0.0 & 466.9 & 9.1 & 0.4 & 0.0 & 0.0 & 476.4 \\
\hline South Dakota & 44.0 & 0.0 & 0.0 & 0.0 & 0.0 & 0.0 & 44.0 \\
\hline \begin{tabular}{|l|} 
Tennessee \\
\end{tabular} & 0.0 & 0.0 & 1.2 & 0.1 & 0.0 & 0.0 & 1.3 \\
\hline \begin{tabular}{|l|} 
Texas \\
\end{tabular} & 2781.6 & 335.6 & 3.8 & 2.4 & 0.0 & 0.0 & 3123.3 \\
\hline Utah & 0.0 & 0.0 & 0.8 & 0.2 & \begin{tabular}{l|}
9.1 \\
\end{tabular} & 0.0 & 10.0 \\
\hline Vermont & 8.3 & 1.7 & 0.5 & 0.2 & 0.0 & 0.0 & 10.7 \\
\hline Virginia & 2.1 & 80.0 & \begin{tabular}{l|l}
11.7 \\
\end{tabular} & 0.1 & 0.0 & 0.0 & 93.9 \\
\hline Washington & 0.0 & 0.0 & 0.2 & 2.6 & 0.0 & 0.0 & 2.8 \\
\hline West Virginia & 1.9 & 0.0 & 0.0 & 0.9 & 0.0 & 0.0 & 2.9 \\
\hline Wisconsin & 16.4 & 0.0 & 8.1 & 1.3 & 0.0 & 0.0 & 25.8 \\
\hline Wyoming & 250.1 & 0.0 & \begin{tabular}{l|l}
0.3 \\
\end{tabular} & 0.2 & 0.0 & 0.0 & 250.5 \\
\hline
\end{tabular}

Continental U.S.

Note: Annual generation shown is incremental to 2013 level. 
Table F-5. Economic Potential Estimates (Primary Case 3a) by State

\begin{tabular}{|c|c|c|c|c|c|c|c|}
\hline \multirow[b]{2}{*}{ State } & \multicolumn{7}{|c|}{ Economic Potential - Annual Generation (TWh) } \\
\hline & Wind & UPV & DPV & $\begin{array}{l}\text { Hydro- } \\
\text { power }\end{array}$ & \begin{tabular}{|l|} 
Geo- \\
thermal
\end{tabular} & $\begin{array}{l}\text { Bio- } \\
\text { power }\end{array}$ & \begin{tabular}{|l|} 
Sum of \\
Assessed \\
\end{tabular} \\
\hline Alabama & 0.1 & 0.0 & 0.6 & 4.3 & 0.0 & 0.0 & 4.9 \\
\hline Arizona & 0.0 & 11.5 & 3.8 & 0.4 & 0.0 & 0.0 & 15.7 \\
\hline Arkansas & 1.5 & 0.0 & 0.0 & 5.8 & 0.0 & 0.0 & 7.3 \\
\hline California & 0.0 & 5.0 & 146.6 & 1.0 & 103.1 & 0.0 & 255.7 \\
\hline Colorado & 0.0 & 0.0 & 10.3 & 0.9 & 0.0 & 0.0 & 11.2 \\
\hline Connecticut & 0.4 & 3.8 & 5.6 & 0.3 & 0.0 & 0.0 & 10.2 \\
\hline Delaware & 0.0 & 0.0 & 0.3 & 0.0 & 0.0 & 0.0 & 0.3 \\
\hline \begin{tabular}{|l|} 
District of \\
Columbia
\end{tabular} & 0.0 & 0.0 & 0.1 & 0.0 & 0.0 & 0.0 & 0.1 \\
\hline Florida & 0.0 & 0.0 & 3.4 & 0.8 & 0.0 & 0.0 & 4.1 \\
\hline Georgia & 0.0 & 0.0 & 0.9 & 0.5 & 0.0 & 0.0 & 1.4 \\
\hline Idaho & 0.0 & 0.0 & 0.1 & 0.0 & 0.0 & 0.0 & 0.1 \\
\hline Illinois & 74.4 & 0.0 & 0.1 & 5.0 & 0.0 & 0.0 & 79.5 \\
\hline Indiana & 58.5 & 0.0 & 0.0 & 0.4 & 0.0 & 0.0 & 58.9 \\
\hline Iowa & 21.0 & 0.0 & 0.0 & 3.2 & 0.0 & 0.0 & 24.2 \\
\hline Kansas & 0.0 & 0.0 & 1.0 & 0.2 & 0.0 & 0.0 & 1.2 \\
\hline Kentucky & 0.0 & 0.0 & 0.8 & 11.0 & 0.0 & 0.0 & 11.9 \\
\hline Louisiana & 0.0 & 20.7 & 3.8 & 4.1 & 0.0 & 0.0 & 28.6 \\
\hline Maine & 10.1 & 0.1 & 0.1 & 2.5 & 0.0 & 0.0 & 12.7 \\
\hline \begin{tabular}{|l|} 
Maryland \\
\end{tabular} & 1.4 & 0.0 & 4.9 & 0.7 & 0.0 & 0.0 & 6.9 \\
\hline Massachusetts & 3.2 & 15.3 & 14.9 & 0.4 & 0.0 & 0.0 & 33.8 \\
\hline Michigan & 19.0 & 0.0 & 0.2 & 0.2 & 0.0 & 0.0 & 19.4 \\
\hline Minnesota & 0.7 & 0.0 & 0.0 & 0.7 & 0.0 & 0.0 & 1.5 \\
\hline Mississippi & 0.0 & 0.0 & 0.0 & 1.0 & 0.0 & 0.0 & 1.1 \\
\hline \begin{tabular}{|l|} 
Missouri \\
\end{tabular} & 0.0 & 0.0 & 0.0 & 7.4 & 0.0 & 0.0 & 7.4 \\
\hline Montana & 1.9 & 0.0 & 0.0 & 0.4 & 0.0 & 0.0 & 2.3 \\
\hline Nebraska & 0.0 & 0.0 & 0.2 & 0.0 & 0.0 & 0.0 & 0.2 \\
\hline Nevada & 59.3 & 131.2 & 5.7 & 0.3 & 31.7 & 0.0 & 228.1 \\
\hline New Hampshire & 3.8 & 0.0 & 2.3 & 1.0 & 0.0 & 0.0 & 7.0 \\
\hline New Jersey & 0.0 & 0.0 & 12.4 & 0.3 & 0.0 & 0.0 & 12.7 \\
\hline New Mexico & 51.7 & 0.0 & 7.8 & 0.5 & 0.8 & 0.0 & 60.7 \\
\hline New York & 12.0 & 13.1 & 23.4 & 1.3 & 0.0 & 0.0 & 49.9 \\
\hline North Carolina & 0.5 & 0.0 & 0.8 & 0.5 & 0.0 & 0.0 & 1.8 \\
\hline North Dakota & 48.2 & 0.0 & 0.1 & 0.1 & 0.0 & 0.0 & 48.4 \\
\hline Ohio & 8.4 & 0.0 & 0.0 & 1.3 & 0.0 & 0.0 & 9.7 \\
\hline Oklahoma & 30.5 & 3.3 & 0.5 & 1.5 & 0.0 & 0.0 & 35.8 \\
\hline Oregon & 0.0 & 0.0 & 0.6 & 0.8 & 8.8 & 0.0 & 10.2 \\
\hline \begin{tabular}{|l|} 
Pennsylvania \\
\end{tabular} & 3.0 & 0.0 & 0.0 & 8.5 & 0.0 & 0.0 & 11.5 \\
\hline Rhode Island & 0.1 & 27.3 & 0.0 & 0.1 & 0.0 & 0.0 & 27.5 \\
\hline South Carolina & 0.0 & 234.4 & 9.1 & 0.6 & 0.0 & 0.0 & 244.1 \\
\hline South Dakota & 2.9 & 0.0 & 0.0 & 0.0 & 0.0 & 0.0 & 2.9 \\
\hline \begin{tabular}{|l|} 
Tennessee \\
\end{tabular} & 0.2 & 0.0 & 1.2 & 0.1 & 0.0 & 0.0 & 1.4 \\
\hline Texas & 397.2 & 58.8 & 3.8 & 2.4 & 0.0 & 0.0 & 462.3 \\
\hline Utah & 0.0 & 0.0 & 0.8 & 0.2 & 9.1 & 0.0 & 10.0 \\
\hline Vermont & 8.1 & 1.2 & 0.5 & 0.4 & 0.0 & 0.0 & 10.3 \\
\hline Virginia & 2.4 & 80.0 & 11.7 & 0.1 & 0.0 & 0.0 & 94.2 \\
\hline Washington & 0.0 & 0.0 & 0.2 & 2.8 & 0.0 & 0.0 & 3.0 \\
\hline West Virginia & 2.1 & 0.0 & 0.0 & 0.9 & 0.0 & 0.0 & 3.0 \\
\hline Wisconsin & 9.9 & 0.0 & 8.1 & 1.3 & 0.0 & 0.0 & 19.3 \\
\hline Wyoming & 36.0 & 0.0 & 0.3 & 0.2 & 0.0 & 0.0 & 36.4 \\
\hline
\end{tabular}

Note: Annual generation shown is incremental to 2013 level. 
Table F-6. Economic Potential Estimates (Primary Case 3b) by State

\begin{tabular}{|c|c|c|c|c|c|c|c|}
\hline \multirow[b]{2}{*}{ State } & \multicolumn{7}{|c|}{ Economic Potential - Annual Generation (TWh) } \\
\hline & Wind & UPV & DPV & $\begin{array}{l}\text { Hydro- } \\
\text { power }\end{array}$ & \begin{tabular}{|l|}
$\begin{array}{l}\text { Geo- } \\
\text { thermal }\end{array}$ \\
\end{tabular} & $\begin{array}{l}\text { Bio- } \\
\text { power }\end{array}$ & $\begin{array}{l}\text { Sum of } \\
\text { Assessed }\end{array}$ \\
\hline Alabama & 0.0 & 0.0 & 0.6 & 4.3 & 0.0 & 0.0 & 4.8 \\
\hline Arizona & 0.0 & 0.0 & 3.8 & 0.3 & 0.0 & 0.0 & 4.2 \\
\hline Arkansas & 0.1 & 0.0 & 0.0 & 5.3 & 0.0 & 0.0 & 5.4 \\
\hline California & 0.0 & 0.0 & 146.6 & 0.9 & 88.7 & 0.0 & 236.1 \\
\hline Colorado & 0.0 & 0.0 & 10.3 & 0.8 & 0.0 & 0.0 & 11.1 \\
\hline Connecticut & 0.1 & 0.0 & 5.6 & 0.3 & 0.0 & 0.0 & 6.0 \\
\hline Delaware & 0.0 & 0.0 & 0.3 & 0.0 & 0.0 & 0.0 & 0.3 \\
\hline \begin{tabular}{|l|} 
District of \\
Columbia
\end{tabular} & 0.0 & 0.0 & 0.1 & 0.0 & 0.0 & 0.0 & 0.1 \\
\hline Florida & 0.0 & 0.0 & 3.4 & 0.8 & 0.0 & 0.0 & 4.1 \\
\hline Georgia & 0.0 & 0.0 & 0.9 & 0.5 & 0.0 & 0.0 & 1.4 \\
\hline Idaho & 0.0 & 0.0 & 0.1 & 0.0 & 0.0 & 0.0 & 0.1 \\
\hline Illinois & 38.9 & 0.0 & 0.1 & 4.8 & 0.0 & 0.0 & 43.7 \\
\hline Indiana & 35.0 & 0.0 & 0.0 & 0.3 & 0.0 & 0.0 & 35.4 \\
\hline lowa & 6.5 & 0.0 & 0.0 & 3.2 & 0.0 & 0.0 & 9.7 \\
\hline Kansas & 0.0 & 0.0 & 1.0 & 0.1 & 0.0 & 0.0 & 1.1 \\
\hline Kentucky & 0.0 & 0.0 & 0.8 & 11.0 & 0.0 & 0.0 & 11.8 \\
\hline Louisiana & 0.0 & 0.0 & 3.8 & 3.8 & 0.0 & 0.0 & 7.6 \\
\hline Maine & 8.0 & 0.1 & 0.1 & 1.7 & 0.0 & 0.0 & 9.8 \\
\hline Maryland & 0.3 & 0.0 & 4.9 & 0.2 & 0.0 & 0.0 & 5.4 \\
\hline Massachusetts & 2.4 & 7.7 & 14.9 & 0.4 & 0.0 & 0.0 & 25.3 \\
\hline Michigan & 14.9 & 0.0 & 0.2 & 0.2 & 0.0 & 0.0 & 15.3 \\
\hline Minnesota & 0.0 & 0.0 & 0.0 & 0.6 & 0.0 & 0.0 & 0.7 \\
\hline Mississippi & 0.0 & 0.0 & 0.0 & 1.0 & 0.0 & 0.0 & 1.1 \\
\hline Missouri & 0.0 & 0.0 & 0.0 & 1.5 & 0.0 & 0.0 & 1.5 \\
\hline Montana & 0.8 & 0.0 & 0.0 & 0.4 & 0.0 & 0.0 & 1.2 \\
\hline Nebraska & 0.0 & 0.0 & 0.2 & 0.0 & 0.0 & 0.0 & 0.2 \\
\hline Nevada & 58.5 & 123.6 & 5.7 & 0.2 & 31.7 & 0.0 & 219.6 \\
\hline New Hampshire & 2.2 & 0.0 & 2.3 & 1.0 & 0.0 & 0.0 & 5.4 \\
\hline New Jersey & 0.0 & 0.0 & 12.4 & 0.1 & 0.0 & 0.0 & 12.5 \\
\hline New Mexico & 7.9 & 0.0 & 7.8 & 0.5 & 0.8 & 0.0 & 17.0 \\
\hline New York & 6.0 & 0.0 & 23.4 & 1.3 & 0.0 & 0.0 & 30.8 \\
\hline North Carolina & 0.2 & 0.0 & 0.8 & 0.5 & 0.0 & 0.0 & 1.5 \\
\hline North Dakota & 24.6 & 0.0 & 0.1 & 0.0 & 0.0 & 0.0 & 24.7 \\
\hline Ohio & 5.0 & 0.0 & 0.0 & 1.2 & 0.0 & 0.0 & 6.3 \\
\hline Oklahoma & 17.3 & 0.0 & 0.5 & 1.3 & 0.0 & 0.0 & 19.1 \\
\hline Oregon & 0.0 & 0.0 & 0.6 & 0.5 & 0.9 & 0.0 & 2.0 \\
\hline Pennsylvania & 0.2 & 0.0 & 0.0 & 7.0 & 0.0 & 0.0 & 7.2 \\
\hline Rhode Island & 0.1 & 1.4 & 0.0 & 0.1 & 0.0 & 0.0 & 1.6 \\
\hline South Carolina & 0.0 & 205.5 & 9.1 & 0.4 & 0.0 & 0.0 & 215.0 \\
\hline South Dakota & 0.6 & 0.0 & 0.0 & 0.0 & 0.0 & 0.0 & 0.6 \\
\hline Tennessee & 0.0 & 0.0 & 1.2 & 0.1 & 0.0 & 0.0 & 1.3 \\
\hline Texas & 273.5 & 14.3 & 3.8 & 2.4 & 0.0 & 0.0 & 293.9 \\
\hline Utah & 0.0 & 0.0 & 0.8 & 0.2 & 9.1 & 0.0 & 10.0 \\
\hline Vermont & 6.9 & 0.0 & 0.5 & 0.2 & 0.0 & 0.0 & 7.6 \\
\hline Virginia & 1.8 & 78.1 & 11.7 & 0.1 & 0.0 & 0.0 & 91.7 \\
\hline Washington & 0.0 & 0.0 & 0.2 & 2.6 & 0.0 & 0.0 & 2.8 \\
\hline West Virginia & 1.7 & 0.0 & 0.0 & 0.9 & 0.0 & 0.0 & 2.7 \\
\hline Wisconsin & 8.7 & 0.0 & 8.1 & 1.3 & 0.0 & 0.0 & 18.1 \\
\hline Wyoming & 26.1 & 0.0 & 0.3 & 0.2 & 0.0 & 0.0 & 26.6 \\
\hline $\begin{array}{l}\text { Total } \\
\text { Continental U.S }\end{array}$ & 48.5 & 0.5 & 37.0 & 64.2 & 31.1 & 0.0 & 161.2 \\
\hline
\end{tabular}

Note: Annual generation shown is incremental to 2013 level. 


\section{Appendix G. Economic Potential Maps for Selected Primary Case 3 Sensitivity Cases}

Scenario Cases - Sum of Assessed Technologies

Framework

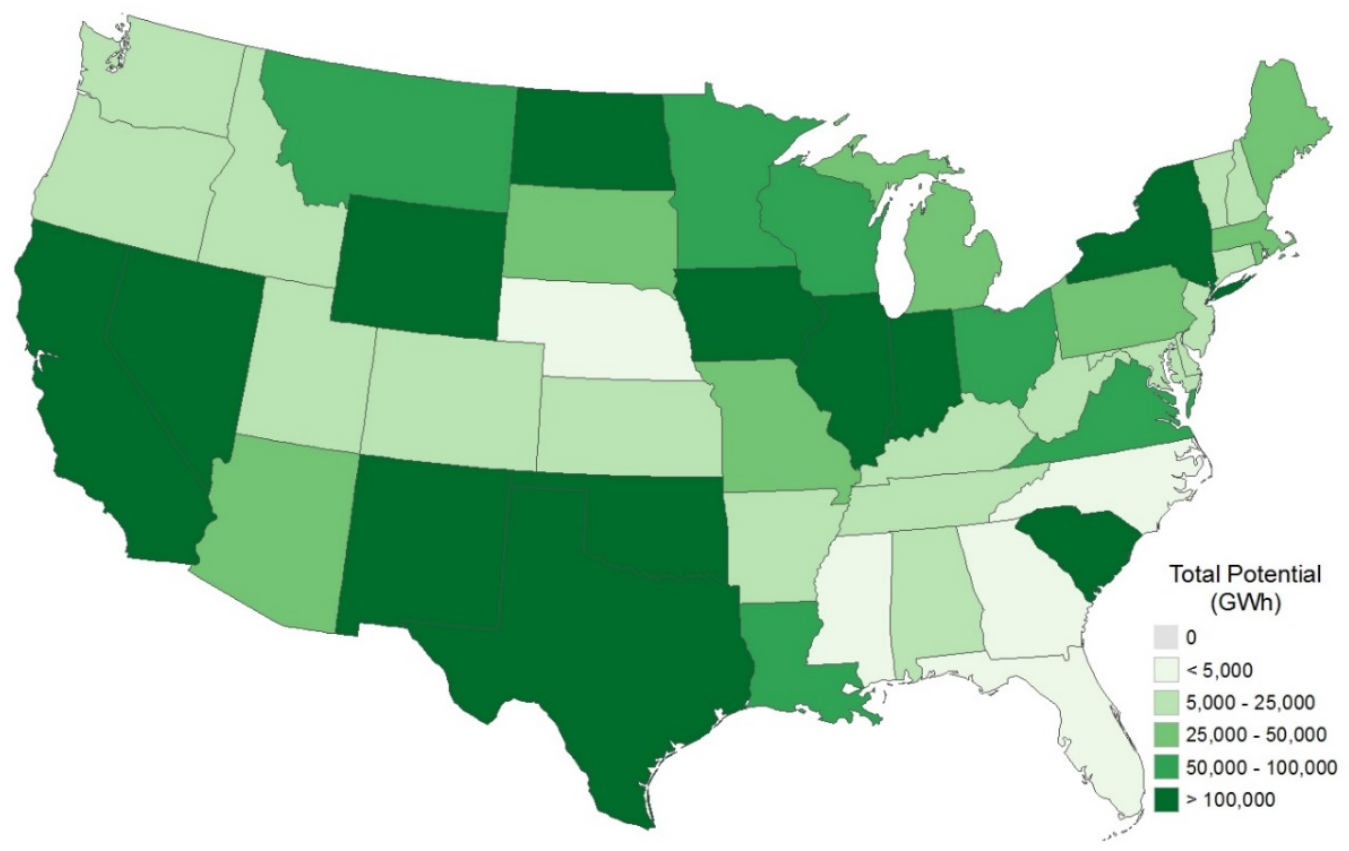

Figure G-1a. Economic potential - sum of assessed technologies (2020 construction date) annual generation (Primary Case 3 with full credit for renewable generation capacity value) 


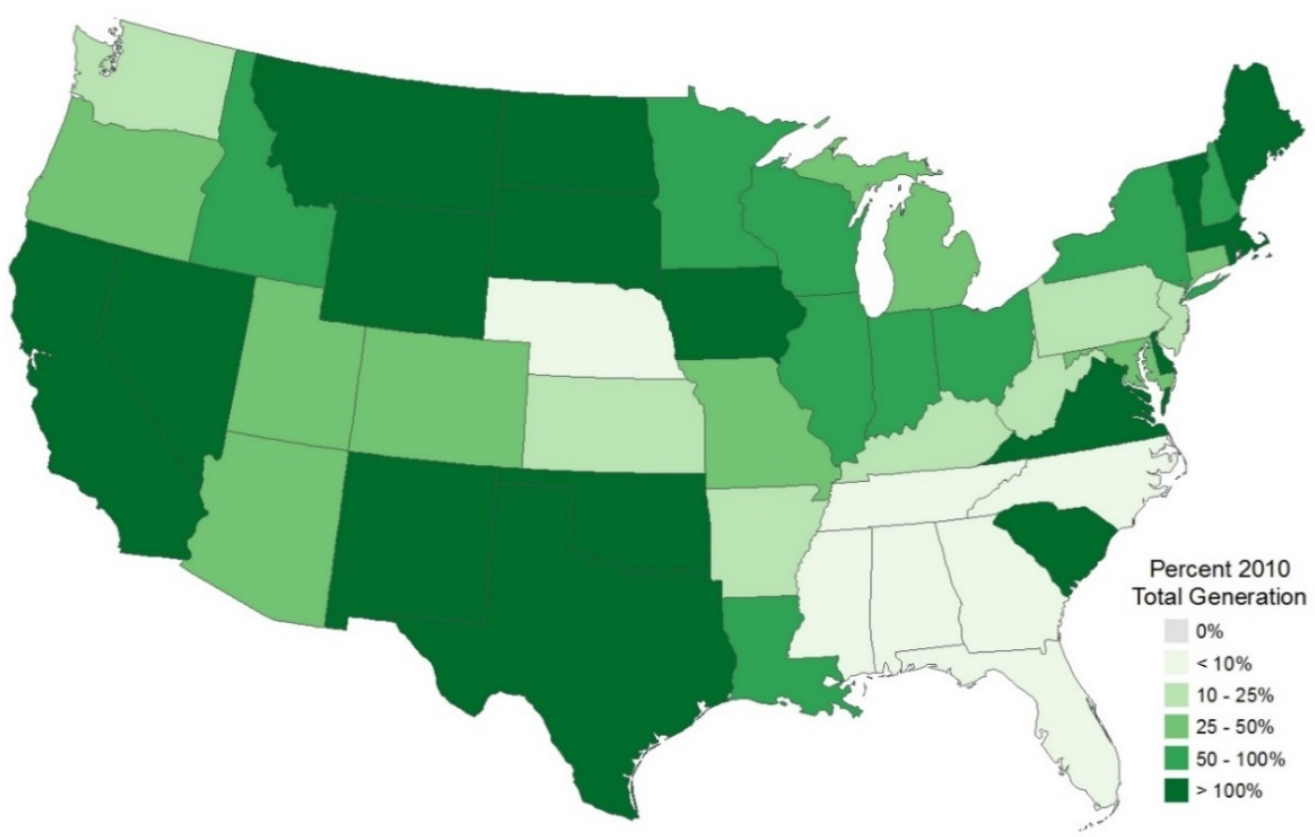

Figure G-1b. Economic potential - sum of assessed technologies (2020 construction date) annual generation as \% of 2010 total generation (Primary Case 3 with full credit for renewable generation capacity value)

Note: Annual generation shown is incremental to 2013 levels.

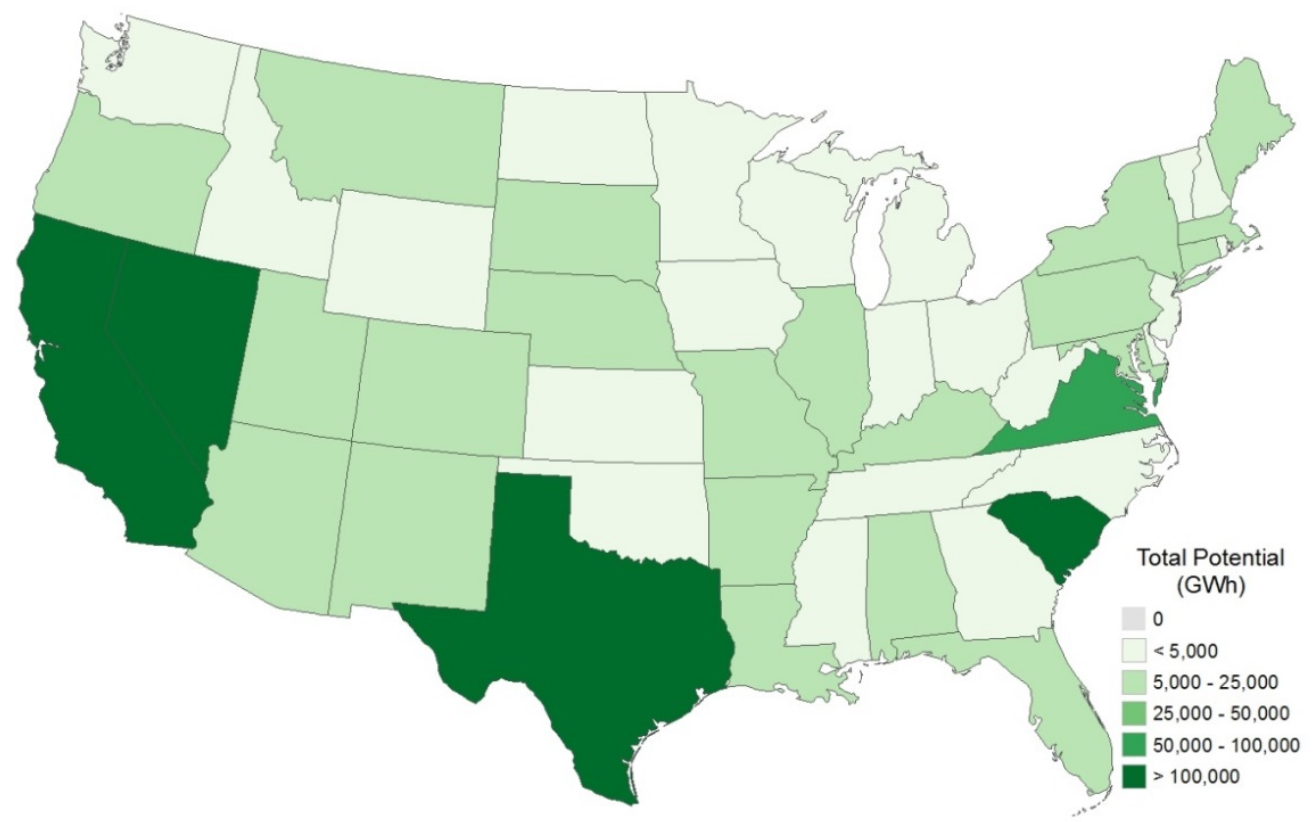

Figure G-2a. Economic potential - sum of assessed technologies (RE Cost - 2014 with PTC and 30\% ITC) annual generation (Primary Case 3 with full credit for renewable generation capacity value) 


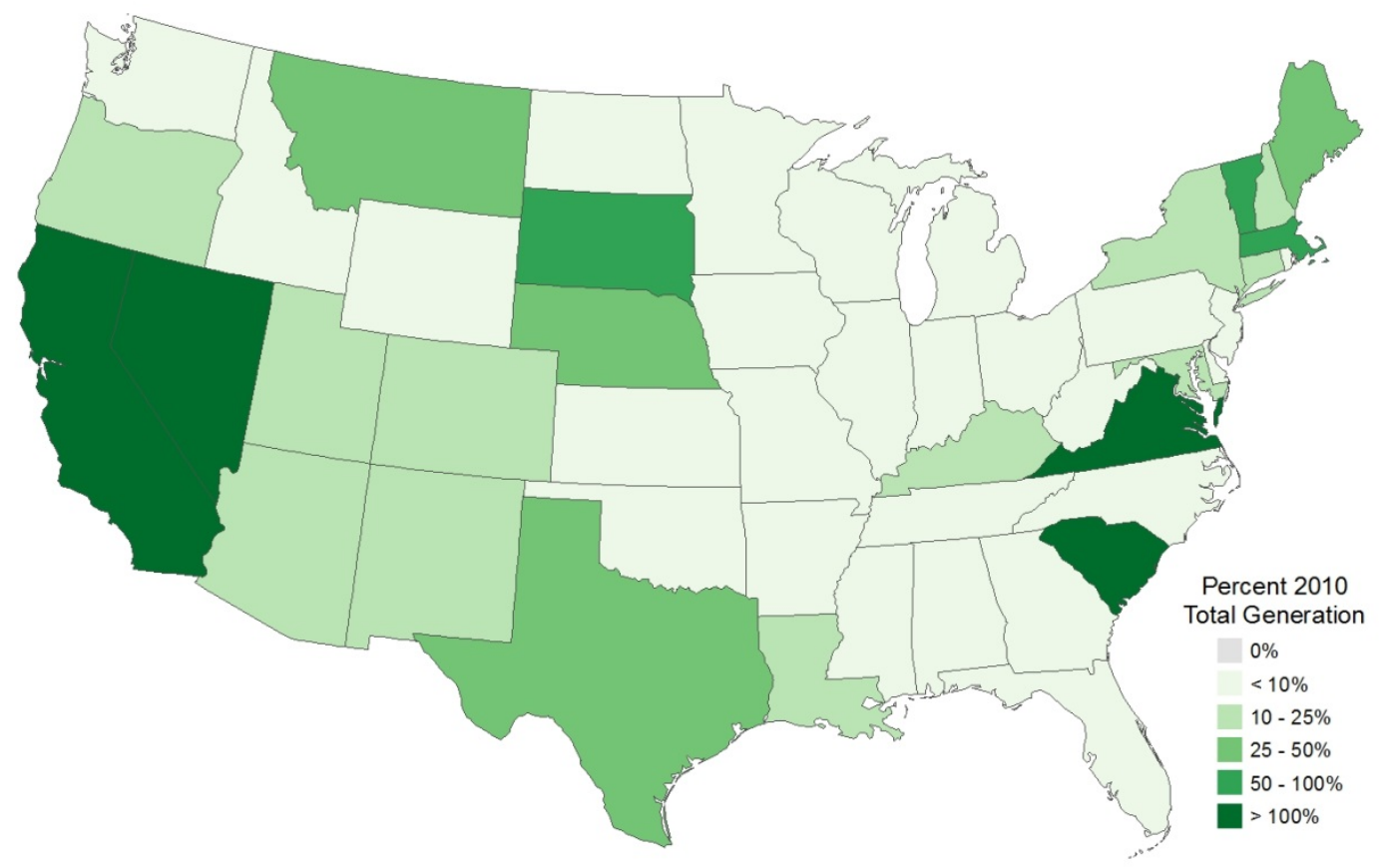

Figure G-2b. Economic potential - sum of assessed technologies (RE Cost - 2014 with PTC and $30 \%$ ITC) annual generation as \% of 2010 total generation (Primary Case 3 with full credit for renewable generation capacity value)

Note: Annual generation shown is incremental to 2013 levels.

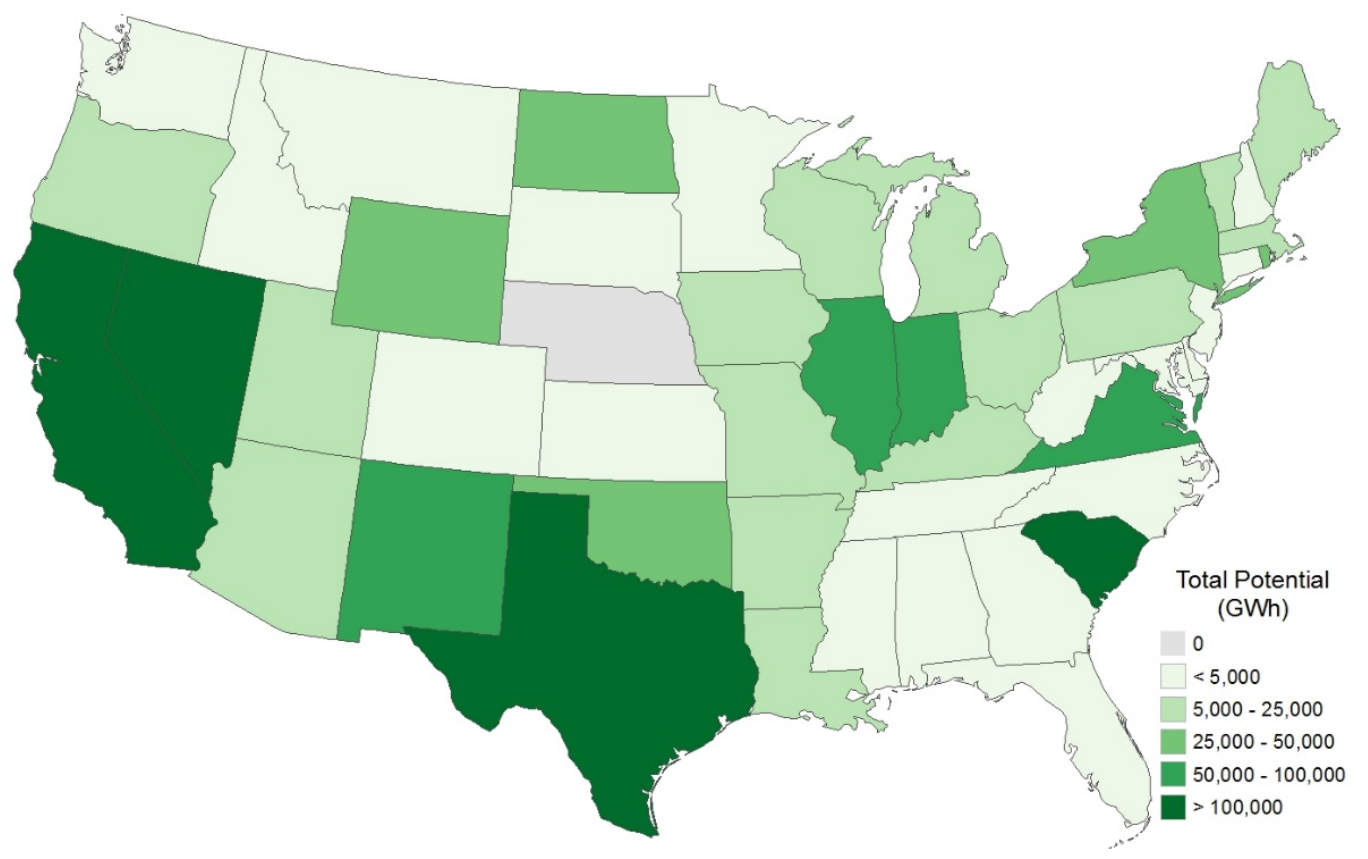

Figure G-3a. Economic potential - sum of assessed technologies (Declining Value Increasing with Regional Limits) annual generation (Primary Case 3 with full credit for renewable generation capacity value) 


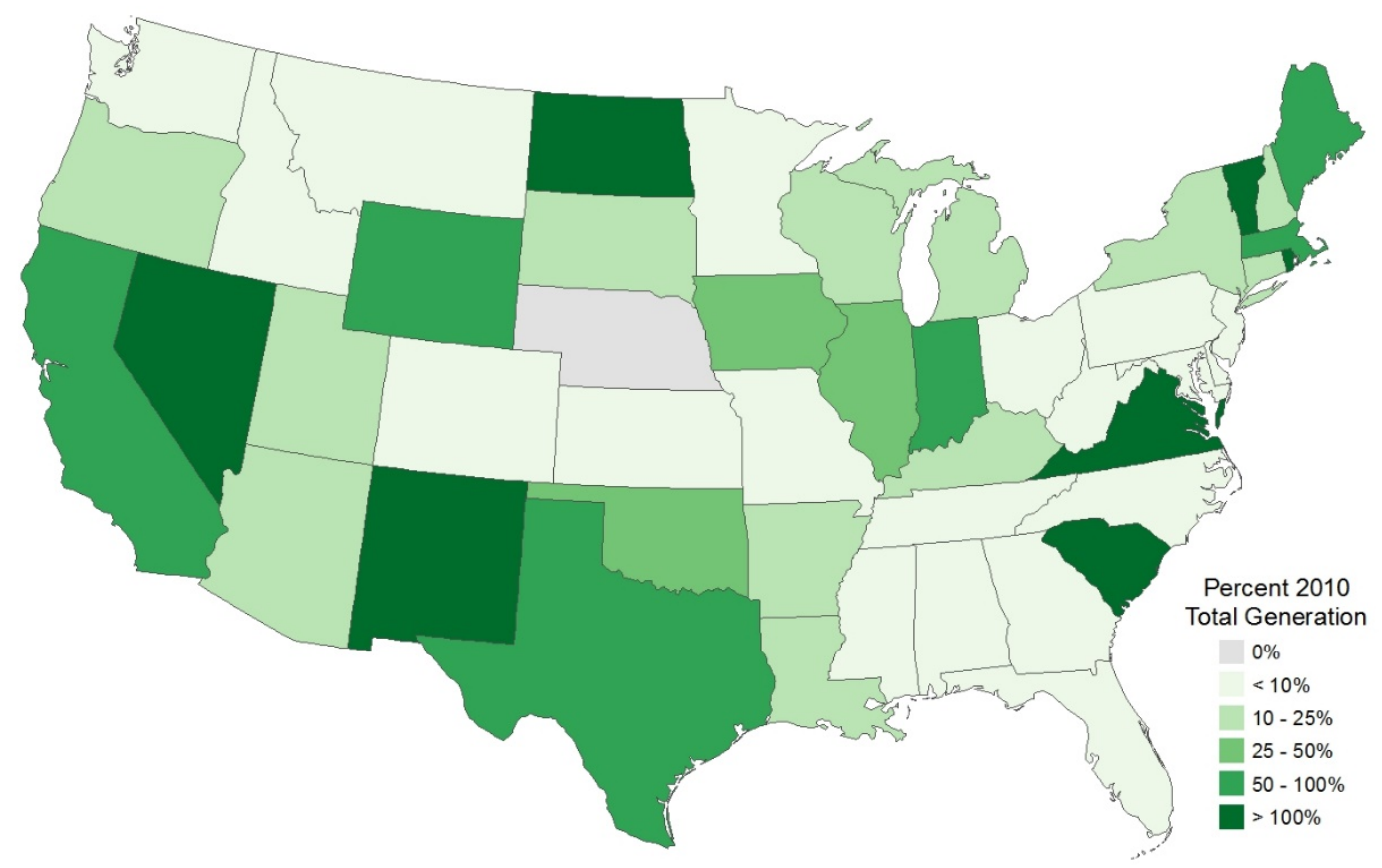

Figure G-3b. Economic potential - sum of assessed technologies (Declining Value Increasing with Regional Limits) annual generation as \% of 2010 total generation (Primary Case 3 with full credit for renewable generation capacity value)

Note: Annual generation shown is incremental to 2013 levels. 


\section{Renewable Technology Cost}

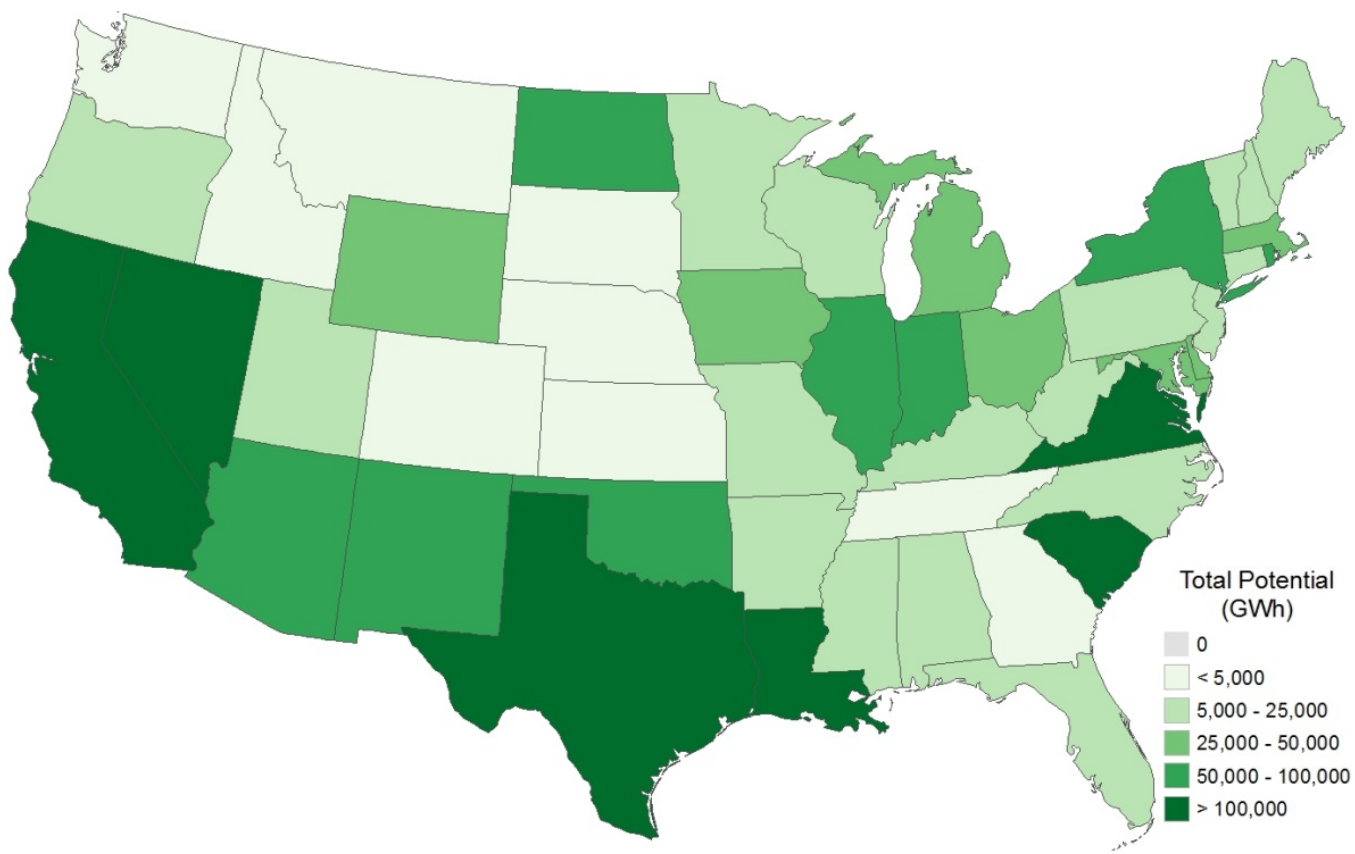

Figure G-4a. Economic potential - sum of assessed technologies (RE Cost - 2030 Mid) annual generation (Primary Case 3 with full credit for renewable generation capacity value)

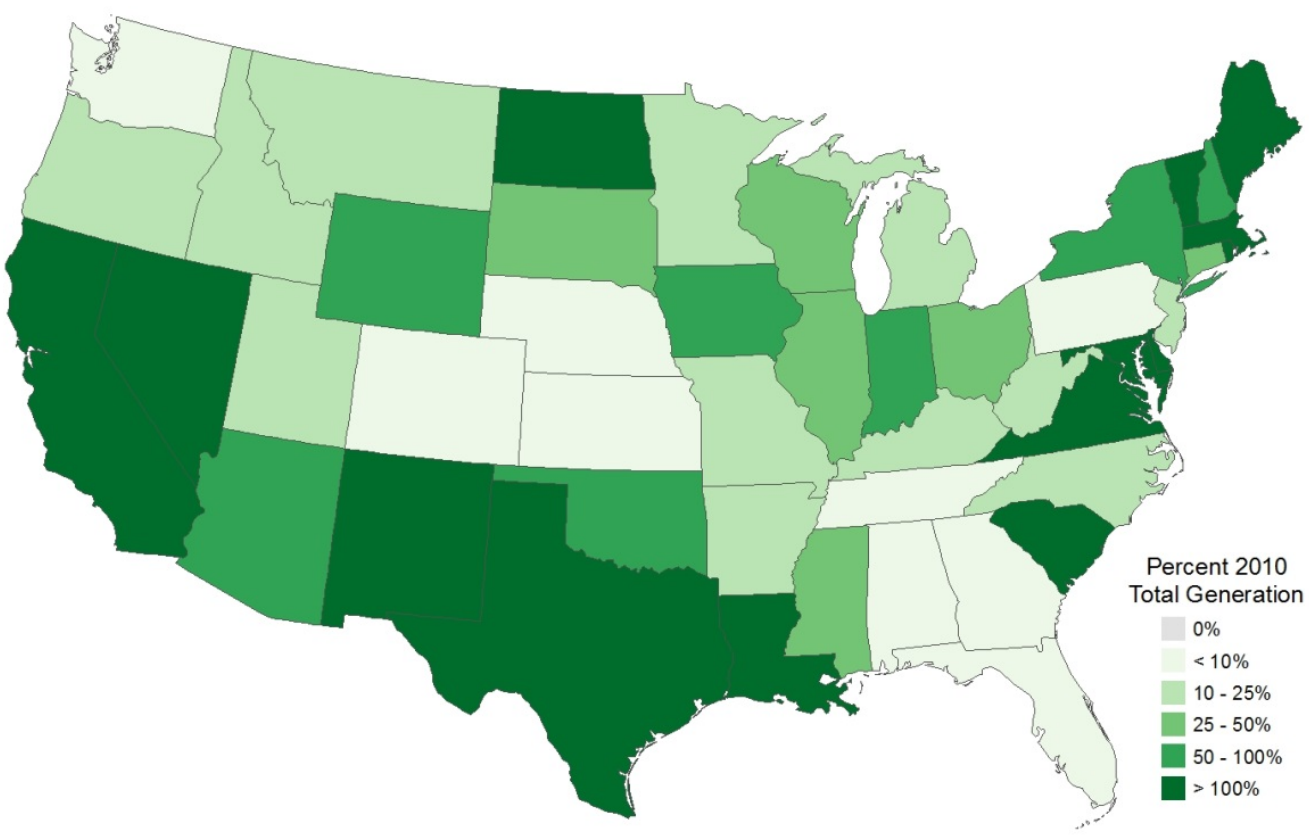

Figure G-4b. Economic potential - sum of assessed technologies (RE Cost - 2030 Mid) annual generation as \% of 2010 total generation (Primary Case 3 with full credit for renewable generation capacity value)

Note: Annual generation shown is incremental to 2013 levels. 